\title{
Chile de todos.
}

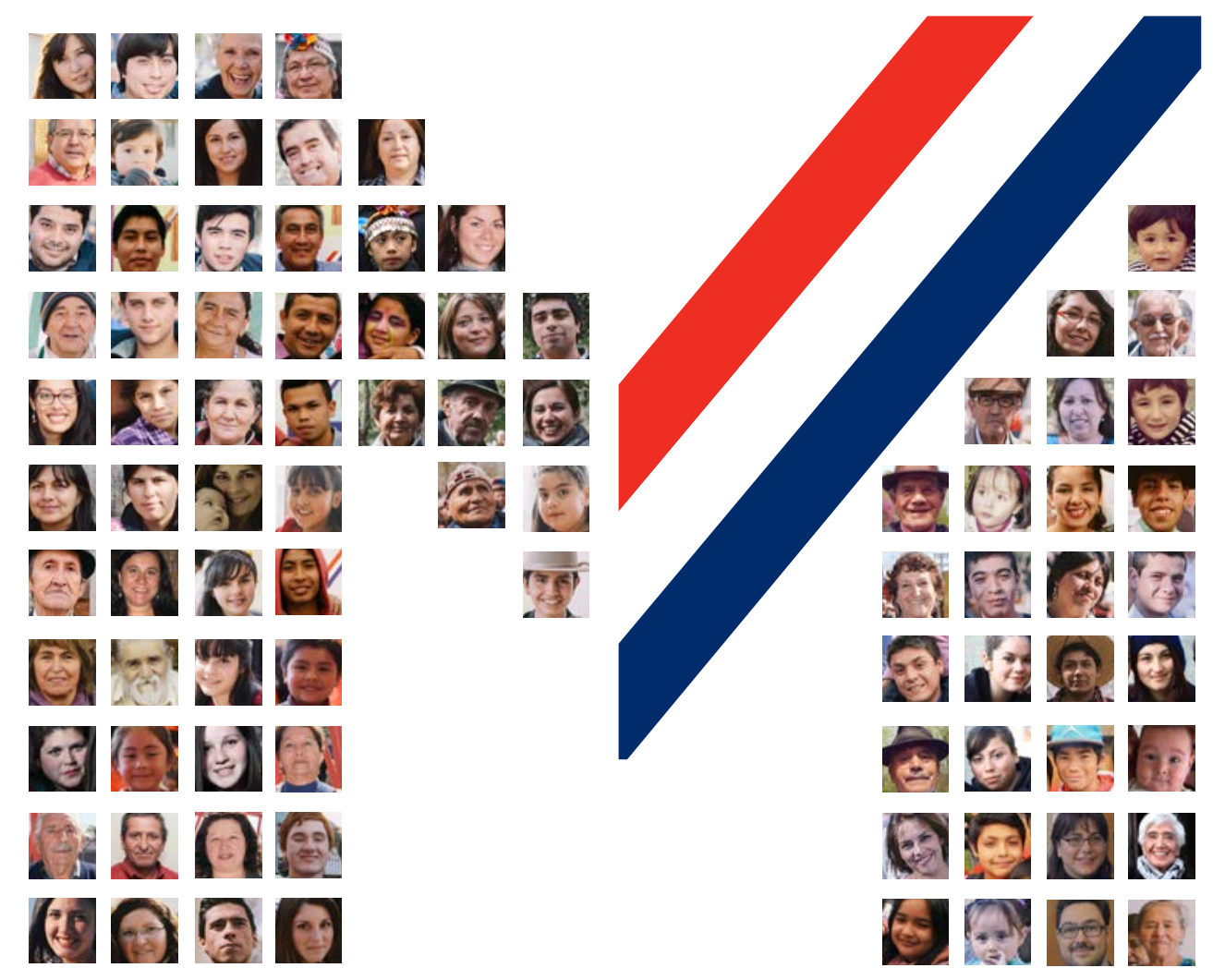

Programa de Gobierno Michelle Bachelet

2014-2018 
Chile de todos. 


\section{Programa de Gobierno Michelle Bachelet \\ 2014-2018}




\section{ÍNDICE}

PRESENTACIÓN

CONSTRUYAMOS JUNTOS UNA

NUEVA MAYORÍA PARA

UN CHILE DE TODOS

8

LAS REFORMAS DE FONDO

Reforma Educacional

Reforma Tributaria

Nueva Constitución

PROGRAMA ECONÓMICO

Buena Economía y Responsabilidad Fiscal

Energía

Ciencia, Tecnología e Innovación

Modernización del Estado

Protección y Defensa de los Consumidores,

Competencia y Transparencia

Agricultura

Pesca y Turismo

Minería y Recursos Hídricos

Inversión Pública y Concesiones 


\begin{tabular}{|c|c|c|c|}
\hline PROTECCIÓN Y OPORTUNIDADES & 82 & DERECHOS CIUDADANOS & 156 \\
\hline Salud & 84 & Superación de la Pobreza & 158 \\
\hline Trabajo & 90 & Derechos Humanos & 162 \\
\hline Pensiones & 96 & Equidad de Género & 166 \\
\hline Seguridad Ciudadana & 100 & Pueblos Indígenas & 170 \\
\hline Justicia & 106 & Infancia y Jóvenes & 176 \\
\hline $\begin{array}{l}\text { DESCENTRALIZACIÓN, TERRITORIO } \\
\text { Y DESARROLLO }\end{array}$ & 110 & Discapacidad & 180 \\
\hline & & Igualdad y no Discriminación y Participación e Inclusión & 184 \\
\hline Descentralización & 112 & Adultos Mayores & 188 \\
\hline Ciudad, Vivienda y Territorio & 118 & & \\
\hline Medio Ambiente & 124 & $\begin{array}{l}\text { AVANCEMOS JUNTOS HACIA } \\
\text { UN CHILE DE TODOS }\end{array}$ & 192 \\
\hline Cultura & 130 & & \\
\hline Deporte & 136 & & \\
\hline Transporte y Telecomunicaciones & 140 & & \\
\hline Municipios & 144 & & \\
\hline Defensa & 148 & & \\
\hline Relaciones Exteriores & 152 & & \\
\hline
\end{tabular}




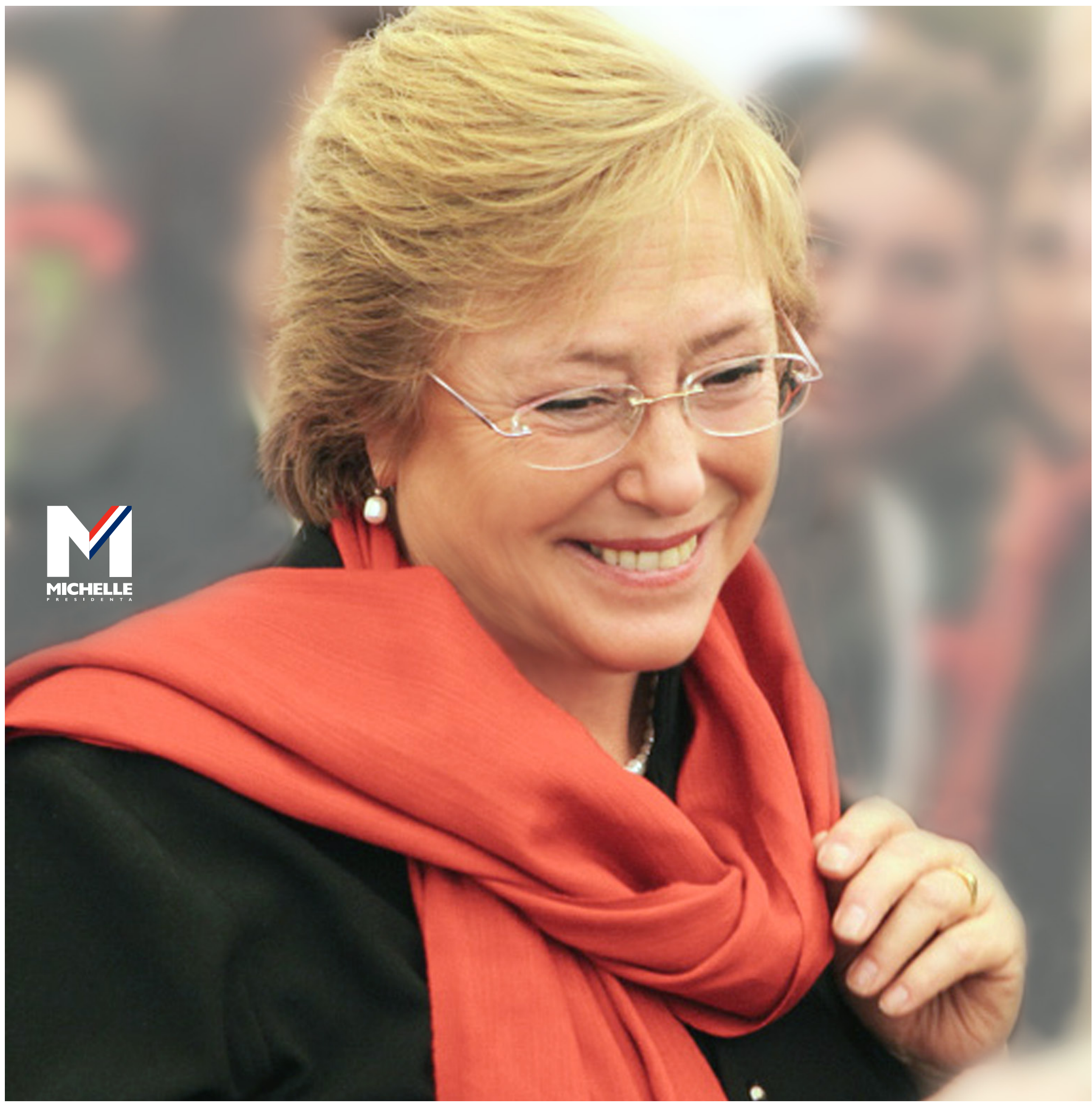




\section{Queridos amigos, queridas amigas,}

Tengo una ilusión. Tengo una esperanza. Tengo un propósito. Y sé que son la ilusión, la esperanza y el propósito de millones de chilenos y chilenas. Este programa recogeesos anhelosy ha nacido de miles de conversaciones en pequeños pueblos, en ciudades, en caletas, al borde del Estrecho de Magallanes y en el desierto, a lo largo y ancho de nuestra geografía. Conversaciones con chilenos $y$ chilenas que en su vida diaria son trabajadores, empleados, emprendedores, comerciantes, empresarios, científicos, profesores o artistas. Han sido diálogos con la diversidad y riqueza de lo que hoy es nuestro país, que no sólo ayudaron a construir este programa, sino que también han sido motivo de alegría, porque me permitieron constatar que Chile está maduro para concretar sus propias ilusiones, esperanzas y propósitos.

Soy testigo de que las personas anhelan un país de todos. Un Chile que no esté condenado a la vulnerabilidad y a la inestabilidad que viven, día a día, tanto las personas pertenecientes a los grupos sociales más vulnerables como las de la clase media.

Nuestra economía ha crecido sostenidamente y hemos construido un sistema de protección social que ha permitido que más chilenos y chilenas accedan a más servicios y bienes públicos. Y hemos incentivado el esfuerzo personal como camino para acceder a una mejor calidad de vida.

Sin embargo, sabemos también que el siglo XXI nos exige aumentar nuestra productividad y capacidad innovadora. Y ese salto sólo podremos darlo con el talento y la creatividad de nuestros compatriotas. Pero hoy no estamos aprovechando nuestros mejores recursos: estamos dejando rezagada a mucha de nuestra gente y sectores amplios de la población viven bajo incertidumbre. Estoy convencida de que abordar este reto es un imperativo para resolver los problemas urgentes y estructurales que vive nuestro país.

La fortaleza del camino que propongo en este programa arranca del gran acuerdo que hoy tenemos como sociedad: Chile está cruzado por numerosas desigualdades que son una traba para que las personas crezcan y se desarrollen, y también para que el país aproveche todo su potencial y talento.

Son las desigualdades que observamos cuando muchas familias ven que el enorme esfuerzo por educar a sus hijos no es retribuido en el campo laboral. O las desigualdades que vemos en el acceso a los bienes y servicios públicos de calidad. Son también las desigualdades que impiden que las mujeres accedan a los mismos sueldos que los hombres, aun cuando realicen las mismas labores. o las que viven personas calificadas de clase media cuando son objeto de arbitrariedades, y su esfuerzo no es reconocido en sus trabajos. 
Desigualdades que, en definitiva, obstaculizan que hoy tengamos un mayor bienestar y una calidad de vida sostenible, y que son un freno para que nuestra economía dé el salto cualitativo que puede y está en condiciones de dar.

El Chile de todos, en el que todos crecen, no llegará si mantenemos esta fragilidad e incertidumbre.

Soy una convencida de que nuestra tarea hoy es transformar estas limitaciones en una oportunidad para dar el paso que el país necesita, porque así tendremos un Chile en el que las personas pueden desplegar todas sus potencialidades, talentos y capacidades para crecer junto a sus familias. Así tendremos un país en el que los sectores más vulnerables tienen la certeza de que saldrán adelante y en el que la clase media tiene la seguridad de que su esfuerzo y sus capacidades serán reconocidas y tendrán una justa retribución. Un Chile con ciudadanos y ciudadanas que viven con confianza su libertad, autonomía y derechos. Un Chile que integra e incluye a sus habitantes, y que aprovecha el talento de todos para crecer sostenidamente. Un país que se desarrolla sobre el más sólido de los pilares: el que le otorgan sus personas.

Asípodremos encarar con confianza el futuro, orgullosos de nuestras capacidades $y$ de nuestros nuevos logros. ¿Acaso alguien podría estar en desacuerdo con un país que aprovecha las capacidades y talentos de todos para crecer y desarrollarse? ¿Acaso alguien podría negarse a ese Chile que quiere y puede ser?

Hoy queremos y podemos dar un gran salto con toda nuestra gente. Un salto que nos permita acceder a una mejor calidad de vida, con mejores servicios y bienes públicos, y con una economía que se distingue por mejorar permanentemente su productividad, por su creatividad, por su capacidad de innovación y emprendimiento. Y todo sustentado en chilenos y chilenas que han recibido del país la oportunidad de desarrollarse de forma plena. Ese es el Chile moderno, plenamente inserto en el mundo y con visión de futuro que podemos construir. Ese es el Chile de todos, en el que todos crecemos.

Las ilusiones, las esperanzas y los propósitos de miles y miles de compatriotas están en la base de la fuerza y convicción de mi candidatura y del programa de gobierno que proponemos. Aquí está la visión sobre lo importante y urgente que implementaremos en los próximos cuatro años. En este documento, se presentan las líneas centrales de aquello que haremos en el gobierno de la Nueva Mayoría. Algunas de ellas han sido recogidas también como parte de los 50 compromisos que implementaremos en los primeros 100 días de gobierno.

Hacer realidad las ilusiones, las esperanzas, los propósitos de la gran mayoría, requiere que llevemos a cabo transformaciones profundas en materia educacional, constitucionaly tributaria. Estos cambios sólo podremos realizarlos si propiciamos y exigimos que los actores políticos estén a la altura del reto. No podemos defraudar las ilusiones y las esperanzas de las personas. Chile necesita de una buena política y de un buen gobierno que permitan el despliegue de una buena economía. 
En el nuevo ciclo histórico que vive el país, mi aporte será asegurar que llevaremos adelante estos cambios, con confianza en nuestras instituciones $y$ con el imperativo de realizar un gobierno centrado en las personas. Haremos las cosas como hay que hacerlas e incorporaremos las mejores prácticas, con eficiencia, con transparencia, con agilidad, con responsabilidad. Otros tendrán que asumir otros retos, pero todos tenemos la responsabilidad de implementar las soluciones que la mayoría espera.

En esta nueva etapa, hacer un buen gobierno implica también que sepamos gobernar los cambios, asegurar las transformaciones con gobernabilidad. Chile requiere de una nueva generación de acuerdos de cara a la ciudadanía, en un clima de tranquilidad social, con un sentido colectivo y con el compromiso de hacernos cargo de que en Chile todos somos importantes. Ese es el propósito de la Nueva Mayoría que me acompaña en esta tarea: incorporar y privilegiar los intereses de todos por sobre los beneficios e intereses de unos pocos. Este programa es de quienes compartimos la firme convicción de que el Chile de todos sólo es posible si gozamos de más y mejores oportunidades para ser protagonistas de nuestras vidas y nuestro futuro.

Este programa compromete a mi futuro gobierno a un gran desafío, por el alcance y profundidad de los cambios que llevaremos a cabo. Las transformaciones que realizaremos son el inicio de un proyecto transformador de largo plazo que apunta a hacer los cambios necesarios al modelo de desarrollo que ha tenido nuestro país. Y nos compromete a tareas que hoy estamos en condiciones de llevar a cabo. Por su amplitud, algunas quizás excedan el horizonte de mi mandato presidencial. Pero nuestro compromiso es avanzar con paso firme en su concreción. Y por cierto, habrá otras prioridades que surgirán en el camino y que requerirán nuestra atención. Seguimos recibiendo nuevas propuestas que son específicas o de carácter local, que serán analizadas para su incorporación al Programa del futuro Gobierno. Tengan la certeza de que este es el momento de abordarlas.

Los invito a leer nuestro programa, y a seguir construyéndolo en cada conversación, en cada diálogo, en cada propuesta. El Chile de todos lo hacemos entre todos. Y ahora es el momento de comenzar a vivirlo.

\section{Anidelle Baclelet}




\section{CONSTRUYAMOS JUNTOS UNA NUEVA MAYORÍA PARA UN CHILE DE TODOS \\ CONSTRUYAMOS JUNTOS UNA NUEVA MAYORIA PARA UN CHILE DE TODOS}

\section{Chilenos y chilenas que quieren ser protagonistas de su futuro}

El programa que usted tiene en sus manos es la constatación de que el país está preparado para entrar a un nuevo ciclo político, económico y social. Este programa tiene el propósito de dar soluciones y gobernabilidad a estos nuevos tiempos.

Nuestra economía crece y hemos reducido de forma relevante la pobreza. Ya nadie discute la importancia de la democracia como principio central de nuestra vida en común. Los ciudadanos y las ciudadanas hemos aprendido a vivir con grados crecientes de libertad. Chile está plenamente inserto en la comunidad internacional y nuestra voz es considerada y respetada.

Este nuevo ciclo que se abre surge de la gran energía y empuje de una ciudadanía que ha decidido participar y ser protagonista de la construcción de nuestro país. Chile ha madurado y sus ciudadanos también. Por lo tanto este programa entrega los cimientos para este nuevo ciclo, colocando a las personas en el centro de las tareas que abordaremos en el gobierno de la Nueva Mayoría.

\section{Abordar la desigualdad para mirar al futuro con confianza}

Pero hoy no estamos aprovechando esta energía y empuje que tienen nuestros ciudadanos. Hoy las desigualdades atraviesan las más amplias esferas de la sociedad chilena e impiden que todos los chilenos y chilenas se incorporen al desarrollo y puedan llevar adelante sus propósitos y proyectos individuales y familiares. Hoy nuestro país está cruzado por enormes diferencias de oportunidades, con un inadecuado acceso a los servicios públicos, con privilegios y abusos de unos pocos por sobre el interés de la mayoría.

Este programa encara decididamente estas desigualdades que 
persisten en el país, pues se funda en la convicción de que la desigualdad es insostenible no sólo desde un punto de vista económico y social, sino que también para una sana convivencia entre los chilenos y chilenas y para asegurar la paz social que requerimos para crecer y desarrollarnos de forma inclusiva. La gobernabilidad se funda en un destino compartido. La desigualdad es la negación de ese sentido común.

$\mathrm{Al}$ abordar este gran reto, este programa busca brindarles a los ciudadanos la confianza necesaria y las oportunidades para que se sumen a la construcción del país que queremos. Este programa se basa en el convencimiento de que debemos incluir para crecer, porque no se puede crecer sustentablemente $\mathrm{y}$ en paz social cuando las mayorías se sienten excluidas, discriminadas o abusadas.

\section{Bases para una transformación social, política y económica}

La necesidad de resolver las brechas de desigualdad que hoy tenemos nos exige realizar cambios profundos y estructurales. La más importante de estas transformaciones nos permitirá avanzar hacia una educación más equitativa y de calidad en todos sus niveles. Esto no sólo producirá una mayor inclusión social, beneficiando a los miles de niños y niñas, jóvenes y sus familias que quieren mejorar su bienestar, también permitirá que numerosos profesionales y técnicos con grados crecientes de calificación den el impulso que necesita nuestra economía. No podemos darnos el lujo de prescindir del talento, creatividad y empuje de todos nuestros ciudadanos y ciudadanas.

La envergadura de esta tarea, así como la implementación de otros programas que apuntan a una mayor igualdad, nos exigen reformar nuestro sistema tributario. Tenemos que contar con los recursos necesarios para hacer realidad estas transformaciones. Nadie puede restarse de este esfuerzo, en especial quienes están en condiciones de hacer una mayor contribución.

Debemos tener claro que estas transformaciones no llegarán a buen puerto si no mejoramos sustancialmente nuestra política. Ya que el desarrollo y el futuro del país lo construimos entre todos, necesitamos una Nueva Constitución que nos represente. Necesitamos prestigiar nuestra política y debemos contar con un sistema electoral que permita representar la amplia diversidad de visiones que tienen los chilenos y chilenas. Un nuevo marco constitucional y político que garantice derechos, defina obligaciones y que responda a las demandas de los ciudadanos por mayor participación y representatividad.

Estos cambios estructurales unidos a algunas políticas sectoriales, como el fortalecimiento de la salud, en el ámbito público y privado, el establecimiento de nuevas condiciones laborales para nuestros trabajadores, la consoludación de un sistema integral de protección social, impulsar una descentralización efectiva, implementar una agenda de género, consolidar mejoras sustantivas en seguridad ciudadana, garantizar el respeto a nuestra diversidad e identidad, cuidar nuestro medio ambiente, avanzar en calidad de vida en el territorio y abrir nuevos canales de participación ciudadana, entre otras, son parte de los énfasis centrales del gobierno de la Nueva Mayoría.

\section{Un Chile que crece con todos}

Enfrentar la desigualdad e implementar las reformas estructurales que propone este programa, permitirán mayores niveles de equidad, de igualdad de oportunidades y derechos para los chilenos y chilenas. Esto no sólo es un imperativo ético. En igual medida es una necesidad de nuestra economía, para asegurar un desarrollo con un sentido moderno y competitivo.

Este programa, al abordar las desigualdades que hay en el 
país y al realizar una reforma estructural en la educación, busca también generar las condiciones para mantener el crecimiento económico. Este es el primer paso para asegurar una economía más competitiva, con una mayor productividad y más innovadora.

De manera complementaria este programa aborda las dificultades actuales que impiden que la productividad de nuestra economía supere su actual estancamiento, que en buena parte se originan en nuestras carencias en desarrollo de recursos humanos, innovación, ciencia y tecnología. Un aspecto central y complementario para avanzar hacia una economía más productiva es resolver sin demora los desafíos que se imponen en materia energética.

Este programa considera a la innovación, la ciencia y la tecnología como un aspecto determinante para el crecimiento del país y la impulsará decididamente. De la misma forma, contempla abordar la capacitación como un eje central, en tanto ésta ha perdido fuerza como herramienta para mejorar la empleabilidad, los ingresos y la productividad. Aborda, adicionalmente, el fomento de la competitividad y diversidad productiva, con cooperación y diálogo entre el ámbito público y privado, traspasando a las regiones mayores grados de poder, recursos y ámbitos de decisión.

Hoy lo moderno es una nueva forma de cooperación entre el Estado, la ciudadanía y el mercado. Este programa se hace cargo de este reto, promoviendo una sabia acción pública, para potenciar la competitividad, la productividad y la innovación, al tiempo que promueve el bienestar, los derechos y la participación de todas las personas. Se funda en la convicción de que es necesario aprovechar en plenitud la capacidad creativa, la disposición al emprendimiento e impulsar la voluntad asociativa de cientos de miles de emprendedores, grandes y chicos. En la convicción de que no hay progreso individual si no hay cohesión en torno al destino común de nuestra patria. 


\section{Un mejor Estado para el nuevo ciclo del país}

La concreción de las principales medidas de este programa requiere de más y mejor Estado. Chile necesita de un Estado moderno que impulse el desarrollo, que asegure condiciones de competencia y vele por el acceso, la calidad y la satisfacción de los servicios públicos que entrega a los ciudadanos. Un Estado innovador, eficiente, que entrega soluciones oportunas y en el que prevalezcan el buen trato y la transparencia.

Este programa se hace cargo de la necesidad de avanzar con decisión en la modernización del Estado. Junto con responder con más agilidad a los ciudadanos y a las nuevas exigencia de emprendimiento económico y productividad, se requiere incorporar a las y los mejores profesionales y técnicos al servicio público, que crean y valoren la importancia de una atención de calidad a los chilenos y chilenas.

El gobierno de la Nueva Mayoría tendrá una profunda vocación de servicio público y será un gobierno que no olvidará nunca que su centro son las personas y ellas su mandante. Será un gobierno con una participación ciudadana efectiva.

\section{Transformaciones con gobernabilidad}

Concretar los propósitos y las soluciones que propone este programa requiere que los cambios los hagamos con responsabilidad y cuidando la gobernabilidad del crecimiento. En este nuevo ciclo que se abre para Chile dar curso a las reformas que el país requiere es el más cierto camino de la responsabilidad. Las reformas profundas y duraderas incluidas en este programa, que guiará el actuar de la Nueva Mayoría, se realizarán sobre bases fiscales sólidas que les den sostenibilidad en el tiempo.

El conjunto de compromisos expresados en este programa tendrá un costo de \$15.100 millones de dólares. Las fuentes de financiamiento para este mayor gasto público serán principalmente tres. En primer lugar, la Reforma Tributaria, que aportará con \$ 8.200 millones de dólares, contituyéndose en la fuente más importante del esquema de financiamiento, sin la cual resulta inviable plantearse el conjunto de transformaciones propuestas, en particular la gran Reforma Educacional que emprenderemos. La segunda fuente corresponde a las disponibilidades derivadas de la proyeccción del Balance del Gobierno Central, que aporta \$ 4.700 millones de dólares, y que, en lo sustancial, se constituye por las holguras del crecimiento económico. Finalmente, realizaremos reasignaciones presupuestarias que aportarán \$2.200 millones de dólares, lo que contempla el esquema de financiamiento.

Nuestra propuesta es ambiciosa, pero podemos llevarla a cabo. Este programa asume las dificultades y responsabilidades que implica abordar estas tareas. Su implementación no persigue satisfacer intereses corporativos o de grupos de poder específicos. Este es un programa pensado en el bien común de todos los chilenos y chilenas. Ciertamente, los desafíos que busca abordar este programa no se resolverán todos dentro de los cuatro años del gobierno de la Nueva Mayoría. Hoy es el momento de empezar este recorrido, sin vacilaciones ni demoras. Y esta es la convicción que transmite el liderazgo de la candidatura de Michelle Bachelet.

Esta es la fuerza y empuje que ha animado a los numerosos diálogos sostenidos con la amplia diversidad social, económica y cultural de nuestro país, que fue la base para la construcción de este programa. Es también la fuerza y empuje que estuvo detrás de los aportes del mundo político y organizaciones sociales. Hoy es el momento de producir el punto de inflexión que nos permita iniciar el camino para derrotar la desigualdad. Y de la invaluable labor de las 33 comisiones integradas por más de 620 profesionales y técnicos en diversas áreas de las políticas públicas.

Este programa busca capitalizar una oportunidad que pocas veces se le presenta a un país. Hoy nos convoca el imperativo de hacer de Chile un lugar que proteja y desarrolle a todos sus hijos e hijas. Un Chile donde todos somos importantes. Este programa es un llamado a que todos seamos sus constructores. 


\section{MICHEELLE}

LAS
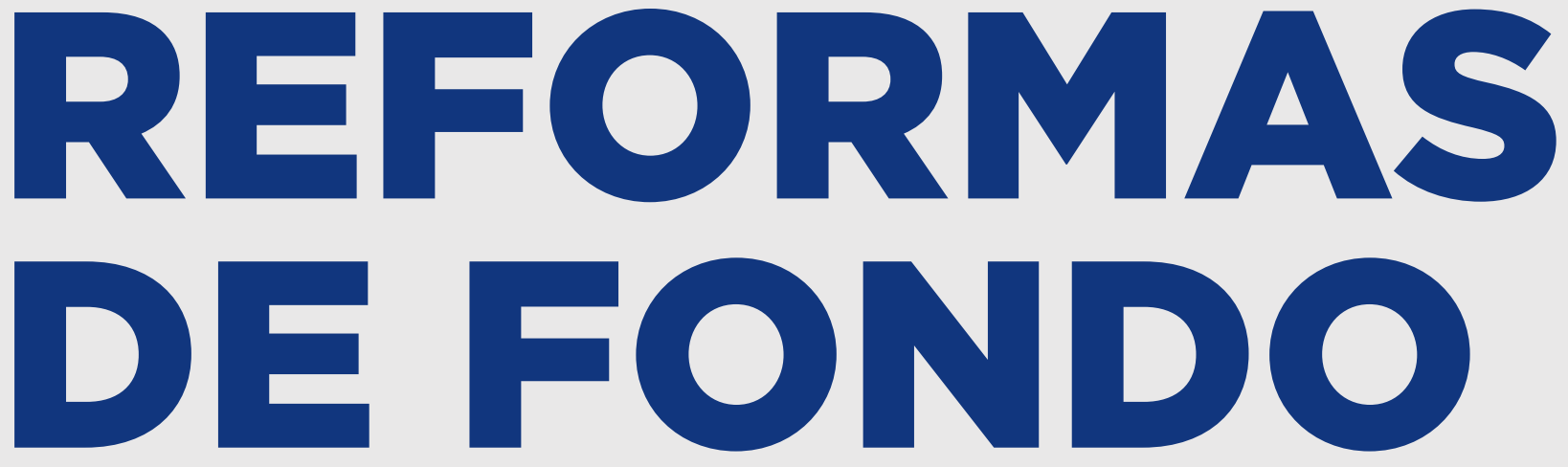

Y

$R=F$ RMA

EDUCACIONAL 

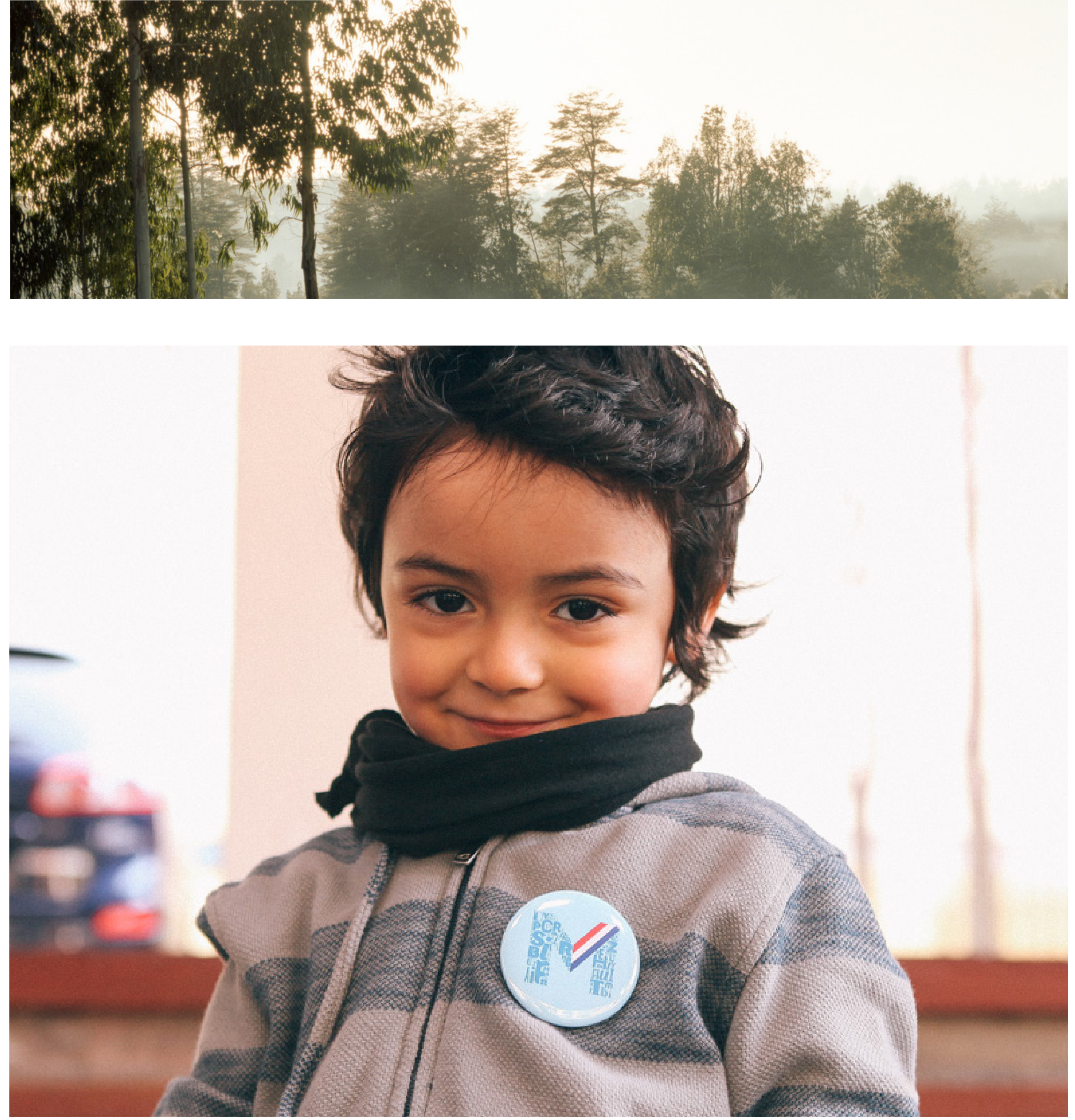


\section{REFORMA EDUCACIONAL}

La sociedad chilena enfrenta variados y significativos desafíos para convertirse en una sociedad verdaderamente desarrollada, que supere sus profundas desigualdades. El desafío primordial es la Educación. Además de aquellos elementos asociados directamente a ganancias en productividad y equidad, un acceso igualitario a educación de calidad ayuda a configurar una sociedad con más oportunidades, más justa, que empodera a la ciudadanía en su quehacer cotidiano.

Chile ha conseguido importantes logros en materia educativa: cobertura, alta inversión en infraestructura, equipamiento y programas focalizados. Sin embargo, a pesar de los esfuerzos, la desigualdad educacional y la segregación continúan en niveles alarmantes y la Educación Pública se ha visto especialmente reducida y fragilizada.

La educación chilena del siglo XXI debe estar al servicio de nobles ideales, de una sociedad fuertemente cohesionada, que supere la segregación social, que promueva la formación integral, la inclusión, la solidaridad y la democracia como valores centrales para el desarrollo nacional y de cada uno de los chilenos y chilenas.

El Estado asegurará que, independientemente del origen, condición, historia o lugar donde se habite, toda niña y niño tendrá el derecho de integrarse a un proceso educativo donde será reconocido, y accederá a experiencias de aprendizaje que le permita desplegar talentos y lograr las competencias requeridas por la sociedad actual, promoviendo un desarrollo ciudadano a escala humana y basado en el bien común.

La gran deuda hoy es mejorar transversalmente la calidad de la educación, entendida integralmente y no sólo como el resultado de pruebas estandarizadas y, también reposicionar a la Educación Pública en todos los niveles. Para entregar una mejor educación resulta imprescindible contar con un sistema más integrado y equitativo, que no deje como hoy, rezagados y excluidos. Ello significa también, que un diseño adecuado no puede implicar una carga financiera insostenible ni para los estudiantes ni para sus familias.

El Estado, a través de la educación pública, desarrollará un rol fundamental en cada nivel educacional. El Estado debe garantizar el ejercicio del derecho a una educación de calidad, fortaleciendo la educación pública, entregando garantías explícitas y exigibles a ciudadanos y ciudadanas.
La reforma educacional en su conjunto requerirá de un mayor gasto público permanente entre 1,5 y 2 puntos del PIB.

\section{Pilares de la Reforma Educacional}

Calidad Educativa. A nivel escolar, debido al uso y consecuencias de los resultados del SIMCE, hemos empobrecido el concepto de calidad y educación y promovido prácticas como la selección, la exclusión y el entrenamiento de pruebas. Debemos superar esta definición e impulsar una comprensión más compleja e integral de calidad para recuperar el sentido de la labor educativa.

Todos los establecimientos educacionales deberán ser de excelencia. Para esto debe entregarse las herramientas y recursos necesarios para mejorar la calidad y asegurar una efectiva fiscalización, como el debido apoyo y acompañamiento. Esto requiere que la profesión docente esté dentro de las más valoradas socialmente y de las más exigentes, así como también entregar el espacio y las herramientas necesarias para que los profesores, directivos y asistentes de la educación puedan desarrollar su labor.

A nivel de educación superior, entre otras medidas, debe aumentarse las exigencias hacia las instituciones, a través de mecanismos potentes de acreditación, procesos más equitativos de acceso y compromisos para reducir la deserción.

Segregación e Inclusión. Reducir la segregación y contar con un país más integrado social y culturalmente, debe ser un objetivo transversal en el diseño de políticas públicas, no sólo la educativa. Chile es el segundo país con más segregación social entre los países evaluados por PISA.

Otra realidad preocupante es que, según UNICEF, existen 300.000 niños y niñas que se encuentran fuera del sistema escolar y que en educación superior la deserción puede superar el $40 \%$ en algunas carreras, sobre todo en los sectores más vulnerables. Igualmente grave es que tras cada uno de estos jóvenes, hay muchos otros que también enfrentan dificultades pero que, a pesar de seguir en el sistema, quedan excluidos de los aprendizajes.

Construir un sistema inclusivo es un desafío mayúsculo, en 
donde uno de los objetivos principales será eliminar la selección al ingreso de las escuelas. El gran propósito es lograr que el proceso educativo llegue a todos los estudiantes, les haga sentido y los motive en su propio desarrollo.

A nivel escolar, esto requiere una mirada sistémica y un trabajo continuo de las escuelas para el que tienen pocas herramientas. Los profesores en su mayoría no son preparados para manejar esta diversidad y las escuelas no suelen desarrollar estrategias para abordarla, ni cuentan con el tiempo y los recursos adecuados para hacerlo.

Gratuidad Universal. Esta propuesta plantea un cambio de paradigma. Ello implica pasar de la educación como un bien que es posible transar en el mercado y la competencia como mecanismo regulador de la calidad, a un sistema educacional coordinado que ofrece a las niñas, niños y jóvenes de Chile un derecho social.

En Chile el nivel socioeconómico al nacer sigue determinando el futuro de nuestras niñas y niños. El rol del Estado es lograr que el derecho a una educación de calidad no dependa de la capacidad de pago de las familias y que por lo tanto su nivel de ingreso o endeudamiento no determine el acceso a la educación y con ello su futuro. Disminuir la desigualdad supone que el nivel socioeconómico y cultural de las y los estudiantes no sea una barrera al acceso, por lo que avanzaremos decididamente hacia la gratuidad universal.

Fin al lucro en todo el sistema educativo. En Chile la educación ha estado dominada por la lógica de cuasimercado, cuyo motor es la competencia por alumnos. Esto ha reducido la participación del Estado en la provisión, limitado las mejoras en calidad y dificultado el resguardo de la educación como un derecho.

Poner fin al lucro no implica terminar con el sector particular subvencionado. Garantizaremos que los padres puedan elegir el modelo educativo que quieran para sus hijos. El Estado seguirá respetando la existencia de un sistema mixto pero debe hacer valer el derecho a una educación de calidad a cada niña y niño. Por ello, todos los recursos que el Estado destine a la educación deben traducirse en un mejoramiento de la calidad.

Se eliminará la existencia de lucro con recursos públicos, por tanto, se dirigirá el financiamiento público únicamente a instituciones sin fines de lucro, que tengan como único fin la entrega de educación de calidad en el marco de un derecho social.

\section{Principios de la Reforma Educacional}

La educación se entiende como un derecho social. Todos los ciudadanos tienen derecho a educarse para poder elegir con libertad sus caminos en la vida. A continuación se presentan los siguientes lineamientos que guían la reforma:

- La Educación es un derecho social fundamental. La Educación tiene un valor público innegable y está a la base de una sociedad más justa, democrática y participativa. Nuestra sociedad debe abandonar las prácticas que han permitido tratar la educación como un bien de consumo.

- El otorgamiento de garantías explícitas para los ciudadanos en materia educativa, respecto deacceso, calidad y financiamiento.

- El fortalecimiento del rol del Estado, como actor activo tanto en la entrega directa de servicios educativos, como en una estricta fiscalización del sistema.

- El fortalecimiento de la Educación Pública como motor y sello del proceso de la Reforma Estructural. La Educación Pública debe fijar los estándares de calidad y tener presencia relevante en todo el territorio. Esta es la base y herramienta más potente sobre la que se construirá el proyecto educativo, la cohesión y la integración social.

- El sistema educativo debe promover la integración y la inclusión social en todos los niveles. No podemos olvidar que las actuales reglas y normas nos han conducido a ser uno de los países cuyo sistema escolar es de los más segregados socialmente. El Estado debe activamente abordar esta situación.

- Poner al centro de las políticas públicas el proceso educativo y los aprendizajes. Es necesario alinear el proceso educativo con los ciudadanos que deseamos formar, el país que soñamos y los desafíos de la enseñanza en todos sus niveles y especialmente la de los más vulnerables. 
- La generación de igualdad de oportunidades educativas desde la cuna, con acciones compensatorias para estudiantes que, producto de las desigualdades pasadas, hoy estén en desventaja. Las brechas educativas se manifiestan desde antes que las niñas y niños ingresen al colegio. Las políticas públicas, tanto en magnitud de los recursos invertidos como en el diseño de instrumentos, deben contribuir a reducir y eliminar las brechas sociales.

- El carácter global de la Reforma Educacional, incluyendo a los niveles Parvulario, General y Superior, de manera de integrar y cubrir a todo el ciclo de la Educación.

En los primeros 100 días de Gobierno enviaremos al Congreso el Proyecto de Ley de Reforma Educacional.

\section{Reforma a la Educación Parvularia}

El Sistema de Protección Integral de la Infancia "Chile Crece Contigo" ya garantiza el acceso gratuito a sala cuna y jardín infantil de jornada extendida, o modalidad equivalente, a los niños y niñas de familias pertenecientes al $60 \%$ más vulnerable de la población. Extenderemos estas garantías con nuevas medidas que aseguren una mayor cobertura, especialmente para los niños y niñas menores de 4 años, aumentando la calidad y con un marco institucional consistente con esta tarea.

Aumentaremos la cobertura incorporando aproximadamente 90 mil niños y niñas en el tramo de 0 a 2 años, con la construcción de 4.500 nuevas salas cuna. En el caso de la población de 2 a 4 años incorporaremos aproximadamente 34 mil niños y niñas (lo que implica 1.200 nuevas salas en jardines infantiles). En relación a la población de pre-kínder y kínder, la cobertura actual es casi completa, por lo que la propuesta es avanzar hacia la obligatoriedad de pre-kinder. En los primeros 100 días de Gobierno se entregará el detalle de las localidades en que se implementarán 500 nuevas salas cuna en 2014 .

Aseguraremos el acceso a sala cuna y jardín infantil de jornada extendida a todo hijo e hija de madre trabajadora, junto con la opción de jornada extendida en pre-kínder y kínder.

A diferencia de las políticas públicas actuales, en nuestro Gobierno, estableceremos estándares más exigentes para este nivel educacional, principalmente a través de mejorar el coeficiente técnico, es decir, más profesionales y técnicos por niño. Adicionalmente, instalaremos un sistema de acreditación y de aseguramiento de la calidad educativa para todos los establecimientos de educación parvularia.

Modernizaremos la institucionalidad de la educación parvularia, separando el rol de diseño de política, creando una Subsecretaría de Educación Parvularia en el Ministerio de Educación (MINEDUC), del rol fiscalizador, ejercido por una Intendencia de Educación Parvularia en la Superintendencia de Educación, y del rol de provisión del servicio, a cargo de JUNJI, Integra y otros prestadores debidamente acreditados.

Pondremos el acento en la formación y capacitación de educadores y educadoras, pues el Estado debe velar por la calidad en la formación de profesionales y técnicos que se desempeñan en este nivel educacional. Para ello se implementará una acreditación más exigente de las carreras respectivas y se desarrollarán programas de apoyo para su fortalecimiento.

Complementariamente, se desarrollarán programas públicos especiales para avanzar en la capacitación y el perfeccionamiento de directoras, educadoras y técnicos de educación parvularia. En particular, se fortalecerá el rol de las directoras y directores, capacitándoles en materia de gestión y administración de los Jardines Infantiles; y se fortalecerá y actualizará el conocimiento de las educadoras y técnicas de educación parvularia, apuntando a mejorar las intermediaciones y acompañamiento en el desarrollo de niñas y niños, así como el trabajo con sus familias.

Implementaremos programas educativos complementarios, que fortalezcan el rol de la familia como principal educadora de sus hijos e hijas, desde una perspectiva de desarrollo integral. Son programas para niños y niñas que viven en ruralidad o en zonas de difícil acceso y, también para aquellas familias cuya opción no es una sala cuna o jardín infantil convencional. Ejemplo de esto, es la conformación de acciones educativas y recreativas para fines de semana. Particularmente importante será la atención integral en modalidades flexibles, para niños y niñas de comunidades indígenas entre 0 a 4 años.

Finalmente, implementaremos una política para hacer efectivo el derecho de las familias a participar y colaborar en el proceso educativo y en la toma de decisiones que conciernen a sus hijos, incorporando orientaciones, estrategias y acciones para asegurar un contacto regular entre los centros educativos y las familias. 


\section{Reforma a la Educación General}

Pondremos fin al lucro en la educación. No se podrá lucrar con recursos públicos. Por lo que dirigiremos el financiamiento público exclusivamente a instituciones educacionales que sean sin fines de lucro, lo que se regulará y fiscalizará debidamente. Para implementar esta medida se considerarán los plazos y mecanismos que permitan a los establecimientos particular subvencionados, que lo requieran, realizar los ajustes necesarios y adaptarse a las nuevas normas.

\begin{abstract}
Terminaremos gradualmente con el financiamiento compartido. Para ello evaluaremos de manera rigurosa y periódica, el monto real del costo de una educación de calidad. Sobre el resultado de este análisis, la subvención estatal irá gradualmente aumentando y el pago por parte de los apoderados disminuyendo hasta ser completamente eliminado. Mientras dure el proceso de transición no se producirán nuevos incrementos a los límites de financiamiento compartido y los establecimientos no podrán elevar este cobro. El fin del financiamiento compartido, junto con otros mecanismos de selección permitirán terminar con la segregación social en la educación financiada con recursos públicos.
\end{abstract}

\section{Estableceremos una nueva institucionalidad para la oferta pública de la educación general, terminando con la administración municipal. \\ Esta nueva institucionalidad debe considerar los avances alcanzados respecto de la participación y tuición del mundo local en la educación.}

Los municipios tienen diversas funciones a su cargo y enfrentan complejidades que dificultan una adecuada y estable gestión educacional, salvo excepciones. Adicionalmente, la educación municipal está sujeta a un conjunto de regulaciones $\mathrm{y}$ restricciones a su gestión que inciden en su desempeño $\mathrm{y}$, particularmente, en la gestión de los recursos humanos.

La administración de los establecimientos de educación pública debe estar en manos de instituciones especializadas. La administración de los establecimientos municipales será reemplazada por una nueva institucionalidad pública, cuya estructura contempla la creación de un Servicio Nacional de Educación Pública descentralizado y Servicios Locales de
Educación Pública, que mantengan la cercanía con la comunidad educativa. Ambas entidades se relacionan con el Presidente de la República a través del Ministerio de Educación.

Los establecimientos educacionales pasarán a depender de los Servicios Locales de Educación Pública. Éstos se definirán geográficamente según distritos escolares. El Servicio Nacional de Educación Pública tendrá por función principal el apoyo técnico pedagógico, administrativo y financiero de los establecimientos públicos, a través de los Servicios Locales.

Cada Servicio Local contará con personalidad jurídica y patrimonio propio y tendrá un Consejo Consultivo integrado por miembros de la comunidad educativa y representantes de las facultades de Educación de instituciones públicas de la región donde se sitúa el distrito escolar.

En lo inmediato, se formulará un plan de acción de corto plazo orientado a recuperar los establecimientos con mayores deficiencias en materias técnico-pedagógicas y a asumir el desafío de recuperar matrícula en la educación pública.

\section{Terminaremos con toda forma de selección a} nivel de la escuela, tanto económica, social, académica y conductual. Adicionalmente, los establecimientos deberán considerar en su proyecto educativo la inclusión de niños con necesidades educativas especiales, y la habilitación para que ello ocurra de manera adecuada.

La Reforma Educacional debe emprenderse con la participación activa de todos los docentes, directivos y el personal asistente de la educación.

Garantizaremos a todas y todos los docentes de la educación pública la oportunidad de participar cada 4 años de manera gratuita, en un programa de perfeccionamiento docente, ampliando la oferta y mejora de la calidad de las acciones de formación continua. Constituiremos en cada región del país un Comité Regional de Desarrollo Profesional Docente, cuya función sea planificar y coordinar acciones de formación continua adecuadas a las necesidades regionales. Desarrollaremos un programa de pos títulos por disciplinas para profesores de segundo ciclo y de formación general para el primer ciclo. Potenciaremos la Red de Maestros de Maestros y retomaremos la formación de mentorías para el apoyo e inducción a docentes principiantes. 
Desarrollaremos una política de liderazgo directivo implementando un programa de inducción para directores que asumen sus cargos por primera vez, además de una Escuela de Directivos para realizar capacitaciones periódicas, tendientes a fortalecer el liderazgo directivo con énfasis en la gestión pedagógica y que promueva la conformación de equipos de trabajo y de comunidades educativas.

\section{Mejoraremos el conjunto de la formación inicial por la vía de promover que las universidades impulsen programas de reformulación curricular; promover el desarrollo de capacidades de los equipos académicos de las instituciones formadoras mediante programas de intercambio a nivel internacional y la utilización de becas de postgrado; establecer mayores exigencias para la acreditación de las carreras de pedagogía y establecer el carácter obligatorio y habilitante de la evaluación de egreso y; aumentar los recursos públicos para fomentar la investigación en temas pedagógicos. Contaremos con Escuelas de Pedagogía de Excelencia. Para esto se desarrollarán y fortalecerán convenios de gestión.}

Estableceremos una carrera docente que, entre otros aspectos, defina mejores remuneraciones; introduzca incentivos y aumente gradualmente el número de horas de la jornada laboral docente que se destine a trabajo fuera del aula. La carrera docente debe instalar el desarrollo profesional y el desempeño de calidad como elemento central de la carrera y debe establecer la reducción gradual del número máximo de estudiantes por curso en la educación subvencionada.

En Educación Técnico Profesional deben enfrentarse al menos dos problemas fundamentales: su actual desvinculación con una trayectoria de formación profesional que incluya la educación media, superior y procesos de capacitación, con su consiguiente falta de pertinencia respecto de los requerimientos del mundo laboral. A esto se suman los altos niveles de deserción y baja titulación oportuna que presenta el sector. Consolidaremos un sistema de formación diversificado que permita que todos los y las jóvenes tengan un proyecto de vida y puedan seguir una trayectoria educativa laboral de acuerdo a sus preferencias y talentos, independientemente de su nivel socioeconómico. Es en esta modalidad educativa donde se requieren mayores esfuerzos para lograr la excelencia en todos los establecimientos.

Modernizaremos el currículum de la Educación Media Técnico Profesional, de manera tal que exista la posibilidad real de hacer una trayectoria conducente a títulos técnicos y profesionales superiores. Crearemos en cada región del país un Centro de Entrenamiento de alto nivel para ofrecer formación práctica a los estudiantes, consistente con la vocación productiva de la región respectiva. Cada región del país contará con un Consejo de Formación Técnico Profesional, de carácter público-privado, que velará por la articulación completa del sistema y dará lineamientos para el desarrollo de especialidades en la región, tanto a nivel medio como superior.

\section{Reforma a la Educación Superior}

En materia de educación superior, los y las jóvenes junto a sus familias enfrentan dos tipos de problemas. En primer lugar de acceso, por la existencia de barreras de financiamiento y académicas. Estas son particularmente relevantes y discriminatorias en el caso de estudiantes pertenecientes a grupos en situación de mayor vulnerabilidad económica.

En segundo lugar, por la existencia de serias dificultades en el control de la calidad de las instituciones de educación superior, cuestión que se ve agudizada por la baja fiscalización de los Institutos Profesionales y los Centros de Formación Técnica.

Desarrollaremos una institucionalidad que permita recuperar la confianza en el sistema y sus instituciones y que dé respuesta a los desafíos del país en el desarrollo productivo, científico y cultural.

La educación superior debe ser un derecho social efectivo. Se establecerán garantías explícitas para los ciudadanos en materia de educación superior, tanto de acceso como de calidad y financiamiento. Estas garantías darán un trato preferente a los y las estudiantes de menores ingresos.

Para cumplir con dichas garantías se requiere de un Estado activo tanto en la entrega directa de servicios educativos como en la estricta fiscalización de los oferentes, tarea a la que nos abocaremos con especial dedicación y premura.

Avanzaremos gradualmente en la gratuidad universal y efectiva de la educación superior, en un proceso que tomará 6 años. Durante el próximo período de Gobierno, accederán a la gratuidad al menos los y las estudiantes pertenecientes al $70 \%$ más vulnerable de la población, abarcando extensamente a la clase media. Esta gratuidad podrá ser ejercida en toda institución de educación superior que cumpla, entre otros aspectos, con: estar acreditada; acatar estrictamente las normas que no permiten la existencia de lucro; estar incorporada a las nuevas normas sobre 
acceso de equidad; desarrollar programas de reforzamiento y acompañamiento para los alumnos vulnerables, y que se rija por el sistema de aranceles que determine el MINEDUC.

Para la fijación de aranceles se creará una nueva institucionalidad, que considerará un grupo de expertos que determinarán y revisarán periódicamente el monto de dichos aranceles.

Quienes se endeudaron para estudiar hoy están viviendo situaciones complejas. Los instrumentos financieros que se utilizaron para ampliar la cobertura en educación superior no siempre cumplieron las expectativas. Avanzaremos a la gratuidad universal en educación superior y al mismo tiempo estudiaremos mecanismos para establecer un trato equitativo a los estudiantes endeudados.

Modernizaremos la institucionalidad pública de la educación superior, creando la Subsecretaría de Educación Superior; la Superintendencia de Educación Superior, con competencias claras y recursos necesarios para cumplir sus funciones, en especial, la fiscalización del uso de los recursos públicos, velar que se cumpla la prohibición de lucro, y la Agencia de la Calidad de la Educación Superior, responsable de la acreditación y de velar por la calidad de la educación superior. Esta nueva institucionalidad permitirá una relación más directa y productiva entre el mundo de la educación superior y las autoridades del sector.

Frente a situaciones observadas de inviabilidad y cierre de establecimientos de educación superior, el Ministerio de Educación dispondrá de los instrumentos necesarios que permitan garantizar la continuidad de estudios de todos los estudiantes involucrados.

Crearemos un nuevo Programa para Incrementar la Equidad en el Acceso a la Educación Superior, que contrapese el sesgo socioeconómico existente en los requisitos académicos. Para ello, las instituciones de educación superior que opten por recibir financiamiento público deberán suscribir un convenio de deberes y derechos con el MINEDUC para aplicar este nuevo mecanismo de acceso. Este mecanismo consistirá en establecer "cupos de equidad", adicionales al sistema regular, equivalente al menos a un $20 \%$ de la matrícula de cada una de las carreras que ofrezca la institución para estudiantes pertenecientes al 40\% más vulnerable.

Como parte del Programa para Incrementar la Equidad en el Acceso a la Educación Superior, implementaremos un programa permanente de acciones de apoyo a los y las estudiantes vulnerables, con el propósito de evitar la deserción de los estudios superiores. Esto incluye programas en los establecimientos de enseñanza media para preparar a los y las jóvenes; involucrar a sus familias; apoyar y desarrollar competencias en los establecimientos de educación superior; y reformar el Aporte Fiscal Indirecto (AFI) para que incentive la matrícula y retención de estudiantes en situación de vulnerabilidad. En los 100 primero días de Gobierno iniciaremos la puesta en marcha del Programa, con la Preparación y Apoyo a Jóvenes, que partirá con alumnos de $3^{\circ}$ medio que ingresarán a la universidad el 2016. Adicionalmente, implementaremos un programa en los establecimientos públicos para apoyar la preparación de la PSU.

Estableceremos un nuevo sistema de acreditación de instituciones de educación superior. La acreditación, tanto institucional como por carreras, será obligatoria para todas las instituciones de educación superior (Universidades, IP y CFT)

Estableceremos un Nuevo Fondo de Apoyo a la Investigación Universitaria, de una magnitud suficiente para que las instituciones no busquen cargar en los aranceles la labor que realizan en materia de investigación. Este fondo estará disponible para todas las universidades públicas, y para todas aquellas que acrediten capacidades de investigación y firmen convenios de desempeño con el MINEDUC.

En este esfuerzo financiero, estableceremos un trato preferente con las universidades de propiedad del Estado. Estas universidades deberán introducir las modificaciones necesarias en su gestión, para rendir cuentas respecto de sus planes de desarrollo y del financiamiento obtenido. Este nuevo trato incluye un fondo de aporte basal permanente exclusivo para las universidades estatales y un fondo permanente de apoyo a las universidades estatales regionales.

Adicionalmente, crearemos universidades estatales regionales en donde actualmente no existen (Aysén y O'Higgins). En los primeros 100 días de Gobierno se enviará al Congreso el proyecto de ley de creación de estas nuevas universidades.

Crearemos Centros de Formación Técnica públicos, que tendrán presencia en todas las regiones. Cada Centro de Formación Técnica estará vinculado a una universidad pública. Aspiramos a que estas instituciones marquen la pauta en cuanto a los estándares esperados de calidad en la educación técnica con una fuerte identificación y vinculación con el desarrollo productivo regional. En los primeros 100 días de Gobierno se firmarán los cinco primeros convenios con universidades para la creación de CFTs públicos en regiones. 

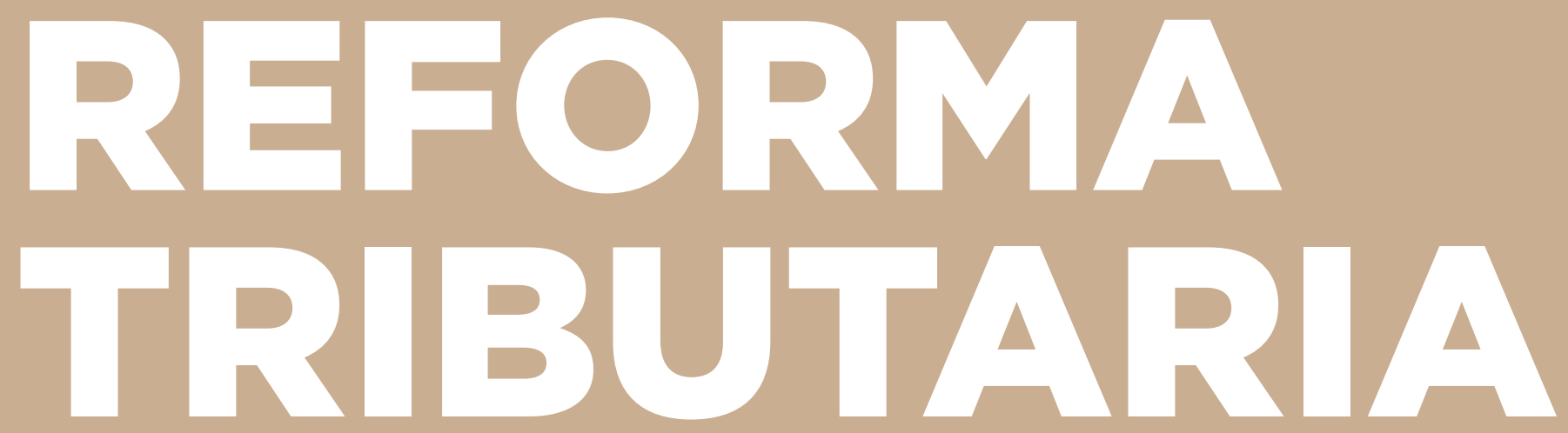


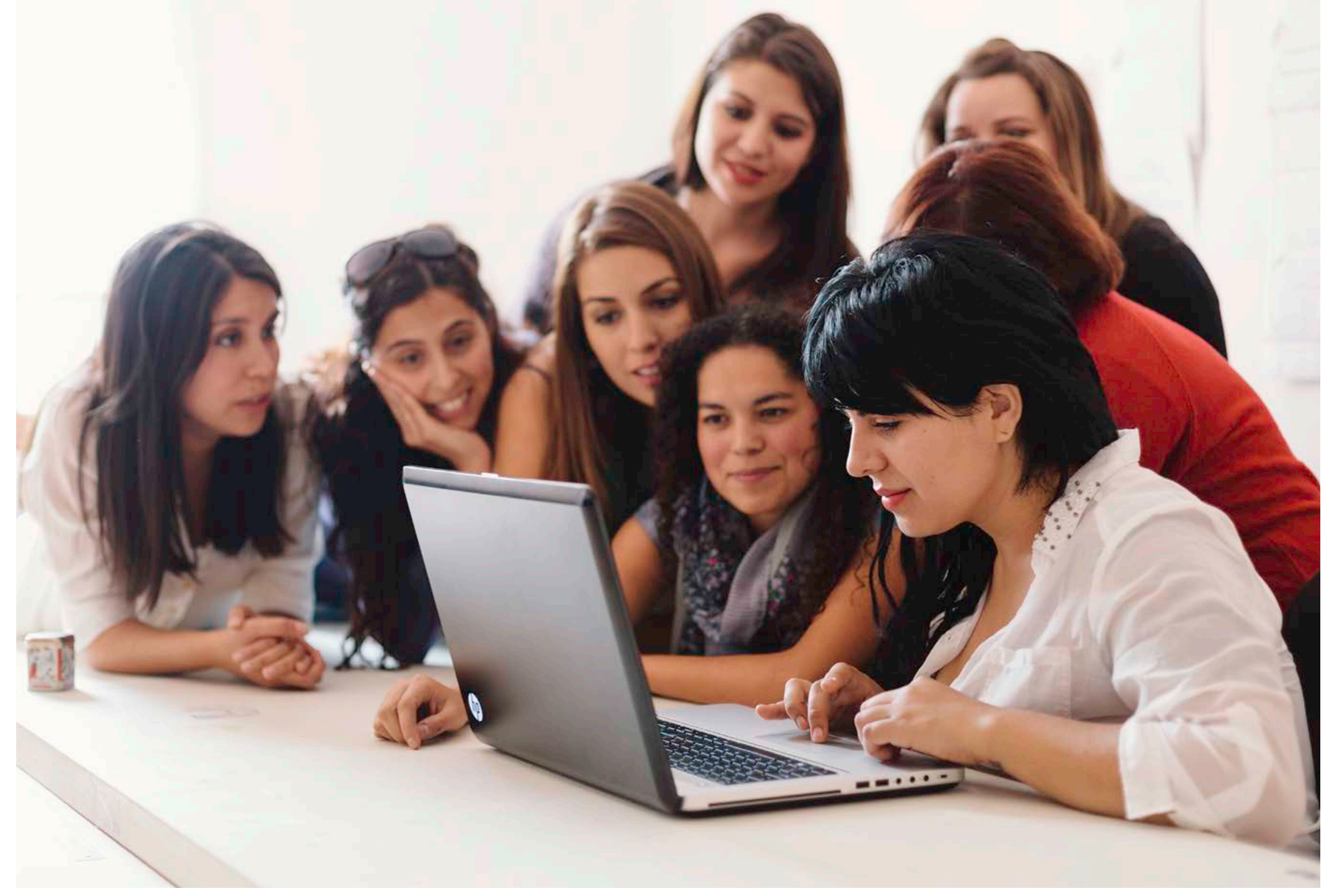




\section{REFORMA TRIBUTARIA}

Para alcanzar el desarrollo, Chile necesita hacer importantes transformaciones en algunas áreas. Una de las principales es una profunda reforma educacional. Estas transformaciones significarán un importante incremento del gasto público. Evidentemente, esto implica la necesidad de realizar una reforma tributaria para contar con ingresos permanentes que permitan alcanzar una sustentabilidad fiscal.

\section{La Reforma Tributaria tiene cuatro objetivos:}

1. Aumentar la carga tributaria para financiar, con ingresos permanentes, los gastos permanentes de la reforma educacional que emprenderemos, otras políticas del ámbito de la protección social y el actual déficit estructural en las cuentas fiscales.

2. Avanzar en equidad tributaria, mejorando la distribución del ingreso. Los que ganan más aportarán más, y los ingresos del trabajo y del capital deben tener tratamientos similares.

3. Introducir nuevos y más eficientes mecanismos de incentivos al ahorro e inversión.

4. Velar porque se pague lo que corresponda de acuerdo a las leyes, avanzando en medidas que disminuyan la evasión y la elusión.

La meta de recaudación del conjunto de las medidas de la Reforma Tributaria será de $3 \%$ del PIB. Esta meta se descompone en $2,5 \%$ del PIB provenientes de cambios a la estructura tributaria y $0,5 \%$ del PIB de medidas que reducen la evasión y la elusión.

Esto es hacer propuestas responsables frente al país, que permitan avanzar sólidamente en las transformaciones que Chile necesita.

\section{Reforma Tributaria y Crecimiento Económico}

Los países que se han desarrollado, junto con el crecimiento sostenido han aumentado continuamente los bienes y servicios que ponen a disposición de sus ciudadanos, a través de las políticas públicas. Esto es posible y sostenible responsablemente, en la medida que han aumentado la carga tributaria, que permite financiar la provisión de estos bienes.

Chile tiene una carga tributaria baja, aún si se la compara con países desarrollados al momento de contar con un PIB per cápita similar al que nuestro país tiene en la actualidad. Las modificaciones que aquí anunciamos, con una elevación de la carga tributaria de 3 puntos del PIB, comienzan a cerrar esta brecha, quedando aún por debajo del promedio de los países de la OECD, al momento en que contaban con nuestro actual PIB per cápita.

Adicionalmente, existen estudios para Chile que establecen que aumentos en la tasa de impuesto a la renta no afectan significativamente las decisiones de inversión. A lo más, el impacto se limita a las empresas más pequeñas, que ciertamente tienen una mayor dificultad de acceso al financiamiento. Aún así, el impacto estimado sobre estas empresas es muy acotado y diseñaremos un conjunto de medidas para revertirlo.

Se ha intentado vincular la propuesta de reforma tributaria con una disminución en el ritmo de crecimiento. Esto no es efectivo. En primer lugar, la tributación es sólo uno de los elementos que inciden sobre la inversión. La literatura sobre el tema concluye que los atributos más relevantes que afectan la inversión son: i) la cohesión social y la estabilidad política; ii) la calidad y credibilidad de las instituciones públicas; iii) la accesibilidad y competitividad de los mercados, entre otros los financieros; iv) la infraestructura y, v) una adecuada legislación económica.

En los primeros 100 días de Gobierno se enviará al Congreso el Proyecto de Ley de Reforma Tributaria.

\section{Reducción de la Evasión y Elusión}

En los últimos años, el SII ha sufrido un estancamiento en su proceso modernizador e incluso un retroceso en áreas claves, como la fiscalización y la inversión tecnológica. El resultado de esto ha sido un incremento de la tasa de evasión, a niveles superiores al $20 \%$ en el caso del IVA. Esto, luego que en la década pasada estuviera bajo el $10 \%$, cifra comparable con la de los países desarrollados con mejor cumplimiento tributario. 
En primer lugar, desarrollaremos una mayor efectividad de la fiscalización, mediante el fortalecimiento de: i) la detección y persecución de delitos tributarios y facturas falsas; ii) las actividades de control preventivo en terreno; iii) la fiscalización de contribuyentes de altos ingresos y, iv) el análisis de riesgo e inteligencia fiscal, que permita, sobre la base de la información disponible de distintas fuentes de datos, identificar a los contribuyentes de mayor riesgo.

En segundo lugar, proveeremos de más recursos y fortaleceremos la administración tributaria: i) aumentando la dotación de fiscalizadores y la inversión en capacitación; ii) revisando y fortaleciendo las facultades de fiscalización y de acceso a información con que cuenta el SII; iii) revisando el nivel de las sanciones al fraude fiscal e incumplimiento tributario; iv) uniformando y transparentando la política de condonaciones; v) incrementando la inversión en tecnología para, entre otras cosas, hacer viable la masificación de la factura electrónica; vi) incorporando al Código Tributario una Norma General Antielusión, que permita sancionar a aquellos que incurran en esta práctica sólo por razones tributarias, y no por la naturaleza de su actividad económica, así como también a aquellos asesores tributarios que colaboren con el diseño de planificaciones tributarias agresivas; y vii) mejorando la coordinación entre el SII, el Servicio Nacional de Aduanas y la Tesorería.

Por último, se realizará un decidido avance en mejorar los servicios y la atención a los contribuyentes. En este plano se contempla i) reducir los costos de cumplimiento para contribuyentes medianos y pequeños, mediante la simplificación de los trámites en oficina, lo que redundará en mayores facilidades para el emprendimiento; ii) reforzar el respeto a los derechos de los contribuyentes en todas las actuaciones de la administración, propiciando un trato justo en los procesos de cumplimiento; iii) establecer compromisos de servicio en los trámites y requerimientos más frecuentes, lo cual redundará en una mayor certeza acerca de los plazos de respuesta a las solicitudes; y iv) desarrollar mejores servicios de atención y asistencia a través de los distintos canales, adaptando la comunicación a los medios actualmente disponibles, lo que permitirá acercar la administración fiscal a las necesidades de los contribuyentes.

La estimación de recaudación producto de estas medidas se estima en $0,51 \%$ del PIB en régimen.

\section{Cambios a la Estructura Tributaria}

Impuesto a la Renta. El mecanismo del FUT con que hoy cuenta Chile, no existe en ninguna parte del mundo. Se trata de una fórmula surgida en los años 80 , posterior a la crisis vivida en esa década, que obedece a las condiciones económicas específicas de ese momento en nuestro país, en especial, debido a las restricciones financieras que enfrentaron las empresas en dicha década en Chile.

El sistema de impuesto a la renta se caracteriza por tener una tributación de las rentas del capital baja, con algunas franquicias tributarias mal diseñadas, que se superponen entre sí. Una parte dela estructura de incentivos, como es el caso del FUT, algunos regímenes especiales o el tratamiento del ahorro, se han desviado sustancialmente de sus objetivos iniciales y se han convertido en fuentes de elusión e incluso de evasión de impuestos.

Para corregir lo anterior, se implementarán las siguientes modificaciones a la Ley de Impuesto a la Renta:

Elevaremos, en forma gradual, la tasa del impuesto a las empresas de $20 \%$ a $25 \%$ en un plazo de 4 años. Ésta seguirá operando como un anticipo de los impuestos personales, manteniéndose así la integración de impuestos entre empresas y personas.

Los dueños de las empresas deberán tributar por la totalidad de las utilidades de sus empresas y no sólo sobre las utilidades que retiran (el sistema operará en base devengada). Esta medida será implementada a partir del cuarto año de la reforma. De esta forma se termina con el actual mecanismo del Fondo de Utilidades Tributables (FUT).

Reduciremos, en forma gradual, la tasa máxima de los impuestos personales, del $40 \%$ actual a un $35 \%$, en el plazo de cuatro años.

Respecto del FUT acumulado o histórico, se propone mantener la regla impositiva vigente. Esto quiere decir que, a partir del año en que comienza el nuevo régimen de tributación, al cuarto año de la reforma, estas utilidades tributarán en la medida en que sean retiradas. 
La estimación de recaudación producto de estas medidas de impuesto a la renta es de $1,92 \%$ del PIB en régimen.

\section{Incentivos al Ahorro y la Inversión}

Incentivo a la Inversión de las Empresas. Frente a los cambios anunciados en el impuesto a la renta, debemos tener un particular cuidado con la inversión, introduciendo mecanismos modernos que superen la situación actual de elusión.

Se implementará un mecanismo de depreciación instantánea, que consiste en que las empresas puedan descontar de las utilidades la inversión total del año en curso, y que beneficie principalmente a la pequeña y mediana empresa y que considere un mecanismo que controle las posibles distorsiones entre sectores productivos con distinta intensidad en el uso de inversión de capital. Este mecanismo se implementará a partir del cuarto año de la reforma, coincidiendo con el cierre del FUT.

Esta es una medida que corresponde al Chile de hoy: i) es un incentivo mayor a la inversión que el sistema de tributación que actualmente nos rige y; ii) elimina muchas de las actuales prácticas de evasión y elusión.

Incentivo al Ahorro de las Personas. Eximiremos de impuestos a las personas por las ganancias percibidas con el ahorro que realicen en instrumentos financieros, hasta un tope correspondiente a la rentabilidad de instrumentos sin riesgo. De esta forma, se premia el ahorro al que acceden normalmente las personas de ingresos medios.

Se estima que estas medidas para incentivar ahorro e inversión significarán una pérdida de recaudación de $0,21 \%$ del PIB en régimen.

\section{Medidas Orientadas a las PYMES}

Incentivo a la Inversión de las PYMES. Ampliaremos y potenciaremos el sistema simplificado bajo el cual tributan las PYMES, establecido en el artículo 14 ter de la Ley de la Renta. Actualmente, pueden acceder a este sistema las empresas individuales, que pagan IVA y que tengan ventas anuales inferiores a 5.000 UTM. Ampliaremos este beneficio a todas las empresas con ventas anuales inferiores a 14.500 UTM, sean empresas individuales o personas jurídicas, e independiente de sus obligaciones respecto del IVA.

Este sistema ofrece como beneficios para las PYMES: i) la inversión se rebaja de las utilidades de una sola vez (depreciación instantánea), cuestión importante dado que este beneficio estará disponible para las PYMES en el primer año de la Reforma; ii) se ahorran los costos de llevar contabilidad completa, que para muchas empresas pequeñas pueden ser mayores que los impuestos pagados; iii) el SII puede preparar y proponer la declaración anual para cada empresa, facilitando más aún el pago de impuestos.

Todas las modificaciones a este régimen comenzarán a regir desde el primer año de aprobada la ley.

Paralelamente, derogaremos otros regímenes simplificados, que han sido utilizados con objetivos de evasión y elusión del impuesto a la renta de empresas de mayor tamaño y que no se han traducido en beneficios significativos para las PYMES (renta presunta, 14 bis y 14 quater).

Por esta medida y por la aplicación de los cambios en el impuesto a la renta, los pagos finales de impuestos para los empresarios se aplican de acuerdo a la tasa de las personas, por lo cual las Pyme no van a desmejorar su situación impositiva.

Por el contrario, mejoran su situación impositiva final si invierten, dada la aplicación del mecanismo de depreciación instantánea. Por ejemplo, una panadería de barrio que vende en total 55 millones de pesos al año (límite de la microempresa), que tiene una utilidad de 5 millones al año, y que invierte un millón de pesos en la compra de maquinarias como hornos o refrigeradores, pagaría actualmente 340 mil pesos en impuestos y en el sistema que proponemos pagaría sólo 140 mil acogiéndose al 14 ter.

Trato Preferente para las PYMES. Por otra parte, uno de los principales problemas que afecta a las PYMES es el trato abusivo que reciben de las grandes empresas, las que les pagan sus productos o servicios a 90 o más días de plazo, en circunstancias que las PYMES deben pagar el IVA al mes siguiente de emitidas sus facturas. 
Con el fin de dar un trato equitativo y aliviar los problemas de liquidez que esta situación genera a las PYMES, realizaremos un cambio de sujeto en el pago del IVA. Esto significa que las grandes empresas, que realicen compras a plazo a sus proveedores, serán las responsables de pagar una proporción del IVA de dichas operaciones.

Se estima que estas dos medidas de incentivo a las PYMES significarán una pérdida de recaudación de $0,18 \%$ del PIB en régimen.

\section{Otras Medidas Impositivas}

Medio Ambiente. Como una forma de desincentivar la compra de vehículos particulares que utilizan petróleo diesel y también aquéllos de alta cilindrada, estableceremos un impuesto proporcional a la misma, que se pagaría anualmente junto con el permiso de circulación, diferenciado según el combustible utilizado.

En la actualidad, los impuestos específicos a los combustibles sólo se aplican a su uso en el transporte. Sin embargo, el uso de combustibles fósiles en la industria también genera efectos negativos sobre el medioambiente y la salud de las personas. Por ello, avanzaremos en la implementación de impuestos a la emisión de contaminantes en la industria. Esta medida también operará como una forma de estimular el cambio hacia tecnologías limpias. Las PYMES no serán incluidas en esta modificación.

Impuestos Correctivos. En Chile, los impuestos a las bebidas alcohólicas y a los cigarrillos se aplican principalmente sobre el precio de venta. Para que este tipo de gravámenes desincentiven el consumo, es importante que se apliquen por cantidad, pues de otra manera terminan incentivando el desvío hacia productos de menor precio y que normalmente son más dañinos para la salud. Asimismo, el impuesto a las bebidas alcohólicas es sumamente bajo, comparado con el que se aplica en otros países y con el que grava a los cigarrillos, lo que no guarda relación con los daños que produce su consumo excesivo.

Dado lo anterior, estableceremos un impuesto a las bebidas alcohólicas específico, en proporción al volumen de alcohol puro incluido en cada tipo de bebida, cuya tasa estará en torno al promedio de las establecidas en los países de la OECD.
Además, en el caso de los cigarrillos, incrementaremos el impuesto específico por cantidad y reduciremos el impuesto ad-valorem, de manera tal que se mantenga la recaudación en su nivel actual. La medida resulta ser un claro desincentivo al consumo y es una forma de aportar a la salud pública desde los impuestos.

Impuestos Indirectos. Terminaremos con la elusión del pago del IVA en la venta de bienes inmuebles nuevos. Para esto gravaremos todas las transacciones de inmuebles, entre constructoras, inmobiliarias y otros agentes intermedios, anteriores a la venta que se realice al consumidor final.

Asimismo, restringiremos el crédito especial de IVA para empresas constructoras, limitándolo sólo a viviendas con precios inferiores a las 2000 UF.

Aumentaremos en el plazo de dos años el impuesto de Timbres y Estampillas, desde el actual $0,4 \%$ a $0,8 \%$. Se mantiene la situación actual para las PYMES, las que pueden recuperar el impuesto descontándolo de su pago de IVA mensual.

Otras Propuestas. Derogaremos, para los nuevos proyectos de inversión, el DL 600, Estatuto de la Inversión Extranjera. Dicho estatuto en la actualidad no se usa. Eliminarlo significa ratificar la estabilidad institucional de Chile para las inversiones extranjeras.

El mercado de capitales en Chile se ha desarrollado y profundizado. Una de las medidas de política pública que ha contribuido a alcanzar este estado, fue la creación de los Fondos de Inversión Privados (FIP), que tienen como objetivo desarrollar el mercado de inversión de riesgo.

Sin embargo este mecanismo lamentablemente ha sido mal empleado por algunos agentes en el mercado. Un ejemplo de esta situación, es que algunas empresas venden su propiedad con una ganancia de capital, traspasan las acciones de ésta a uno de estos fondos y la ganancia queda en el FIP, de esta manera eluden el impuesto a las empresas debido a las franquicias que tienen los FIP. Por tanto, modificaremos la tributación de los Fondos de Inversión Privados, asimilándola a la tributación de las empresas para cerrar potenciales fuentes de elusión.

Se estima que el conjunto de estas Otras Medidas Impositivas generan en régimen una recaudación de 0,97\% del PIB. 


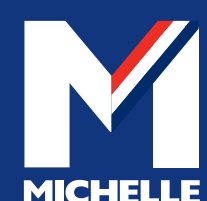

NUEVA

cONSTITUCIÓN 

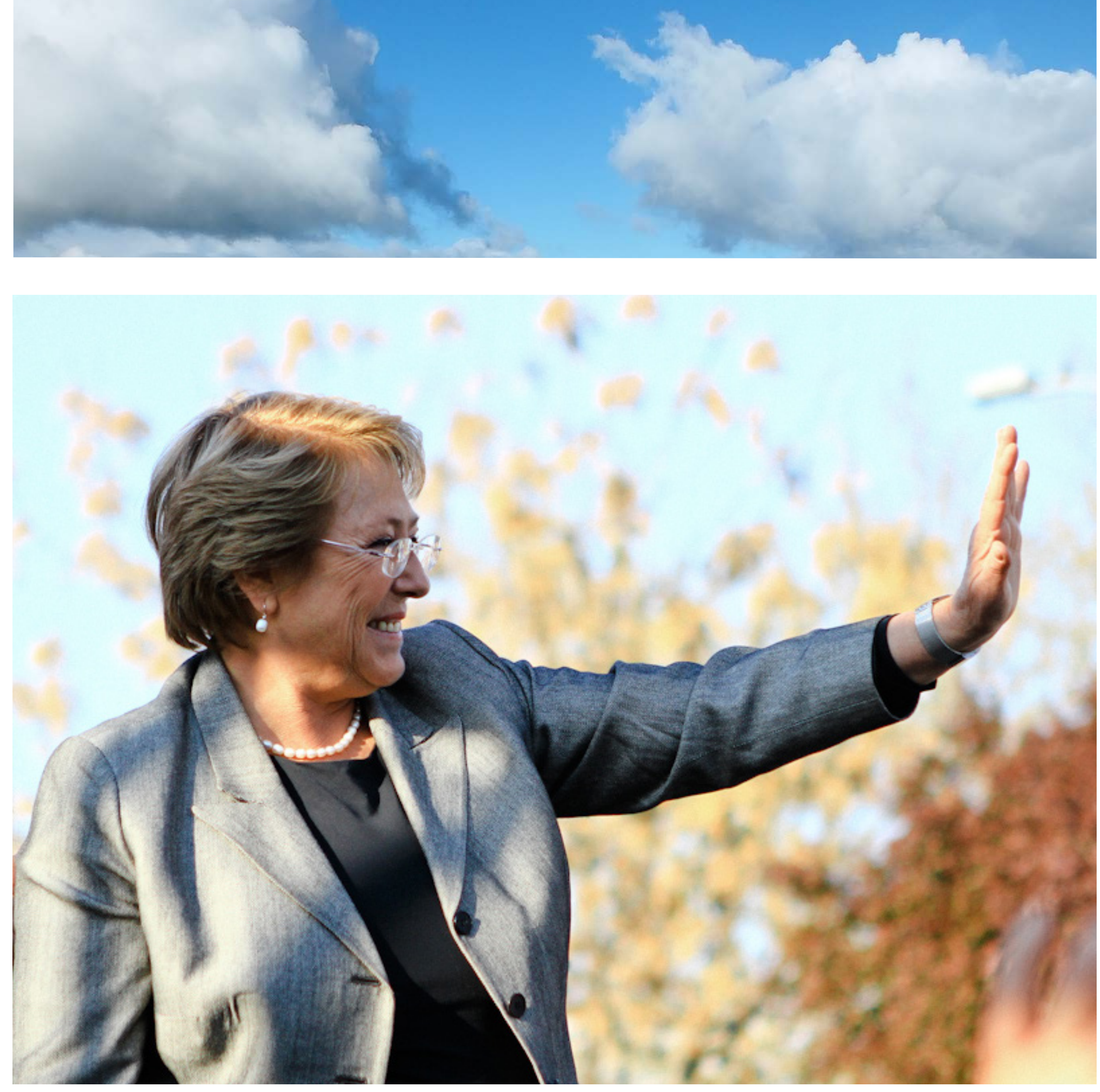


\section{NUEVA CONSTITUCIÓN}

Chile merece que el texto constitucional vigente reconozca y se base en un sistema plenamente democrático; y que recoja las normas y principios de derechos humanos reconocidos en Chile y en el ámbito internacional, en toda su extensión.

El Pueblo Chileno merece que la Constitución Política reconozca y garantice sus derechos.

La idea que recorre el texto actual, aún con las modificaciones que se le han efectuado, está sustentada en una desconfianza a la soberanía popular; de allí las diversas limitaciones a la voluntad popular mediante los mecanismos institucionales de contrapesos fuertes a dicha voluntad, siendo el ejemplo más evidente el mecanismo de los quórum contra mayoritarios para la aprobación y modificación de las leyes importantes. Ello no es propio de un sistema democrático; contribuye a la deslegitimación del sistema político; y actualmente constituye un freno al desarrollo del país, y a su gobernabilidad.

Este déficit no ha sido superado no obstante haberse planteado por las fuerzas políticas democráticas, desde los orígenes de la Carta Política; y la permanencia de este déficit explica hoy, en parte, una crisis de legitimidad y eficiencia de las instituciones y del sistema político.

Chile debe reencontrarse con sus tradiciones republicanas y dar origen a la Nueva Constitución, en la que confluyan las tradiciones constitucionales liberal, democrática y social y que sea fruto de un auténtico consenso constitucional.

El reclamo por una nueva Carta Fundamental no es un prurito de especialistas ni la obsesión de élites sobre ideologizadas. Es un objetivo planteado desde larga data por sectores democráticos; y levantado actualmente por una gran cantidad de organizaciones políticas, sociales, juveniles, regionales, sindicales, de género y representativas de pueblos indígenas; basada en los cuestionamientos antes referidos.

De esta manera, basada en una fuerte convicción democrática, se recoge la demanda nacional por una Nueva Constitución Política para Chile a impulsar en un proceso democrático, institucional y participativo que permita alcanzar este propósito.

La Nueva Constitución Política deberá sustentarse en nuestras mejores tradiciones democráticas; en el desarrollo doctrinal y experiencias de las democracias modernas del mundo occidental; y en el conjunto de derechos, principios y normas plasmados en el derecho internacional de derechos humanos.

\section{Contenidos Básicos de una Nueva Constitución Política}

En lo que respecta a los contenidos que debieran considerarse en la Nueva Constitución que Chile necesita y que chilenas y chilenos nos merecemos, y entendiendo que esa definición le corresponderá al Pueblo en su conjunto, quisiéramos, sin embargo, adelantar los que consideramos los pilares fundamentales sobre los cuales debiera edificarse la Nueva Constitución y que desde el Gobierno impulsaremos.

\section{Derechos Humanos}

La Nueva Constitución debe asumir un compromiso categórico con el reconocimiento y la protección de los derechos humanos; mínimo ético universal en que los pueblos civilizados basan sus formas de convivencia.

La Carta Fundamental debe reconocer el máximo valor a los principios y convenciones internacionales que reconocen los derechos de la persona humana. Es deber de los órganos del Estado respetar, promover y asegurar, en todos sus niveles de protección, el pleno ejercicio de los derechos humanos, propendiendo a su progresividad, expansividad y óptima realización posible.

La Nueva Constitución, fruto de la confluencia de las tradiciones liberal, democrática y social requiere de un completo y equilibrado catálogo de derechos, deberes y garantías que plasme los derechos establecidos en los principios, declaraciones y convenciones internacionales de derechos humanos; reconociendo explícitamente que ellos constituyen limitaciones a la soberanía.

La Nueva Constitución Política debiera basarse por consiguiente en los valores de la dignidad de la persona; de la libertad, de la igualdad y de la solidaridad; estableciendo en plenitud un sistema democrático que reconozca el pluralismo propio de las sociedades democráticas modernas y, con ello, la autonomía moral de las personas y su libre desarrollo de la personalidad.

El catálogo de derechos que debe reconocer la nueva Constitución Política deberá sustentarse básicamente en el desarrollo de las normas y principios consagrados en las declaraciones y convenciones de derechos 
humanos establecidos en el ámbito internacional.

En particular, el desarrollo de este catálogo debiera contener, básicamente, los siguientes aspectos:

Derecho a la vida, integridad física y psíquica. El Estado debe reconocer el derecho a la vida y a la integridad física y moral de todas las personas, sin que puedan ser sometidas a torturas o tratos crueles, inhumanos y degradantes. Se requiere abolir efectivamente la pena de muerte, prohibir el trabajo forzado y la trata de seres humanos.

Hombres y mujeres tienen derecho a una vida libre de violencia física, psicológica, moral y sexual tanto en el ámbito público como privado. Es deber del Estado adoptar las medidas necesarias para prevenir, eliminar y sancionar toda forma de violencia de género, en especial la ejercida contra las mujeres y niñas.

\section{Derecho a la igualdad y a la no discriminación. La} Nueva Constitución debe reconocer el derecho a la igualdad ante la ley y el derecho a la no discriminación arbitraria, sea por razón de sexo, origen étnico, origen social, opinión, orientación sexual o cualquier otra condición o circunstancia personal o social.

La mujer y el hombre gozan de los mismos derechos y el Estado debe promover la realización efectiva y real de la igualdad de derechos. Se debe promover la igualdad de derechos y obligaciones entre mujeres y hombres dentro de la familia en relación con las tareas domésticas y el cuidado de los hijos e hijas. La acción permanente del Estado debe instar a la modificación de los patrones socioculturales de conducta que mantienen estereotipos, prejuicios y prácticas basadas en la idea de inferioridad o superioridad de algunos de los sexos.

Le corresponde al Estado favorecer el igual acceso de mujeres y hombres a cargos de elección popular, así como a puestos de responsabilidad profesional y social. Para ello, la Ley debiera reglamentar medidas de acción positiva que permitan alcanzar la mayor igualdad posible efectiva considerando los estándares de temporalidad, proporcionalidad y afectación.

Las medidas especiales de carácter temporal encaminadas a acelerar la igualdad de facto entre hombres y mujeres no se considerarán discriminación arbitraria.

Derecho a la libertad y seguridad personal. Toda persona tiene derecho a la libertad y a la seguridad personal. Se reconocerá este derecho de acuerdo a los estándares de su establecimiento y protección en las Convenciones Internacionales de Derechos Humanos.

\section{Derecho a la tutela judicial y garantía del debido}

proceso. La Nueva Constitución debe reconocer un derecho general a la tutela judicial efectiva, con todas las obligaciones que para el Estado importa, y una garantía de debido proceso que comprenda tanto el proceso civil como el proceso penal. La presunción de inocencia, no ser juzgado por la misma causa y la prohibición de declarar contra uno mismo son garantías básicas del imputado.

El legislador fijará las reglas del debido proceso en las leyes de enjuiciamiento que se dicten, de todo tipo de orden jurisdiccional.

Derecho a la libertad de conciencia. Una Constitución laica y pluralista debe garantizar a todos el derecho a la libertad de conciencia y a la libertad de cultos con igualdad de tratos para todas las iglesias.

Derecho a la libertad de expresión. Sobre la base de lo dispuesto en la Convención Americana sobre Derechos Humanos, la Nueva Constitución debiera dar las más amplias garantías de libertad de pensamiento y de expresión asegurando a todas las personas la libertad de buscar, recibir y difundir informaciones e ideas de toda índole, sin censura previa, así como el derecho de acceso a la información pública.

Una ley determinará los límites a la concentración de la propiedad de los medios de comunicación social, tanto mono-medial como multimedial, así como la apertura plural del espectro radioeléctrico, y la distribución del avisaje público, de modo de garantizar el pluralismo informativo y el libre acceso a la información.

Derechos de los niños, niñas y adolescentes. Se deben reconocer los derechos de los niños y niñas, de acuerdo a lo establecido en la Convención sobre Derechos del Niño.

La Nueva Constitución debiera resguardar el principio de que ambos padres tienen obligaciones comunes en lo que respecta a la crianza y el desarrollo del niño y niña.

El Estado procurará comprometerse a implementar todas las medidas legislativas, administrativas, sociales y educativas apropiadas para proteger al niño o niña contra toda forma de perjuicio o abuso físico o mental, descuido o trato negligente, malos tratos, explotación y abuso sexual. Se requiere prohibir el trabajo infantil y cualquier tipo de violencia contra los niños y niñas, sea física o psíquica. 


\section{Derecho a la identidad, a la intimidad, a la imagen, al honor, y a los derechos sexuales y reproductivos.}

La Nueva Constitución debe garantizar el derecho a la identidad, a la intimidad personal, a la propia imagen, al honor y al nombre; declarando inviolables el domicilio y las comunicaciones de todo tipo, salvo por orden o resolución judicial.

Se deberá reconocer también el derecho a la identidad sexual, la orientación sexual y los derechos sexuales y reproductivos de las personas.

Derecho de propiedad. La Nueva Constitución junto con reconocer el derecho a la propiedad privada, debiera contemplar la idea de que la propiedad obliga y que su uso debe servir al mismo tiempo al bien común. En esa línea, se requiere reconocer que la función social del derecho a la propiedad privada y a la herencia, delimitará su contenido, de conformidad a la ley.

Se debe garantizar la libre iniciativa económica privada, con las limitaciones establecidas en la ley.

La Nueva Constitución debe reconocer el dominio público pleno, absoluto, exclusivo, inalienable e imprescriptible de los recursos hídricos, mineros y del espectro radioeléctrico. El Estado tiene derecho a regalías por el aprovechamiento de los recursos naturales, especialmente minerales.

Se declara las aguas como bienes nacionales de uso público, cualquiera sea el estado en que se encuentren, el lugar en que estén depositadas o el curso que sigan, incluidos los glaciares.

Se delegará en el legislador la regulación del procedimiento de constitución, reconocimiento, ejercicio y extinción de los derechos que se reconozca a los particulares sobre las aguas, sin perjuicio de reservar caudales de aguas superficiales o subterráneas para asegurar la disponibilidad, calidad, seguridad y continuidad del recurso hídrico para todas las personas.

Derechos políticos. Se debe reconocer el derecho de participar en la vida pública y política del país. El sufragio es un derecho esencial de la ciudadanía. Por tanto debe ser fortalecido para asegurar la más plena participación, fijando la Constitución y la ley los requisitos para su ejercicio. Se reconocerá el derecho de asociación política, el derecho de protección del Estado a los nacionales, el derecho a la nacionalidad, el derecho a una buena administración, el derecho de acceso a los documentos, el derecho de petición a la autoridad y el derecho de reunión y manifestación.
Se debe garantizar el derecho a formar partidos políticos y el derecho de asociación política a fin de que los ciudadanos puedan constituir movimientos o asociaciones políticas.

El sufragio es universal, igualitario, secreto y debe poder ser ejercido por todos los chilenos mayores de 18 años, en su dimensión pasiva y activa, sin que su domicilio o lugar de residencia puedan limitar o condicionar el derecho al sufragio.

El Estado debe favorecer el acceso y participación en condiciones igualitarias entre mujeres y hombres a cargos de elección popular. Se debe garantizar el ejercicio efectivo de los derechos políticos de las mujeres prestando especial atención al derecho a ser elegidas y a ocupar cargos de elección popular, así como nominación en las instancias de dirección y decisión de los poderes públicos. La ley deberá establecer las medidas de acción positiva que permitan alcanzar la paridad en los cargos de representación popular.

\section{Derechos colectivos y reconocimiento de los pueblos} indígenas. Chile, en cuanto nación, es indivisible y pluricultural. Chile incluye a los pueblos indígenas, quienes gozan de identidad y cultura propia.

Los derechos colectivos se relacionan con el medio en que viven estos pueblos y en el uso de sus recursos, y el derecho a conservar, desarrollar y fortalecer su identidad, lengua, instituciones y tradiciones sociales y culturales.

El Estado debe fomentar la valoración y difusión de las manifestaciones culturales de los pueblos indígenas, los cuales tienen derecho a una educación propia y a un régimen educativo de carácter intercultural y bilingüe, atendiendo a sus particularidades socioculturales, valores y tradiciones.

Derechos económicos, sociales y culturales. La Nueva Constitución deberá consagrar un Estado social y democrático de derecho, que asume los derechos económicos sociales y culturales como verdaderas obligaciones de la actividad estatal, para asegurar mínimos de igualdad social para un disfrute efectivo de todos los derechos.

Derecho a la participación política y social. La Nueva Constitución debe garantizar el derecho a la participación política y social en las diferentes áreas de la vida nacional como garantía del orden político e institucional y como derecho incluyente de los grupos históricamente excluidos de los espacios de toma de decisiones públicas.

La Ley determinará las normas y requisitos para el registro legal y las 
formas específicas de intervención de los partidos políticos, en tanto instituciones de interés público, cuyo fin es promover la participación de la ciudadanía en la vida democrática, asegurando la transparencia, las prácticas democráticas y la representación equilibrada de mujeres y hombres en su vida interna. El Estado procurará remover la desigualdad de acceso a los recursos económicos, una de las principales barreras de entrada que enfrentan las mujeres para ejercer su ciudadanía, en particular el derecho a ser elegidas.

El Estado reconoce el derecho a la participación ciudadana en la generación de políticas, definición de prioridades y gestión de las mismas. El ejercicio de este derecho deberá compatibilizarse con el buen servicio de los órganos administrativos. La ley arbitrará los mecanismos e instrumentos para hacer efectivo el derecho.

Corresponde también al Estado garantizar el derecho a la educación, al trabajo, a la vivienda, a la protección de la salud, a la seguridad social, el derecho de las personas con discapacidad y de la tercera edad, el derecho al goce del medio ambiente libre de contaminación. Se reconoce el derecho a la cultura, entendido tanto como el derecho a bienes culturales como al patrimonio cultural. El Estado deberá promover la ciencia y la investigación científica y técnica en beneficio del interés nacional.

\section{Garantías}

La Nueva Constitución debe garantizar el desarrollo y la efectividad del conjunto de derechos fundamentales. En esa dirección se deben establecer las acciones y recursos que permitan su reclamo ante las instancias judiciales, tales como el amparo, la protección y el acceso a la información; también se debe establecer que las limitaciones a estos derechos sólo puede hacerse por ley; y no afectar el derecho en su esencia. Por otra parte, los estados de excepción constitucional sólo pueden limitar los derechos en los supuestos fácticos que la Constitución Política establezca; con estricta sujeción a estándares internacionales.

\section{Deberes}

En materia de deberes constitucionales, la Nueva Constitución debe hacerse eco de la fórmula de la Declaración Universal de los Derechos Humanos de 1948, que sitúa a las personas y sus grupos no sólo frente al Estado, sino frente a la comunidad en que viven, de suerte que los deberes superen concepciones individualistas que niegan la necesidad de la cooperación y la solidaridad social.
En consecuencia, la Constitución deberá establecer deberes relativos a la vida pacífica, el respeto de los derechos, la contribución a una sociedad solidaria, el cumplimiento con las cargas reales y personales que establezca la ley; los deberes para con el Estado nacional, sus valores e intereses permanentes y los deberes relativos al respeto y cumplimiento de la Constitución y la ley.

\section{Sistema Político}

La Nueva Constitución Política deberá establecer que Chile es un Estado social y democrático de Derecho; siendo su forma política una República Democrática. Y que la soberanía nacional reside en el pueblo de Chile, del que emanan los poderes del Estado. Se deberá plasmar una democracia representativa.

El Estado Social, y Democrático de Derecho. En la Constitución Política se deberá reconocer bajo esta cláusula que el Estado no sólo es un sistema de potestades, sino un conjunto de deberes de "buen Gobierno" y de satisfacción de necesidades públicas que son consustanciales a la legitimidad misma del Estado y del Poder. Se funda en la dignidad, libertad e igualdad de las personas, así como los principios participativo, pluralista y de solidaridad.

Se trata, ante todo, el Estado social de un Estado de Derecho, fundado en el principio de legalidad y en el respeto de derechos fundamentales, de suerte que la fuentey medida de toda autoridad sea el Derecho mismo. El Estado Social es un Estado democrático, en que el poder electoral reside en el pueblo y su ejercicio se verifica en el poder a través de instituciones, procedimientos y técnicas representativas y participativas.

Finalmente, el Estado social es un Estado de garantías, que protege el goce efectivo de derechos económicos, sociales y culturales.

La República Democrática. Las democracias pluralistas combinan elementos de representación y participación en su versión contemporánea. Sus principios básicos son la representación políticay la participación, en una ecuación de equilibrio. Esta definición republicana es una opción histórica por la electividad de los cargos públicos, la alternancia en el poder y la responsabilidad en el ejercicio del poder.

La República Democrática exige un sistema de rendición de cuentas y, por tanto, de controles y responsabilidades sociales, políticas y jurídicas en el ejercicio del poder.

La Nueva Constitución confiere derecho de sufragio activo y pasivo a 
todos los ciudadanos, de suerte que la mayoría de edad política de 18 años es requisito suficiente para ser ciudadano y para optar a cualquier cargo público de elección popular, sin perjuicio de los demás requisitos que determine la ley.

Sistema Electoral. La Nueva Constitución debe consagrar los principios que aseguren un sistema electoral que recoja los principios básicos de una democracia representativa.

En este ámbito, específicamente, impulsaremos la sustitución del actual sistema electoral binominal para la elección parlamentaria por uno de representación proporcional.

Quórum para aprobar leyes. De acuerdo a la esencia del sistema democrático, se deberá consagrar el principio de mayoría; siendo la mayoría absoluta el máximo quórum de aprobación y modificación de las leyes, recogiendo con ello nuestra propia historia constitucional democrática, así como el derecho comparado y el desarrollo de las doctrinas democráticas.

Igualdad entre mujeres y hombres. La Nueva Constitución reconoce a la mujer iguales derechos que los hombres en materia civil, familiar, cultural y económica. Se reconocen sus derechos sexuales y reproductivos. La igualdad política también exige adoptar decisiones constitucionales que pongan fin a las barreras que entraban la participación paritaria de la mujer en la vida política del país.

Partidos Políticos. La Nueva Constitución reconoce y valora la importancia de los partidos políticos. Junto con garantizarles los recursos indispensables para el cumplimiento de sus múltiples e importantes tareas, la Carta Fundamental define mecanismos eficaces para velar por su transparencia y su democracia interna.

Estado Laico. La Nueva Constitución, junto con reafirmar la separación entre el Estado y las Iglesias, y la neutralidad del Estado frente a la religión, con el pleno respeto por las creencias religiosas y éticas de las personas, y la práctica del culto; garantizará la igualdad entre las distintas confesiones religiosas.

Asimismo, deberán suprimirse de la ley y de las reglamentaciones relativas a poderes del Estado toda referencia a juramentos, libros o símbolos de índole religiosa.

Pueblos indígenas. Pasado el bicentenario Chile debe saldar la deuda histórica que tiene con sus pueblos indígenas, reconociendo su identidad mestiza y sus raíces indígenas. Ello se verifica en el reconocimiento constitucional de los pueblos indígenas, sus tradiciones, lenguas, costumbres, aporte a la cultura y derechos colectivos.

El conjunto de derechos colectivos exige reconocer que el Estado de Chile es una Nación indivisible, plural y pluricultural. Asimismo obliga a establecer que el Estado deberá proteger, promover y asegurar los derechos individuales y colectivos de los pueblos indígenas y, además, deberá desarrollar políticas inter-culturales, participativas, inclusivas y de bienestar.

Participación Ciudadana. La Nueva Constitución incorporará nuevos mecanismos de democracia directa o semi directa en distintos niveles de decisión pública.

\section{Hacia una efectiva descentralización y poder de las \\ Regiones. La Nueva Constitución romperá con el centralismo del Estado chileno. Se establecerán gobiernos regionales que, liderados por jefes ejecutivos elegidos por votación directa, dispondrán de autonomía, facultades y recursos suficientes para constituirse en verdaderos ejes del desarrollo territorial.}

Poder Judicial. El Poder Judicial es clave, no sólo en la tutela judicial del derecho y la seguridad jurídica, sino en el Estado de Derecho mismo. Porloanterior, junto con asegurar suindependenciayautonomía, sehace necesario fortalecer al Poder Judicial en sus funciones jurisdiccionales asegurando la plenitud y unidad de la jurisdicción.

La Constitución asegurará la unidad de la jurisdicción, sometiendo a la justicia militar y al Ministerio Público Militar a un régimen compatible con la administración de justicia de un Estado de Derecho. En este mismo sentido la justicia militar conforme su propia naturaleza y origen histórico sólo será aplicable a los militares y bajo ningún pretexto a los civiles en tiempos de paz, velándose por el respeto de la garantía constitucional al debido proceso.

Tribunal Constitucional. La Nueva Constitución debe hacerse cargo de que el Tribunal Constitucional es una institución contra mayoritaria, pues tieneel poderdecontrarestar decisiones democráticas.

Para ello, se propone una nueva generación del Tribunal Constitucional desde los poderes públicos democráticos, sin injerencia de la Corte Suprema, en número impar, eliminando el voto dirimente o de calidad de su Presidente.

Con la finalidad de racionalizar el rol contra mayoritario del Tribunal, se requiere reordenar sus competencias, fortaleciendo su comprensión como tribunal, resolviendo conflictos, por lo que se hace imperioso suprimir las competencias de control preventivo de constitucionalidad 
de normas, tanto del control preventivo obligatorio como facultativo. Asimismo, el Tribunal Constitucional tendrá una nueva competencia consultiva para, a petición de cualquiera de las cámaras, examinar la necesidad de adecuación del derecho interno con motivo de la aprobación parlamentaria de tratados internacionales de derechos humanos.

Finalmente, la Constitución debe establecer mecanismos de coordinación sistemática del Tribunal Constitucional con los tribunales que integran el Poder Judicial y la Justicia Electoral, para asegurar el debido cumplimiento de sus decisiones cuando corresponda.

Fuerzas Armadas. Para la Nueva Constitución las Fuerzas Armadas, de Orden y Seguridad Pública serán instituciones esencialmente obedientes al poder constitucional, no deliberantes, disciplinadas y partícipes del desarrollo del país a nivel nacional y regional. Las Fuerzas Armadas, de Orden y Seguridad Pública tendrán el monopolio instrumental de la fuerza coactiva. Tendrán como fines la defensa nacional, la seguridad y el orden público, según sea el caso, con pleno respeto de los derechos humanos, del medio ambiente y los recursos nacionales estratégicos de la nación.

Defensoría del Ciudadano. Las quejas de los administrados en relación a la mala administración o deficiente funcionamiento de los servicios públicos de la Administración del Estado o gestionados por empresas privadas, y que importen la lesión de derechos fundamentales y de derechos humanos, pasan a ser campo de las tareas de una Defensoría del Ciudadano que se propone crear. Esta Defensoría del Ciudadano es una magistratura moral, revestida de auctoritas, pero no de imperio, que formula exhortaciones a la autoridad, recomendaciones, informes, contribuyendo a activar el control político y el control social de los gobernantes.

\section{Banco Central, Consejo para la Transparencia y las instituciones fiscalizadoras son situadas en la Administración} institucional, se les reconoce su autonomía y la ley establecerá la medida de la autonomía y de la configuración de sus competencias.

Reforma de la Constitución. La actual Constitución tiene un déficit de legitimidad democrática que se proyecta a su capítulo relativo al ejercicio de poder constituyente derivado, sometido a quórum reforzados que aseguran el bloqueo de las minorías, la imposición de un falso consenso constitucional y la nula participación de la ciudadanía.

La Nueva Constitución prevé para el ejercicio del poder constituyente derivado las siguientes reglas básicas: i) La potestad constituyente derivada reside esencialmente en el Congreso Nacional quedando sometida al principio de doble lectura y de rol co-constituyente del Gobierno; ii) Las diferencias entreel Congreso Nacionaly el Presidente de la República que se traduzcan en un desacuerdo sobre el contenido de la reforma constitucional, en cualquiera de sus trámites constitucionales, deberán ser sometidas a referéndum constituyente de forma que sea el pueblo el que arbitre ante tales diferencias; iii) La reforma constitucional despachada por las cámaras del Congreso Nacional, sancionada por el Gobierno, deberá ser sometida a ratificación del pueblo mediante referéndum, antes de su promulgación, y iv) El ejercicio del poder constituyente derivado admite la reforma total o parcial, debiendo someterse a las reglas procedimentales fijadas para su ejercicio en la Constitución.

Con la finalidad de garantizar la estabilidad normativa de la Constitución y su rigidez se establece como regla general el quórum reforzado de mayoría absoluta de los miembros en ejercicio de cada cámara; sin perjuicio de los quórum especiales previstos para el veto gubernamental.

Asimismo, supletoriamente se aplicará al procedimiento de reforma constitucional las reglas acerca del procedimiento legislativo.

\section{Sobre el proceso para la elaboración de una Nueva Constitución Política}

La Nueva Constitución Política deberá elaborarse en un proceso: i) democrático; ii) institucional, y iii) participativo.

Proceso Democrático: La Nueva Constitución debe generarse en un contexto en que se escuchen todos los puntos de vista, se hagan presentes todos los intereses legítimos y se respeten los derechos de todos los sectores.

Proceso Institucional: El logro de una Nueva Constitución exigirá de todas las autoridades instituidas una disposición a escuchar e interpretar la voluntad del pueblo. La Presidencia de la República y el Congreso Nacional deberán concordar criterios que permitan dar cauce constitucional y legal al proceso de cambio; y que permitan la expresión de la real voluntad popular en el sentido de los cambios.

Proceso Participativo: La ciudadanía debe participar activamente en la discusión y aprobación de la Nueva Constitución. Para tal efecto, el proceso constituyente supone, de entrada, aprobar en el Parlamento aquellas reformas que permitan, precisamente, una deliberación que satisfaga esta condición. 


\section{MICHEELLE}

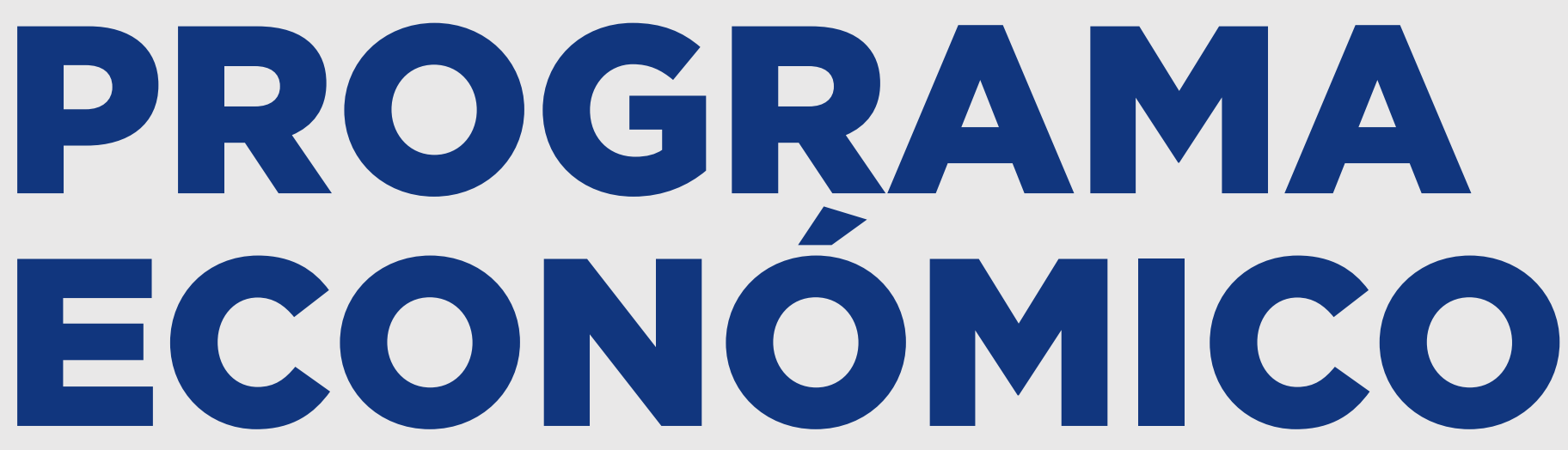




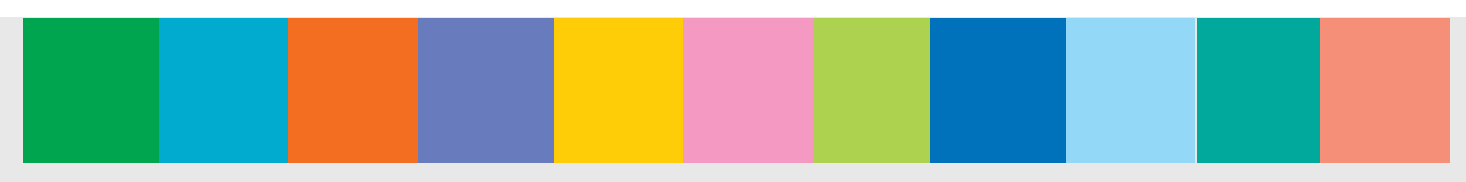




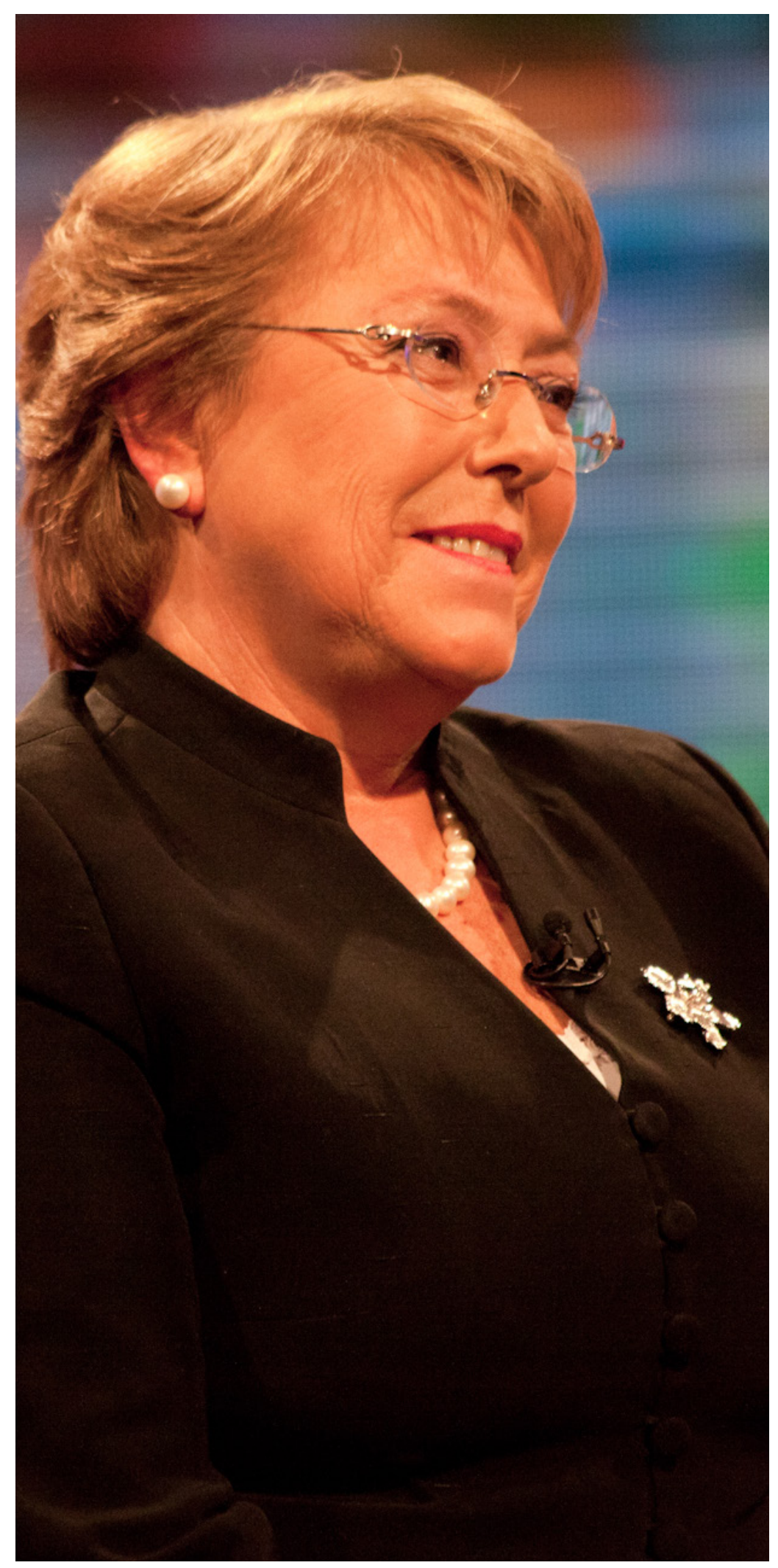

PROGRAMA ECONÓMICO

Junto con las políticas públicas, el crecimiento económico es una vía fundamental para enfrentar la desigualdad, erradicar la pobreza, elevar las condiciones de vida de las personas, abrir más oportunidades al desarrollo y generar ingresos que permitan sostener el esfuerzo público para implementar políticas de protección social. Así ha ocurrido en Chile, donde bajo los gobiernos de la Concertación se lograron importantes avances sociales de manera fiscalmente sustentable, asociados a una economía activa y bien manejada.

En el período 2008-2009 la economía chilena enfrentó la mayor crisis económica mundial desde la Gran Depresión de los años 30. Chile logró enfrentar esta gran crisis como nunca antes en su historia, gracias al buen manejo macroeconómico, con políticas fiscal y monetaria contra-cíclicas, que hicieron que ya en 2010 nuestra economía estuviese nuevamente creciendo. Así, entre 2010 y 2012 el crecimiento promedio del PIB ha sido de 5,7\% y el desempleo se ha reducido. Estas son buenas noticias para las chilenas y chilenos. Sin embargo, estas cifras no reflejan cambios de fondo en nuestra estructura productiva que permitan sostener este crecimiento en el mediano y largo plazo, sino que son consecuencia de factores cíclicos.

El empuje que ha mostrado la economía proviene, por la parte externa, de un positivo escenario global en materia de condiciones financieras y de precios del cobre; y en el frente interno, por el impulso monetario y fiscal que se implementó como respuesta a la crisis global de 2008-2009. Todo esto le permitió a nuestra economía sortear la crisis más grande desde la Gran Depresión, con una velocidad y efectividad como nunca antes lo habíamos hecho.

Como en el escenario más probable las condiciones financieras internacionales no seguirán mejorando y el precio del cobre no seguirá subiendo, los factores externos que ayudaron al crecimiento dejarán de ser un motor relevante. Pero además, por el lado de la actividad doméstica, la actividad está retornando a su nivel potencial tras agotarse el impulso macroeconómico del período 2008-2009 y sin que se realizaran reformas relevantes para potenciar el crecimiento. Esto queda demostrado en que el crecimiento tendencial para 2014 ha sido estimado en $4,8 \%$.

Hoy vemos que al comenzar a decaer el precio de cobre, se evidencia una estrechez fiscal y más vulnerabilidad de la 
política fiscal frente a potenciales vaivenes en el precio del cobre. La economía no está creciendo como debería. Estas son las condiciones de crecimiento que el próximo gobierno heredará: estamos hablando de un crecimiento estimado en torno al $4 \%$ el próximo año. Sin embargo, a partir del 2015 retomaremos la senda sostenida de crecimiento y en la segunda mitad de la próxima administración, Chile crecerá en torno al $5 \%$, es decir, al nivel de su PIB potencial.

Y de acuerdo con estas estimaciones, nuestra economía estará en condiciones de generar entre 600 y 650 mil nuevos empleos en los próximos 4 años.

Aunque este crecimiento potencial no es despreciable, hace varios años que como país no hemos sido capaces de aumentarlo. Más aún, en años recientes se han incubado desequilibrios, que de no revertirse a tiempo, significarán una amenaza a las sólidas bases de nuestra economía. En efecto, en 2014 este gobierno entregará las finanzas públicas con un déficit estructural de $1 \%$ del PIB, a pesar de que dicho déficit se alcanzó en 2011 y en 2012 fue de 0,4\% del PIB. Además, por cuarto año consecutivo seguirá ahondándose el déficit en la cuenta corriente de la balanza de pagos, lo que significa que como país estamos gastando más de lo que producimos. Como en cualquier hogar, esa diferencia la cubrimos con financiamiento externo. Seguir ampliando esa brecha no parece prudente.

Estas amenazas no logran ser compensadas por la fortaleza de otros factores que inciden en el crecimiento. Por ejemplo, la productividad total de factores creció sólo 0,4\% en 2012 y se proyecta que se expandirá $0,5 \%$ entre los años 2013 a 2017, variación insuficiente para lograr el nivel de desarrollo al que aspiramos. Esto se debe a carencias en la formación de nuestros recursos humanos, el desarrollo de la innovación, la ciencia y la tecnología, las inversiones en infraestructura, especialmente en materia de generación y transmisión eléctrica.

A pesar de la coincidencia en el diagnóstico de mejorar la calidad de la educación y los esfuerzos que se han dedicado a esta tarea, aún estamos lejos de los niveles que necesitamos. El acceso a educación de calidad sigue concentrado en quien puede pagarla. La capacitación ha perdido efectividad y la evidencia muestra que, la mayor parte, no tiene efectos relevantes sobre la empleabilidad ni los salarios. Más aún, aquella financiada vía franquicia tributaria se concentra mayoritariamente en los trabajadores que menos la necesitan, que son los más educados, de mayores ingresos y que trabajan en empresas de mayor tamaño.

Los indicadores internacionales revelan que el gasto total en innovación en Chile es muy bajo comparado con el de los países con los que aspiramos competir, brecha que incluso es más amplia en el sector privado que en el público. Sin una promoción más decidida de la investigación científica, el desarrollo tecnológico y la innovación, no lograremos el salto productivo que necesitamos para hacer la diferencia en una economía como la nuestra, que depende fundamentalmente de un recurso natural no renovable como el cobre.

En materia de inversión en generación y transmisión eléctrica necesitamos de manera urgente recuperar el tiempo perdido. El costo de la electricidad se ha encarecido, lo que afecta a toda la cadena productiva y también a las familias. Considerando la escasez de nuevos proyectos en construcción, el tiempo que demoran para poder operar, y el crecimiento esperado de la demanda, podría generarse una situación crítica. Este complejo escenario responde a retrasos en la obtención de autorizaciones y permisos, conflictos sociales mal resueltos que entraban los proyectos y su creciente judicialización. Es evidente que ha faltado liderazgo político para construir soluciones que permitan asegurar el acceso a la energía que Chile necesita. Más aún, esta falta de liderazgo ha producido un deterioro en la institucionalidad del sector.

En otras palabras, en los últimos años el gobierno desaprovechó las oportunidades de la bonanza económica para generar mejores condiciones de fondo para sustentar nuestro crecimiento futuro. Ello pasó desapercibido mientras las fuentes de crecimiento cíclico estuvieron presentes, pero hoy que ellas están en retirada, las falencias se hacen evidentes.

Creemos firmemente que los gobiernos deben trabajar para mejorar las condiciones de vida de los ciudadanos de manera permanente, y no sólo por los años que dura su administración. Por ello nuestro desafío es realizar las reformas necesarias para aumentar nuestro crecimiento potencial de manera sostenida, para crear empleo de calidad y construir una sociedad más inclusiva. 


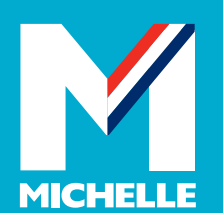

BUENA

ECONOMIA Y

RESPONSABILIDAD

FISCAL 

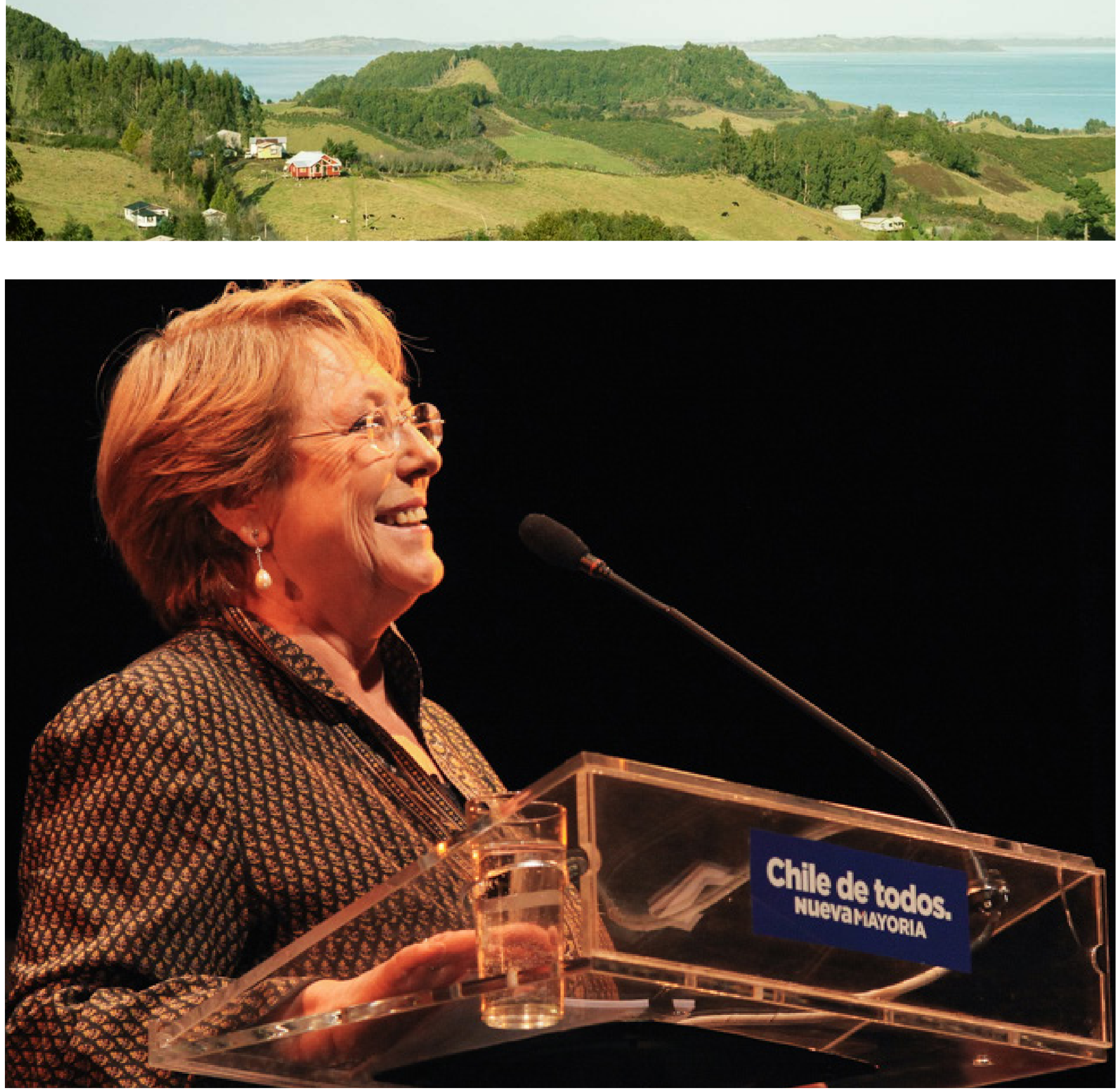


\section{BUENA ECONOMÍA}

Nuestro principal objetivo es enfrentar la desigualdad para que los beneficios del desarrollo sean percibidos por todos. No es sostenible la situación actual, donde las oportunidades se concentran en quienes tienen mayores recursos económicos y capital social. Necesitamos crecimiento económico, pero construido sobre bases sólidas, con una economía moderna. Estas bases requieren inclusión, pues tenemos la convicción de que debemos crecer para incluir, e incluir para crecer. Para ello realizaremos un conjunto coherente de reformas de política pública. Muchas de ellas rendirán frutos en el mediano plazo, lo que representará un quiebre respecto del cortoplacismo de las acciones que se han implementado en los años recientes.

Realizaremos una reforma estructural en educación en todos sus niveles, con foco en calidad e inclusión, a la vez que recuperaremos la capacitación laboral como una herramienta para el desarrollo y mejoramiento de la productividad. Estas reformas tienen que responder también a los desafíos productivos que esperamos tenga Chile en el futuro, es decir, están pensadas también desde la perspectiva de la productividad y de las oportunidades de desarrollo en el mundo laboral.

Aumentaremos sostenida y fuertemente la productividad, elevando la inversión en ciencia, tecnología e innovación y generando estímulos para su aplicación en la solución de los problemas del país.

Pondremos en marcha medidas para asegurar la provisión de la energía que el país necesita para su crecimiento y recuperaremos el normal funcionamiento de la institucionalidad del sector, que ha perdido capacidad resolutiva, en especial, por la intervención del Poder Ejecutivo.

Seguiremos fortaleciendo el Estado mediante modernizaciones para que pueda responder con agilidad a los ciudadanos, integrando a las y los mejores profesionales y técnicos al servicio público, y asegurando un uso eficiente de los recursos públicos y una atención de calidad para las personas. Esto implica fortalecer la institucionalidad pública pro competencia y de protección a los consumidores, para darle gobernabilidad al crecimiento económico. También implica emplear con mayor creatividad las tecnologías de la información, tanto para atender a las personas como para incrementar el control de calidad de las políticas públicas. Asimismo, desarrollaremos una institucionalidad pública de estadísticas altamente tecnificada, que genere confianza transversal, pues es un insumo fundamental para poder diseñar e implementar buenas políticas públicas.

Además, recuperaremos la senda de la responsabilidad fiscal en la administración de las finanzas públicas, que es la base para que el Estado pueda sostener sus compromisos en el mediano y largo plazo. Para ello reforzaremos la ley sobre responsabilidad fiscal que aprobamos en 2006 y realizaremos todos los esfuerzos para retornar a una situación de balance estructural en 2018.

Complementariamente, impulsaremos un ambicioso plan de inversión pública y concesiones, a la vez que implementaremos un conjunto de medidas de apoyos sectoriales.

En los primeros 100 días de Gobierno realizaremos cuatro acciones ligadas al programa económico. En primer lugar lanzaremos la Agenda de Productividad, Innovación y Crecimiento Económico, que contempla acciones en cuatro áreas estratégicas: políticas de competencia, modernización del Estado, desarrollo productivo, e innovación. Esta agenda busca que Chile tenga una economía realmente moderna y dinámica

En segundo lugar, anunciaremos una detallada Agenda de Energía que se pondrá en marcha el 2014. Ésta contemplará propuestas de corto plazo, que permitan aminorar los efectos de restricción y alzas de precio en el período $2014-2018$. Paralelamente, incluirá medidas de mediano plazo, dirigidas a lograr un desarrollo equilibrado y sustentable del sector para las próximas dos décadas.

En tercer lugar, enviaremos al Congreso el proyecto de ley del fortalecimiento del SERNAC, que permitirá que tenga atribuciones reales y efectivas para defender los derechos de los consumidores.

A esto se sumará el proyecto de ley de Reforma Tributaria, con el objeto de aumentar los ingresos permanentes del Fisco en $3 \%$ del PIB en régimen. 


\section{RESPONSABILIDAD FISCAL}

La crisis económica de muchos países desarrollados, y las crisis experimentadas en el pasado en Chile, son evidencia de la necesidad de actuar con responsabilidad fiscal para generar estabilidad macroeconómica y mejorar de manera sustentable el bienestar de ciudadanos y ciudadanas.

Desde el primer día ha sido nuestro sello enfrentar las necesidades sociales con un financiamiento estructural y sustentable.

Para robustecer este compromiso, introdujimos una regla fiscal para construir los presupuestos del sector público aislándolos del ciclo económico y del precio del cobre, mediante el establecimiento de metas explícitas de balance estructural. Luego impulsamos una ley sobre Responsabilidad Fiscal, que formalizó el enfoque estructural para guiar la política fiscal y creó los fondos de riqueza soberana para mantener e invertir el ahorro público resultante.

Nuestra política fiscal seguirá guiándose por la máxima de comprometer gastos permanentes siempre asociados a ingresos permanentes, a diferencia del actual gobierno. Por ello y atendiendo a la necesidad de emprender una reforma estructural en educación, otros requerimientos de la protección social (salud, pensiones) y el déficit estructural de $1 \%$ del PIB que se heredará de la actual administración, implementaremos una Reforma Tributaria que permita al Estado contar con los ingresos necesarios de manera sustentable.

Así, este mayor gasto proyectado en educación y en otras áreas de la protección social, no implicará inestabilidad en las finanzas públicas.

Al mismo tiempo, el presupuesto público debe tender a equilibrarse en términos estructurales, convergiendo gradualmente desde el déficit estructural de 1\% del PIB que dejará el actual gobierno a un balance estructural de
0\% del PIB en la formulación del presupuesto de 2018.

Además, desde la política fiscal velaremos por mantener un tipo de cambio real competitivo para nuestras exportaciones y también contribuiremos a conservar la inflación controlada, apoyando así el esfuerzo que realiza el Banco Central a través de la política monetaria.

Dado el nivel de desarrollo que han alcanzado las finanzas públicas en Chile, el próximo paso que debemos dar es perfeccionar la planificación presupuestaria de mediano plazo. Ello permitirá aumentar la transparencia de la política fiscal e incrementar la previsibilidad de los flujos financieros, brindando una mejor herramienta de planificación del financiamiento de las políticas públicas y entregando al mercado mayor información respecto de la posible evolución de la política fiscal.

Como un reforzamiento de la Ley sobre Responsabilidad Fiscal que aprobamos en 2006, crearemos por ley un Consejo Consultivo Fiscal. A este organismo le corresponderá evaluar la metodología de cálculo del balance estructural y proponer perfeccionamientos; como también administrar los comités de expertos que entregan los parámetros clave para el cálculo del balance estructural de cada año, alertar sobre riesgos fiscales emergentes y evaluar periódicamente la sostenibilidad de la política fiscal. Si el gobierno se desvía de la meta de balance estructural, el Consejo tendrá la obligación de pronunciarse públicamente sobre las razones invocadas para ello.

Con la responsabilidad fiscal en mente, procederemos a capitalizar CODELCO. Esta capitalización es necesaria para que la empresa lleve adelante sus proyectos estructurales, para que su producción no disminuya y para que retome su competitividad internacional. Sólo de esta forma será posible mantener su contribución al financiamiento de la política fiscal. 


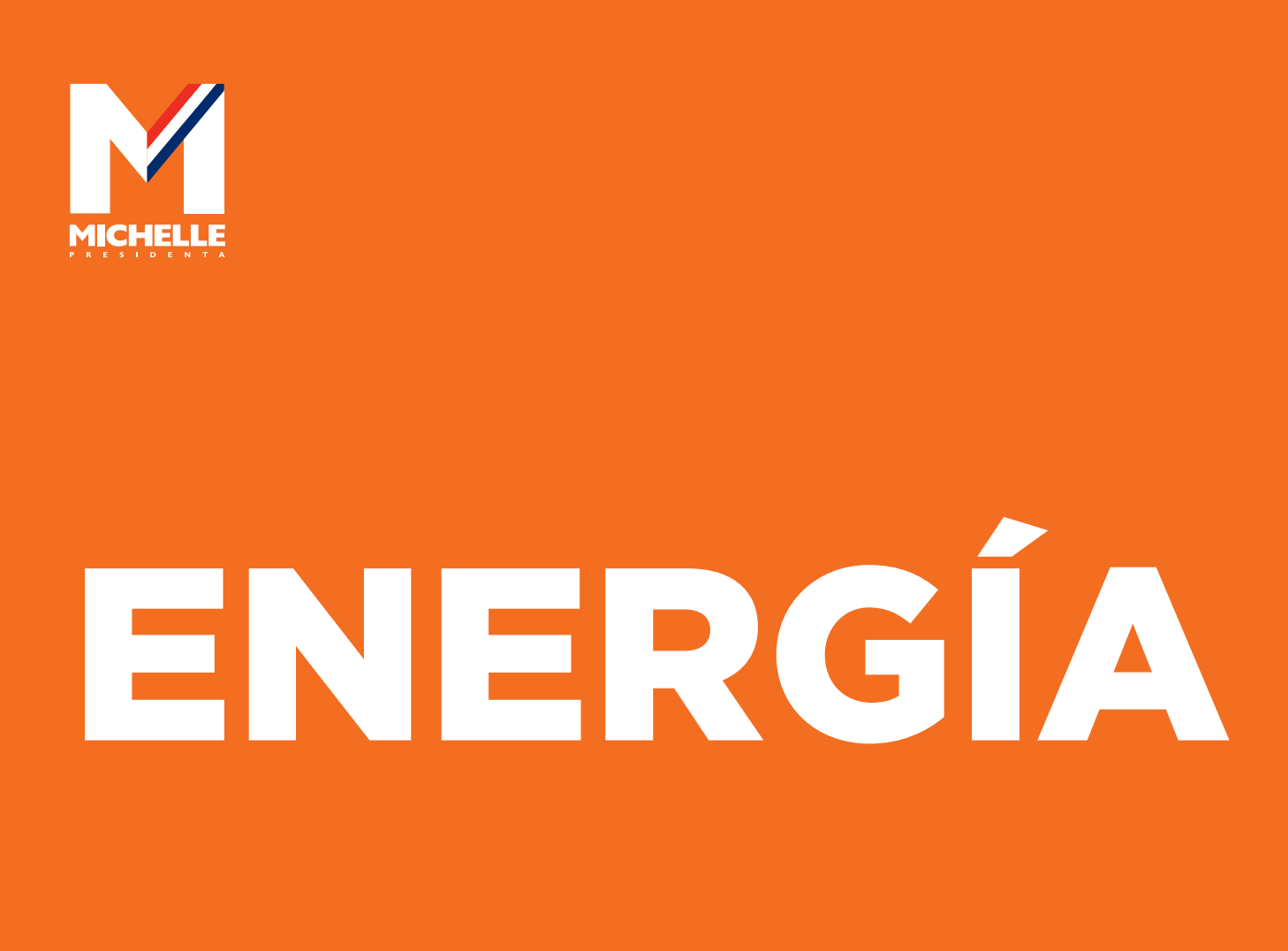

\section{MICHEILE r}

ENERGIA

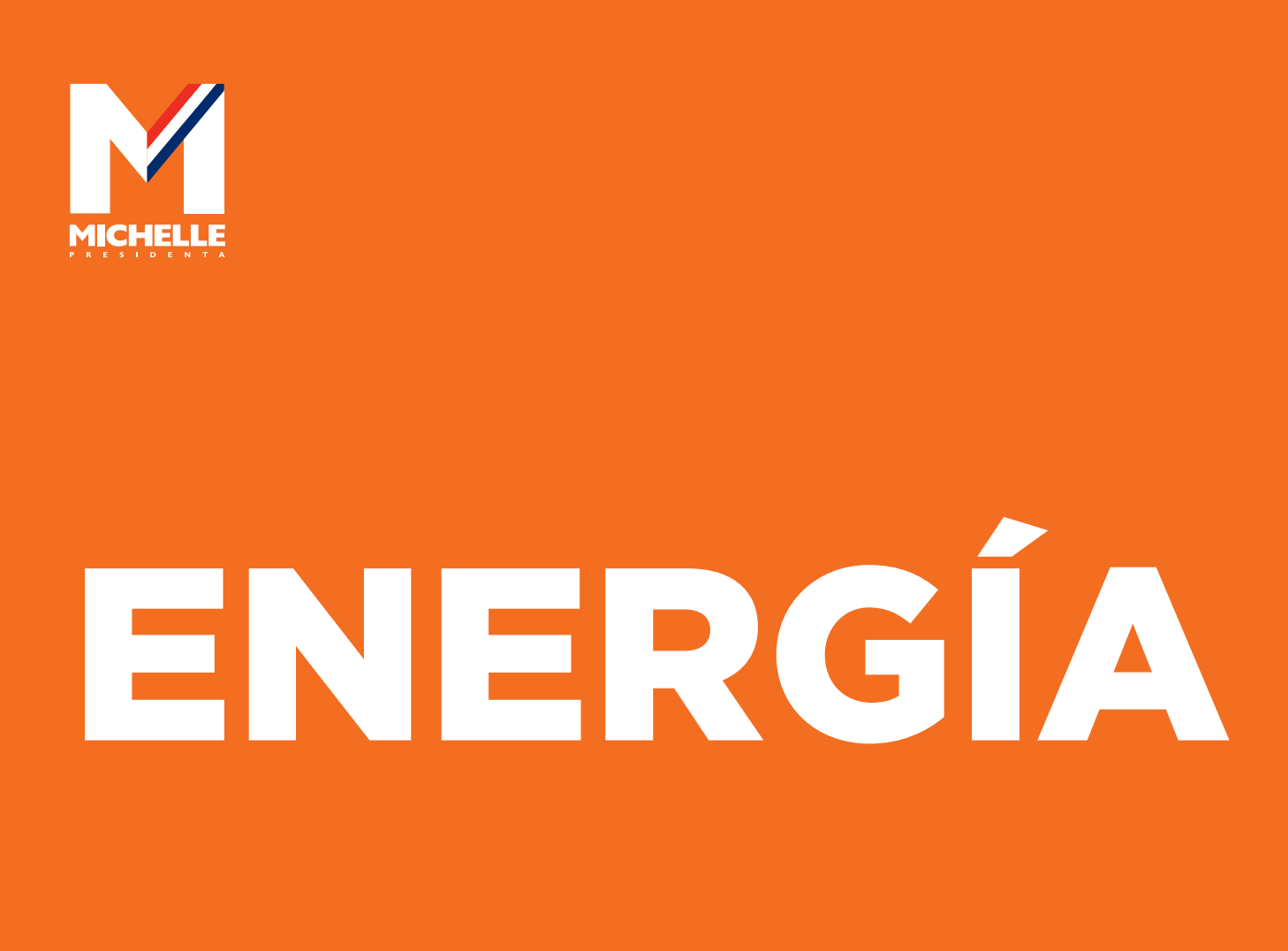

ENER

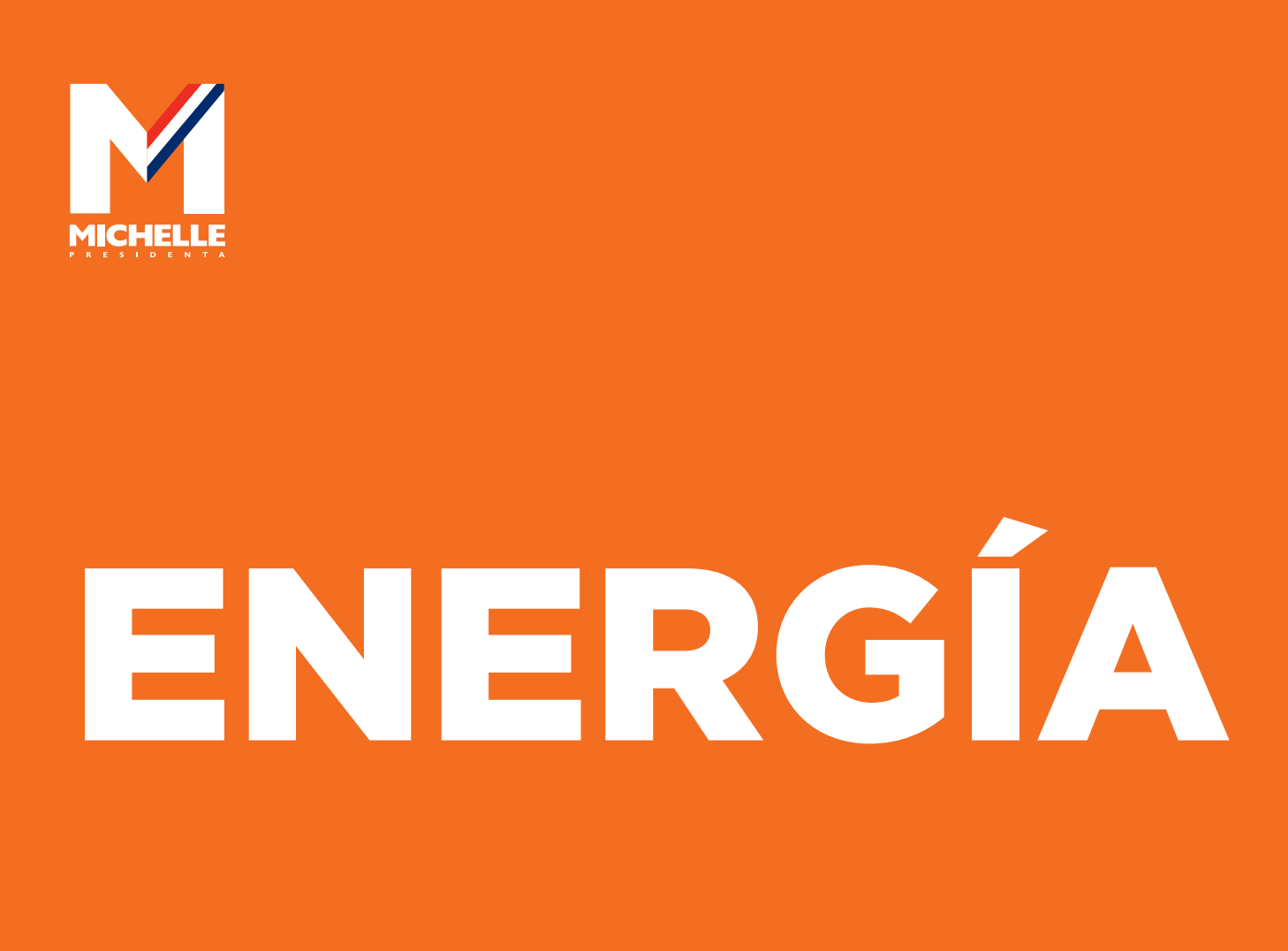

.

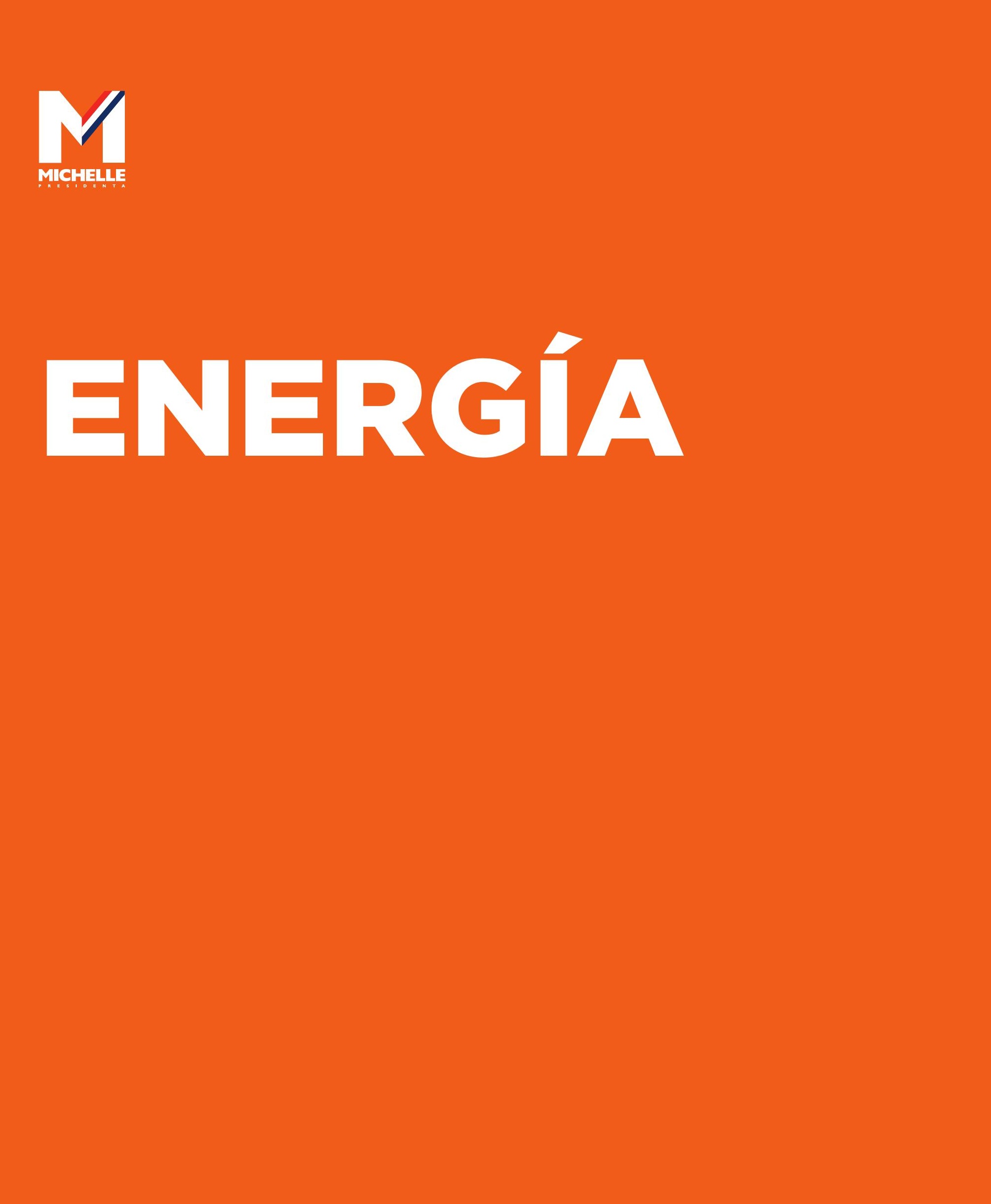

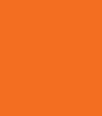

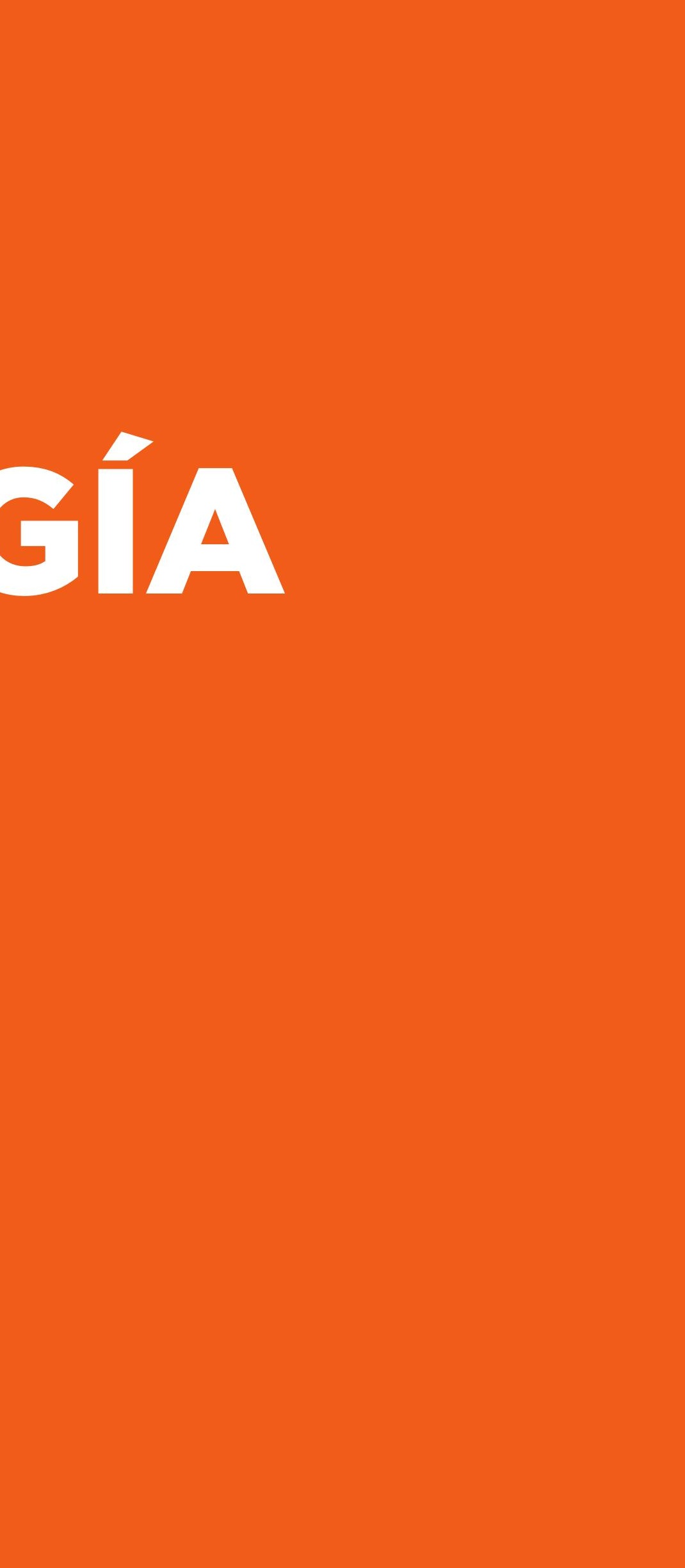




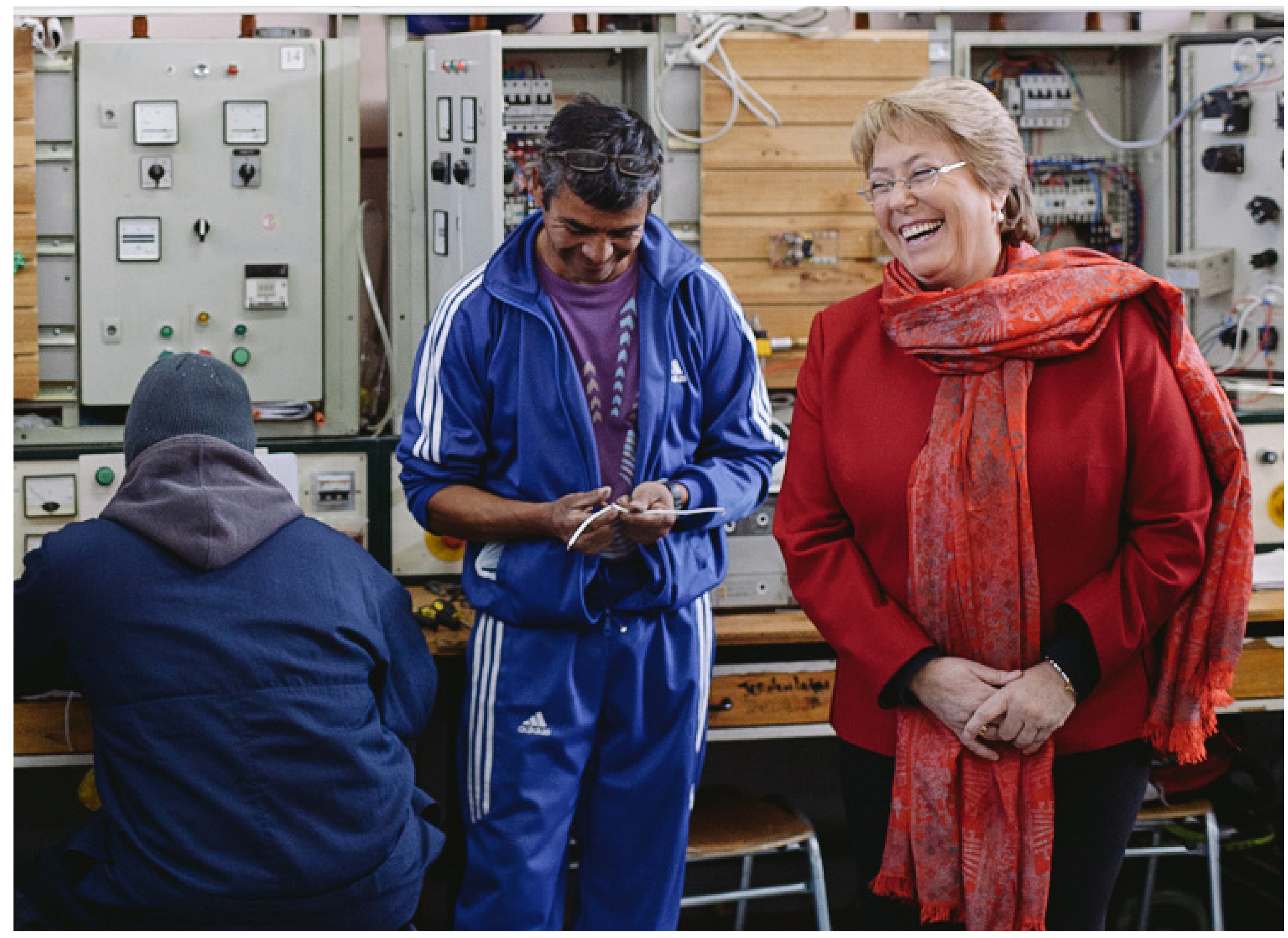




\section{ENERGÍA}

Debemos aspirar a un desarrollo energético seguro, eficiente, con precios razonables, que aproveche nuestros recursos renovables en forma sustentable y no contaminante. En la percepción ciudadana el desarrollo eléctrico ha sido crecientemente asociado con deterioro ambiental y costos sociales para algunas comunidades. Esta percepción es potenciada tanto por errores en la gestión ambiental gubernamental, como por la existencia de algunos episodios ambientales que generan preocupación en la opinión pública, lo que afecta la legitimidad de nuestro sistema de Evaluación de Impacto Ambiental. También influye en la oposición a los proyectos el hecho de que en diversas ocasiones estos generan costos económicos locales inevitables, siendo los beneficios de carácter nacional. La falta de una participación local adecuada en los beneficios implica una falta de equidad geográfica, además de generar oposiciones esperables al desarrollo de la inversión. Lo anterior afecta tanto a las energías convencionales como a las Energías Renovables no Convencionales (ERNC).

Los análisis de los expertos indican que el sector eléctrico se aproxima a una situación crítica, no existiendo claridad sobre las fuentes de energía en que se basará la oferta eléctrica en el mediano plazo, pues no existen proyectos en construcción que permitan asegurar los requerimientos energéticos.

La seria restricción de energía ha elevado los precios significativamente en el Sistema Interconectado Central (SIC) y ya está teniendo efectos adversos.

También existe un elevado riesgo de que se sigan declarando sucesivamente desiertas las licitaciones de energía de las distribuidoras que abastecen a los hogares y las PYMES, debido a que en el corto plazo no existen nuevos proyectos capaces de hacer frente a la demanda. Si bien en el Sistema Interconectado del Norte Grande (SING) existen precios inferiores y ciertas holguras de capacidad, ellas actualmente no pueden aprovecharse en el SIC por la inexistencia de una conexión entre sistemas.

Esta situación, podría impactar los precios de los clientes regulados en los próximos años. Frente a esta disyuntiva actuaremos con decisión para enfrentar los desafíos de corto plazo y con un rol más activo del Estado para definir la estrategia de largo plazo, de modo de generar las condiciones de un desarrollo energético eficiente y sustentable. Para ello será necesario fortalecer la institucionalidad para que este a la altura de los desafíos que enfrenta el país en energía. El respeto a la institucionalidad fortalecida será el factor fundamental para generar la confianza de los ciudadanos, las comunidades locales y los inversionistas en el proceso de inversión y aprobación ambiental de los desarrollos energéticos que requiere el país.

\section{Propuestas de corto plazo}

En 2014, el Ministerio de Energía desarrollará una Política Nacional de Energía, que estará en el marco de la Agenda de Energía que se establecerá en los 100 primeros días de Gobierno.

Ante la situación descrita, entre 2014 y 2018 el principal instrumento disponible será la buena gestión de la autoridad política y regulatoria. Es imprescindible establecer tempranamente un plan de acción dirigido a concordar con todos los actores del sector medidas inmediatas que reduzcan los efectos de las restricciones de capacidad, así como identificar opciones para acelerar la entrada en operación de proyectos en marcha y/o proveer abastecimiento de gas a centrales de ciclo combinado, que quedaron sin abastecimiento por la crisis de abastecimiento de Argentina, incluyendo la promoción de un sistema de compras coordinadas de volúmenes atractivos para encontrar mejores ofertas de precios de GNL, con el objeto de reducir la potencial escasez de energía en el período 2016-2018.

Adicionalmente deben tomarse medidas para realizar mejoras en eficiencia y ahorro energéticos, que impliquen ahorros en el corto plazo, ya sea mediante medidas ligadas al funcionamiento del sector público, sistemas de reducción compensada de consumo, 
campañas informativas sobre el uso energético domiciliario, programas de eficiencia energética industrial, entre otras.

El plan de corto plazo incluye también la implementación de la Ley de Fomento de las ERNC y la de Fomento de la Energía Distribuida y extender la de incentivo a la instalación de paneles termo solares en vivienda. Además, con el objetivo de facilitar el desarrollo de los proyectos de transmisión eléctrica implementaremos a la brevedad la Ley de Concesiones y Servidumbres Eléctricas, introduciendo mecanismos expeditos que garanticen los derechos ciudadanos y el cumplimiento de la normativa ambiental correspondiente.

Asimismo, impulsaremos la aprobación de una norma que facilite la implementación de la interconexión de los sistemas SIC y SING, como troncal de transmisión, en el menor de los plazos, en tanto se cumplan los requisitos técnicos, ambientales y económicos correspondientes. Finalmente, identificaremos las posibilidades de ampliación de la capacidad en el corto plazo, con empresas nuevas y actuales con capacidad instalada y/o proyectos de ejecución inmediata en el SING y el SIC, y las medidas regulatorias y administrativas requeridas para su materialización.

\section{Propuestas de mediano y largo plazo}

En el sector energía es fundamental una visión de largo plazo, debido a los largos períodos de gestación de los proyectos, no podemos repetir la falta de perspectiva de los últimos años. Nuestro objetivo es lograr el desarrollo equilibrado y sustentable del sector energía para los próximos 15 a 20 años. Para ello, promoveremos cambios institucionales respecto al rol del Estado en el sector. Con este propósito los elementos esenciales a trabajar son los siguientes:

Planificación participativa. Se plantea un proceso participativo de estudio y discusión de la política eléctrica, similar a lo aplicado en diversos países de la OECD, en que sobre la base de los objetivos de las estrategias nacionales y regionales de desarrollo, se analice el desarrollo eléctric o. Se considerará el crecimiento de la demanda futura, los requisitos técnicos para la estabilidad de los sistemas, los efectos ambientales, los costos actuales y previstos de las diversas fuentes y tecnologías convencionales y no convencionales, que están disponibles para el país entre otros aspectos necesarios para una adecuada comparación entre alternativas. Los planteamientos tanto de las autoridades así como de los diversos grupos deben estar a disposición de toda la ciudadanía, en formas que faciliten su comprensión y participación respecto de las opciones que el país tiene.

El gobierno deberá resolver considerando y dando respuesta a todas las materias tratadas, planteadas y consultadas en el proceso, y entregar al país el plan estratégico de desarrollo de largo plazo, que aborde muy especialmente los aspectos ambientales y sociales ligados al desarrollo energético. Este ejercicio, permitirá dar orientaciones a los inversionistas, seguridades a la ciudadanía que el Estado vela por el interés común, orientar la planificación del troncal de transmisión y las propias decisiones del Ejecutivo en materia ambiental energética, a través de la institucionalidad correspondiente.

Mejor Regulación de la Transmisión Eléctrica. Realizaremos las modificaciones normativas necesarias para no desincentivar a empresas generadoras entrantes y promover la competencia que nos permita reducir los precios de la energía.

Promoción de las ERNC. Para la promoción de las ERNC se consideran diversas medidas de política: i) Fortaleceremos y extenderemos el Troncal de Transmisión Eléctrica y Sistemas Adicionales de Interés Público: los proyectos de ERNC a menudo enfrentan altos costos de transacción para desarrollar en coordinación con otros proyectos líneas adicionales de transmisión eficientes para su conexión con el troncal; ii) Licitaremos energía de ERNC para el suministro de las empresas distribuidoras: complementaremos la ley de fomento a las ERNC con un esquema de licitaciones de energía de las empresas distribuidoras para su 
consumo regulado que faciliten la participación de ERNC y se pueda cumplir con la meta de $20 \%$ en el 2025 rebajando los costos marginales en el corto plazo; iii) Promoveremos la Geotermia: es una fuente de energía limpia no convencional que puede proveer energía estable, a diferencia de otros tipos de ERNC, por lo cual diseñaremos esquemas de riesgo compartido para su fomento; iv) Fomentaremos la distribución de ERNC generada por pequeños consumidores, creando mecanismos para resolver restricciones de liquidez que inhiben la inversión inicial para su conexión a los sistemas, e; v) incorporaremos en el subsidio habitacional un componente para sistemas que aprovechen la energía solar, ya sea para calentar agua o generación distribuida.

Desde ya asumimos el compromiso de aumentar la participación de energías renovables no convencionales (ERNC), para que al año 2025 un $20 \%$ de las inyecciones de electricidad provengan de fuentes limpias y propias. Realizaremos todos los esfuerzos necesarios para sentar las bases para que el $30 \%$ de la generación de electricidad provenga de fuentes de ERNC.

\section{Mayor Esfuerzo en Eficiencia Energética}

En los últimos cuatro años se ha avanzado muy poco en materia de Eficiencia Energética (EE). En el próximo gobierno aspiramos a lograr cambios más estructurales en este ámbito y entrar a una fase de masificación de los proyectos de EE, generando un mercado de EE. Algunos elementos claves para hacer avances más significativos son los siguientes: i) Implementar estándares mínimos de desempeño energético para iluminación, motores industriales y refrigeradores; ii) una campaña revitalizada del etiquetado de eficiencia energética; iii) fijar estándares $\mathrm{y} / \mathrm{o}$ metas para toda nueva construcción pública; iv) el desarrollo de políticas para que las empresas grandes consumidores de energía, incluyan sistemas de gestión de energía; v) trabajar el tema de un transporte eficiente (público y no motorizado), y; vi) fortalecer y profundizar el programa de ahorro en edificios públicos. A nivel de vivienda trabajaremos enestándares dehabitabilidad y eficiencia energética en vivienda, considerando un subsidio a la incorporación de calentadores solares en vivienda social. Avanzaremos, evaluando alternativas de introducción de buses híbridos y a gas natural en el transporte público para generar las condiciones que las futuras renovaciones de flota se puedan establecer premios por la introducción de tecnologías más limpias.

\section{Empresa Nacional de Petróleo (ENAP)}

La Empresa Nacional del Petróleo, es un patrimonio de Chile que debemos resguardar. Hoy enfrenta una situación crítica que deberá ser solucionada en los próximos cuatro años. Avanzaremos en una estrategia que lleve a incorporar decididamente a ENAP en la estrategia energética de Chile, la que debe incluir la capitalización de la empresa, la reforma al gobierno corporativo, la revisión del modelo de negocio, y los cambios en la ley de ENAP necesarios para permitir estas reformas. Todo esto, con el objeto, entre otras materias, de que ENAP sea un actor importante en el acceso y fomento de la exploración de gas en nuestro país.

\section{Innovación en Energía}

Chile debe pasar a la etapa de desarrollo de tecnologías en aquellas áreas en las que puede crear ventajas competitivas, como en la energía solar, geotérmica, mareomotriz e hidratos de metano. Para ello se requiere de un esfuerzo a mediano y largo plazo, focalizado en el desarrollo de tecnologías sobre la base de construcción de prototipos, con la participación coordinada del Estado, las universidades $\mathrm{y}$ la industria. Impulsaremos consorcios tecnológicos universidad-empresa como herramienta para promover la investigación aplicada en estos ámbitos. 


\section{Fortalecimiento de la capacidad de las instituciones}

Las instituciones del Estado de mayor incidencia en el desarrollo energético presentan fuertes debilidades. En el sector eléctrico la Comisión Nacional de Energía (CNE) ha ejercido un rol cada vez más débil en su papel de regulador. Es urgente fortalecer a la CNE, en especial, fortaleciendo su capacidad reguladora. También debe dotarse al Ministerio de Energía de capacidades para el diseño de política y la planificación energética, dentro de un marco en que el Estado asume un rol proactivo de orientación del desarrollo del sector.

\section{Mayor competencia en generación}

La generación eléctrica en Chile se encuentra concentrada. Tres empresas generan el $90 \%$ de la energía del SIC. Una estrategia clave para la entrada de nuevos actores al mercado es facilitar la obtención de contratos de largo plazo para el suministro de energía a clientes regulados, a través de empresas distribuidoras de energía. Sin embargo, el sistema actual de licitaciones no ha generado incentivos para la entrada de nuevos actores. Revisaremos el sistema de licitaciones a la luz de la experiencia desde su instauración, considerando especialmente los plazos, la división en bloques y la modificación de los mecanismos de integración de la oferta y su adaptación al perfil de demanda.

El Centro de Despacho Económico de Carga (CDEC) es el órgano que coordina la operación de los sistemas y debe garantizar la operación segura y a mínimo costo y no discriminatoria con potenciales operadores. La evolución del sector eléctrico hacia una mayor complejidad implica mayores exigencias para este órgano coordinador del sistema respecto a los estándares de seguridad, confiabilidad y transparencia; por otra parte, la tensión entre la función pública que cumple el CDEC y los intereses individuales de las empresas es creciente, y hace conveniente que el organismo tenga capacidades e independencia efectiva para dictar instrucciones vinculantes para las empresas y para cumplir adecuadamente con un rol de supervisión sobre la forma en que éstas operan dentro de los sistemas. En este ámbito, daremos seguimiento estrecho a la implementación de las medidas de mayor autonomía y profesionalización de los CDEC, e implementaremos aquellos cambios adicionales que se requieran.

\section{Planificación territorial}

Como se indicará en el capítulo de Ciudad, Vivienda y Territorio, impulsaremos un Plan de Ordenamiento Territorial, con participación ciudadana, que permita establecer un nuevo equilibro entre los requerimientos del crecimiento económico, las necesidades de las comunidades y el respeto y cuidado por el medio ambiente. Los proyectos energéticos compiten por el uso territorial con variadas otras actividades económicas y acciones de conservación y desarrollo medioambiental y cultural. El Plan debe identificar aquellos lugares en donde se permitirán actividades productivas o de generación de energía sin afectar negativamente a las personas, y donde se podrán realizar los proyectos con la agilidad que Chile requiere.

El Plan deberá identificar las zonas donde estará permitida la instalación de proyectos para cada tipo de tecnología, bajo estrictas normas y estándares ambientales.

Como todo proyecto implica algún impacto económico local y beneficios nacionales tomaremos medidas para que las comunidades locales a través de sus municipalidades participen en mayor grado de los beneficios de los proyectos.

\section{La energía a leña y las zonas aisladas}

Desarrollaremos una Política Nacional de la energía obtenida a través de la leña, que mejore las condiciones de vida de cientos de miles de familias que usan este recurso, asegurando adecuados estándares de calefacción y mejorando las condiciones ambientales de ciudades que hoy se encuentran saturadas. Impulsaremos sistemas híbridos solar-eólico diesel en las islas que en la actualidad sólo se abastecen con generación diesel. También diseñaremos mecanismos para incentivar el uso de energías renovables de bajo costo en sistemas aislados, como los de la zona austral. 


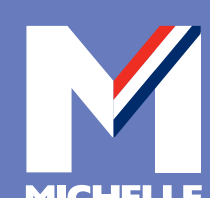

CIENCIAy
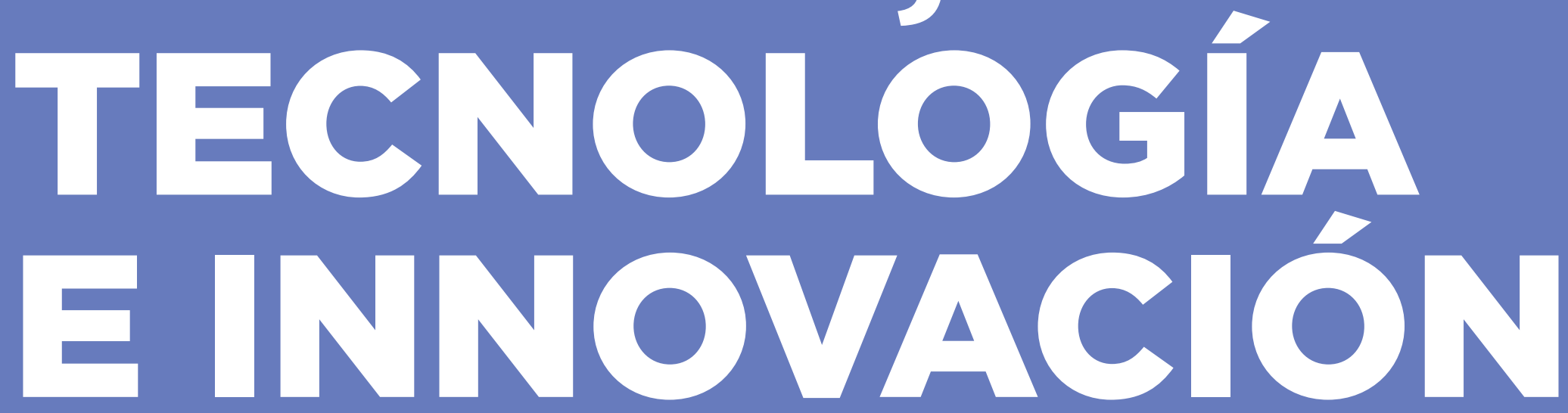

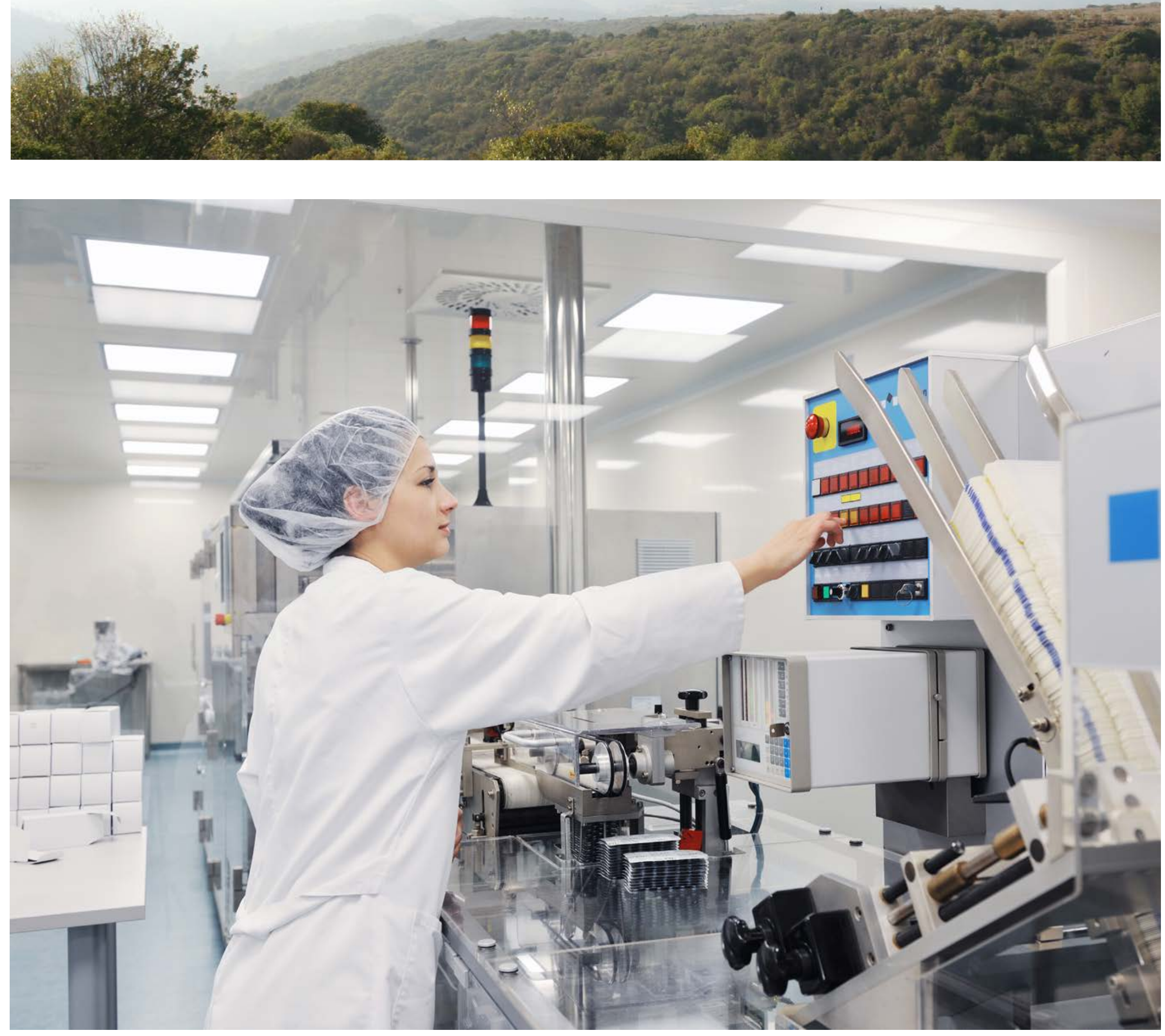


\section{CIENCIA, TECNOLOGÍA E INNOVACIÓN}

Chile presenta un déficit evidente y conocido en materia de innovación. La ciencia, la tecnología y la innovación son herramientas fundamentales para un desarrollo inclusivo, sostenible y sustentable y, también son fundamentales para hacerse cargo de las grandes preocupaciones globales, como el cambio climático, para diseñar soluciones novedosas a los problemas nacionales, como el uso eficiente del agua y la energía y para crear nuevos servicios, productos o prácticas que aumenten el bienestar de todos los chilenos, como es el caso de las tecnologías digitales o los alimentos funcionales.

En los primeros 100 días de Gobierno anunciaremos la Agenda de Productividad, Innovación y Crecimiento Económico que contempla acciones en cuatro áreas estratégicas: i) políticas de competencia; ii) modernización del Estado; iii) desarrollo productivo, y; iv) innovación.

Lograr que Chile se convierta en un país en que el conocimiento y la innovación sean palancas reales de un desarrollo dinámico, inclusivo y sustentable, requiere de impulsos significativos y transformadores al menos en tres frentes. En primer lugar, un fuerte incremento en el fomento a la ciencia, la investigación y la formación de recursos humanos avanzados. En segundo lugar, generar incentivos para que los actores del sistema incrementen sus esfuerzos en materia de innovación y los orienten hacia objetivos relevantes de desarrollo nacional. Y en tercer lugar, contar con una institucionalidad que tenga la fortaleza y la estabilidad, pero también la flexibilidad en la acción, para conducir este proceso en un mundo de cambios profundos. Un aspecto específico pero fundamental en materia de desarrollo científico y tecnológico, consiste en retomar la política de clusters que fue impulsada con fuerza en el período 2006-2010.

La creación del Consejo Nacional de Innovación para la Competitividad (CNIC) permitió generar un espacio público y privado para elaborar una mirada de largo plazo sobre los retos que enfrenta el país en estos temas, más allá del gobierno de turno. A su vez, el Fondo de Innovación para la Competitividad (FIC) permite disponer de un flujo significativo de recursos para financiar parte de la política pública en este campo. Sin embargo, ambas son creaciones que no han sido aún sancionadas legalmente, lo que las hace muy frágiles. En la próxima administración, tanto el CNIC como el FIC, contarán con un nuevo estatus legal, que les permita estabilidad, junto con ampliar su ámbito de preocupación desde la competitividad al desarrollo nacional, manteniendo el énfasis en los temas de la investigación científica, el desarrollo tecnológico, la innovación y el emprendimiento, tanto en su dimensión productiva como social.

Un ejemplo en materia de desarrollo de capacidades, es la baja disponibilidad de estudiantes de ingeniería, siendo esta una de las principales dificultades que tienen las empresas locales de alta tecnología y lo que además limita la instalación de filiales extranjeras en Chile. Para este desafío, crearemos un programa de incentivo para universidades que tengan carreras de ingeniería acreditadas y que firmen convenios con el Estado, para que generen 1.000 cupos adicionales para postulantes que cumplan requisitos básicos. También apoyaremos la reinserción de los profesionales postgraduados de Becas Chile que retornarán al país con maestrías o doctorados en el exterior, cuyo aporte en empresas y universidades es muy relevante.

Otro aspecto importante en el ámbito de la innovación es que la población cuente con un amplio acceso a servicios de internet de banda ancha, de alta calidad y bajo costo, para no enfrentar restricciones en materia de acceso a contenidos y servicios que se ofrecen en los países desarrollados a través de la red. Licitaremos concesiones de infraestructura de banda ancha de las características descritas, de acceso abierto a todos los 
proveedores de telecomunicaciones, en comunas de menores ingresos de las áreas metropolitanas del país. Estas redes permitirán a los proveedores de servicios competir por ofrecer banda ancha de alta velocidad telefonía y televisión a un precio menor al actual.

En materia de incentivos, crearemos programas de innovación para el desarrollo que apunten a identificar los retos o cuellos de botella que afectan a sectores con ventajas competitivas evidentes y/o latentes. El objetivo es desarrollar líneas de investigación aplicada orientada a dominar tecnologías propias del sector, que puedan darle sustentabilidad económica, social y ambiental en el mediano plazo. También crearemos un programa de fomento a innovaciones de alto impacto social, que permita utilizar las mejores capacidades, con el objeto de resolver dificultades específicas que enfrentan distintas comunidades.

Repondremos la política y programas de desarrollo de clusters regionales y de sectores de alto potencial. Esto tiene una mirada consistente con las políticas de descentralización, ya que existen regiones que por su identidad y vocación pueden emprender iniciativas en materia de innovación.

Crearemos el Fondo de Innovación Pública para bienes y servicios. Reimpulsaremos los programas de promoción a la innovación empresarial y el emprendimiento innovador administrados por CORFO, retomando los mecanismos de desarrollo del ecosistema de emprendimiento dinámico, en particular mediante el apoyo a los mecanismos de incubación, aceleración, capital semilla, riesgo de fase temprana, formación de redes y esquemas de mentores.

Mejoraremos las normas y estándares para impulsar la innovación, proponiendo un programa que incluya: i) mayores recursos para el SERNAC, para generar información pública que permita evaluar la calidad de los productos y servicios ofrecidos; ii) la revisión de normas y estándares en sectores claves de la actividad económica, de modo de llevarlos de manera progresiva a niveles similares a los de los países de la OECD y iii) el apoyo a las empresas, cuando corresponda, en la introducción de los cambios requeridos para adoptar los nuevos niveles de exigencia. Además estableceremos un programa para el apoyo al extensionismo tecnológico para las PYMES del país, creando alianzas entre oferentes de tecnologías y las PYMES mediante acuerdos que mejoren su capacidad de absorción y el desarrollo de competencias.

En el ámbito institucional, fortaleceremos al Ministro de Economía en su rol de autoridad responsable en el campo de la innovación y el desarrollo productivo, creando la Subsecretaría de Ciencia, Tecnología e Innovación. Así, esta autoridad establecerá las políticas y las orientaciones de los recursos públicos, incluyendo: la formación de recursos humanos altamente avanzados; la actividad de las agencias de financiamiento de la ciencia, la tecnología y la innovación; el manejo de la propiedad intelectual derivada de la actividad científica y tecnológica; la promoción de una cultura de la innovación y de valorización de la ciencia; y la colaboración internacional.

Crearemos un Consejo para la Coordinación de las Políticas de Ciencia, Tecnología e Innovación, presidido por el Ministro de Economía e integrado por todas las agencias ejecutoras de las políticas de ciencia, tecnología e innovación tales como CONICYT, CORFO y otras.

Finalmente, realizaremos una simplificación, reagrupamiento y rediseño de los procesos de ejecución de los instrumentos de fomento a la ciencia, tecnología e innovación, generando indicadores de gestión para dar cuenta de las mejoras obtenidas. Estos indicadores deberán ser seguidos y controlados por una institución que busque un mayor nivel de eficiencia de los procesos. 


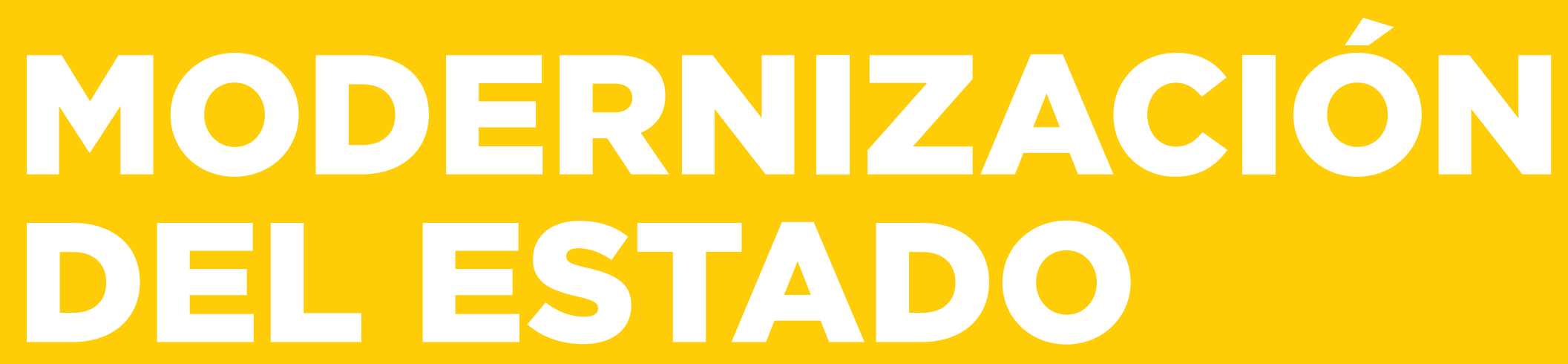




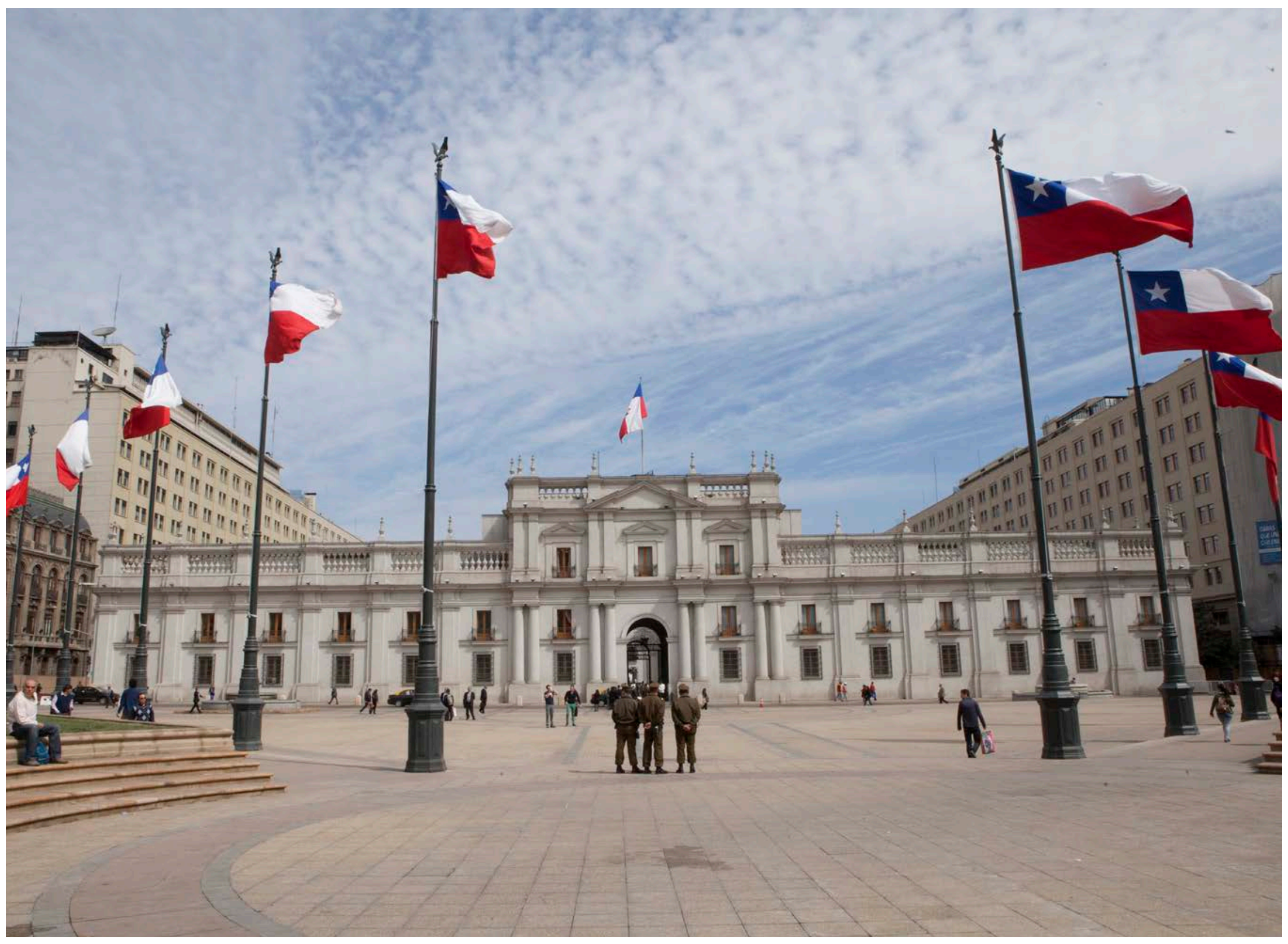




\section{MODERNIZACIÓN DEL ESTADO}

Aspiramos a un Estado moderno para Chile que promueva el fortalecimiento de la democracia y facilite el diálogo y la participación; un Estado que garantice el ejercicio de los derechos políticos, económicos, sociales y culturales de la ciudadanía y que impulse políticas públicas para disminuir las desigualdades, combatir los abusos y contribuir a una distribución del ingreso más igualitaria.

Aspiramos a un Estado moderno que cumpla con fuerza su rol de regulador y fiscalizador en la provisión de bienes y servicios, asegurando condiciones de competencia y velando por el acceso, la calidad y la satisfacción de los usuarios. Un Estado que asegure, entre otras materias, las condiciones apropiadas para el emprendimiento y la inversión privada, contribuyendo a la apertura de nuevos mercados y al desarrollo de tecnologías innovadoras.

Aspiramos a un Estado innovador que garantice el acceso a servicios públicos de calidad, donde prevalezca el buen trato, en condiciones laborales dignas y que actúe con transparencia.

Estas propuestas son para un Estado al servicio de sus ciudadanos y para actuar con eficiencia ante los desafíos del desarrollo.

Una nueva institucionalidad responsable de la evaluación de las políticas públicas. El sistema de evaluación de políticas públicas que ha desarrollado nuestro país ha permitido que se disponga de más y mejor información para los procesos de análisis y toma de decisiones, contribuyendo así a la transparencia de la gestión pública. Sin embargo, si queremos evaluar para mejorar, los resultados de las evaluaciones deben estar vinculados al proceso de toma de decisiones de política pública. Para eso se hace necesaria una nueva institucionalidad, que interactúe con los distintos organismos públicos en el ciclo de definición de políticas.

Para ello crearemos la Dirección Nacional de Evaluación, que tendrá la misión de contribuir al mejoramiento continuo de la calidad de las políticas, programas y proyectos públicos, a través de la incorporación de procesos de evaluación que asesoren la toma de decisiones. La Dirección tendrá como objetivos: desarrollar evaluaciones de alta calidad técnica que entregue recomendaciones para mejorar la gestión, la eficacia, la eficiencia y la calidad de las políticas y programas públicos; establecer estándares metodológicos para todas las evaluaciones realizadas en el sector público; difundir la información respecto de las evaluaciones realizadas en el sector público, favoreciendo la transparencia, la rendición de cuentas; y realizar el seguimiento a la puesta en marcha de las recomendaciones que surjan de las evaluaciones.
Enviaremos al Congreso el proyecto de ley que creará este servicio público. El director del Servicio será nombrado por el Sistema de Alta Dirección Pública. La nueva institucionalidad tendrá como meta evaluar anualmente el $25 \%$ de los programas del presupuesto, de modo que en una administración cubra el 100\% de los programas del presupuesto público.

Un Nuevo Trato para el empleo público. Aspiramos a un sector público que se identifique con una gestión de calidad, que disponga eficientemente de los recursos que se le asignan y en permanente proceso de innovación, para lo que resulta fundamental que los funcionarios públicos trabajen en condiciones de dignidad. Para ello, evaluaremos la institucionalización de la negociación colectiva en el sector público, estudiando mecanismos que se hagan cargo de sus especiales particularidades. En relación al personal a contrata estudiaremos esquemas que ofrezcan mayor estabilidad a estos trabajadores. También evaluaremos la situación de los trabajadores con contratos a honorarios, revisando aquellas situaciones que puedan ser consideradas funciones permanentes.

Un empleo decente debe permitir a los funcionarios de mayor edad, retirarse dignamente de la función pública. Para ello impulsaremos planes especiales de retiro que faciliten el cumplimiento del objetivo señalado.

En el ámbito de la capacitación, los Planes Anuales de Capacitación serán indispensables para lograr mejores resultados en el desempeño de los funcionarios, cuya pertinencia y vigencia serán evaluadas periódicamente por los comités bipartitos de capacitación recibiendo más recursos cuando sea necesario para su mayor eficacia.

\section{Perfeccionamiento del Sistema de Alta Dirección} Pública. A 10 años de su creación, el Sistema de Alta Dirección Pública ha confirmado su relevancia entrelas reformas delEstado que se han implementado en nuestro país. Ha sido exitoso al implantar un exigente sistema de selección de altos directivos. Sin embargo, al producirse el cambio de gobierno en 2010 mostró debilidad, convirtiendo la facultad para despedir a los altos directivos en un mecanismo de remoción política. Por lo tanto, es indispensable incorporar mejoras al sistema; hacer del convenio de desempeño del alto directivo un instrumento que apoye el mejoramiento de la gestión; y avanzar en la ampliación del sistema con carácter mixto, que contemple diferencias de régimen entre el primer y segundo nivel jerárquico, con criterios explícitos de delimitación técnico-política, aumentando la cobertura del sistema.

Adicionalmente, vamos a restringir, sólo a casos especiales, el uso de la figura de los cargos transitorios y provisorios. Estos nombramientos no podrán exceder los 6 meses y se limitará el número de directivos que simultáneamente puedan tener esa calidad en un mismo servicio. 
Agenda Digital. La globalización en el siglo XXI nos obliga a enfrentar institucionalmente el desarrollo digital de nuestro país. Este desafío digital cubre tanto la promoción de la utilización de nuevas tecnologías por parte de la ciudadanía, como el uso de tecnologías de la información para profundizar la transparencia, elevar la eficiencia del Estado y promover una mejor calidad de los servicios al ciudadano. Para lograr estos objetivos es preciso que el Ministerio de Economía asuma en plenitud el rol conductor de la política pública de desarrollo digital de nuestro país, contemplando materias tales como: diseño de políticas del área, promoción de iniciativas de gobierno electrónico, desarrollo de la industria de las TIC y promoción del acceso a las nuevas tecnologías.

Hoy resulta relevante que nos planteemos desarrollar una estrategia de seguridad digital que proteja a los usuarios privados y públicos contra posibles acciones de violación de fuentes de datos, junto con la protección de la privacidad de nuestros ciudadanos.

En las propuestas del área de Transporte y Telecomunicaciones, se establecen medidas para mejorar el acceso a la banda ancha de internet, particularmente en el sistema educativo y las comunas más vulnerables de las áreas metropolitanas. Adicionalmente a este esfuerzo, desarrollaremos el concepto de gobierno digital en línea, que permita un mejor acceso a la información y los servicios, especialmente en los campos de la salud, la educación, la previsión y otros servicios sociales, dando especial preferencia a regiones y municipios.

Probidad y Transparencia. Hoy la ciudadanía tiene una creciente demanda por mayor transparencia en el accionar de las autoridades públicas. Esto tiene que ver con el acceso a la información y la participación en el debate, pero también, con los conflictos de intereses de las propias autoridades. Implementaremos un sistema de fideicomiso ciego para las nuevas autoridades, sin esperar la aprobación del proyecto de ley que se discute actualmente en el Congreso, yel cual fortaleceremos y aceleraremos.

Al realizar nombramientos de autoridades públicas pondremos especial atención en la revisión de eventuales conflictos de interés. Además profundizaremos la normativa que regula el conflicto de interés en las funciones posteriores al ejercicio de cargos públicos, así como perfeccionaremos las declaraciones de patrimonio e intereses de las autoridades públicas a fin de que constituyan efectivamente un mecanismo de transparencia y fiscalización ciudadana.

Complementariamente fortaleceremos la función de auditoría interna de gobierno, e impulsaremos acciones para contar con un mejor y mayor control ciudadano sobre las actividades de lobby.
Perfeccionamiento de los Gobiernos Corporativos de las Empresas Públicas. Vamosa perfeccionarel marcoinstitucional de las empresas del Estado y de aquellas en que éste tenga participación, fortaleciendo sus gobiernos corporativos, para que estas empresas logren aumentar su transparencia y capacidad estratégica, mejorando la calidad de la gestión y la supervisión de las mismas.

Crearemos el Consejo Superior de Empresas Públicas como un servicio público descentralizado, encargado de representar los derechos y deberes del Estado en su rol de propietario, modificando tanto su composición y facultades como las normas referentes a los directores de las empresas públicas, de forma de facilitar la separación de las diversas funciones del Estado.

Desde el primer semestre de Gobierno se integrará al menos una mujer, a cada uno los directorios de las empresas públicas. Y buscaremos durante el Gobierno la forma de incentivar una mayor presencia de mujeres en los directorios de las empresas públicas, poniéndonos como meta alcanzar un $40 \%$ en el período de Gobierno.

Modernizaremos los gobiernos corporativos de las empresas públicas, para que adopten las mejores prácticas internacionales en la materia.

\section{Institucionalidad de confianza y alto estándar} técnico para las estadísticas públicas. Si queremos políticas públicas de país desarrollado, para diseñarlas y evaluarlas necesitamos generar estadísticas con estándares de país desarrollado. Los lamentables episodios de la CASEN 2011 y del Censo 2012 han dejado en evidencia que existe una brecha entre ese anhelo y la capacidad institucional para alcanzarlo. Invertir en cerrar esta brecha es indispensable para lograr las dos características más importantes de la institucionalidad estadística: confianza de la ciudadanía y capacidad técnica.

Para lograr lo anterior perfeccionaremos el proyecto de ley que moderniza el INE, haciendo un verdadero esfuerzo en términos de su fortalecimiento institucional.

En el caso particular del Censo, la Comisión Externa Revisora convocada por el actual gobierno recomendó realizar uno nuevo, posición que fue respaldada por CELADE, la institución experta en censos en América Latina. Más aún, la Comisión recomendó no utilizar los datos recolectados para fines de políticas públicas. Por lo tanto, es imprescindible realizar un nuevo Censo. Para no repetir los errores del Censo 2012, debemos planificar su implementación con rigurosidad y el cuidado que amerita. Por ello, realizaremos un nuevo Censo en el próximo período de Gobierno. 


\section{M \\ MCHEILE}

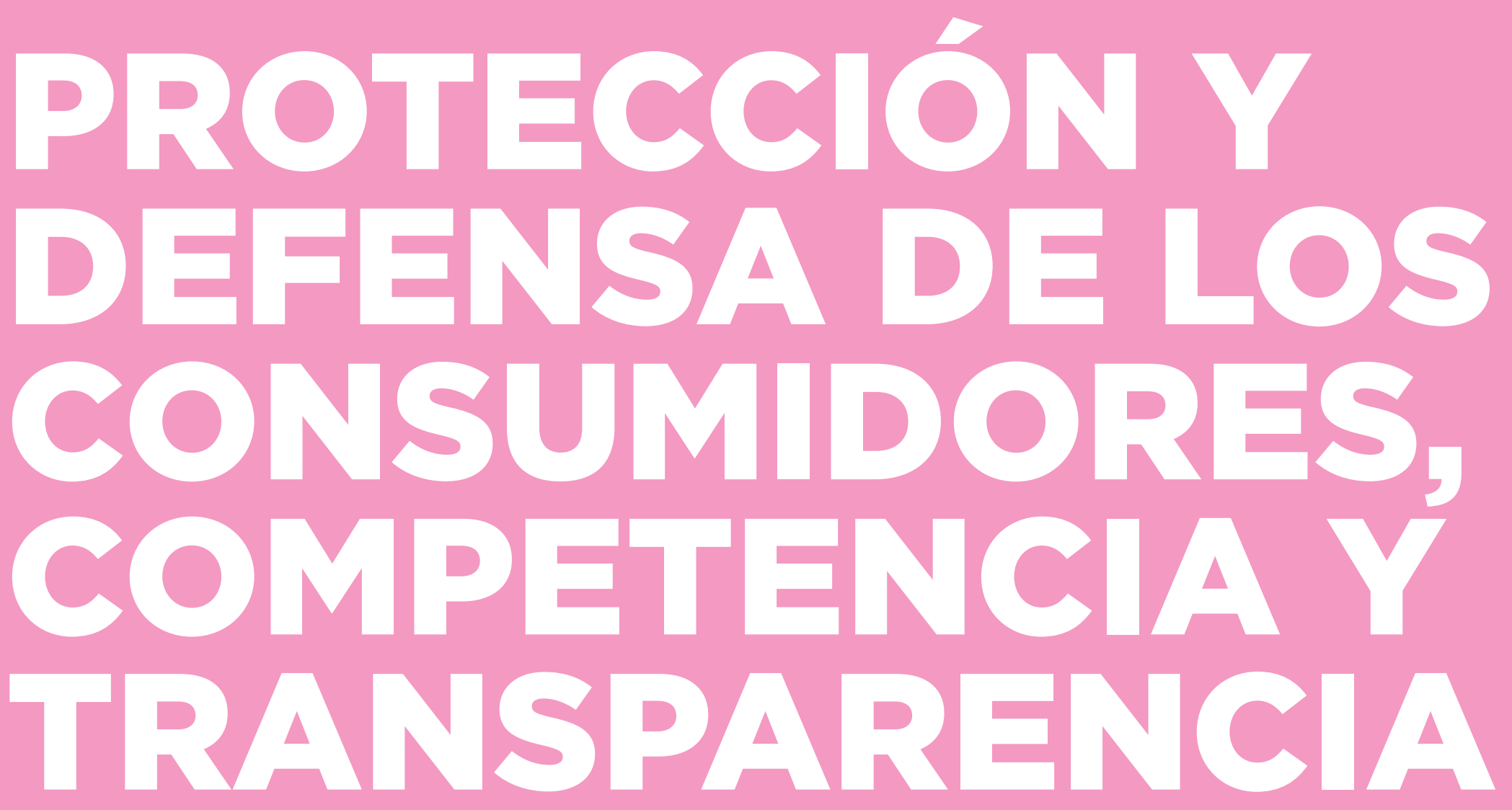




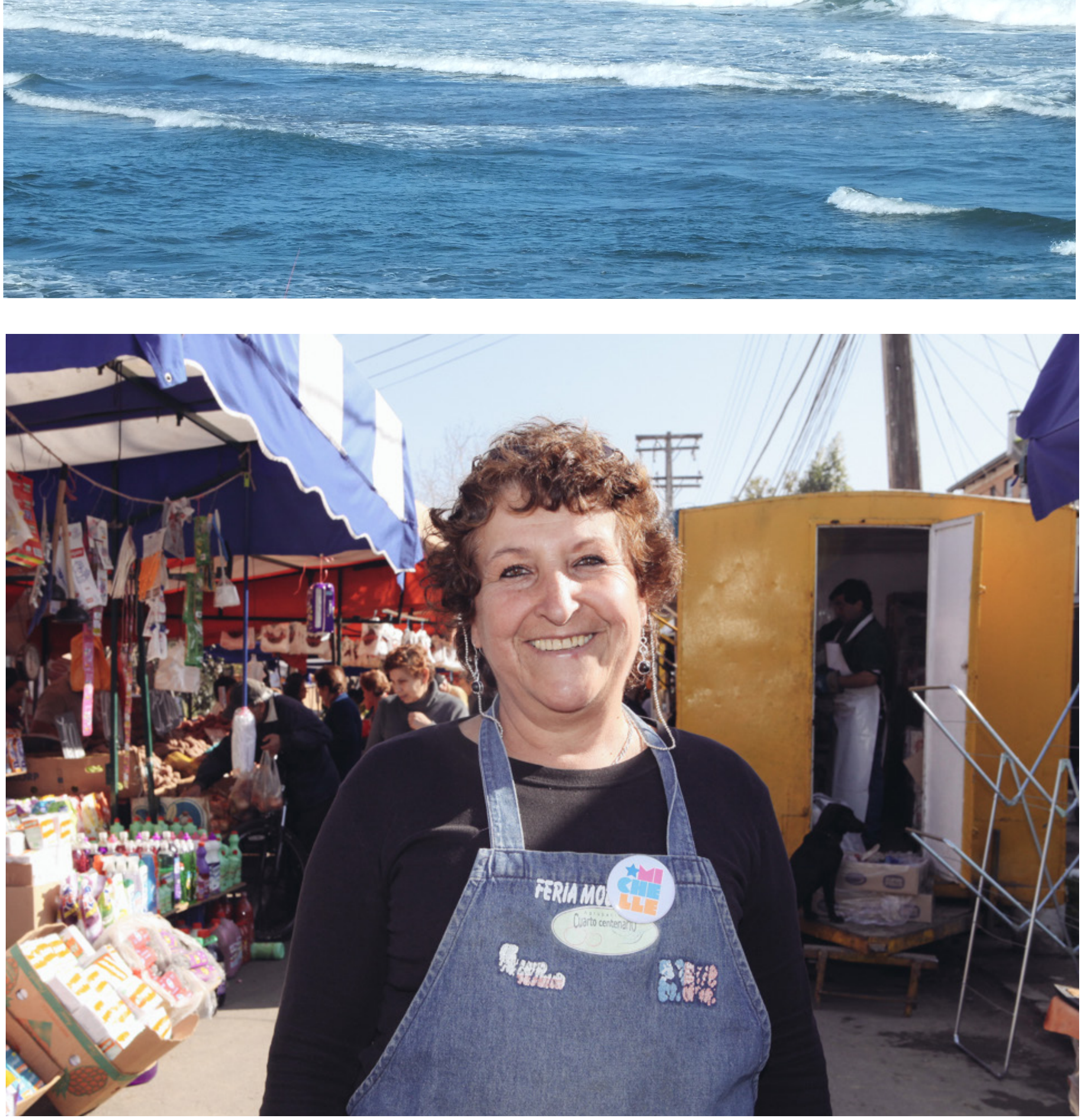




\section{PROTECCIÓN Y DEFENSA DE LOS CONSUMIDORES, COMPETENCIA Y TRANSPARENCIA}

En los últimos años, muchos ciudadanos, de sectores vulnerables y de capas medias, han sufrido abusos al consumir bienes o utilizar servicios, incluyendo servicios de interés público y bienes que satisfacen necesidades básicas. Dichos abusos afectan la convivencia nacional, producen enojo en la población, minan la confianza entre los chilenos y socavan la credibilidad en el funcionamiento de las empresas y en las instituciones que regulan la economía. En buena parte, estas situaciones se derivan de la concentración de poder de mercado, de la presencia de barreras a la entrada y de prácticas que facilitan acuerdos de colusión así como de exclusión de competidores. Esta concentración y falta de competencia afecta además la eficiencia,la innovación en los mercados y el emprendimiento, así como la posibilidad real de distribuir los beneficios que se generan en ellos. También son consecuencia de una institucionalidad que, a pesar de los avances, sigue siendo débil en la protección de los consumidores, quienes tienen una posición de desventaja natural frente a intereses económicos organizados y con objetivos bien definidos.

\section{Mecanismos para exigir el cumplimiento legal de los derechos de los consumidores y para que existan compensaciones e indemnizaciones adecuadas. Por lo antes expuesto, en los primeros 100 días de Gobierno, enviaremos al Congreso el proyecto de ley del fortalecimiento del SERNAC, que permitirá que tenga atribuciones reales yefectivas para defender los derechos de los consumidores. Dotaremos al SERNAC de facultades para fiscalizar, multar, interpretar la ley y dictar normativas, proveyendo de criterios claros de cumplimiento legal con efecto general. Junto a ello, fortaleceremos la institucionalidad y los recursos humanos destinados a la fiscalización y la defensa contra los abusos.}

Estableceremos un procedimiento administrativo ante el SERNAC, que reemplace la competencia general de los Juzgados de Policía Local para conocer materias de consumo individuales, y que podrá culminar con la aplicación de multas, entre otras sanciones, y la orden de reintegros.

Otorgaremos un rol central a las Asociaciones de Consumidores, flexibilizando sus formas de financiamiento. Se avanzará en las siguientes materias: i) eliminar las restricciones legales que establece que las Asociaciones sólo pueden realizar actividades lucrativas para la recuperación de sus costos y como contrapartida, incrementar las obligaciones de transparencia de su financiamientoy exigir normas de contabilidad regulatoria; ii) elevar los fondos estatales para su financiamiento, por medio de convenios, con evaluaciones de desempeño y modificar la reglamentación de los fondos concursables que asigna el Estado para permitir que puedan financiar gastos operativos con una parte de estos recursos. Se establecerán estándares de eficacia, gestión y transparencia para acceder a estos fondos.
Reglamentaremos las mediaciones colectivas en la Ley de Protección al Consumidor, señalando cuándo proceden, qué plazos tienen, ordenando su publicidad para que los consumidores afectados o las Asociaciones de Consumidores puedan efectuar observaciones y sugerir ajustes en las soluciones identificadas.

Revisaremos la regulación de los juicios colectivos, para asegurar un procedimiento eficiente que procure soluciones adecuadas, en particular, la revisión y clarificación de los plazos de prescripción para ejercer las acciones, y la revisión de las multas, de manera que tengan relación con el daño causado por la infracción cometida. También avanzaremos en establecer compensaciones e indemnizaciones que aseguren una disuasión efectiva y una reparación adecuada.

Para una mejor coordinación institucional, estableceremos en la Ley de Protección de los Derechos de los Consumidores un Sistema Integrado cuya coordinación técnica corresponderá al SERNAC, y que considerará la creación de un Consejo en el que participarán representantes de agencias públicas reguladoras y fiscalizadoras. Su fin será solucionar conflictos entre normas sectoriales y de protección al consumidor, asegurando un reconocimiento explícito de la relevancia que debe tener la tutela del consumidor en todos los mercados.

Protección al consumidor financiero. Las asimetrías de información en el caso de la industria financiera adquieren una complejidad y alcance tales que justifican la existencia de unidad especializada dentro del SERNAC. Daremos al SERNAC facultades en materia de inspección, sanciones y normativas respecto del mercado financiero.

Necesitamos dar mayor protección a los consumidores en materia de sobre endeudamiento por consumo. La Superintendencia de Bancos e Instituciones Financieras estará a cargo de administrar el Sistema de Obligaciones Económicas, que contempla la consolidación de la información bancaria, del comercio y de cualquier otro agente crediticio relevante; velar por el buen funcionamiento del sistema en todos sus aspectos operacionales, de seguridad y resguardo de la información y supervisarlo; y registrar y supervisar a las entidades distribuidoras de información. Complementariamente, profundizaremos un modelo de información de costos financieros para créditos de consumo. Sabemos que el negocio crediticio es un negocio de riesgo, por lo cual no todos los clientes califican a la misma tasa. En este sentido, lo que corresponde es mejorar el sistema de información de costo del crédito. Adicionalmente, profundizaremos la estandarización del producto crédito de consumo, a efectos de facilitar la comparación a los clientes. 
Defensa de la libre competencia en mercados específicos. Encargaremos a la Fiscalía Nacional Económica (FNE) la tarea de evaluar aquellos mercados que presentan fallas persistentes o que sufren el impacto de regulaciones en la competencia, con el fin de dictar normas especiales cuando las fallas de mercado lo justifiquen y modificar aquellas normas que propician o permiten restricciones injustificadas al correcto funcionamiento competitivo. Para esto aumentaremos las capacidades de la FNE.

\section{Fortalecimiento de la institucionalidad pro} competencia. Cambiaremos el régimen de los ministros del Tribunal de la Libre Competencia (TDLC), hacia uno de dedicación preferente o exclusiva, estableciendo remuneraciones acordes y fijando una compensación para cuando los ministros cesen en el cargo. Con ello se aumentan los incentivos para la postulación de profesionales de calidad y experiencia.

Sanciones en temas contenciosos. Cambiaremos el tope máximo de las sanciones por porcentaje de ventas obtenidas; introduciremos una sanción adicional para personas involucradas de inhabilitación para directorios, organismos públicos, asociaciones gremiales y colegios profesionales y una sanción adicional para empresas involucradas, excluyéndolas de participar en licitaciones del Estado.

Reforzamiento de normas contra colusión. Evaluaremos la inclusión de un tipo penal explícito para carteles más gravosos para los mercados, que sancione los acuerdos entre competidores que les confieran poder de mercado.

Control de operaciones de concentración. Introduciremos en la legislación normas sobre control de operaciones de concentración, explicitando la figura de disminución sustancial de la libre competencia. La FNE cuando identifique problemas de competencia tendrá la facultad de negociar medidas de mitigación en un plazo breve.

\section{Cambios referidos a los procedimientos ante la FNE.} Fortaleceremos las capacidades técnicas y profesionales de la FNE; estableceremos plazos acotados para sus investigaciones; la facultad para que emita fundadamente advertencias y para requerir información estadística a otros organismos del Estado.

Regulación Financiera. La institucionalidad financiera en Chile tuvo la última reforma importante en temas referidos a la solvencia en el año 1997. Desde entonces el mundo experimentó una crisis financiera muy significativa, que ha llevado a generar importantes cambios en los estándares internacionales en materia de adecuación de capital y en la manera como se entiende la supervisión. Actualmente, los estándares internacionales apuntan a dotar a los organismos supervisores de facultades para elevar las exigencias de capital, utilizar el capital como herramienta contra cíclica, supervisar a las entidades en base a riesgos y no por modelo institucional. Ninguno de estos cambios ha operado en el caso chileno. Seguimos con un modelo de supervisión de tipo institucional, existen entidades financieras que potencialmente pueden representar riesgos sistémicos que no están bajo el alero de la supervisión, no existen facultades para regular conglomerados financieros, y existen debilidades en las facultades institucionales para abordar riesgos macro-prudenciales y problemas en los mecanismos de resolución bancaria.

Para hacerse cargo de este diagnóstico, entregaremos facultades a la Superintendencia de Bancos e Instituciones Financieras (SBIF) para supervisar por solvencia cualquier agente financiero y crediticio relevante. Esto debe incluir a cajas de compensación, cooperativas y empresas de comercio, entre otras. La SBIF estará facultada para decidir las entidades específicas que serían supervisadas bajo su alero, en base a criterios de ser entidad financiera, tener un tamaño mínimo y un cierto apalancamiento relevante.

Complementariamente incorporaremos un capítulo de conglomerados financieros en los cuerpos legales pertinentes, donde se defina al conglomerado financiero como objeto de supervisión, se determinen sus requerimientos de capital, liquidez y gobierno, se defina al supervisor, y se separe la parte financiera del conglomerado del resto del grupo económico.

También avanzaremos hacia la adopción de los estándares internacionales de Basilea. Chile hoy no cumple con los estándares de adecuación de capital de países desarrollados. Esto genera debilidades en la capacidad que tiene la industria bancaria de absorber choques sistémicos, debilidades en la gestión del riesgo de liquidez y daña la competitividad internacional de la industria financiera al no cumplir con los estándares exigidos por los inversionistas y reguladores de otras plazas. Asimismo, genera una debilidad de los bancos locales respecto de los bancos internacionales que operan en Chile, y que han adoptado el nuevo estándar por requerimiento de las autoridades de sus países de origen. 
Los sectores agropecuario, silvícola y pesca, representan un $4 \%$ del PIB y en algunas regiones del país son la principal actividad. En las últimas dos décadas su importancia se ha acrecentado impulsado por los acuerdos comerciales.

Chile, gracias a su condición sanitaria cuenta con ventajas comparativas y competitivas que, con el liderazgo y compromiso de la autoridad, pueden llevar a constituirnos en una potencia alimentaria y, adicionalmente, en un líder mundial en oferta de alimentos saludables. Para alcanzar este objetivo, es necesario avanzar en un proyecto inclusivo, incorporando a este esfuerzo a pequeños productores, jóvenes, mujeres e indígenas, poniendo especial énfasis en la Agricultura Familiar Campesina.

Requerimos potenciar nuestros recursos humanos, romper con el crecimiento desigual y excluyente que se observa en algunos sectores, y atacar los problemas que presentan los pequeños productores en financiamiento, acceso a instrumentos de cobertura de riesgo, a mejores tecnologías de producción, a recursos hídricos y a los mercados en igualdad de condiciones.

En el ámbito de la Agricultura Familiar Campesina (AFC) crearemos, fortaleceremos e implementaremos un programa de desarrollo competitivo para sus principales rubros, que permita que los productores mejoren significativamente su productividad, competitividad y acceso a mercados. Se establecerán estrategias para cada uno de los rubros priorizados, diferenciadas por territorio, identificando los principales puntos críticos para mejorar su inserción competitiva.

Existirán diferentes líneas de acción: inversión, capital humano, investigación y transferencia de innovación, calidad y diferenciación y acceso a mercados. Los programas potenciarán la asociatividad campesina. Se potenciarán los Grupos de Transferencia Tecnológica y las cooperativas, las que tendrán un acceso privilegiado a las asesorías técnicas.

Para fomentar la formalización se ampliará la cobertura del Plan de Regularización de Títulos de Dominio.

Especial importancia tendrá ampliar la formación y las habilidades de los productores familiares y medianos. Esto debe incluir aspectos de gestión, informática, comercialización y gestión de capital social en territorios. Para esto, se establecerá un nuevo convenio INDAP y SENCE, y se buscarán alianzas con escuelas agrícolas, centros de formación técnica y universidades de cada zona.

En Chile hay muchos deudores de INDAP que son pequeños agricultores y que se han visto afectados producto de sequías, inundaciones y heladas, situación que los ha hecho atrasarse en el pago de sus deudas. Por ello, en los 100 primeros días de Gobierno revisaremos la situación de los deudores de INDAP y estudiaremos líneas de apoyo destinadas a quienes se encuentren en situación de vulnerabilidad.

En materia laboral, diseñaremos e implementaremos un plan de fiscalización permanente, coordinado entre los organismos fiscalizadores en materias de higiene y seguridad, a efectos de hacer cumplir las normas sanitarias en los lugares de trabajo y aplicar las sanciones respectivas cuando corresponda. Durante el próximo Gobierno, enviaremos al Congreso un proyecto de ley que contenga el Estatuto del Temporero y la Actividad Agrícola de Temporada, que consagre protección a estos trabajadores y trabajadoras.

En el Gobierno anterior, enviamos el proyecto de Ley de Obtentores Vegetales, conocida como "Ley Monsanto". El sentido original del proyecto era promover el desarrollo tecnológico para aumentar la productividad y competitividad del sector agrícola, con el debido resguardo del patrimonio biológico y genético de Chile.

Hemos conocido nuevos antecedentes y presenciado un debate sobre si esa ley es pertinente y cuáles pueden ser sus riesgos. Vamos a revisar ese proyecto de ley, escuchando todas las opiniones, salvaguardando y respetando la soberanía alimentaria y las semillas tradicionales: vamos a resguardar nuestros recursos y a nuestros pequeños y medianos productores.

Fortaleceremos e incentivaremos el uso del Seguro Agrícola, colocándonos como meta alcanzar un aumento de $50 \%$ en su cobertura en el próximo Gobierno, poniendo un esfuerzo especial en la incorporación de los pequeños y medianos productores agrícolas. 
Por otro lado, necesitamos recuperar el liderazgo perdido en los últimos 4 años por el MINAGRI, reinstalando las instancias de colaboración público privadas, con el conjunto de actores de las cadenas alimentarias, desde productores primarios hasta las organizaciones de consumidores. La institucionalidad vigente no da cuenta de las necesidades del paradigma de desarrollo del sector alimentario. Se debe transitar desde una aproximación sectorial y desarticulada y de rubros hacia una de clusters y cadenas (del campo a la mesa).

Potenciaremos la Agencia Chilena para la Inocuidad Alimentaría (ACHIPIA) como entidad responsable de la gestión de las políticas de inocuidad alimentaria, incluyendo la evaluación de riesgos de los asuntos más relevantes. También deben potenciarse las capacidades técnicas y de fiscalización del Servicio Agrícola y Ganadero (SAG).

Para mejorar la calidad y lograr diferenciar nuestros productos apoyaremos a productores o redes de productores, en sus proyectos de mejoramiento de la calidad y diferenciación, poniendo énfasis en el acceso a certificaciones especializadas. El Instituto de Investigaciones Agropecuarias (INIA) deberá orientar sus programas y proyectos de investigación hacia la identificación, obtención y uso de ingredientes funcionales para la producción de alimentos saludables. Estas medidas requieren un reordenamiento y fortalecimiento del sistema institucional de los servicios del agro que están dedicados a la investigación y a la innovación.

Debemos mejorar la gestión del agua para riego eficiente. Potenciaremos las políticas de mejoramientos de canales, pozos profundos y de riego técnificado. Para esto se realizarán los cambios legales y se destinarán los recursos necesarios. Se implementará el plan nacional de construcción de captadores de agua no aprovechada. En materia de nuevas grandes obras para riego, avanzaremos en un programa de construcción de embalses en distintas regiones, que forma parte de un programa de largo plazo que permitirá un aumento sustantivo de la superficie regada.

También se requiere mejorar la comercialización de los productos, facilitando el acceso a mercados externos, reduciendo los costos y riesgos financieros. Para esto ampliaremos el Fondo de Promoción de Exportaciones. Se crearán productos específicos de cobertura cambiaria o de precios de productos básicos, para el agro. Se estudiarán instrumentos financieros modernos para el sector ganadero bovino y ovino, complementándolos con mejoras a los instrumentos existentes.

Formaremos en la Oficina de Estudios y Políticas Agrarias (ODEPA) un equipo de desarrollo de institucionalidad, regulación y normas de libre competencia que permita revisar las normativas de comercio de tal manera de impedir la operación de formas de comercio en la agroindustria o en el sector forestal que atentan contra los consumidores o los productores.

Estableceremos un Fondo de Defensa de Mercados, que sirva para defender a los productores y exportadores chilenos frente a acusaciones de dumping y subvenciones.

En relación al medio ambiente y los recursos naturales, en el corto plazo constituiremos las Mesas Territoriales del Agua, en las principales regiones, que incorporen a los actores relevantes -organizaciones de usuarios de aguas y representantes de las instituciones públicas involucradas, que puedan diagnosticar los problemas particulares de cada territorio, particularmente en aquellas regiones en que los acuíferos han sido declarados Áreas de Restricción y/o Zonas de Prohibición para efecto del otorgamiento de nuevos derechos de aprovechamiento en los respectivos acuíferos.

En materia forestal, enviaremos al Congreso un proyecto de ley que prorrogue por dos años los incentivos a la forestación, junto con legislar para eliminar las barreras de entrada que han limitado la incorporación de pequeños y medianos propietarios forestales a los beneficios de la actual legislación sobre bosque nativo. Ejecutaremos un Programa Sectorial de Investigación, Transferencia e Investigación Forestal para la protección y conservación de los sistemas forestales. Desarrollaremos una estrategia de fortalecimiento de las PYMES forestales para facilitar su acceso a los recursos productivos y diversificar y agregar valor a su producción. 

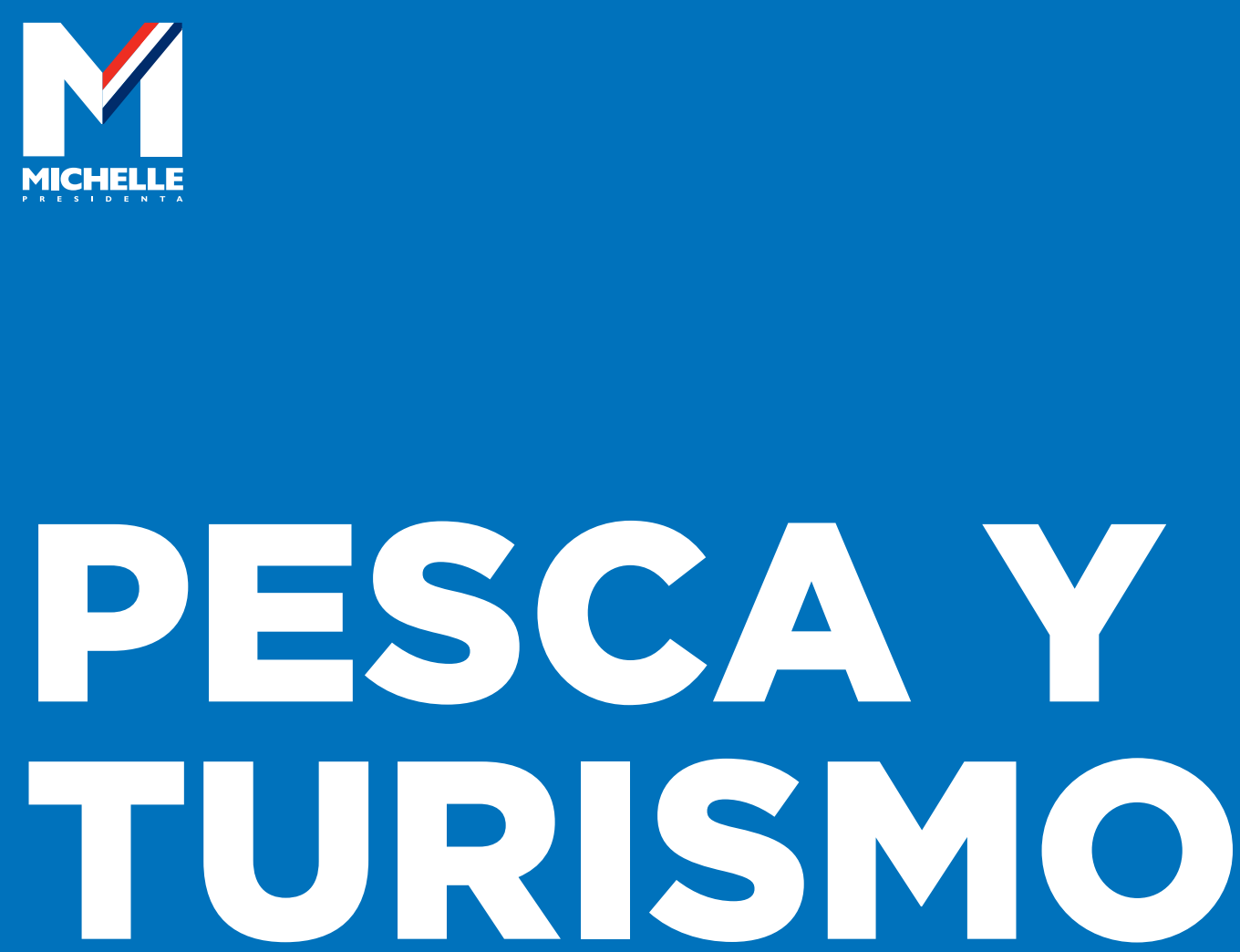


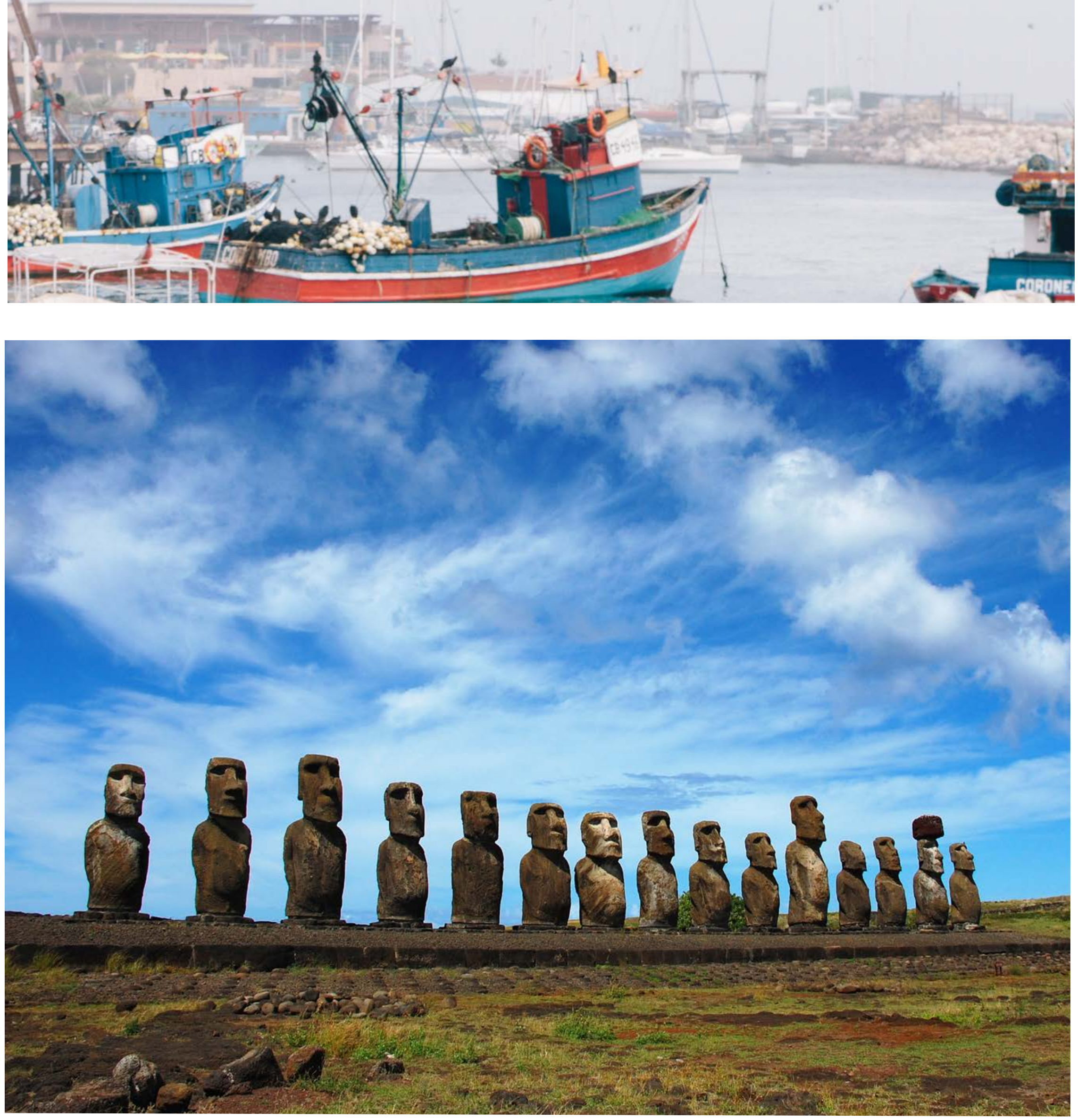




\section{PESCA}

Uno de los temas que abordaremos con fuerza es asegurar un tratamiento sustentable de los recursos pesqueros, dado que pertenecen a todas las chilenas y chilenos, presentes y futuros. Nuestra agenda en pesca centrará sus esfuerzos en asegurar la sustentabilidad de la biomasa, el fortalecimiento de la pesca artesanal y el desarrollo productivo de pequeños emprendedores y la industria nacional.

En materia de sustentabilidad, de 33 pesquerías (especies explotadas) informadas por la Subsecretaría de Pesca en marzo de 2013, tres están en estado de colapso, diez sobre explotadas y respecto de cinco de ellas se desconoce su estado por falta de información científica. Esto demuestra que es fundamental que exista una institucionalidad que garantice la sustentabilidad de los recursos pesqueros. Garantizaremos que el Instituto de Fomento Pesquero (IFOP) realice una labor con independencia de los intereses sectoriales, en materia científica, le garantizaremos su independencia científica, con los más altos estándares internacionales en materia de investigación, a semejanza de los institutos de las principales potencias pesqueras en el mundo.

Complementariamente, es esencial modernizar el Servicio Nacional de Pesca (Sernapesca). El sub-reporte, la pesca ilegal, o simplemente la no fiscalización de los desembarques, contribuyen a la sobreexplotación. Contar con una institucionalidad fiscalizadora a la altura de los desafíos es también fundamental. Asimismo, consideraremos la veda biológica legal de pesquerías declaradas colapsadas, junto con la eliminación progresiva de la pesca de arrastre, mediante una transición que genere los mínimos impactos en la industria nacional.

En cuanto al sector artesanal, que representa a más de 80.000 chilenas y chilenos, promoveremos condiciones que les permitan mejores ingresos y mayor valor agregado por la comercialización de sus productos, evitando la destrucción del tejido social y las características culturales propias de este sector. Por ello, impulsaremos el Instituto de Desarrollo de la Pesca Artesanal, con recursos y presencia regional, para que sea un motor de desarrollo social y económico de este sector. Mediante esta entidad mejoraremos los canales de comercialización, para asegurar precios justos. Crearemos, una "Bolsa de la Pesca Artesanal", a la que puedan acceder voluntariamente los pescadores artesanales de todo Chile, para vender sus productos al mercado mayorista con mecanismos transparentes, abiertos y competitivos. Sumado a esto, en el primer año de Gobierno duplicaremos los recursos del Fondo de Fomento para la Pesca Artesanal, para darles soporte en infraestructura, capacitación, repoblamiento de recursos y comercialización.

Adicionalmente, asumimos el compromiso de concretar durante el próximo período presidencial la extensión de las 5 millas de protección artesanal desde Chiloé hasta el extremo sur, para que en todo el país exista una zona exclusiva para pescadores artesanales, y no se discrimine a los pescadores australes. En cuanto al consumo humano de recursos marinos, utilizaremos el máximo que establece la ley como reserva, para que sea procesada por PYMES pesqueras y sean destinadas exclusivamente a la elaboración de productos en esa línea.

En materia de seguridad social, realizaremos los esfuerzos necesarios para incorporar a los pescadores artesanales, tanto al sistema de pensiones, como a la salud laboral, participando de la ley de Accidentes del Trabajo y Enfermedades Profesionales.

En el ámbito de la pesca debemos velar por que los instrumentos legales cautelen los intereses y demandas de todos los sectores involucrados, con una preocupación especial por aquellos más vulnerables. Por esto, realizaremos una evaluación de la Ley de Pesca aprobada durante la actual administración. 
El turismo no es sólo una actividad económica cuya importancia ha ido creciendo en el tiempo, sino que además tiene características que hacen de su fomento un objetivo de alto interés público, pues contribuye a construir identidad nacional y territorial, genera desarrollo local incluso en las áreas más apartadas, crea actividad económica relacionada, aporta a la protección de recursos naturales y favorece el intercambio cultural.

Para fomentar esta actividad impulsaremos aquellas líneas estratégicas que garanticen un crecimiento turístico basado en la sustentabilidad, es decir, asegurando que el desarrollo económico de la industria se traduzca en mejores condiciones de vida para las chilenas y chilenos participantes, y protegiendo el medio ambiente, principal activo turístico de Chile.

\section{Potenciaremos el desarrollo turístico sustentable en áreas Silvestres Protegidas del Estado.} Considerando que los turistas visitan que Chile lo hacen en su mayor parte atraídos por nuestra naturaleza, se hace necesario contar con un sistema que incentive el desarrollo del turismo en esta área, actuando en colaboración con los ministerios de Medio Ambiente, Agricultura (CONAF) y Bienes Nacionales, generando mecanismos para que operadores de turismo y los organismos del Estado efectivamente realicen una labor de calidad, sustentable y atractiva turísticamente.

\section{Avanzaremos en el establecimiento de Zonas de Interés Turístico (ZOIT). Convocaremos a todos los actores involucrados en la identificación de las ZOIT -muy especialmente a las municipalidades- para que en conjunto se avance en la definición de nuevas zonas de interés turístico, lo que permitirá coordinar programas e instrumentos públicos de fomento que aseguren la valoración y conservación del patrimonio natural y/o cultural presente y su posterior implementación con fines turísticos.}

\section{Impulsaremos la oferta y promoción de la oferta turística con elementos culturales. En este ámbito se encuentra el desarrollo de la oferta turística que contenga elementos culturales tradicionales. Es una actividad para que las comunidades locales ejerzan un rol más activo en la creación de una oferta turística atractiva y, al mismo tiempo, para que los canales de distribución $\mathrm{y}$ viajeros se interesen en conocerlas a través de rutas o programas donde se mezclen los recursos turísticos más tradicionales y conocidos con los nuevos elementos de la oferta cultural.}

\section{Facilitaremos el acceso expedito a} instrumentos de fomento a la inversión turística. El turismo se compone principalmente por micro, pequeñas y medianas empresas, que son el motor de la industria turística nacional. Apoyaremos el emprendimiento con instrumentos de fomento adecuados a los distintos ciclos de la empresa pero principalmente para la micro y pequeña empresa. En esta labor se hace fundamental la colaboración de las autoridades regionales y locales para coordinar la entrega de información a los distintos actores que la necesiten.

Para fomentar el turismo crearemos un Fondo Nacional para el Fomento del Turismo, orientado a financiar actividades que potencien su desarrollo, incluyendo la capacitación, la promoción y la innovación. Realizaremos un programa de liderazgo orientado a dar un salto significativo en la calidad de los recursos humanos que trabajan en el sector. Incentivaremos el turismo social y nacional, aumentando la cobertura de los programas de giras de estudios, de vacaciones de la tercera edad y de turismo mujer, especialmente en temporadas de baja demanda. Crearemos un nuevo programa de vacaciones familiares, enfocado especialmente en familias de menores ingresos y en aquellas cuya jefatura de hogar es femenina, que ofrecerá paquetes turísticos con actividades recreativas, culturales y deportivas.

Impulsaremos un plan de desarrollo de destinos turísticos distribuidos a lo largo de Chile, y coordinaremos esfuerzos con los actores privados para potenciar sus atractivos. Ello incluye inversión en infraestructura turística (paseos peatonales, costaneras, pasarelas, luminarias, pavimentación, habilitación de plazas, señales viales y miradores, entre otras), además de plataformas de información presenciales y digitales para los visitantes.

Adicionalmente potenciaremos la articulación turística latinoamericana, aprovechando las sinergias y economías de escala destinadas a atraer a turistas de otras regiones del planeta. Fortaleceremos el marketing internacional a público final, considerando las particularidades e intereses de los visitantes internacionales y aprovechando las tecnologías digitales que permiten organizar viajes sin intermediarios. 
V

MINIERIA Y RECURSOS HÍDRICOS 

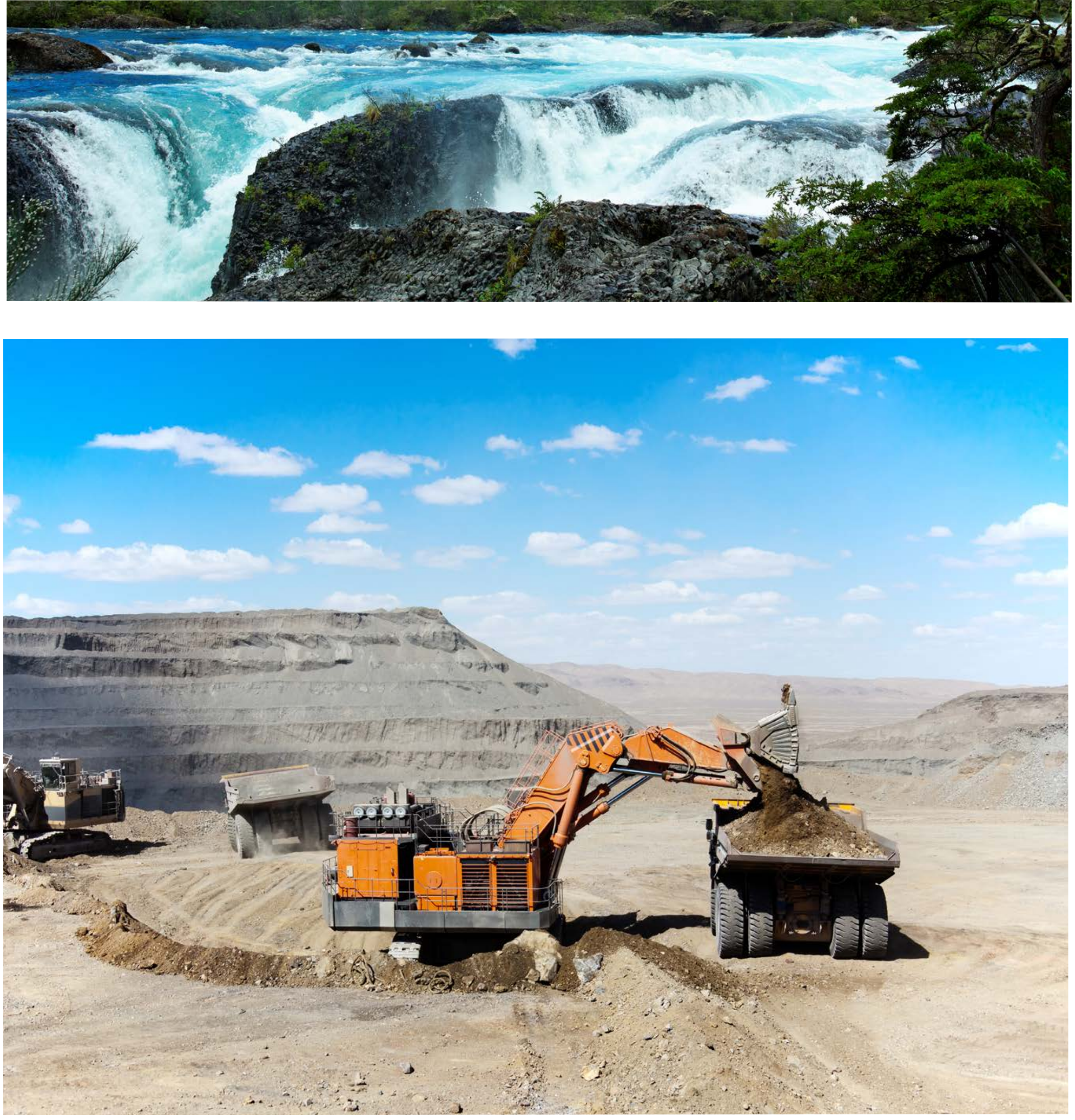
La minería sin duda tiene una enorme importancia en la economía nacional y ha sido motor del crecimiento del país en los últimos años. La minería representa el $13 \%$ del PIB y hoy tanto las exportaciones como el aporte al PIB son 10 veces superiores a los valores de principios de la década pasada. Los aportes de la minería del cobre a los ingresos del Estado también han crecido a la par. La minería lidera el desarrollo de cinco regiones del norte de Chile y constituye el $60 \%$ de las exportaciones. Chile es el mayor productor de cobre del mundo con $33 \%$ de la producción mundial y tiene un $28 \%$ de las reservas mundiales de cobre. Actualmente, Chile produce cerca de 5,4 millones de toneladas métricas de cobre al año.

Asimismo, Chile ocupa el tercer lugar en el ranking mundial en la producción de molibdeno, con $13 \%$ de la producción mundial; ocupa el sexto lugar como productor de plata con una participación del $5 \%$ a nivel mundial; y está en el lugar $16^{\circ}$ como productor de oro con una participación de $2,1 \%$ en la producción mundial. Además es productor de sales mixtas, que incluyen potasio y litio.

El peso de la minería en nuestra economía nos obliga a mantenernos como el principal y más eficiente productor de cobre a nivel mundial. Pero hay varios factores que nos han hecho perder parte de estas ventajas, reduciendo nuestra productividad. Hemos sufrido una caída de las leyes de los minerales superior a la registrada en el resto del mundo, la que además de exigir más trabajo para producir lo mismo, se traduce en mayor consumo de combustibles y de energía por tonelada producida.

Los costos de energía en Chile se han disparado y figuran en niveles muy superiores a los de otros países mineros. Para varias de las empresas mineras locales la energía representa alrededor del $20 \%$ de sus costos, tres veces más que el sector minero en Perú y Estados Unidos. Recuperar la competitividad minera, entre otras materias, exige tener energía a precios competitivos.

También se requiere un mayor esfuerzo en tecnología y recursos humanos calificados. El buen momento de la minería mundial ha generado una escasez de trabajadores calificados. Focalizaremos esfuerzos en la formación de recursos humanos especializados, con énfasis en las propias regiones mineras, ante la evidencia de que el aumento de los jóvenes que acceden a formación superior en esta área es aún insuficiente para cubrir la demanda. También estableceremos un sistema de certificación de competencias para los técnicos que se preparen para trabajar en la industria, a través de una iniciativa conjunta entre las empresas, las entidades de formación y el Estado.

Apoyaremos el desarrollo de las empresas que prestan servicios para abastecer a la minería, las que muestran un importante dinamismo. Los proveedores de la minería ya llegan a más de 4.600 empresas que dan empleo a 700 mil personas. Impulsaremos una política de asociatividad y colaboración entre empresas mineras y proveedoras, Estado e instituciones de investigación para potenciar el desarrollo minero. Fortaleceremos el cluster minero estimulando la colaboración entre las instituciones de investigación para evitar la fragmentación de los esfuerzos.

La institucionalidad del Estado en el sector minero requiere una modernización para enfrentar el desarrollo del sector. Fortaleceremos al Ministerio de Minería, en especial en recursos humanos y personal técnico calificado.

Los desafíos de la industria minera, también requieren de una institucionalidad técnica especializada, que desarrolle y monitoree permanentemente la aplicación de las políticas públicas del sector, las condiciones del mercado del cobre y otros minerales, y que identifique los riesgos que pueden afectar a éste mercado. Ante el incremento de la inversión estatal en proyectos mineros, fortaleceremos a COCHILCO con mayores atribuciones para cumplir a cabalidad su rol de resguardo de los intereses del Estado en sus empresas mineras, por medio de la fiscalización y evaluación de inversiones y contratos.

El Estado a través del Servicio Nacional de Geología y 
Minas (SERNAGEOMIN) cumple importantes funciones para el desarrollo de la minería, para la inversión, el monitoreo de la red volcánica, y para la fiscalización de la seguridad minera. Una de las tareas en que avanzaremos es completando la Cartografía Geológica, ya que actualmente sólo tenemos cubierta la cuarta parte del territorio. No tener información geológica sobre todo el territorio implica no poder ejercer plenamente los derechos que la Constitución otorga al Estado sobre las minas. Adicionalmente, realizaremos un fortalecimiento institucional del SERNAGEOMIN para que desarrolle su labor de control de la seguridad en las faenas mineras.

Además, revalorizaremos el rol de la Empresa Nacional de Minería (ENAMI), referido a favorecer la movilidad social, fomentar el poblamiento del interior de las regiones del norte y, por tanto, la descentralización de las mismas, entregando trabajo, desarrollo y contribuyendo en forma sostenible a la disminución de la pobreza. Para ello, se asignarán recursos para fomentar la explotación y beneficio de toda clase de minerales existentes en el país. Su actual estructura corporativa le dificulta mostrar eficiencia en su función, por lo que estableceremos un gobierno corporativo moderno.

La creciente demanda mundial de litio y sus altos precios en el mercado internacional otorgan a Chile una importante oportunidad para diversificar su producción con la explotación de este recurso natural. Las reservas conocidas de este mineral a nivel mundial se encuentran mayoritariamente en nuestro territorio, en el Salar de Atacama. Constituiremos una comisión técnica de alto nivel integrada por expertos, que proponga una política nacional del litio que considere éstos y otros factores para una eficiente y efectiva explotación de este mineral, que permita una óptima rentabilidad para el país.

Estudiaremos y aplicaremos nuevas normas para el perfeccionamiento del sistema de concesiones mineras, de forma que este fomente la exploración y no se constituya en una potencial barrera a la entrada de nuevos actores.
El establecimiento de un mercado de derechos de uso de agua ha contribuido al desarrollo agrícola. Pero también ha traído aparejado una serie de inconvenientes, como el insuficiente resguardo del patrimonio ambiental, el deficitario acceso del mundo rural al agua y los nulos incentivos para gestionar la utilización de una fuente de agua común a partir de derechos individuales, generando la sobre explotación de múltiples acuíferos.

La transacción de derechos de agua ha venido aumentando en la medida que se hace más escaso el recurso. La institucionalidad pública en este ámbito es insuficiente y no efectiva para cumplir los roles fundamentales de planificación, normativo, de fomento, diseño de política, regulación y fiscalización.

Los nuevos desafíos en materia de recursos hídricos demandan una especial atención del Estado. En los primeros 100 días de Gobierno, nombraremos un Delegado Presidencial para los Recursos Hídricos, con dedicación exclusiva, a fin de identificar y avanzar en soluciones a la escasez de agua en el país.

Avanzaremos en una normativa que haga posible la existencia de la figura recursos hídricos con fines sociales. Estos usos serán prioritarios y establecerán restricciones al ejercicio de todos los demás usos con fines competitivos.

También modificaremos la normativa para redefinir la utilización de los acuíferos sobre-otorgados de acuerdo al uso efectivo de los derechos.

Adicionalmente, estableceremos la normativa que permita el intercambio de derechos provisionales y eventuales por aquella proporción no utilizada de los derechos. En el caso de acuíferos con baja recarga pero con gran volumen almacenado, definiremos volúmenes de agua que se pueden extraer en plazos determinados sin generar efectos ambientales adversos. 

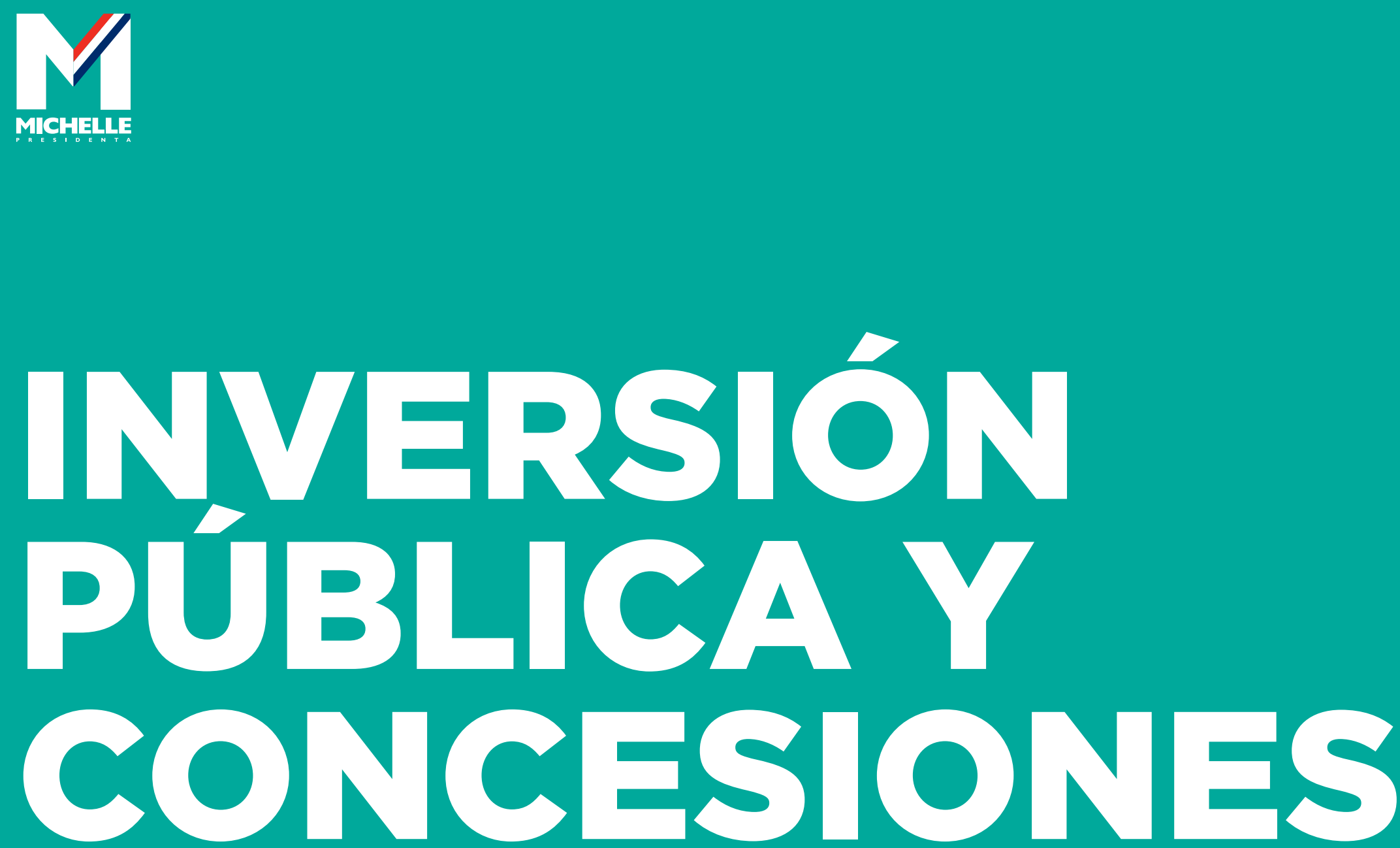


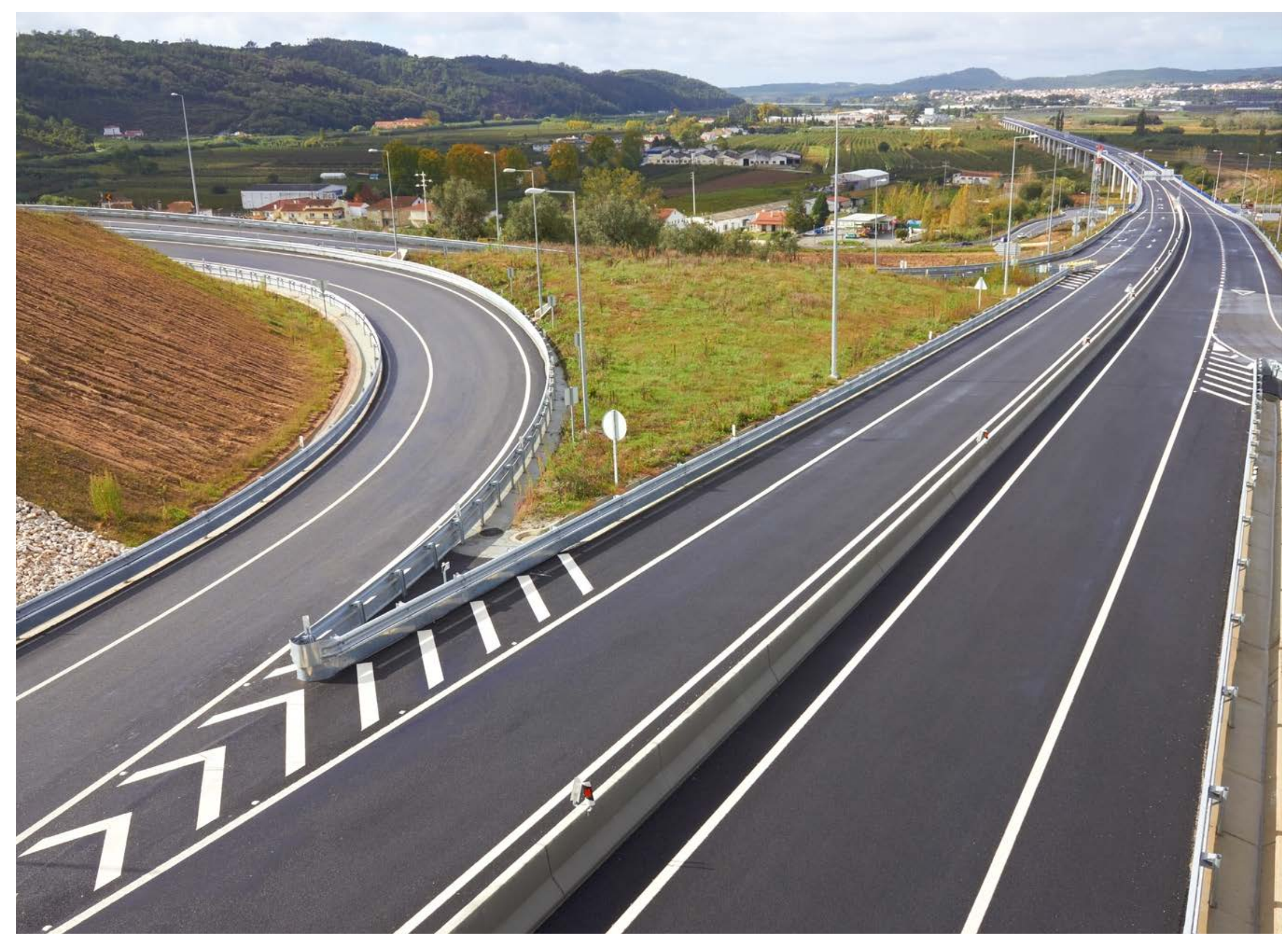




\section{INVERSIÓN PÚBLICA Y CONCESIONES}

La infraestructura juega un rol fundamental para el desarrollo de un país. Disponer de infraestructura para el uso público y con estándares de calidad es crucial para promover el crecimiento y la mejora en la competitividad. Al mismo tiempo, la infraestructura impacta en la calidad de vida de las personas y es una herramienta de inclusión social.

A partir de 1990 Chile dio un paso gigantesco en materia de desarrollo de infraestructura vial, portuaria y aeroportuaria, generando con ello las bases necesarias para reducir los costos logísticos y mejorar la conectividad en el país y más allá de sus fronteras. Ello ha sido un pilar fundamental para el desenvolvimiento del comercio exterior, y también ha permitido que los chilenos y chilenas disfruten más de nuestro territorio, al poder desplazarse de modo más expedito y seguro.

Para mantener el crecimiento del país y de nuestro comercio exterior necesitamos ser capaces de planificar, evaluar, programar, construir, operar y mantener la inversión en el sector de infraestructura con elevados niveles de eficiencia.

La planificación de la infraestructura, requiere fortalecer una visión multimodal, incorporando el transporte terrestre, ferroviario, marítimo yaéreo. La fragmentación institucional es una de las grandes debilidades que se enfrenta en el transporte. Esta falta de visión integral reduce la rentabilidad social de la inversión y aumenta los costos logísticos, de contaminación, gases de efecto invernadero y de accidentes entre otros problemas y deteriora la calidad de vida en las ciudades. No obstante, las soluciones de Infraestructura en el territorio no son independientes de las dimensiones ambientales y de la interacción entre actividades económicas y las vocaciones productivas de los diferentes territorios. Incorporar estas dimensiones en el desarrollo de la infraestructura requiere establecer la capacidad de ordenamiento territorial a nivel interurbano y en las regiones. Por ello, realizaremos un proceso de evaluación de la institucionalidad del sector en los niveles de diseño de política, evaluación de proyectos y planificación de las inversiones en materia de transporte. Esta evaluación debe dar paso al diseño de los mecanismos de coordinación y reordenamiento institucional, que se implementarán en el próximo gobierno.

Obras de Reconstrucción. En materia de inversiones, la primera prioridad la tiene la reconstrucción. El gobierno actual realizó esfuerzos en la materia. Pero quedan tareas pendientes. Velaremos especialmente para que las soluciones a las familias afectadas se realicen y sean definitivas. Se trata de reconstruir vidas, de que las personas damnificadas sientan que ha terminado una época de enorme vulnerabilidad y que cuentan con un suelo y un techo donde volver a instalar su vida y sus esperanzas. Para asegurar esta prioridad, dentro de los100 primeros días de gobierno se realizaráun diagnóstico del estado de la reconstrucción en las diversas zonas que han sido afectadas. En función de dicho diagnóstico se generará un plan de acción. Se designará en los primeros días también un delegado presidencial para la reconstrucción, con facultades de coordinación institucional y de recursos para realizar esta tarea.

Cartera de proyectos de concesiones. La modalidad de concesiones de obra pública está bien asentada en el caso de autopistas interurbanas y urbanas, con una visión de que la participación del sector privado genera "valor" aumentando la eficiencia en la provisión de los servicios de infraestructura de transportes. A futuro estos proyectos se deben seguir realizando en esta modalidad. El principal desafío que se enfrenta en el corto plazo es mejorar el estándar de varias concesiones que se realizaron hace algunos años. A modo de ejemplo, los diversos accesos a Santiago deben ser transformados en autopistas urbanas, con similares modalidades de cobro a estas. El objetivo fundamental es evitar la interferencia de la ciudad en ejes logísticos fundamentales y aumentar la capacidad de acceso a la ciudad, especialmente en los fines de semana largo. Las inversiones de cientos de millones de dólares requeridas para avanzar en esta materia, de preferencia deberían ser realizadas mediante nuevas concesiones licitadas y/o con los concesionarios actuales.

En Santiago se deberá concluir la integración de las autopistas existentes incorporando Américo Vespucio Oriente. Existen otros proyectos de autopistas urbanas en Santiago y en capitales regionales. Todos estos proyectos deberán ser evaluados para asegurar una adecuada perspectiva multimodal de transporte en las ciudades, evitando sesgar la partición modal en favor de un uso excesivo del automóvil con las consecuencias de contaminación y congestión. Cada ciudad cabecera de Región, área metropolitana o conurbación deberá contar con planes de transporte.

En hospitales, cárceles, edificación pública y obras de riego, sobre la base de la experiencia reciente, se evaluará si la modalidad de concesiones es una modalidad de inversión que entregue valor, aumentando la eficiencia en la provisión de los servicios.

Desarrollo del sector portuario. Incrementaremos la capacidad de transferencia de los puertos estatales de la Región de Valparaíso en un horizonte de 15 años. Ello implica la construcción de un puerto a gran escala en la zona central. Parte de la inversión será realizada por los privados que obtengan la concesión para construir los nuevos terminales, pero otra parte, la infraestructura de 
abrigo, debe ser financiada directamente por el Estado y recuperada posteriormente mediante tarifas a la operación de naves.

Adicionalmente, el Ministerio de Transporteestablecerá una autoridad para cada puerto, la que tendrá competencia en aspectos operativos navieros dentro de las áreas portuarias como de coordinación de las agencias públicas que fiscalizan la actividad comercial (Aduanas y SAG). Asimismo, realizaremos auditorías a los contratos de concesiones portuarias, de modo de fiscalizar el cumplimiento de los términos establecidos en los contratos de concesión.

Complementariamente, desarrollaremos planes de protección de áreas costeras reservadas a puertos, que aseguren la expansión de la capacidad portuaria en el territorio y en el borde costero, compatibilizándolo con otros usos y su relación con el territorio en que se emplazan. Esto posibilitaría la planificación de redes de transporte y la consagración de la actividad portuaria en los instrumentos de planificación territorial como los Planes Intercomunales o Comunales.

Plan de Protección de Zonas Aeroportuarias. El crecimiento urbano impacta las actividades propias de los aeropuertos. Se estima necesario proteger las áreas adyacentes a las bases aéreas, de modo que la operación aeroportuaria sea compatible con el resto de las actividades que allí se realicen. Introduciremos en los instrumentos de planificación territorial, como planes reguladores e intercomunales, la consideración de usos urbanos que sean compatibles con la normal operación y crecimiento de los aeropuertos.

Pasos Fronterizos. El Paso Los Libertadores, que es la principal conexión de Chile con Argentina, se cierra un promedio de 25 días al año, generando importantes costos y perturbaciones al normal flujo de turistas y de carga entre los países. Para enfrentar esta situación, desarrollaremos infraestructura para otorgar una mayor continuidad de servicio. Adicionalmente, mejoraremos, entre otras, vías alternativas como, por ejemplo, el paso Aguas Negras en la Región de Coquimbo y el Paso Pehuenche en la Región del Maule.

Infraestructura Recreativa y Social. La Infraestructura también aporta a la calidad de vida, a la cultura y a la recreación de los ciudadanos. Por ello continuaremos y profundizaremos los programas destinados a dotar a las ciudades costeras de infraestructura que les permita mejorar su relación con el mar, lagos o ríos.

Continuación del proyecto de cruce sobre Canal Chacao. La primera acción del Gobierno será revisar los nuevos antecedentes generados sobre la materia en los últimos cuatro años, evaluar las diferentes y contratar el estudio de ingeniería básica del nuevo proyecto y el estudio de impacto ambiental asociado, licitándolo como concesión de obra pública para asegurar la mantención y operación al más alto estandar de servicio y con tarifas similares a las que hoy se pagan a los transbordadores.

Continuación del Camino de la Fruta. Resolveremos a la brevedad la concesión del Camino de la Fruta, proyecto que fue abandonado por el concesionario por diferencias con esta administración (MOP) y que ha enfrentado problemas medioambientales.

Conectividad Marítima. Durante los primeros 3 meses de gobierno, revisaremos los avances reales que se han realizado en la infraestructura marítima, las naves y los servicios que se están prestando en el marco del Plan de Conectividad Austral. A partir de dicho diagnóstico propondremos un programa de proyectos que mejoren la conectividad marítima entre los principales centros poblados de la Zona Austral de Chile en las regiones de Los Lagos, Aysén y Magallanes, prestando un servicio de primera calidad.

Infraestructura de Riego. Avanzaremos en el desarrollo de grandes embalses en diferentes regiones del país. Iniciaremos la construcción, entre otros, de los embalses en el río Aconcagua en la región de Valparaíso, en el LLuta de la región de Arica y Parinacota yen Punilla en la región de Bio Bio. Perfeccionaremos el sistema de cobro a los beneficiados, asegurando que se asignen los derechos de agua a los propietarios agrícolas que carecen de ellos. También se avanzará en el desarrolllo de un programa efectivo de apoyo a la ejecución por parte de privados de medianas y pequeñas obras de riego. Finalmente, se incentivará la infiltración de napas, de modo de generar verdaderos embalses naturales en los acuíferos.

Drenaje de Aguas Lluvias. Desarrollaremos un plan permanente de protección de riberas, con especial énfasis en zonas urbanas. En materia de aguas lluvias, se continuará con el programa elaborado por el MOP, que permite invertir en obras para enfrentar el déficit de canalización y drenaje de aguas lluvias en las ciudades.

Agencia de Concesiones. Crearemos la Agencia de Concesiones, con personalidad jurídica propia, competencias y atribuciones. Esta agencia asesorará a los distintos ministerios, servicios y municipalidades que requieran ejecutar proyectos mediante el mecanismo de concesiones. 


\section{M \\ MICHELLE}

EMPRENDIMIENTO

DE MICRO,

PEQUENA Y

MEDIANA

EMPRESA 

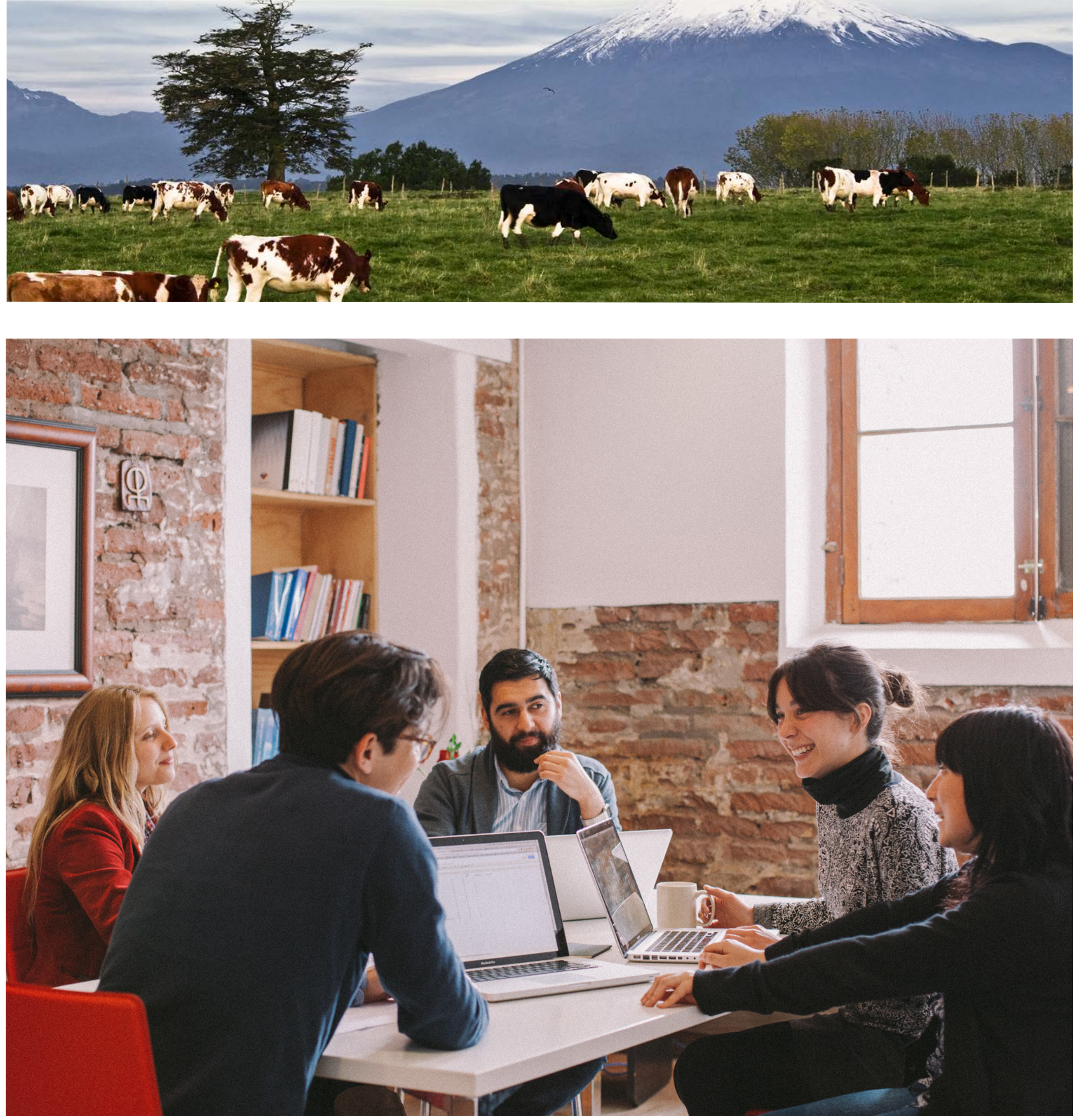


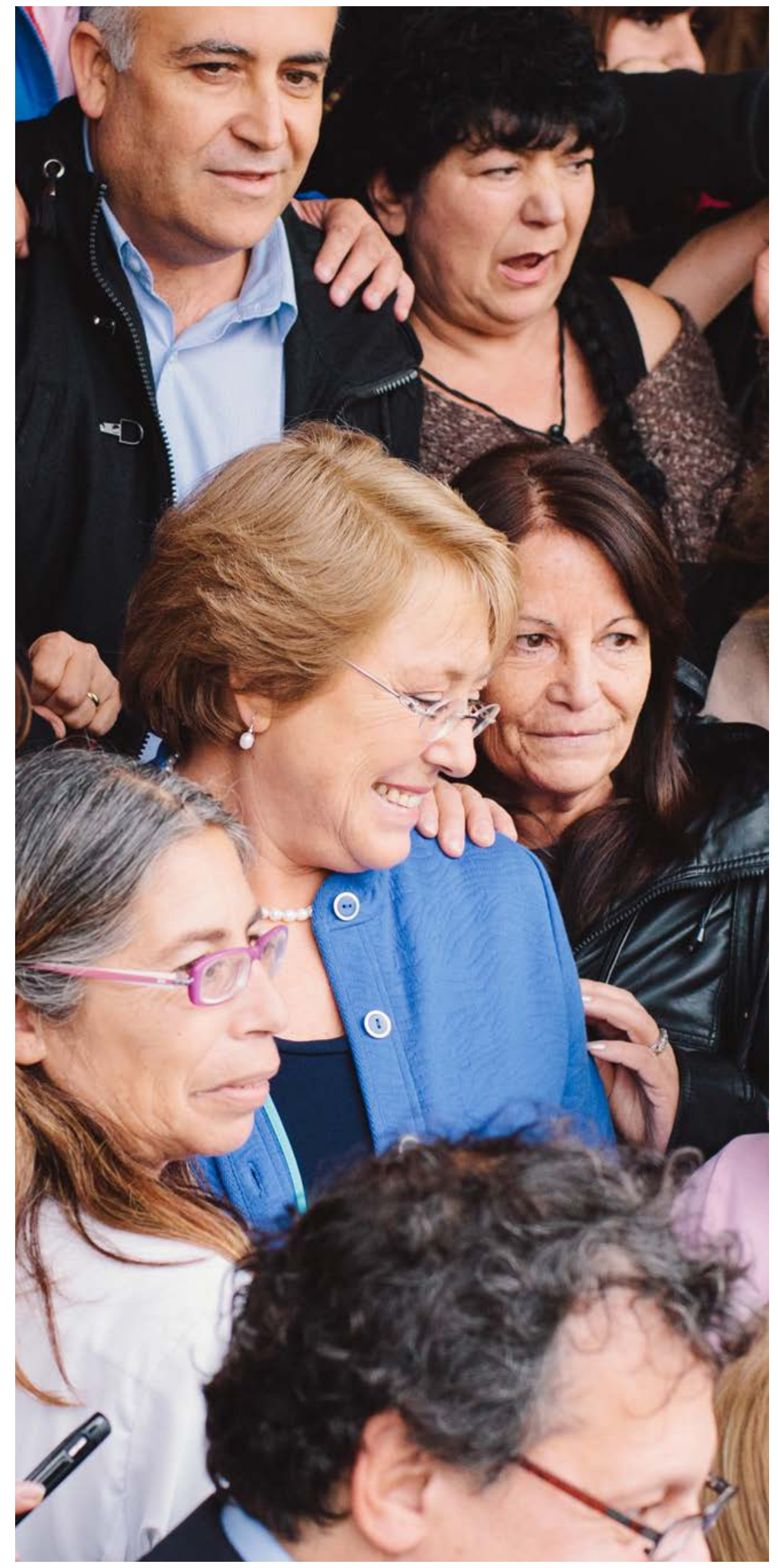

\section{EMPRENDIMIENTO DE MICRO, PEQUEÑA Y MEDIANA EMPRESA}

La participación de las empresas de menor tamaño en las ventas totales ha ido declinando en el tiempo. Con ello una porción importante de la población laboral (más del $55 \%$ ) ha visto disminuida su participación relativa en la producción nacional. Un conjunto de factores ayudan a explicar esta situación: un contexto normativo y regulatorio que ha tendido a favorecer a las firmas de mayor envergadura, la baja cobertura de los programas destinados a apoyar a las empresas más pequeñas, la inferior calidad de las intervenciones en esos estratos, la concentración de algunos mercados y las dificultades de acceso al financiamiento.

Para revertir esta situación desarrollaremos un contundente programa de apoyo al mejoramiento de la gestión y la productividad de la Micro y Pequeña Empresa (MYPE), así como medidas que apuntan a generarles un entorno más propicio. Para ello abordaremos sus problemas relacionados con su limitada capacidad de gestión y la dificultad para acceder a servicios de apoyo. Crearemos una red de Centros de Desarrollo Empresarial que ofrecerán un diagnóstico de la situación de la empresa y asesoría para desarrollar un plan de negocios, servicios que no tendrán costo para empresas pequeñas y proyectos de emprendimiento que buscan iniciar un negocio.

El sistema de Compras Públicas incorporará activamente a las empresas de menor tamaño, la participación de las PYMES productivas nacionales en este mercado es limitada. Para corregir esta situación: i) estableceremos un Registro Nacional de Proveedores, que caractericen tamaño, giro, dependencia, entre otras características, que servirá de base para una política de incentivos a las PYMES productoras; ii) los Centros de Desarrollo Empresarial darán asistencia técnica a las empresas de menor tamaño para participar adecuadamente en el sistema de Compras Públicas, y; iii) evaluaremos mecanismos que otorguen preferencias a las empresas de menor tamaño. 
Impulsaremos reformas para favorecer el financiamiento de las MYPE. La actual legislación bancaria plantea restricciones de capital demasiado elevadas para que surjan bancos de nicho que puedan focalizar su acción en las empresas más pequeñas. Evaluaremos medidas para facilitar la creación de vehículos financieros con foco en el sector y promoveremos que CORFO canalice recursos más significativos hacia entidades financieras que trabajen con ese segmento. Adicionalmente, haremos del BancoEstado un actor efectivo de apoyo financiero a las empresas de menor tamaño, potenciando la actividad de Banco Estado Microempresas hacia el segmento de empresas de menor tamaño. Generaremos una base de información de tasas de interés cobradas a la MIPYME, a partir de la información de la SBIF, la que permitirá obtener información semanal y comparativa que ayudará tanto a diseñar políticas públicas como a generar más competencia en este segmento. También avanzaremos en un sistema de garantías mobiliarias, soportado en un registro informático sin participación de notarios, que permita a estas empresas usar sus activos móviles (vehículos, facturas, cuentas por cobrar, entre otros) para mejorar las condiciones de plazo y tasa de las operaciones de crédito.

Las empresas de menor tamaño sufren en muchas ocasiones por la competencia desleal de grandes empresas que actúan como cartel. Incrementaremos los recursos de operación de la Fiscalía Nacional Económica para que pueda promover investigaciones sobre posibles colusiones que afecten tanto a los consumidores como a estas compañías. Adicionalmente, crearemos una unidad especializada en la Subsecretaría de Economía, cuyo propósito será la vigilancia de los abusos en contra de las empresas de menor tamaño e impulsar, a través de un amplio proceso participativo, un exhaustivo proceso de revisión y ajuste de la normativa que afecta el desempeño de las empresas de menor tamaño.
Eliminaremos las diversas formas de discriminación que afectan la constitución y el funcionamiento de las cooperativas, las cuales hoy agrupan a más de un millón de chilenas y chilenos. Entre los aspectos discriminatorios más relevantes se cuentan: el pago de derechos para financiar la labor fiscalizadora del departamento de cooperativas; el establecimiento de provisiones más elevadas a las cooperativas de ahorro y crédito que a otras instituciones financieras; y los mayores costos y plazos para constituirse en comparación con otro tipo de empresas. Estableceremos en CORFO programas especiales de fomento para estos sectores, para así apoyar el desarrollo y fortalecimiento de las cooperativas, del comercio justo, las empresas B que solucionan problemas sociales y ambientales desde los productos y servicios que comercializan, el turismo comunitario y otras formas de emprendimiento asociativos o que promueven la inclusión social.

Fortaleceremos a las ferias libres e impulsaremos su desarrollo y modernización, a través del apoyo de organismos públicos como SERCOTEC. De esta manera, duplicaremos los recursos asignados al fondo de modernización de ferias libres, creado en $\mathbf{2 0 0 8}$, en beneficio directo de las ferias y los feriantes a lo largo del país.

A las medidas descritas se deben sumar el conjunto de incentivos para las empresas de menor tamaño, que se establecen en la Reforma Tributaria, particularmente, los nuevos incentivos para la inversión, la aplicación de sistemas simplificados de tributación y, el cambio de sujeto en el pago del IVA, cuando la PYME como empresa proveedora recibe pagos a plazo. 


\section{MICHEELLE}

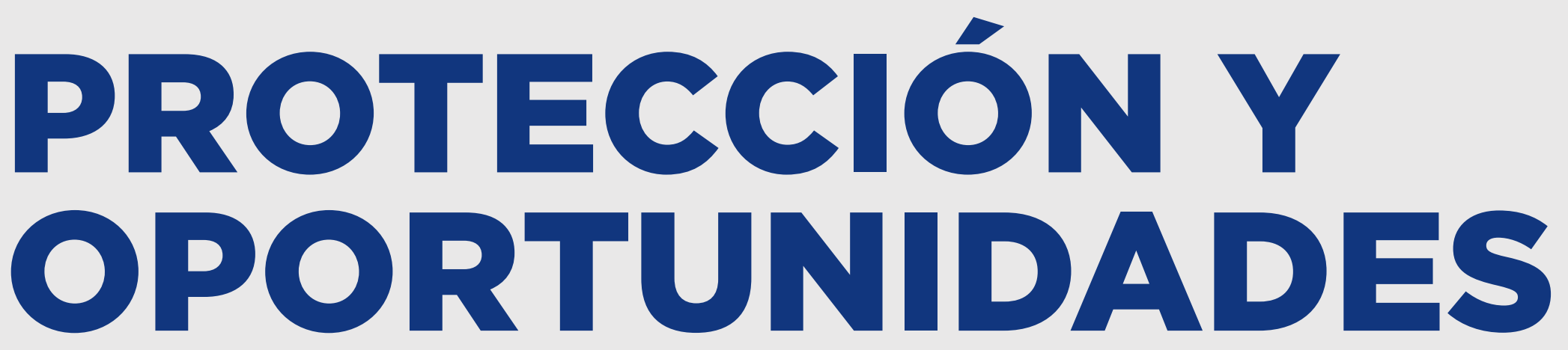




SALUD

MICHELLLE$$
\text { (n) }
$$
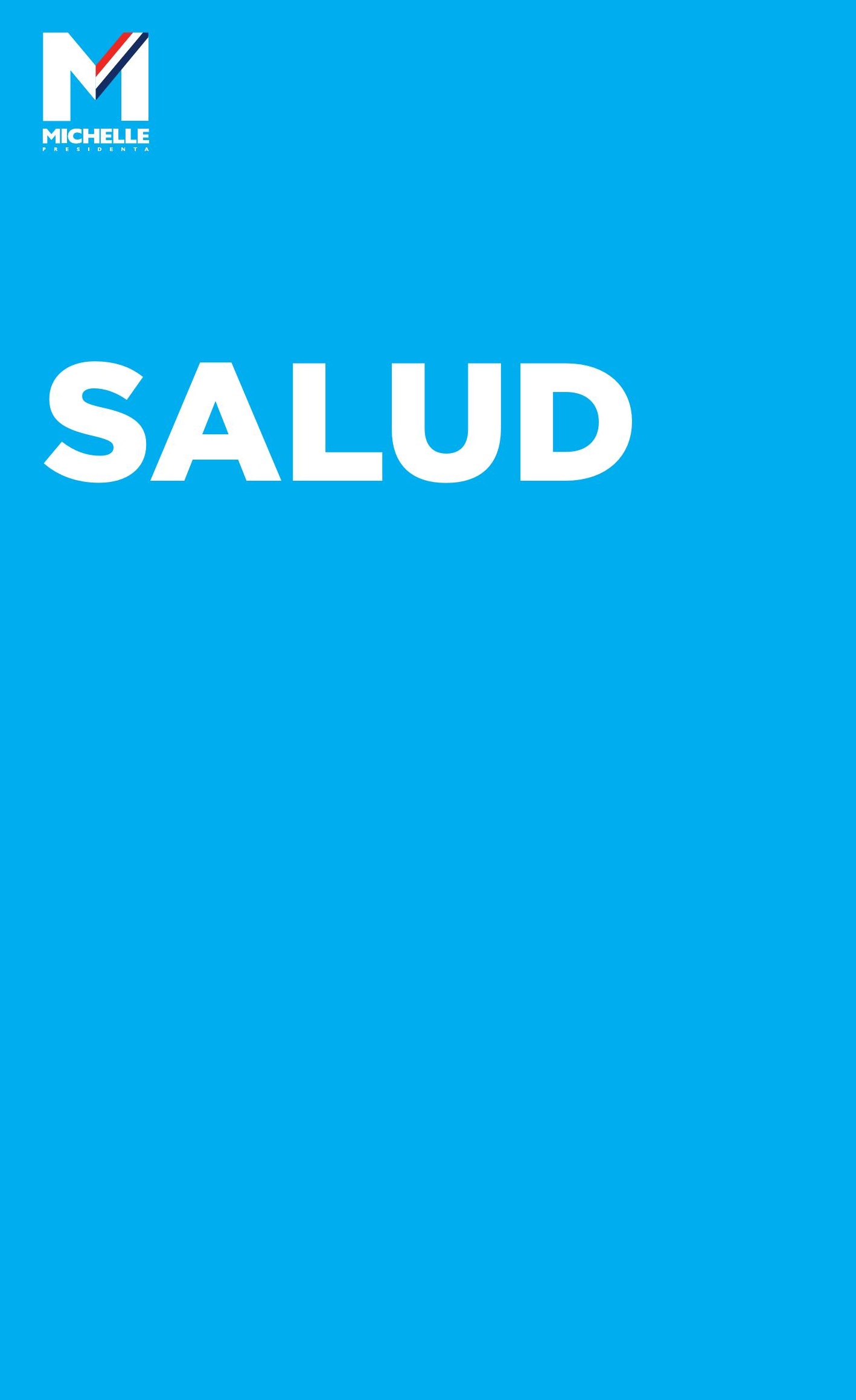

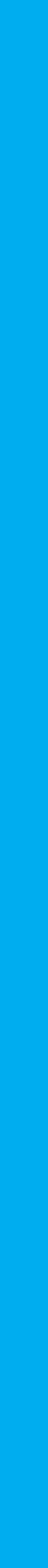




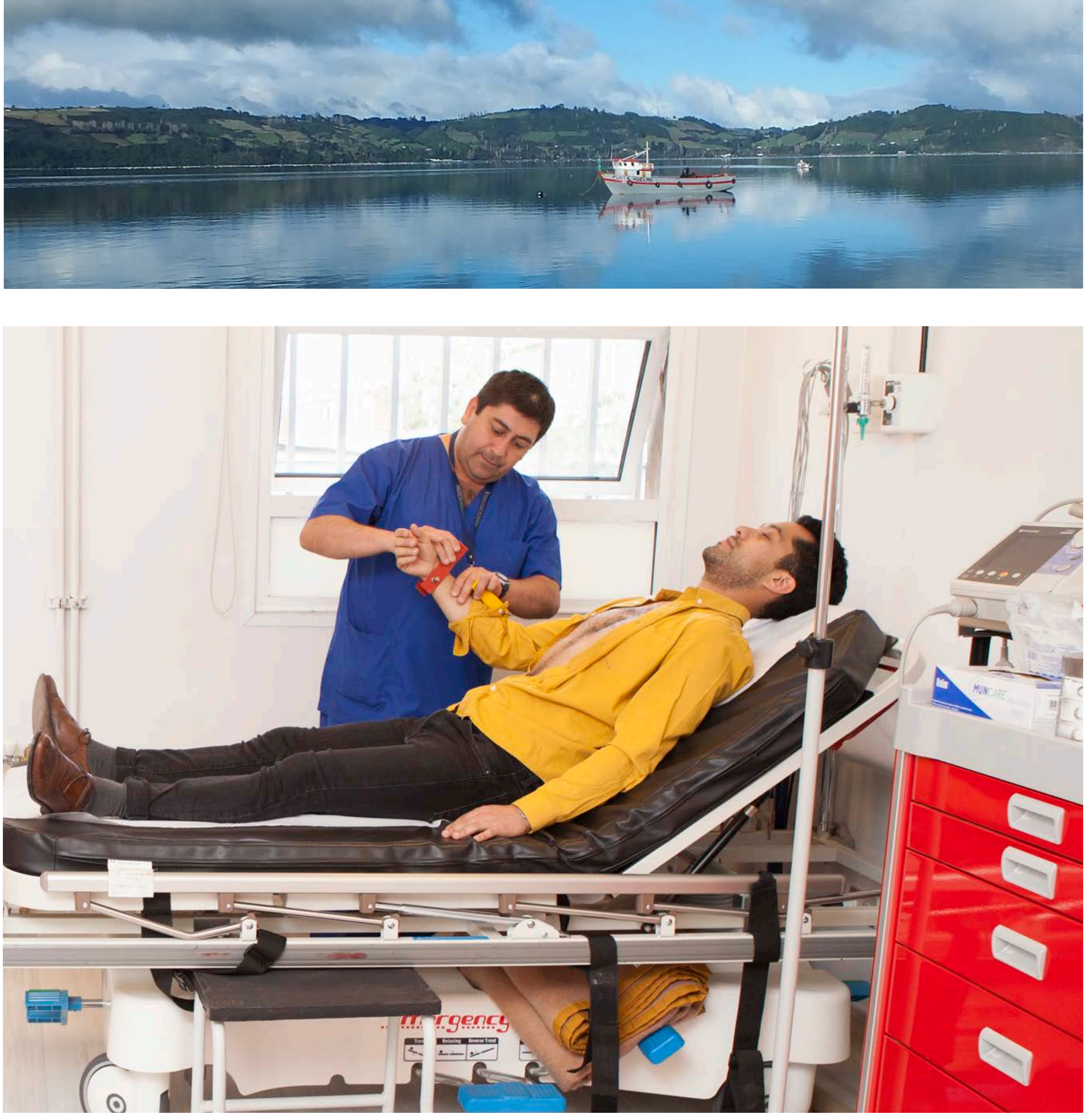




\section{SALUD}

La reforma que reconoció el acceso a salud como un derecho y estableció garantías explícitas de oportunidad de atención y protección financiera para las personas, independientemente de sus niveles de ingreso, fue un gran avance. Gracias al Plan AUGE, que cubre hoy más del $60 \%$ de la carga de enfermedades, las familias pueden enfrentar una enfermedad crónica o catastrófica sin el temor a no poder acceder a un tratamiento oportuno o a que sus costos financieros sean devastadores.

Pese a los esfuerzos realizados, aún hay importantes falencias en el sector público que afectan la atención de salud de la población. Entre estas carencias figura el déficit en especialidades médicas; la falta de infraestructura, especialmente en hospitales; la necesidad de una mejor gestión y mayor efectividad de la Atención Primaria, para que las personas puedan resolver sus problemas de salud cerca de sus domicilios y en menor tiempo.

Para abordar estas necesidades es necesario destinar mayores recursos públicos a salud. Hoy los recursos destinados a salud equivalen a $8 \%$ del PIB, sumando el esfuerzo público y privado. Sin embargo, en los países de la OCDE el $72 \%$ del gasto total en salud corresponde a gasto público, en Chile esta cifra está en torno al 50\%. Es imperioso un mayor compromiso del Estado.

Avanzaremos en todas estas áreas, lo que permitirá cubrir necesidades prioritarias para los sectores medios y los grupos más vulnerables.

\section{Ampliando la Red Pública de Salud}

En los primeros 100 días de gobierno se hará el lanzamiento del Plan Nacional de Inversión Pública en Salud 2014 - 2018. Se destinarán \$4.000 millones de dólares en inversión pública en el período, lo que significa más que duplicar la inversión efectiva de los últimos 4 años. Dicho plan representa un esfuerzo en inversión pública en salud sin precedentes, indispensable para elevar la capacidad diagnóstica y resolutiva, que comprenderá la ampliación y fortalecimiento de la red asistencial en todos sus niveles.

Este plan incluye la construcción de 20 nuevos hospitales, dejar en construcción otros 20 y avanzar tanto en los estudios técnicos de arquitectura e ingeniería como en la licitación de obras civiles de otros 20. También fortaleceremos la red de Atención Primaria de Salud con 100 nuevos Centros de Salud Familiar, 100 Centros Comunitarios de Salud Familiar y 132 Servicios de Atención Primaria de Urgencia de Alta Resolución, SAR.

Impulsaremos un conjunto de iniciativas para hacer más expedita la atención de urgencia en casos complejos. En primer lugar, mejoraremos los SAMU, dotando a los Centros Reguladores Regionales de infraestructura y tecnología de punta, sumado a recursos humanos especializados, para una respuesta oportuna y más efectiva hacia o desde los móviles adscritos.

Aseguraremos la expansión de 200 camas críticas, con el fin de agilizar la hospitalización de quienes esperan en los Servicios de Urgencia. También se dispondrá de 100 camas socio sanitarias, como forma de dar respuesta a aquellas personas que siendo dadas de alta médica, no poseen una red de apoyo, familiar o social que iremos incrementando según sea el comportamiento de la demanda para este tipo de solución.

También mejoraremos la disponibilidad de recursos de apoyo diagnóstico y terapéutico para los pacientes, como exámenes de laboratorio, imagenología y procedimientos, para resolver con más rapidez la atención de la población.

La Posta Central es el único Hospital de Urgencia del país y dada su relevancia en el contexto de la Red Asistencial Pública impulsaremos el proyecto de 
"Reposición de la Posta Central", porque nuestro país requiere y se merece un Hospital de Urgencia de clase mundial.

Desarrollaremos un plan de mantención del parque tecnológico de las unidades críticas y de los servicios generales de los principales centros hospitalarios del país. Pondremos en marcha un programa de adquisición y reposición de ambulancias, que reemplazará todos los vehículos en mal estado y duplicará el actual parque, de modo que a fines del gobierno tendremos 1.900 ambulancias en estado óptimo de funcionamiento. A este total sumaremos 132 nuevas ambulancias destinadas a los Servicios de Atención Primaria de Urgencia de Alta Resolución.

\section{Atención y Prevención}

Las personas necesitan tener atención de salud oportuna y de calidad en los centros públicos de sus comunas. La atención primaria debe ser la puerta de entrada al sistema de salud y el primer paso en una cadena de atención continua de creciente complejidad.

Esto implica aumentar el gasto per cápita a nivel comunal, destinando recursos e incentivos para atraer y retener a profesionales de la salud, especialmente a médicos, y contar con los medios tecnológicos para hacer diagnósticos precoces. Este mayor esfuerzo financiero debe orientarse a acortar la brecha que hoy existe entre las comunas ricas y pobres.

Vamos a crear 132 SAR, Servicios de Atención Primaria de Urgencia de Alta Resolución, beneficiando potencialmente a casi 10 millones de personas que se atienden en el sistema público. La mayor resolución se logrará con la incorporación de tecnología apropiada y dotación del personal médico necesario, contando con camillas de observación de pacientes para derivar sólo a quienes requieran atención secundaria. Esta es una manera efectiva de acercar la salud a la gente. En los primeros 100 días de Gobierno serán definidas las comunas y los centros de salud donde se habilitarán los SAR.

Vamos a enfrentar la falta de médicos en la Atención Primaria, para que la población tenga acceso a prestaciones y atenciones de calidad y oportunas. En los próximos 4 años vamos a incorporar a 1.000 nuevos médicos a la Atención Primaria. Para esto, entregaremos incentivos económicos con el objeto de mejorar los sueldos de ingreso y también para retenerlos. Junto con esto, se creará un programa para que los médicos recién egresados que así lo estimen sean contratados por los Servicios de Salud del país y destinados a trabajar por un período asistencial obligatorio, que oscilará entre 3 y 6 años, en establecimientos de atención primaria de salud municipal, al cabo de los cuales podrán postular a becas de especialización, con devolución en el sistema público.

Nos enfocaremos en la prevención de enfermedades crónicas no transmisibles, que afectan la calidad de vida de los adultos. Entre otras medidas, desarrollaremos un programa de prevención para adultos con riesgo de desarrollar diabetes o hipertensión arterial, que buscará generar hábitos de alimentación saludable, manejo de stress y actividad física. Pondremos en marcha una red de equipos profesionales dedicados a mantener su autovalencia y evitar que el sedentarismo, los estados depresivos y el aislamiento potencien sus niveles de dependencia y postración de los adultos mayores. Este programa beneficiará potencialmente a más de $\mathbf{1 . 1 0 0 . 0 0 0}$ personas, que representan al 50\% de la población de adultos mayores del país.

Desarrollaremos el plan "Más Sonrisas para Chile" para ampliar la cobertura de atención odontológica para mujeres de grupos socioeconómicos vulnerables que buscan empleo, apoyándolas 


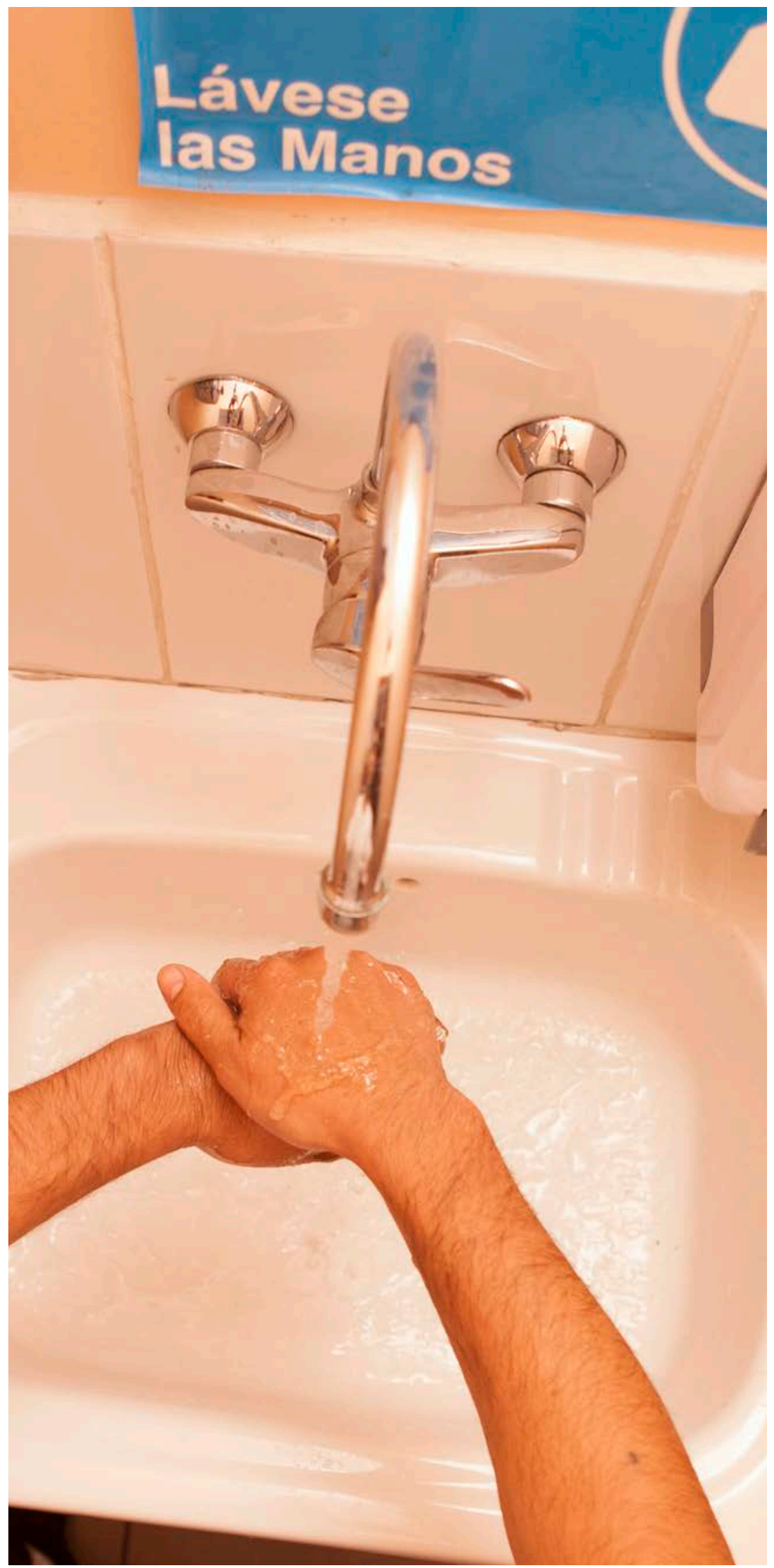

en sus esfuerzos de integración laboral y en el fortalecimiento de su autoestima. La meta es que desde el primer año de gobierno dupliquemos las altas odontológicas con este programa, llegando a 400.000 mujeres en el período de Gobierno, con más y mejores prestaciones que el programa vigente gracias a la contratación de especialistas endodoncistas y protesistas, con el propósito de recuperar integralmente la salud bucal de las mujeres.

El programa "Sembrando sonrisas" estará destinado a todos los niños y niñas de 2 a 5 años, es decir a 400.000, pertenecientes a Jardines infantiles de JUNJI, INTEGRA y de escuelas municipalizadas y particulares subvencionadas del país. Consistirá en la aplicación 2 veces al año de barniz de flúor a preescolares de 2 a 4 años y entrega de pastas y cepillos de dientes. A los niños de pre-kínder y kínder de colegios municipales se les entregará pasta y cepillo de dientes.

Brindaremos atención odontológica integral a los jóvenes de $4^{\circ}$ año de enseñanza media de colegios municipales y particulares subvencionados, beneficiando cada año a más de 180.000 jóvenes, para que se incorporen a la vida adulta en excelentes condiciones de higiene bucal.

Mejoraremos el acceso a atención odontológica para la población adulta, hoy limitada a urgencias. La demanda espontánea será resuelta en la Atención Primaria en horarios ampliados y mediante un programa que considerará las prestaciones más necesarias. Si el paciente que accede a esta atención requiere atención protésica y/o de endodoncias, podrá ser derivado a estas especialidades.

\section{Plan Nacional de Formación de Médicos Especialistas}

Es inaceptable que muchos enfermos deban postergar sus tratamientos de salud o sufrir extensas demoras en su atención debido a que Chile no cuenta con un adecuado contingente de especialistas, déficit que llega a ser crítico en 
algunas áreas. Esta carencia reduce la oportunidad en la atención y limita la capacidad resolutiva del sistema público.

Vamos a desarrollar un Plan Nacional para la formación y retención de especialidades médicas para apoyar la formación de 4.000 nuevos especialistas y que incentive el ingreso de más de 5.00o médicos a los programas de formación, junto con articular una política moderna para el desarrollo del recurso humano médico especializado. Esto implicará un nuevo trato con las universidades, que permita promover modificaciones y ajustes en los programas de formación de especialidades críticas y complementar mejor el término de los estudios con el inicio de la especialización. En los primeros 100 días pondremos a disposición los recursos necesarios para que los Servicios de Salud puedan contratar 33.000 horas médicas semanales adicionales, equivalentes a la contratación de 750 médicos especialistas.

\section{Más solidaridad para financiar la Salud y terminar con los abusos de las Isapres}

Las Isapres discriminan a las personas según el riesgo que tienen de enfermarse y provocan segregación de la población. Esto afecta especialmente a las mujeres, personas mayores, personas con problemas de salud y a quienes pertenecen a hogares de menores recursos.

Además, no existen mecanismos que regulen los copagos de las prestaciones de salud, haciéndolos iguales para todos y asociándolos al ingreso de las familias. Tampoco existen regulaciones efectivas respecto de los reajustes del precio base de la prima de salud, ni sobre los pagos asociados a la prima por las prestaciones AUGE. Respecto a este último punto, no se observan las condiciones para que las personas dispongan de información suficiente para acceder a los beneficios del AUGE en las Isapres.

No es justo que a una persona mayor o que tiene mayor probabilidad de enfermarse o aumentar sus gastos de salud, las Isapres le cobren mucho más caro o simplemente el sistema privado de salud lo expulse, entre otros de los problemas antes presentados. Poreso, en los primeros 100 días de Gobierno, convocaremos a un equipo de expertos con el mandato de redactar una propuesta de Proyecto de Ley de Isapres, que esté en el contexto del funcionamiento global del sistema de seguridad social en el ámbito de la salud.

\section{Una Política Nacional de Medicamentos}

Los usuarios de la Atención Primaria de Salud, tanto de grupos vulnerables como de sectores medios, que se encuentran bajo tratamiento no debieran tener que efectuar gastos en medicamentos. Escuchamos a diario la demanda legítima de muchas chilenas y chilenos que nos dicen que no reciben sus medicamentos y deben cubrir con sus pocos ingresos los remedios que necesitan.

Para la provisión adecuada de medicamentos para nuestra población, se requiere una Política Nacional. Desde el primer año de gobierno, vamos a crear un Fondo Nacional de Medicamentos, que beneficiará directamente a 5 millones de chilenos que se atienden en la Salud Primaria. Comenzaremos asegurando que el $100 \%$ de las personas mayores de 15 años, con diabetes, hipertensión, colesterol y trigliceridos altos, reciban sus medicamentos oportunamente. Estos problemas de salud son las más caros de tratar y los recursos que se destinan hasta ahora desde el nivel central y los que aportan los municipios son insuficientes. En los primeros 100 días de Gobierno, se firmarán convenios con las 345 municipalidades con el objeto de constituir una red de entrega de medicamentos que resuelva los problemas actuales de acceso a los medicamentos.

Haciéndonos eco de la demanda de la ciudadanía por sentirse asegurados ante una patología de alta complejidad, especialmente desde el ámbito de acceso a fármacos de alto costo, generaremos un Fondo Especial de Medicamentos de Alto Costo, que pueda responder a la demanda de nuestros beneficiarios, bajo protocolos y guías clínicas elaboradas por grupos de expertos. De esta manera, si los médicos de la Red Asistencial respectiva recetan, bajo protocolo, alguno de estos fármacos que no esté cubierto por el seguro público, se recurrirá a este fondo para financiarlo. 


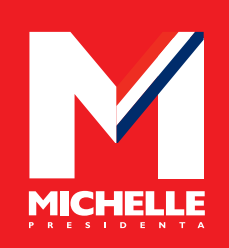

TRABAJO 


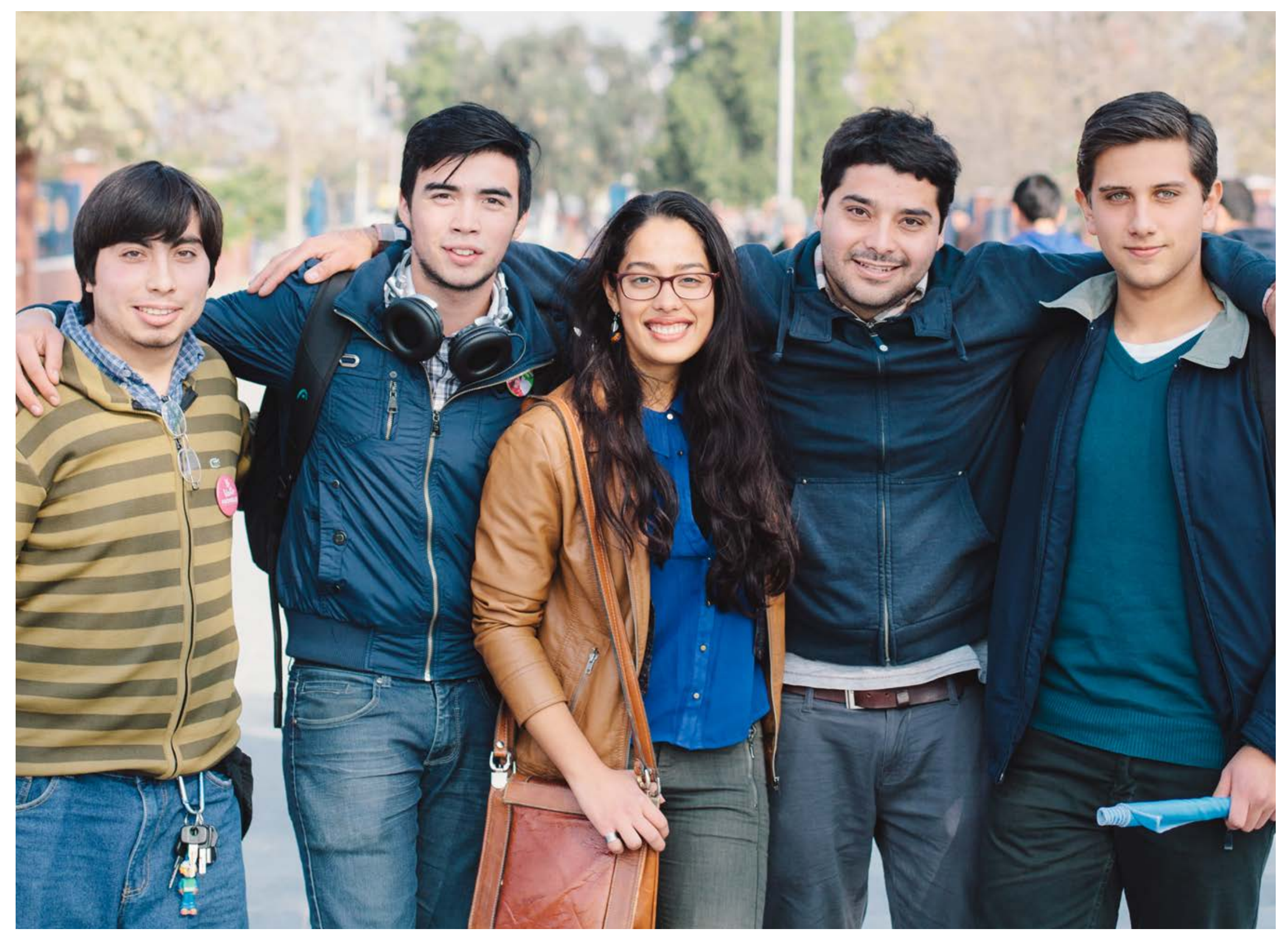




\section{TRABAJO}

El trabajo no puede ser visto sólo como un factor de producción, ni el trabajador como un mero consumidor. Un trabajo de calidad, un trabajo decente, es mucho más que eso: es fuente de dignidad personal; de desarrollo y estabilidad de las familias chilenas; de paz en la comunidad; de credibilidad de las políticas públicas y privadas y en definitiva de la gobernanza nacional.

En este contexto, debemos realizar cambios a nuestra institucionalidad laboral. Muchos aspectos se han modificado, pero aún persisten disposiciones que no ayudan o niegan a los trabajadores sus derechos. El respeto a los derechos en el trabajo y la dignidad del trabajador, son parte integral de la identidad social y política de la Nueva Mayoría.

También entendemos que la persistente desigualdad se debe, junto a la educación, a la desigual distribución del ingreso y las oportunidades en el mercado del trabajo. En el mercado laboral ésta se expresa en bajas tasas de participación laboral en determinados grupos (especialmente en mujeres y jóvenes) $\mathrm{y}$ en empleos precarios e informales, sin derechos individuales ni colectivos. Tenemos 600.000 jóvenes que no trabajan ni estudian, y el nivel de negociación colectiva alcanza sólo al $12 \%$ de los trabajadores.

Hay que nivelar la cancha entre empleadores y trabajadores. Debemos promover la capacidad y autonomía de las partes para negociar en igualdad de condiciones y al mismo tiempo la cultura de cooperación y colaboración. Debemos avanzar en modernizaciones que permitan compatibilizar demandas que derivan del dinamismo, la competitividad y productividad con relaciones laborales que dignifiquen el trabajo, que fortalezcan la sindicalización, la negociación colectiva y una justa distribución de las ganancias.

Fortalecer la actividad sindical y la negociación colectiva son materias que apuntan a enfrentar la desigualdad en el mundo laboral. Sólo de esta forma podremos tener relaciones laborales equilibradas, acuerdos entre trabajadores y empleadores que favorezcan el real desarrollo de nuestro país. Al equilibrar la cancha en el ámbito laboral, las organizaciones de empleadores y trabajadores podrán formular acuerdos que orienten las políticas públicas, generando un verdadero diálogo social.

Implementaremos políticas en diversas áreas, dentro de las cuales destacaremos tres. Un primer grupo de políticas se orientan a emparejar la cancha entre los actores sociales, ampliando la sindicalización y la negociación colectiva. Un segundo grupo busca aumentar la participación laboral, la calidad del empleo, los salarios (salario mínimo y pago de gratificaciones) y aumentar la productividad. Un tercer grupo tiene la finalidad de fortalecer y mejorar la institucionalidad laboral, avanzando hacia un cumplimiento efectivo de la ley laboral, y hacia políticas que lleguen efectivamente a todas y todos los trabajadores.

\section{Negociación Colectiva y Fortalecimiento de la Actividad Sindical}

Para reducir la desigualdad es necesario superar las diferencias que existen en las relaciones entre trabajadores y empresarios. Para aumentar los ingresos de los trabajadores es necesario aumentar la productividad, para lo cual el presente programa considera un conjunto amplio de materias y medidas, entre las que destaca la reforma educacional y las transformaciones al sistema de capacitación y formación para el trabajo. Sin embargo, para aumentar los ingresos de los trabajadores también es necesario aumentar su poder de negociación al interior de la empresa.

Debemos fortalecer los sindicatos y realizar un conjunto de modificaciones a la negociación colectiva que permita ampliar la cobertura de trabajadores que pueden ejercer este derecho.

Como primer paso terminaremos a la brevedad con el uso artificioso del multirut o razones sociales para efectos laborales, lo que se ha traducido en limitaciones al ejercicio de derechos laborales básicos de los trabajadores como los de sindicalización y de negociación colectiva. Enviaremos una indicación al actual proyecto que se encuentra en el Congreso. A pesar de tener RUTs distintos, debe considerarse como una empresa a las firmas cuando tengan un mismo controlador, se presten los mismos servicios o se hagan productos similares y se tenga una dirección laboral común.

Es necesario fortalecer el sindicato como sujeto de la negociación colectiva. Vamos a impulsar una negociación colectiva con titularidad sindical. Adicionalmente, se extenderán los beneficios, de manera automática, al trabajador que se afilie al sindicato que negoció el contrato colectivo. 
Para impulsar y fortalecer los procesos de negociación colectiva debemos antes informar a las trabajadoras y trabajadores cuáles son sus derechos y deberes. Por este motivo implementaremos acciones de formación ciudadana sobre el ejercicio de los derechos individuales y colectivos en el ámbito laboral, así como de los deberes, en particular el de exigir un contrato formal.

Adicionalmente, para contar con una negociación colectiva más técnica e informada es necesario establecer la normativa que permita que el sindicato cuente con información oportuna sobre la situación económica de la empresa, en particular la información sobre el Estado de Resultados y Balance General, que el empleador deberá entregar de manera obligatoria.

También entendemos que para fomentar la negociación colectiva debemos impulsar las organizaciones de trabajadoras y trabajadores potenciando el programa de formación sindical que existe en el Ministerio del Trabajo. Estableceremos mecanismos de promoción sindical con financiamiento público permanente y fondos concursables, que permitan a las organizaciones y líderes sindicales tener acceso a fondos de desarrollo y gestión sindical. Se debiera poner especial énfasis en la sindicalización femenina, los sindicalistas noveles o jóvenes, como asimismo en programas de acercamiento de sindicatos a organizaciones de la sociedad civil.

El actual Código del Trabajo establece un proceso de negociación colectiva engorroso y complejo, que no favorece ni facilita el acuerdo entre las partes. Modificaremos estas normativas para introducir mejoramientos $y$ simplificaciones al proceso de negociación colectiva reglada, otorgando capacidad y autonomía a las partes durante el proceso de negociación.

El año 200o, entró en vigencia el Convenio OIT $\mathrm{N}^{\circ} 87$ sobre Libertad Sindical y la Protección del Derecho de Sindicalización, ratificado por el Congreso Nacional. El país ha sido notificado en distintas oportunidades tanto por la OIT (2008 y 2012) como por Naciones Unidas (2004) en cuanto a que la norma laboral de los reemplazos durante la huelga constituyen un incumplimiento de este convenio y de la libertad sindical. Avanzaremos en el respeto a la libertad sindical conforme a las normas y convenios que Chile ha ratificado en materia laboral.

Otra de las materias debatidas en el proceso de negociación colectiva tiene relación con los beneficios obtenidos en negociaciones anteriores. Avanzaremos para regular que, considerando la situación económica de la empresa, la negociación tenga como base las condiciones de la negociación colectiva anterior.

No podremos potenciar las organizaciones sindicales si no somos capaces de hacerlas más atractivas. Más participación en los sindicatos debe ser sinónimo de mejores condiciones para los trabajadores y mayores niveles de productividad.

Modernizaremos nuestra ley laboral para permitir la ampliación de las materias que se puedan acordar en una negociación colectiva con el empleador, cuando esto sea por acuerdo de las partes, teniendo los resguardos para asegurar la representatividad de los sindicatos.

Adicionalmente, avanzaremos en un nuevo marco legal que contenga el Estatuto del Temporero y la Actividad Agrícola de Temporada, que consagre la protección a los trabajadores y trabajadoras del mundo rural.

Respecto de la protección a la libertad sindical, debemos fomentar y facilitar la actividad de estas organizaciones, para lo cual una de las áreas a estudiar es que los permisos sindicales deberían ser ampliados y de cargo de la empresa, en particular, los que se utilizan para labores de educación y capacitación sindical y otras actividades propias de la labor sindical.

Tenemos que ser conscientes que, aunque tengamos implementadas las medidas anteriores, todavía existirá un grupo importante de trabajadores, en particular los menos calificados que laboran en empresas más precarias, que no accederán a negociaciones en igualdad de condiciones. Por ello los ingresos del trabajo, salario más políticas pro empleo deben converger a un monto que permita superar la pobreza. Impulsaremos consultas a las organizacionales nacionales de empleadores y trabajadores, junto con la creación de una instancia técnica de carácter tripartita e integrada además por especialistas, que asesore al Gobierno 


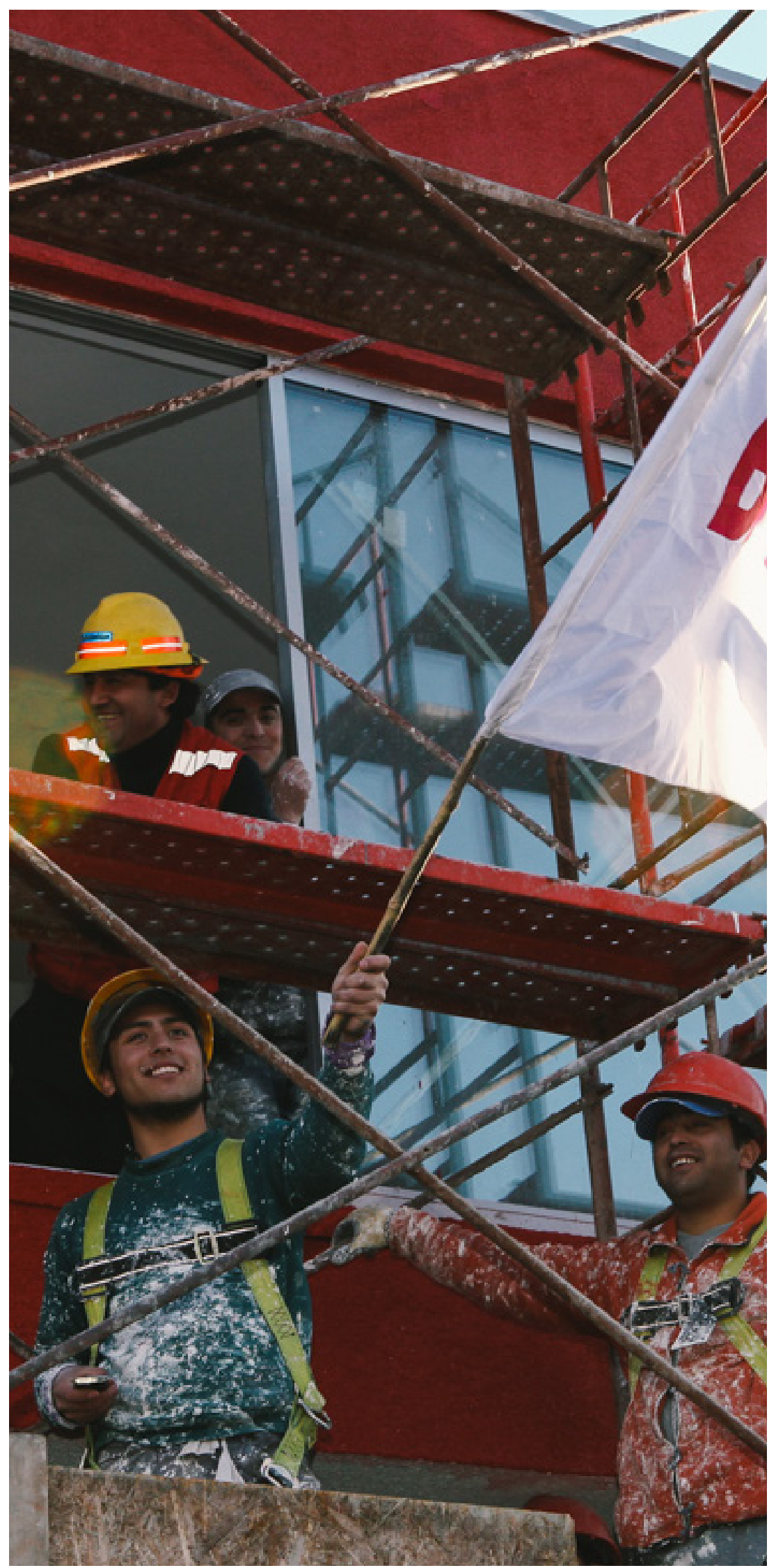

en el reajuste del salario mínimo. Esta comisión deberá presentar un informe público que analice el mercado del trabajo. Durante la transición, dentro de los márgenes del crecimiento previsto, el reajuste al ingreso mínimo debe alcanzar los $\$ 250.000$ a mediados del próximo período presidencial.

Respecto a las condiciones laborales de los trabajadores de casa particular, que es un grupo especialmente desprotegido y de bajos ingresos, avanzaremos en la ratificación de los compromisos internacionales sobre trabajo decente para trabajadores y trabajadoras domésticas y así otorgar valor y dignidad a la importante función que cumplen estas personas en nuestra sociedad.

Para lograr la plena efectividad de las medidas propuestas, debemos fortalecer las instituciones de fiscalización y control de la aplicación de la legislación laboral y de la protección de los derechos individuales y colectivos de los trabajadores y de los empleadores. Impulsaremos el rediseño institucional y modernización de la Dirección del Trabajo, dotándola de mayores atribuciones, mejorando sus capacidades técnicas e identificando funciones claves en su organización interna, potenciando la especialización en temas de género. Adicionalmente, estableceremos un Sistema de Certificación de Buenas Prácticas Laborales que considere incentivos, reconocimientos, distinciones, asistencia al cumplimiento normativo, entre otros mecanismos promocionales, que se establezca sobre la base de un modelo objetivo y consensuado en que se evalúen los niveles de calidad del trabajo y de prácticas empresariales.

Además, debemos avanzar hacia una cultura que previene, controla y reduce los riesgos laborales, implementando una Política Nacional de Seguridad y Salud en el Trabajo que incorpora activamente a los actores y moderniza la institucionalidad.

\section{Fomento a la Participación Laboral}

Debemos aumentar el número de chilenas con empleo. Sólo 5 de 10 chilenas tiene trabajo, este número cae a 3 de cada 10 mujeres en el 60\% de los hogares más pobres. Queremos llegar a los niveles de los países desarrollados donde 6 de cada 10 mujeres tiene empleo. Estos empleos deben ser formales, con todos sus beneficios, y con salarios justos que no presenten una brecha entre hombres y mujeres. 
Para aumentar la ocupación femenina en empleos formales elevaremos la cobertura del subsidio al empleo femenino llegando al $60 \%$ de hogares de menores ingresos. Esto implicará aumentar sustantivamente las beneficiarias. Hoy el universo potencial de mujeres que puede beneficiarse, que están trabajando asalariadas y pertenecen al $40 \%$ más desvalido son del orden de $350 \mathrm{mil}$, al $60 \%$ pasaríamos a cerca de 550 mil.

En nuestro país el peso del cuidado de los hijos cuyos padres trabajan recae sólo en las mujeres. Para evitar esta discriminación negativa eliminaremos el artículo 203 del Código del Trabajo que impone tener una sala cuna en las empresas con 20 ó más mujeres. Para cubrir los costos de las salas cunas, crearemos un fondo solidario - constituido con aportes de trabajadores, empleadores y del Estado- que financiará un sistema universal de cuidado infantil y estimulación temprana para todos los hijos e hijas de trabajadores y trabajadoras. De este modo, eliminaremos el mayor costo de contratación que pesa hoy sobre las mujeres por este concepto y aseguraremos igual bienestar para todos los niños y niñas.

El Estado no puede quedar atrás en el objetivo de aumentar la participación laboral femenina, para esto incorporaremos acciones afirmativas para la contratación femenina dentro de las políticas de selección del Sistema de Alta Dirección Pública. Una mayor equidad en el sector público, se espera que induzca al sector privado en la misma dirección.

\section{Capacitación para el Desarrollo y Seguro de Cesantía}

El sistema de capacitación vigente, regresivo respecto de la asignación de recursos e ineficiente en el logro de sus objetivos, enfrenta una crisis que hace patente la necesidad de una reforma. No resulta razonable que gracias a una franquicia tributaria especial, las empresas financien la capacitación de sus trabajadores, mientras que quienes están cesantes, enfrentan procesos de reconversión o buscan trabajo por primera vez no tengan esa misma oportunidad.

Sabemos que conseguir trabajo no es fácil, muchas veces sólo se logra a través de un "contacto". Chile necesita un nuevo sistema de intermediación y capacitación laboral, que apoye a todos quienes tengan problemas de inserción en el mercado de trabajo en el mejoramiento de sus condiciones de empleabilidad, con particular foco en aquellos que presentan una situación de mayor vulnerabilidad. El nuevo sistema integrará servicios de información y orientación, diagnóstico de empleabilidad, apresto laboral, certificación de competencias laborales y capacitación.

Complementariamente, se desarrollarán programas de capacitación especializados para aquellos segmentos de población con dificultades particulares para acceder al empleo. Uno de los focos prioritarios serán los jóvenes de 15 a 19 años que no estudian ni trabajan, que junto con quienes desertarán de la educación media en los próximos años pertenecen mayoritariamente a los primeros dos quintiles de ingreso. El programa de capacitación de jóvenes buscará entregar capacitación y prácticas laborales a 150.000 jóvenes en el período 2014-2018, junto con nivelación escolar y vinculación a la educación superior.

Las mujeres también serán un grupo prioritario para las políticas de capacitación. Desarrollaremos un programa destinado a mujeres que no están insertas en el mercado laboral, a quienes se les ofrecerá acompañamiento y recursos para optar por una formación que las habilite para ingresar al mercado de trabajo o por acciones de apoyo al microemprendimiento. Este esfuerzo beneficiará a 300.000 mujeres en el período 2014-2018, de las cuales 40.000 recibirán capacitación para que desarrollen sus propios proyectos productivos.

Para enfrentar el conjunto de programas y desafíos descritos se requiere implementar un importante proceso de modernización y fortalecimiento del SENCE. Separaremos las funciones de fiscalización, de administración y de los recursos asignados a la capacitación laboral. Incorporaremos a los actores sociales en la formulación y evaluación de las políticas de formación, fortaleciendo el sistema de acreditación de los centros que optan a recursos públicos para proveer servicios de capacitación. Adicionalmente, eliminaremos los programas que no muestran impacto en materia de empleabilidad, remuneraciones y tienen problemas de focalización, y reorientaremos sus recursos hacia trabajadores con mayores dificultades de inserción laboral.

Impulsaremos un conjunto de perfeccionamientos al Seguro de Cesantía. Evaluaremos ajustes en el esquema de financiamiento del seguro, generando incentivos para los empleadores que registran menores niveles de rotación laboral de sus trabajadores. Potenciaremos el rol contra cíclico del seguro (otorgando mayor protección a los trabajadores cesantes, especialmente cuando se hace más difícil encontrar empleo). Además, estudiaremos el aumento del uso del componente solidario del seguro, favoreciendo con ello, en especial, a los trabajadores de clase media. Realizaremos un esfuerzo importante de difusión de los beneficios del seguro. 

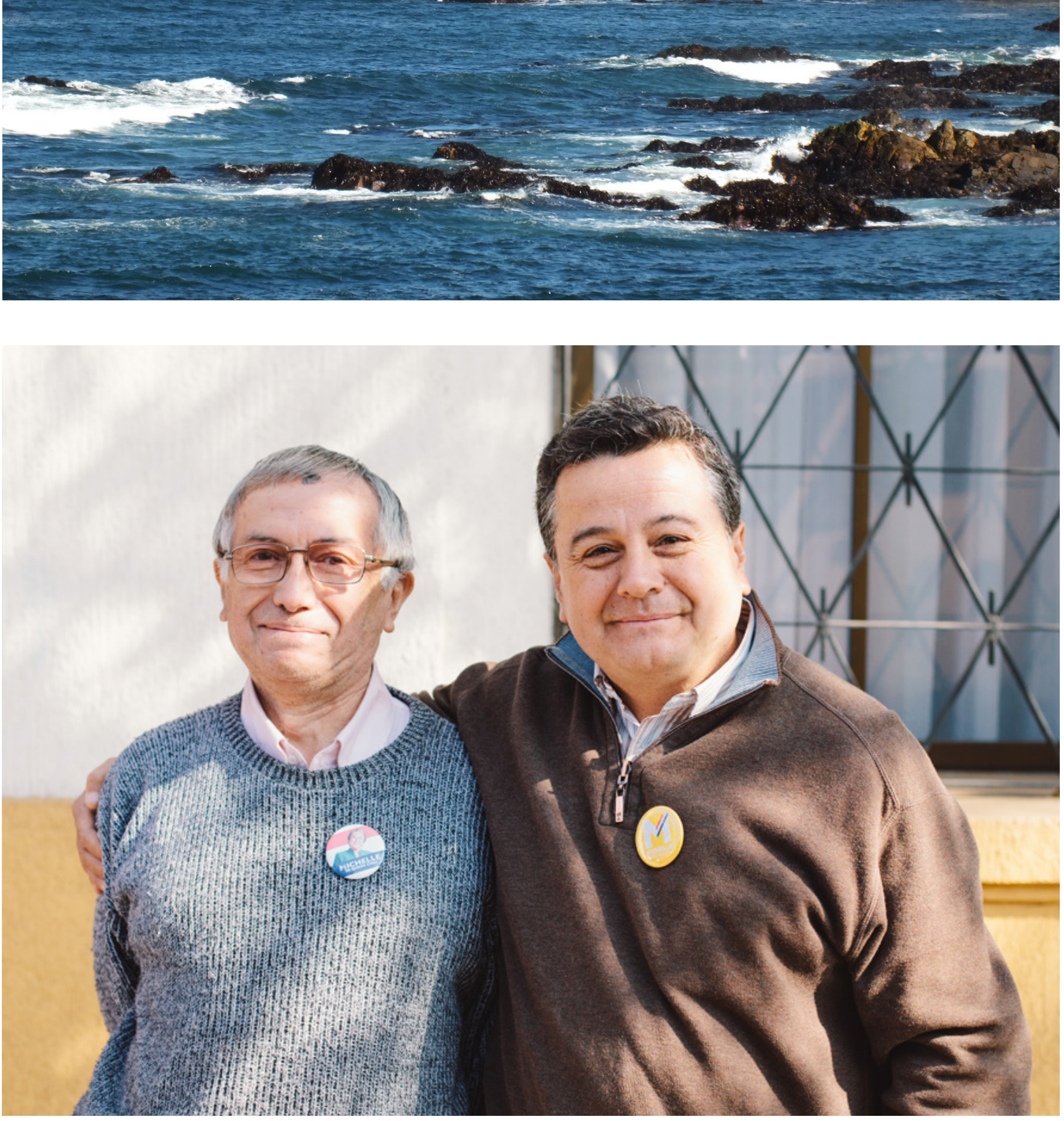


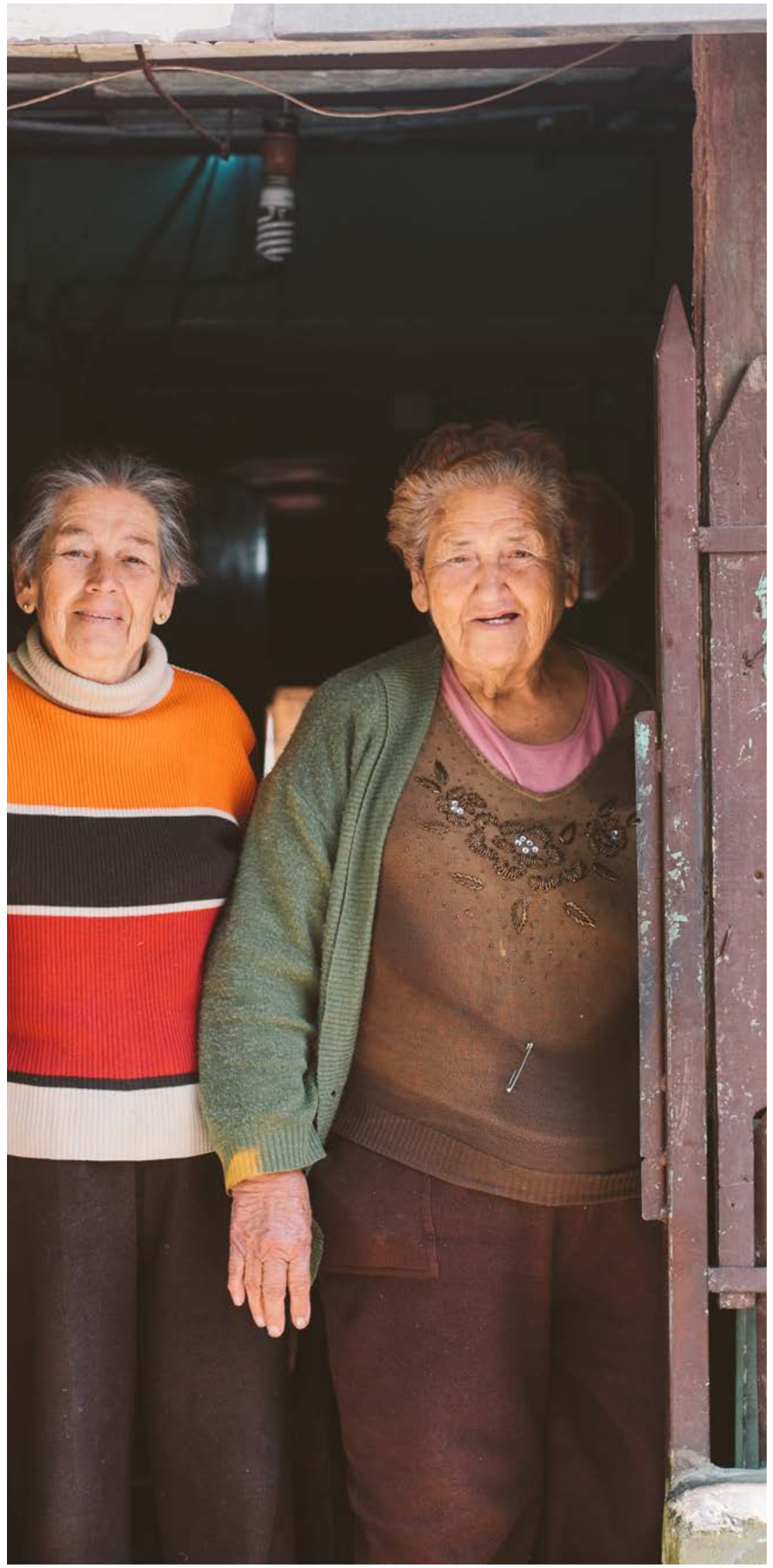

\section{PENSIONES}

En el ámbito del Sistema de Pensiones, gracias a la Reforma Previsional de 2008, hoy 450.000 hombres y 750.000 mujeres son beneficiarias del Sistema de Pensiones Solidarias. En total cerca de 1.200.000 personas han accedido a este sistema que devolvió al Estado su rol de garante de la Seguridad Social, entregando a todas y todos la seguridad de envejecer sin temor a quedar desamparados frente a la invalidez. $\mathrm{Si}$ a la pensión contributiva, se suman los beneficios del sistema de pensiones solidarias, se aumenta sustantivamente la denominada tasa de reemplazo, en especial, de los beneficiarios pertenecientes a los primeros quintiles de ingreso.

Asimismo, se aumentó la cobertura previsional de grupos vulnerables como jóvenes, mujeres y trabajadores independientes, y se implementaron numerosos perfeccionamientos al Sistema de Capitalización para aumentar su competencia, disminuir sus costos y fortalecer el Ahorro Previsional Voluntario.

Sin embargo, tenemos importantes desafíos. Existe un importante descontento respecto de la calidad de las pensiones, ya que luego de años de esfuerzo en el mercado laboral, los trabajadores ven como el nivel de la pensión que reciben, no se condice con sus expectativas, es decir, es muy bajo el monto de su pensión.

Dar una solución satisfactoria a estos temas requiere un análisis riguroso, responsable con los ciudadanos y profundizar en su diagnóstico. Adicionalmente, la credibilidad del sistema de capitalización individual se ve aminorada por la existencia de ganancias extranormales de las AFPs.

Otra materia corresponde a las altas tasas de evasión y elusión de las cotizaciones entre los asalariados, las que varían según sector económico, región geográfica, género y oficio del afiliado.

En Chile existe un amplio consenso de que es necesario revisar el sistema de pensiones. Por ello en los primeros 
100 días de Gobierno, encargaremos un estudio sobre el Sistema de Pensiones a un equipo de expertos nacionales e internacionales, para que propongan alternativas de solución frente a estos problemas.

Sin perjuicio de lo anterior, respecto del Sistema de Pensiones Solidarias, avanzaremos en las siguientes medidas: i) las cuentas de afiliados que no han alcanzado niveles de ahorro para autofinanciar una pensión sin apoyo solidario deberán ser administradas en un fondo de bajo riesgo; ii) asociaremos al pilar solidario con programas de Protección Integral del Adulto Mayor, que incluya protección y envejecimiento activo, como medidas destinadas a generar seguridades en los ingresos de los adultos mayores; iii) una vez otorgada la Pensión Básica Solidaria (PBS) de vejez este será un beneficio que no esté sujeto a cambios coyunturales de la situación socioeconómica del pensionado; iv) que los pensionados con PBS de invalidez automáticamente pase a contar con la PBS de vejez a partir de los 65 años; v) hacer extensiva la asignación por muerte a la totalidad de los adultos mayores que tienen PBS y a los beneficiarios de APS con saldo cero en su cuenta individual en su totalidad.

Adicionalmente, una vez aprobada la reforma tributaria la que permitirá contar con nuevos recursos permanentes equivalentes a $3 \%$ del $\mathrm{PIB}$ en régimen, se avanzará en cambios paramétricos que aumenten los beneficios y la cobertura del Sistema de Pensiones Solidarias.

Respecto del funcionamiento del Sistema de Capitalización Individual: i) en los primeros 100 días de Gobierno se enviará al Congreso un proyecto de ley que crea una AFP estatal, que permita mayor competencia de precios, la atención preferente de grupos de la población de menor interés para las AFP existentes, como los trabajadores independientes, de menores rentas y quienes laboran en zonas apartadas de los grandes centros urbanos; ii) fortaleceremos el Fondo de Educación Previsional para la difusión y educación sobre las tasas de reemplazo que potencialmente obtendrán del sistema distintos grupos de la población, abriendo un debate sobre cuál es la meta factible y razonable para el sistema de pensiones chileno, atendiendo, entre otras materias, la realidad de los países con nuestro nivel de desarrollo; iii) estudiar la introducción de tecnologías informáticas de uso público que reduzcan los costos de tránsito de los afiliados cuando optan por cambiarse de AFPs, y; iv) promover en diferentes instancias de participación ciudadana, el fortalecimiento de la educación e información sobre los derechos y deberes de la seguridad social, y en particular sobre materias previsionales.

También se continuará mejorando la cobertura (afiliación, cotización) y ahorro en el sistema contributivo. La Reforma Previsional de 2008 generó la obligatoriedad de cotización para los trabajadores independientes remunerados por medio del pago de honorarios. Lamentablemente, en los últimos años no se avanzó adecuadamente en esta materia, en especial, en lo relativo a la educación previsional de este grupo de trabajadores. Por esto, revisaremos la gradualidad de incorporación de los trabajadores independientes $\mathrm{y}$ de los instrumentos de recaudación que tomen en cuenta la precariedad de sus rentas.

Fortaleceremos la Dirección del Trabajo en materia de fiscalización del pago de las cotizaciones previsionales, mejorando la coordinación interinstitucional de esta tarea, que involucra a reparticiones con diferentes dependencias, ampliando el monitoreo de metas y revisando el sistema de multas y fortaleciendo la justicia especializada en la cobranza previsional

Fortaleceremos los mecanismos de ahorro previsional voluntario para generar una cobertura más amplia de la clase media y de menores ingresos.

Adicionalmente, se aumentarán los recursos destinados a la educación previsional, fundamental para dar a conocer a la ciudadanía sus derechos y deberes en materia de ahorro para vejez y pensiones, así como la comprensión de las instituciones que se ocupan de una sociedad de rápido envejecimiento. 


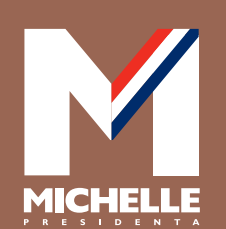

SECURIDAD

GIUDADANA 

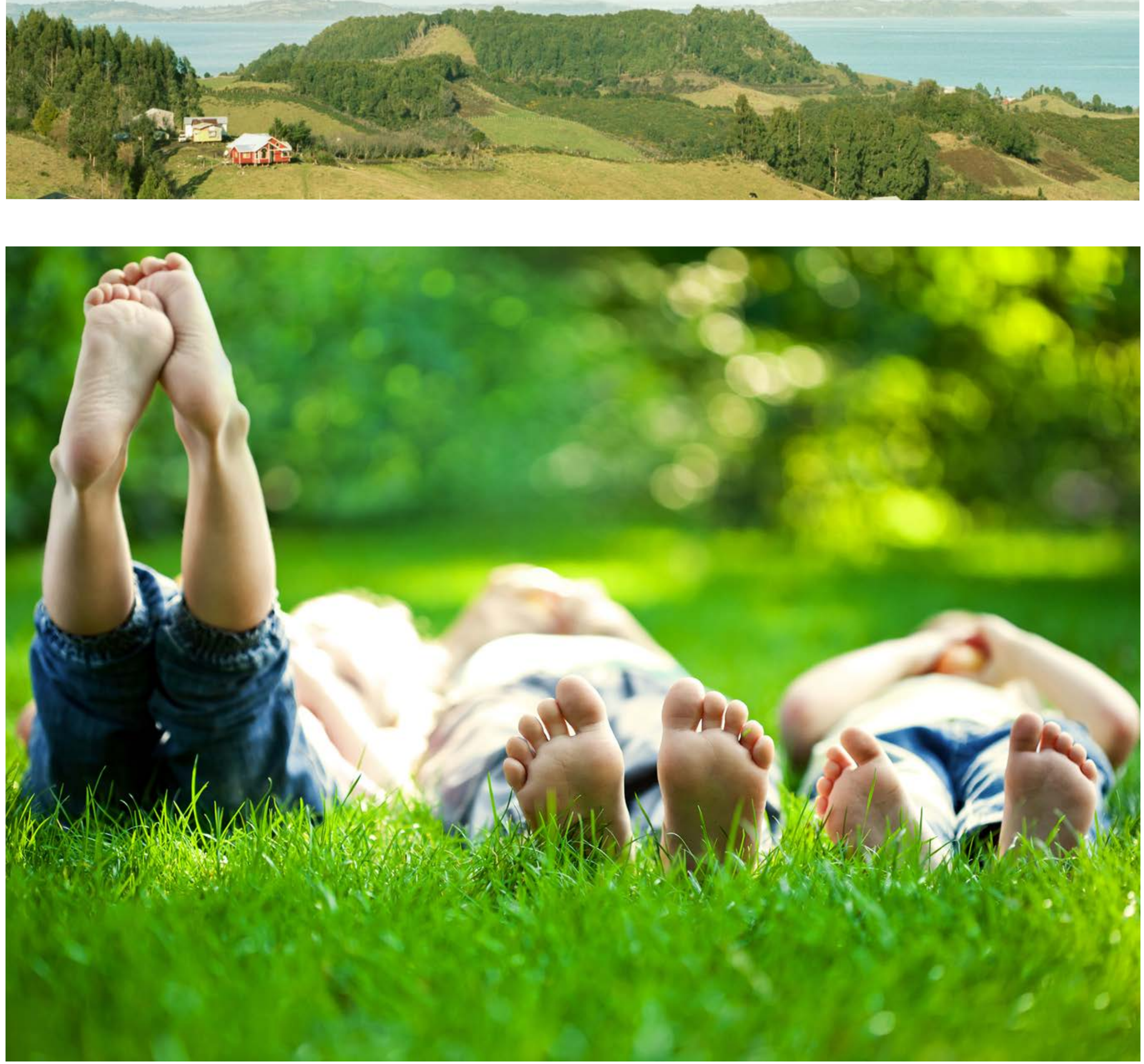


\section{SEGURIDAD CIUDADANA}

En toda sociedad democrática es necesario contar con un ambiente seguro, entendido éste como el respeto colectivo entre los ciudadanos en su convivencia.

La seguridad es una de las principales necesidades que demanda la población, ya que afecta directamente su calidad de vida. Dichas necesidades son diversas en la medida que corresponden a dinámicas locales por lo que requieren de respuestas territoriales descentralizadas y adaptadas a cada una de las particularidades de los entornos específicos en que se producen. Debemos plantearnos nuevas reformas que nos permitan ponernos al nivel de países desarrollados en reducción del delito.

La experiencia que hemos acumulado como país, nos muestra que la prevención es mucho más eficiente en la lucha contra la delincuencia que la disuasión mediante penas u otros mecanismos afines.

\section{Prevención}

Elaboraremos un Plan de Gobierno para el período 2014- 2018 denominado "Seguridad para Todos". Revisaremos el marco institucional existente que permita facilitar el rol municipal en materia de seguridad ciudadana y de cooperación con la policía y la justicia.

Crearemos en la Subsecretaría de Prevención del Delito una Unidad Técnica de apoyo a los municipios. Impulsaremos el Programa "Juntos más seguros" de apoyo a comunas vulnerables y barrios críticos. Este programa deberá ejecutarse de manera conjunta por policía, gobierno central, municipio y mesas comunales de participación ciudadana.

Extenderemos el programa 24 Horas a 25 comunas del país que dan origen a cerca de $50 \%$ de los ingresos de niños, niñas y adolescentes a unidades policiales por razones de infracción y vulneración. En los primeros 100 días de Gobierno anunciaremos las 11 nuevas comunas que se sumarán al programa 24 horas.

Fortaleceremos la atención de salud mental a través de los centros comunitarios de salud mental(COSAM) creando equiposespecialmente destinados a estos fines, en las comunas más vulnerables del país, en conjunto con el Ministerio de Salud.

\section{Violencia de Género}

Duplicaremos el número de las Casas de Acogida para proteger a las víctimas de violencia grave y a sus hijos(as), llegando a 48 en todo el país y aumentaremos los Centros de la Mujer en las comunas con mayores índices de violencia.

Reforzaremos el programa de atención inmediata del Ministerio Público para víctimas de violencia intrafamiliar que implica contactar a la víctima en 24 horas y adoptar medidas protección dentro de las primeras 48 horas como máximo, y así cubrir el 100\% de casos de denuncias de violencia intrafamiliar.

Crearemos al interior de 150 comisarías del país las denominadas salas de familia, que serán atendidas por funcionarios llamados al servicio, de modo de no afectar el desvío de personal activo policial destinadas a la atención de casos de violencia intrafamiliar y temas de niños niñas y adolescentes como programa 24 horas.

Capacitaremos a policías, Poder Judicial y al sector salud en la sensibilización de la problemática de la violencia de género para mejorar la eficiencia, eficacia y acogida de las familias.

Desarrollaremos un programa nacional de formación de monitoras comunitarias -dirigentas sociales- en materias de violencia de género. Incluiremos el tema de la violencia de género y la resolución no violenta de conflictos, en los textos y programas de educación pre básica y escolar, en la malla curricular de las carreras de educación, y de la escuela de formación de carabineros y policías.

\section{Drogas}

Respecto del Consumo, adicionaremos a las campañas de prevención de consumo abusivo de drogas y alcohol, aquellas orientadas al consumo abusivo de psicofármacos, para que manejen claramente los riesgos del consumo no supervisado por un médico. Aumentaremos la cobertura de la prevención selectiva escolar en 1.000 establecimientos de educación básica y media bajo el programa denominado "Liceo Libre de Droga". 
Crearemos el Programa Nacional de Escuelas de Segunda Oportunidad que permita atender las necesidades de niños y adolescentes que hayan desertado del sistema escolar en estas comunas más vulnerables del país, que los habilite a una reinserción plena al sistema tradicional.

Revisaremos la ley 20.000, entregando el conocimiento de las faltas consideradas en esta norma, ya no a la justicia penal, sino a los Juzgados de Policía Local. Entregaremos a la potestad reglamentaria de ejecución, la determinación de los niveles o cuantía de droga que debe considerarse constitutiva de micro tráfico y, consecuentemente, aquella que le está permitido portar a una persona para su consumo personal inmediato en el tiempo. Revisaremos el Reglamento que considera a la marihuana en la lista 1) entre las drogas más peligrosas.

Respecto de la Prevención, aumentaremos la cobertura de la prevención selectiva escolar en 1.000 establecimientos de educación básica y media bajo el programa denominado "Colegio Libre de Droga", con una cobertura de 15.000 niños y adolescentes de alto riesgo, incluyendo a su familia si así se pudiese.

Concentraremos la prevención en la alta vulneración social (comunas vulnerables y barrios críticos); es decir, en quienes tienen alta probabilidad de consumo de drogas. Se trata de programas preventivos selectivos en estas poblaciones (5.000 cupos, que hoy no existen).

Respecto del Tratamiento, duplicaremos la cobertura de tratamiento de drogas, ambulatorio y residencial, para población adulta masculina y femenina mayor de 20 años. Triplicaremos la cobertura de tratamiento de población adulta masculina y femenina mayor de 20 años con programa de detección temprana de consumo de riesgo y problemático e intervención breve. Reforzaremos los tratamientos para población adolescente menor de 20 años, que AUGE no cubre (casos más complejos).

Adicionalmente, mejoraremos la gestión de los programas dirigidos a adolescentes menores de 20 años con consumo problemático de drogas y alcohol. Focalizaremos y ampliaremos la oferta y cobertura para mujeres, para lo que se propone aumentar la cobertura para aquellas que tienen hijos menores de 5 años y que puedan permanecer con ellos durante el tratamiento.

También impulsaremos un Plan Nacional contra el Narcotráfico que incorpore fortalecimiento de vigilancia en fronteras, en aduanas, en puertos; trabajo conjunto de especialización de los Fiscales y Policías; fortalecer las capacidades operativas de fiscales y policías en la lucha contra el narcotráfico; incrementar el uso de la inteligencia financiera en temas de lavado de activos, así como la cooperación internacional. Dotaremos de adecuado sustento institucional a los Tribunales de Tratamiento de Drogas, y extenderemos su competencia a diversos casos.

\section{Persecución Penal}

Revisaremos y mejoraremos los mecanismos legales de rendición de cuentas públicas previstos en las leyes orgánicas respectivas tanto de la gestión administrativa, presupuestaria y sustantiva del Ministerio Público y las policías.

Promoveremos la creación de una Comisión Nacional de Política Criminal y Persecución Penal, convocada por el Ministerio Público, e integrando también a las policías, Gendarmería y Ministerios de Justicia e Interior, destinada a apoyar la elaboración de una política de persecución penal de carácter bi-anual.

El Ministerio Público está enfrentando una delicada situación institucional que impide desarrollar al máximo su potencialidad en la persecución de los delitos, tanto por la carga de trabajo que enfrenta como por los nuevos desafíos que surgen de formas más complejas y sofisticadas de delincuencia que enfrenta nuestro país. Dotaremos al Ministerio Público de los recursos necesarios para fortalecer la persecución penal de delitos complejos en especial aquellos que afectan a grupos extensos de la población, vinculados a crimen organizado y los que dañan la estabilidad y credibilidad del sistema económico. Mejoraremos la tramitación de causas masivas de menor complejidad (baja y mediana), por medio de la instalación a nivel regional de Unidades de Análisis Delictual. Fortaleceremos los controles internos sobre la calidad de las investigaciones, la estandarización de criterios y procedimientos; y el cumplimiento de las políticas generales de persecución penal.

Adicionalmente, revisaremos la Ley Orgánica del Ministerio Público y enviaremos un proyecto de ley al Congreso con el objetivo de flexibilizar su diseño, de manera de permitir un funcionamiento más eficaz de la institución en materia de persecución de los delitos, coordinación interinstitucional y estructura organizacional. Fortaleceremos los procesos de capacitación de fiscales y funcionarios del organismo. 


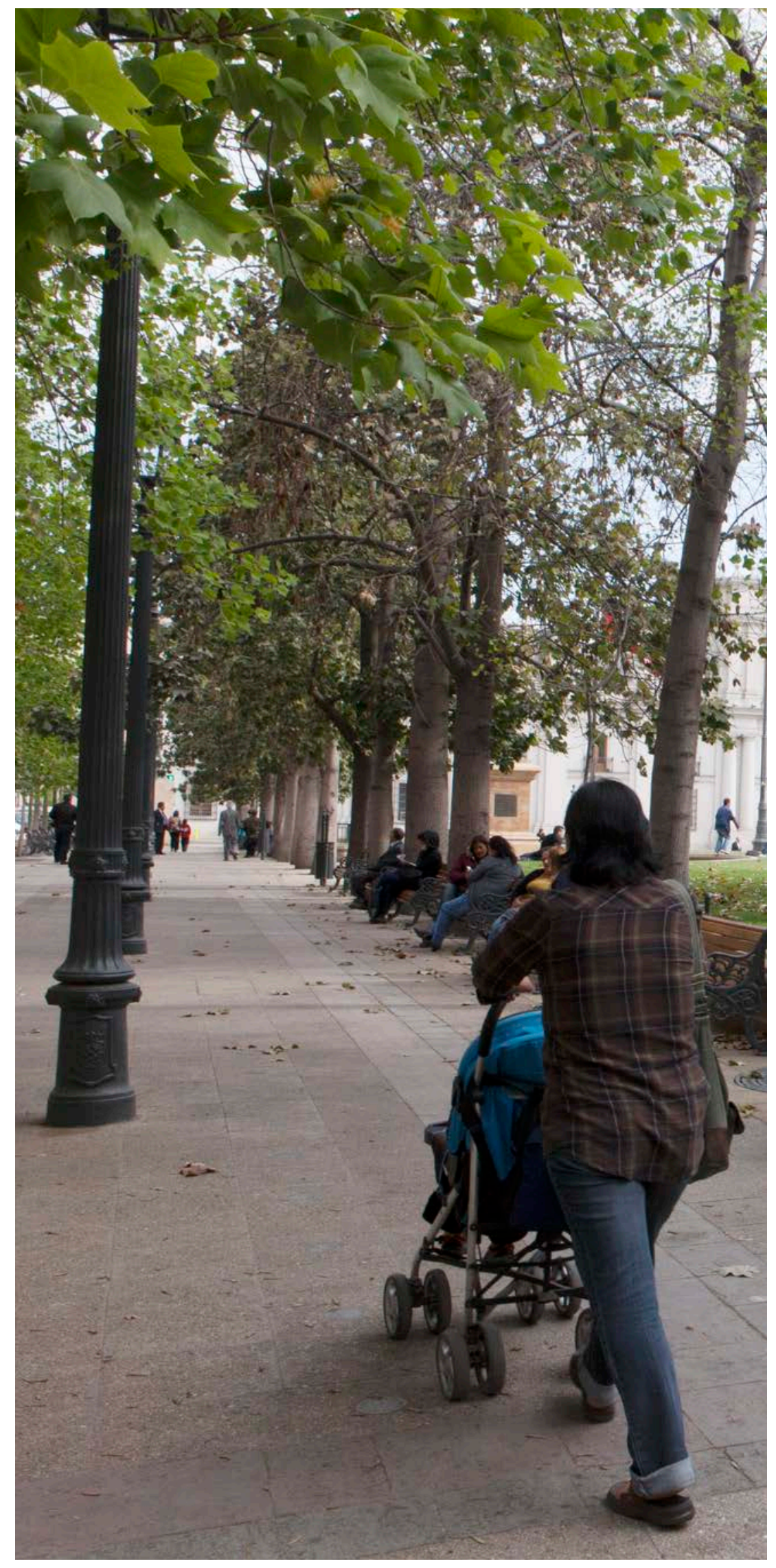

El Ministerio Público personifica el interés estatal, y por ende público, en la persecución oficial de los hechos constitutivos de delito, lo que resulta de la mayor importancia tratándose de fenómenos criminales que se caracterizan por la afectación masiva (delincuencia de "cuello blanco"). También tratándose de fenómenos de criminalidad más tradicionales, es imprescindible que el ejercicio de la acción penal se encuentre radicado en un órgano que personifique el interés público. Por ello, fortaleceremos la capacidad de las agencias vinculadas al proceso penal (Ministerio Público, y policías) para dar atención oportuna, tratar de manera digna, entregar información de calidad y proteger a las víctimas.

Adicionalmente, crearemos un Servicio Público Descentralizado de Apoyo a Víctimas -radicado en el Ministerio de Interior y Seguridad Pública- que asuma la dirección de los Centros de Atención de Víctimas, y lidere de Red de Atención a Víctimas. Aumentaremos la oferta programática estatal de la red de atención a víctimas, respecto de la atención médica, psicológica y de apoyo a víctimas de delitos violentos y de otra naturaleza que generen consecuencias graves.

Desde el inicio del nuevo sistema procesal penal, un cuello de botella para su funcionamiento ha sido la capacidad de los organismos auxiliares (Servicio Médico Legal, Instituto de Salud Pública, Laboratorios Policiales, etc.). Realizaremos una modernización y fortalecimiento de los servicios auxiliares que tienen por función producir evidencia científica para el sistema.

\section{Policía}

Hoy se requiere de estrategias policiales diversificadas, especializadas y focalizadas, adaptadas a las necesidades locales, en las cuales la mirada local y situacional, deben ser el eje del trabajo. Enviaremos al Congreso dentro de los primeros 100 días de Gobierno el proyecto de ley para aumentar la dotación a 6.000 de nuevos carabineros a razón de 1.500 por año, y aumentar los denominados llamados al servicio. Aumentaremos la dotación de la Policía de Investigaciones en 1.200 nuevos funcionarios.

Incrementaremos la descentralización del trabajo policial en el territorio, creando un protocolo de coordinación policía municipio. Lograremos una mayor permanencia de los comisarios en sus cargos a fin de que puedan realizar un trabajo más efectivo y de largo plazo. 
Impulsaremos fuerzas de tareas policiales abocadas principalmente al desbaratamiento de redes de narcotráfico, y presencia de armas en los barrios críticos y poblaciones vulnerables. Consolidaremos el acercamiento a la comunidad organizada potenciando el Plan Cuadrante 2.0, que implique no sólo un reforzamiento logístico de los planes en actual ejecución (150 municipios), sino un proceso de reingeniería que asegure resultados demostrables y duraderos, entregando mayor protección a amplios sectores de la población, particularmente pertenecientes a sectores medios y vulnerables.

Revisaremos y reforzaremos los programas de entrenamiento y formación policial, los programas de especialización y de formación continua del personal de ambas policías. Reforzaremos los Departamentos o Unidades de Análisis Criminal, tanto en Comisarias como en Brigadas de Investigación Criminal, con personal civil y profesional.

\section{Sistema Penitenciario}

Debe promoverse una política penitenciaria integral, cuyo eje sea la rehabilitación y reinserción social. Crearemos una Comisión Biministerial (integrada por Ministerio de Interior y Seguridad Pública y Justicia) de modo de evaluar funcionamiento de las cárceles concesionadas. Avanzaremos en la construcción de nuevos recintos penitenciarios, de manera de disminuir el porcentaje de hacinamiento que actualmente asciende a 38\% (19.000 plazas faltantes).

Estableceremos el carácter público del provisionamiento de programas de reinserción y rehabilitación en las cárceles, ya sea que se trata de un establecimiento de administración directa (pública) o concesionado. Aumentaremos la oferta programática de reinserción que incluyan los ámbitos tradicionales (educación, laboral, salud física y mental), y programas específicos (conductas violentas, adicciones, grupos y pandillas, entre otros).

Mejoraremos la cantidad y proporción de técnicos y profesionales que trabajan directamente con la población penal.

Implementaremos un sistema nacional de clasificación y segmentación de la población penitenciaria. Impulsaremos un programa nacional de profesionalización y capacitación del personal de Gendarmería, que incorpore materias de diversidad y la no discriminación.

\section{Justicia Penal de Adolescentes}

Definiremos una Política Nacional de Reinserción Social de Adolescentes y crearemos el Primer Sistema Estadístico y de Indicadores deI Sistema Penal de Adolescentes. A partir de la división del actual Servicio Nacional de Menores (SENAME), crearemos el Servicio Nacional de Reinserción Social de Adolescentes, entidad pública especializada y altamente calificado que asuma responsabilidad directa, en coordinación con las demás agencias del Estado, por el proceso de reinserción social de cada adolescente infractor. Respecto la otra función de SENAME, la protección de menores en situación irregular, quedará radicada en el Servicio Nacional de Protección de Menores, dependiente del Ministerio de Desarrollo Social.

Especializaremos todos los órganos de la justicia penal de adolescentes (policía, jueces, fiscales y defensores), mediante su capacitación y formación profesional, la creación por ley de incentivos de carrera para la dedicación exclusiva o preferente, y la orientación de metas e indicadores hacia el favorecimiento del proceso de reinserción y el respeto de los derechos y garantías de los adolescentes.

Revisaremos el modelo de atención y la oferta de centros privativos de libertad de adolescentes, mejorando su impacto en reinserción social.

Reformaremos las sanciones alternativas a la cárcel y las medidas alternativas al proceso, asegurando su cumplimiento efectivo e idoneidad.

\section{Gestión e Información}

La Subsecretaría de Prevención del Delito deberá generar un sistema de evaluación y auditorías. Se creará además un consejo de expertos independientes y representativos de todos los sectores que orienten el accionar de la Unidad.

Desarrollaremos un Banco Nacional de Proyectos en materia de prevención y control de la violencia y la criminalidad. Pondremos en marcha el sistema unificado de indicadores de seguridad.

Crearemos indicadores transversales de seguridad y convivencia en las políticas públicas, por ejemplo, a nivel de diseño de espacios públicos y vivienda. Desarrollaremos encuestas de "violencia y convivencia", para registrar otras realidades delictivas, más allá del delito de oportunidad más común (delitos contra propiedad principalmente). 


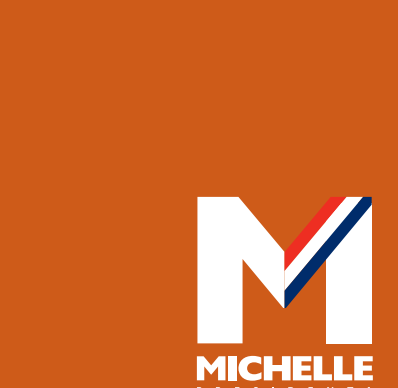

JUSTIGIA

MICHELLE 

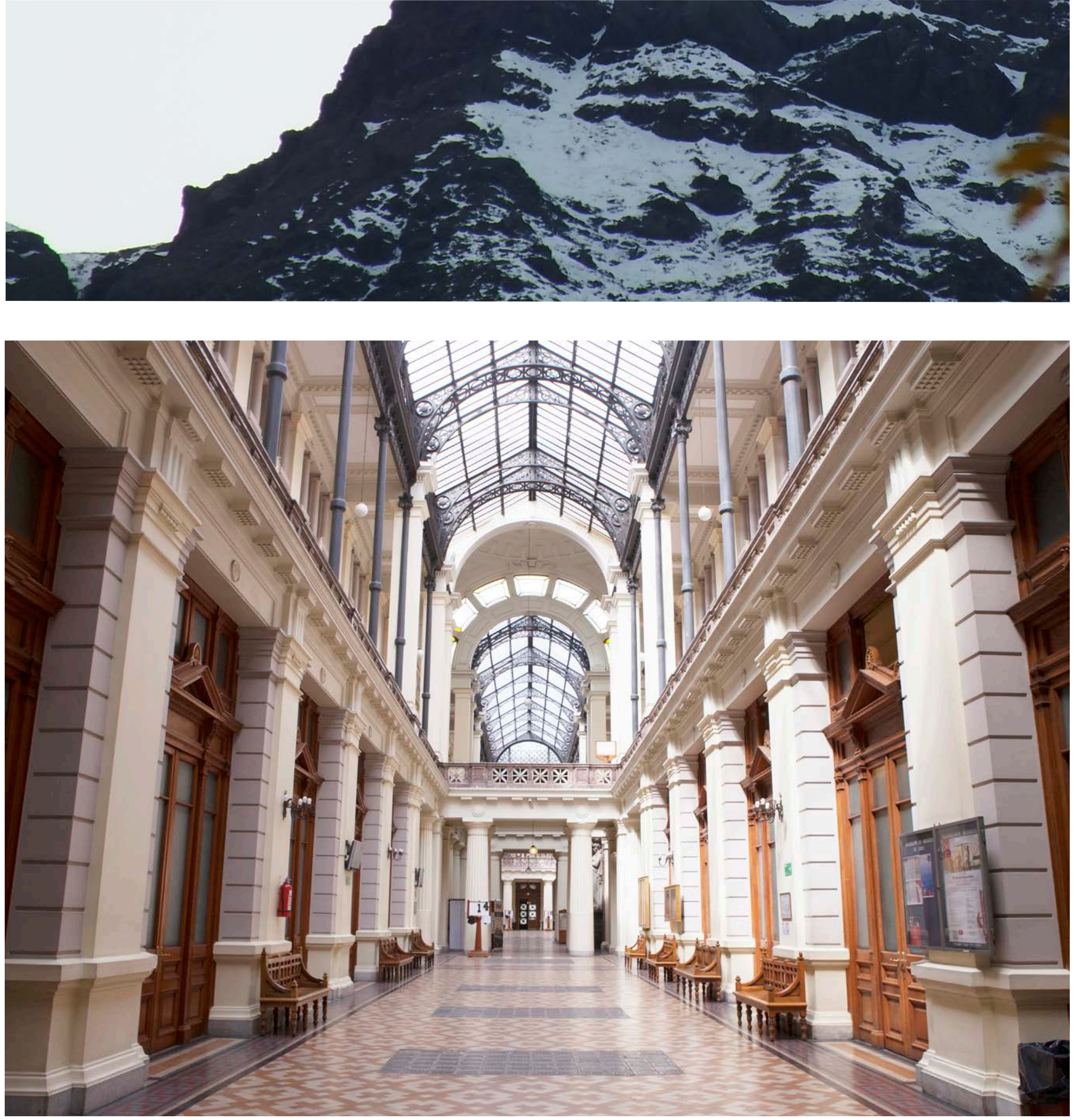


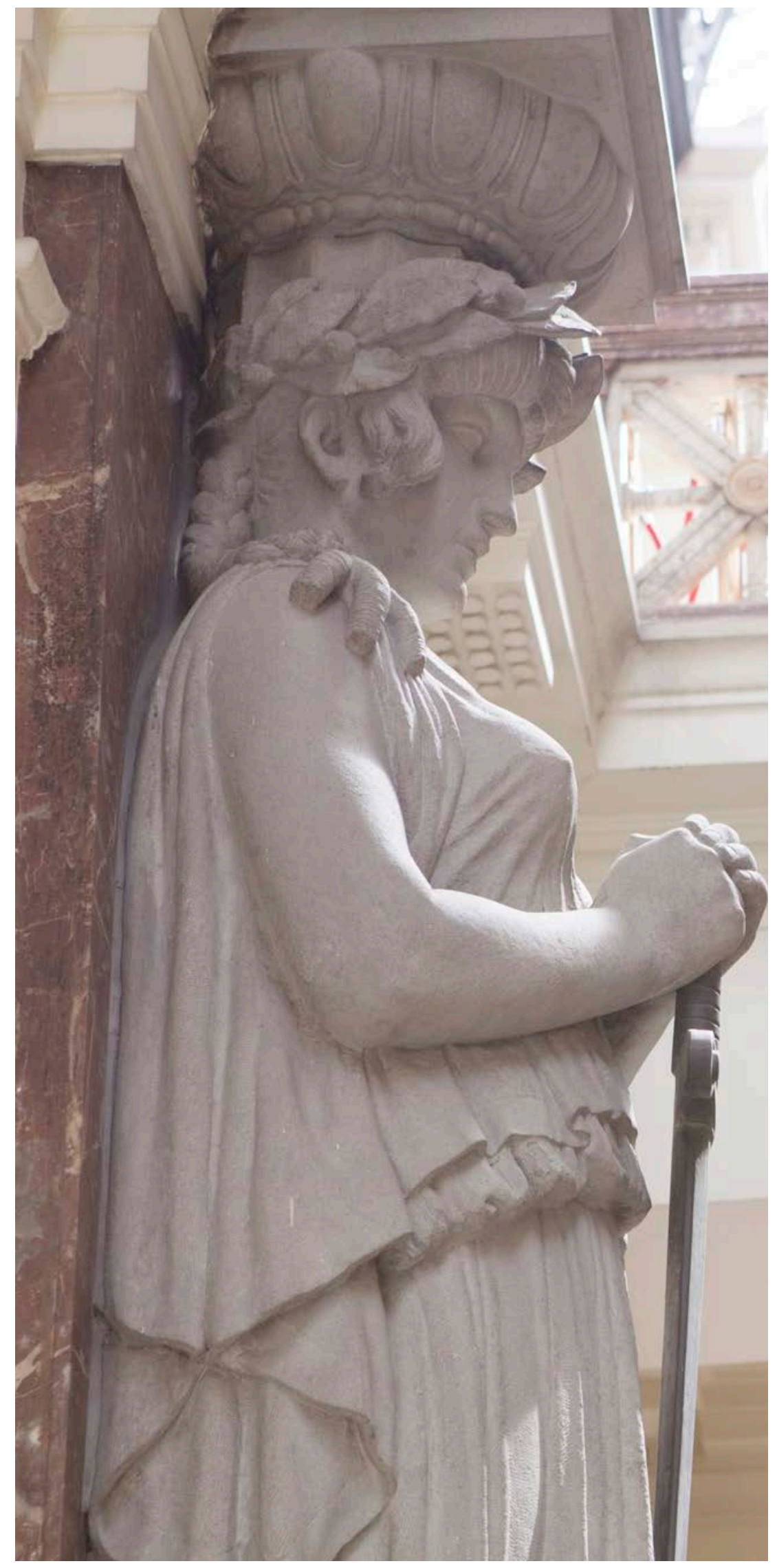

\section{JUSTICIA}

En un Estado democrático de derecho, el sistema de administración de justicia tiene como una de sus misiones fundamentales constituirse en un mecanismo de garantía y protección frente a las situaciones de abuso e injusticias a las cuales puede verse enfrentada gran parte de la ciudadanía. En el actual momento de nuestro país esto conlleva dos preocupaciones fundamentales: la primera, consiste en asegurar la independencia de los jueces; la segunda, consiste en garantizar un genuino acceso a la administración de justicia, de la que hoy se encuentran, en los hechos, privados importantes sectores sociales.

Durantelos primerosveinteaños delos gobiernos democráticos, se desarrolló en Chile un vigoroso proceso de reforma judicial, que incidió ante todo en los ámbitos procesal penal, laboral y de familia. Sin embargo, el sistema judicial y los múltiples servicios vinculados al sector justicia, pueden hacer un mayor esfuerzo para la atención de grupos vulnerables, así como de la clase media. Lamentablemente, para la mayor parte de la población, los servicios y las posibilidades de defensa de derechos que el sistema judicial ofrece son percibidos todavía lejanos, quedando en muchos casos sin la posibilidad de ejercerlos, situación que dificulta la cohesión social que nuestro país requiere, y que estimula el ambiente de desapego de la población respecto de las instituciones, escenario que es nuestra obligación revertir.

Todo lo anterior nos insta a redefinir una nueva y consistente agenda de modificaciones en el ámbito de justicia que se constituya en una guía para los años que vienen, sobre la base de un gran objetivo: un real acceso a justicia para todos.

En este contexto, impulsaremos un Nuevo Sistema de Asistencia Jurídica para Chile. El objetivo de un nuevo sistema de asistencia jurídica debe ser asegurar servicios jurídicos preventivos, de asesoría en asuntos jurídicos y de representación en juicio, para personas que no pueden financiarlos total o parcialmente, de una calidad equivalente a los que se pueden procurar las personas que cuentan con los recursos para ello.

Trabajaremos conjuntamente con el Poder Judicial en el desarrollo de una Justicia de Calidad, como una política de Estado, de desarrollo gradual, evaluando las mejoras a introducir en los ámbitos del sistema judicial que ya han sido 
objeto de reformas y continuando con aquellas que demanda el Chile de hoy. Al respecto, impulsaremos la discución en torno al gobierno judicial, con una amplia participación de este poder. También sobre una carrera judicial alineada con nuevos incentivos, de modo que responda a la diversidad y complejidad de los cambios que Chile demanda en acceso a la justicia, transparencia, rendición de cuentas y equidad.

Continuaremos adelante con el proceso de Reforma a la Justicia Civil, con un horizonte de mediano plazo, promoviendo, un reordenamiento de competencias, tanto a nivel local como de jueces de letras; propiciando una revisión del sistema de ejecución, particularmente en áreas tan sensibles como el cobro de pensiones alimenticias y de cotizaciones previsionales impagas; propiciando la revisión del sistema de ejecución y; revisando el proyecto de ley propuesto para el nuevo Código Procesal Civil. Como resultado de un nuevo mapa de las competencias de la Justicia Civil debemos hacernos cargo del diseño de una nueva judicatura, priorizando la creación de una nueva justicia local verdaderamente independiente de los gobiernos comunales.

En otra área, nos haremos cargo de implementar una reforma al Sistema de Notarios, Conservadores de Bienes Raíces y Archiveros, cuya institucionalidad es anacrónica, y se organiza como una fuente de excesivo lucro personal, no asignado en razón de mérito, que además provee servicios muchas veces ineficientes y de alto costo para la ciudadanía. Debemos organizarlos verdaderamente como un servicio público para las personas, sujeto a estándares de transparencia y calidad, que resguarden la fe pública en forma eficiente, accesible y responsable.

Particular atención nos merece la revisión de la normativa referida a la protección de personas en situación de vulnerabilidad o discriminadas. Al respecto, un ámbito prioritario lo constituye la promoción del derecho de cada niño y niña a crecer en el seno de un hogar familiar que resguarde adecuadamente sus derechos y asegure su bienestar, y sólo transitoriamente bajo la protección del Estado, impulsando una profunda reforma en materia de adopción, que racionalice sus etapas y plazos. Otra iniciativa relevante será eliminar discriminaciones contra la mujer, sustituyendo la sociedad conyugal por una comunidad de bienes, fundada en la igualdad y en la protección del patrimonio familiar; consagrando en todo matrimonio una responsabilidad común y efectiva frente a las deudas familiares; y, modificando la regulación de la compensación económica.

Dentrodelámbito dela protección delasfamiliasyla eliminación de discriminaciones propiciaremos una regulación legal que permita, sin discriminación, proteger patrimonialmente a los convivientes que no opten por el matrimonio u otra forma de regulación civil, en particular al menos favorecido en términos patrimoniales o previsionales, en caso de ruptura o muerte.

El Acuerdo de Vida en Pareja (AVP), propuesto por el actual gobierno, es insuficiente y no constituye un mecanismo de solución "integral" a los problemas de las uniones heterosexuales y homosexuales. Por ello, para las parejas que no optan por el matrimonio propiciaremos una regulación alternativa, que otorgue derechos y protección integral a los convivientes en sus relaciones mutuas personales y patrimoniales. Sin perjuicio de esto, como lo establecemos en el capítulo de Igualdad y no Discriminación, convocaremos a un debate abierto, con participación amplia para la elaboración y posterior envío de un proyecto de ley de matrimonio igualitario.

Otra área que merece nuestra atención se refiere a prevenir y sancionar todo abuso y violencias en las relaciones familiares. Dentro de ella, buscaremos se sancione directamente el incumplimiento de medidas de protección en caso de violencia intrafamiliar y que el delito de maltrato habitual sea debidamente juzgado, y apoyaremos la capacitación de funcionarios judiciales y de la policía en derechos humanos de la mujer, así como la generación de protocolos de entrevista que eviten la reiteración injustificada de los hechos de violencia.

En el ámbito del Derecho Penal, impulsaremos una revisión integral de la legislación penal vigente, sin perjuicio de lo cual nos haremos cargo de reformas urgentes, especialmente en el ámbito de los delitos económicos, frente a la premisa de superar el paradigma de una legislación anclada en una visión clasista y estereotipada de la delincuencia. La sanción penal de la colusión constituye un claro ejemplo en esa línea.

Por último, dentro de la agenda de Justicia para los próximos años, debemos considerar los temas de Derechos Humanos, impulsando la creación de la Subsecretaría de Derechos Humanos y del Ombudsman o Defensor del Pueblo. 


\section{MICHELLE}

DESCENTRALIZACIÓN,

TERRITORIO Y

DESARROLLO 

Y

DESCENTRALIZACIÓN 

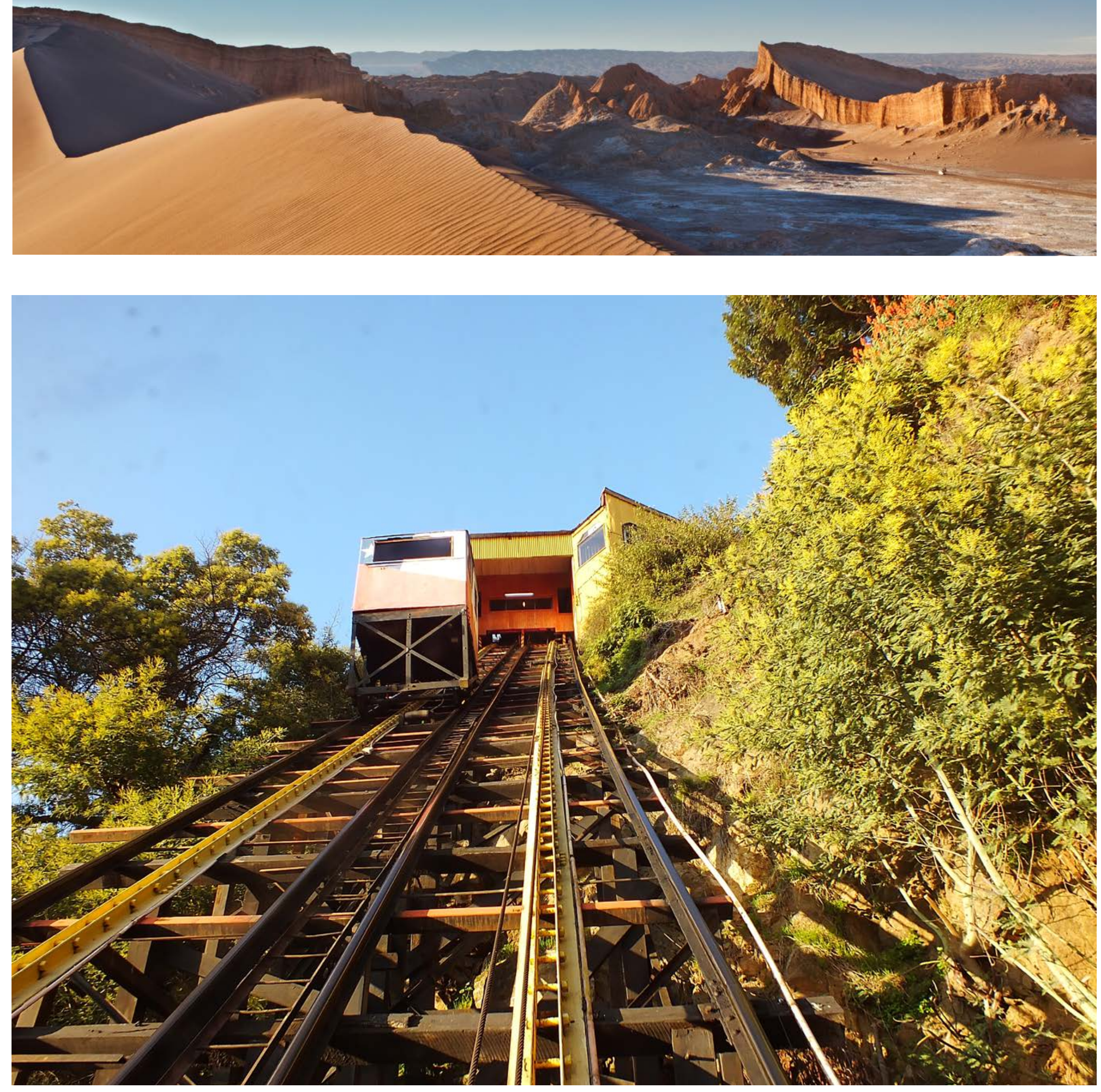


\section{DESCENTRALIZACIÓN}

Una de las mayores desigualdades que enfrentamos en el país es de carácter territorial. Son demasiadas las decisiones sobre aspectos importantes para el desarrollo de las regiones que se toman en Santiago. También son demasiado distintas las oportunidades que enfrentan las personas dependiendo del lugar donde nacen y residen. Debemos incorporar a todos los ciudadanos y ciudadanas por igual, tanto a la construcción como a los beneficios del desarrollo, independientemente del lugar donde vivan. Esto exige una efectiva descentralización. Necesitamos los aportes de las regiones al país. Necesitamos cerrar las grandes diferencias de bienestar y de oportunidades entre regiones y comunas de Chile. Si no lo hacemos, no alcanzaremos un desarrollo inclusivo.

En la década pasada Chile desarrolló una política de fomento de cadenas productivas o clusters sobre la base de cinco sectores (acuícola, minería, sector alimentario, servicios globales y turismo de intereses nacionales). En todos ellos tenemos ventajas comparativas y buenas perspectivas de crecimiento. Necesitamos retomar este camino, fomentar más competitividad y diversidad productiva. Por ello debemos restablecer y potenciar la política de clusters, basada en una fuerte cooperación y diálogo entre el ámbito público y el privado. Dichos clusters deben ser definidos en función de la vocación productiva de cada región. Impulsaremos una Agenda de Descentralización con un cronograma de iniciativas coherentes, integradas y viables, que sin alterar la organización políticoadministrativa del país, transfiera a las regiones mayores grados de poder. Se trata de avanzar en una descentralización efectiva que incluya la representación política, planes de desarrollo e inversiones, fortalecimiento del capital humano y mayor respaldo a las zonas extremas y los territorios con estatutos especiales.

Vamos a potenciar las oportunidades económicas de las regiones de Chile y lo haremos con: más descentralización; mayores competencias regionales para la gestión financiera; más recursos de inversión, y con un fuerte acento en los recursos humanos y el aliento a los talentos en las regiones.

\section{Institucionalidad: Representación y Gestión de los Gobiernos Regionales}

En el plano político, nuestra convicción es que cada región debe elegir a las autoridades que representan mejor los anhelos, sueños y proyectos de la comunidad. Si hoy se eligen alcaldes, parlamentarios y Consejeros Regionales, ese mecanismo debe extenderse a la máxima autoridad regional, hoy su intendente o intendenta. Nuestro compromiso es dotar al gobierno regional de autonomía política y administrativa especialmente en las materias relacionadas con el desarrollo y competitividad del territorio.

En los primeros 100 días de Gobierno crearemos una Comisión Asesora Presidencial para el Desarrollo Regional que propondrá un cronograma de traspaso de atribuciones y competencias y los contenidos específicos de las actividades a ser traspasadas, las materias de financiamiento, la gradualidad de la implementación y la identificación precisa de los cambios normativos que se requerirán a partir de las medidas descritas. La Comisión estará compuesta por un grupo de expertos en materia de descentralización y desarrollo territorial, representativos de distintas sensibilidades políticas, que reciba en audiencia a todas las entidades de la sociedad civil, académicas, gremiales, internacionales y los expertos, que deseen entregar propuestas sobre estas materias.

El desarrollo económico regional contará con los mecanismos, atribuciones y recursos para 
desplegarse, buscando una eficaz cooperación público privada para fortalecer la competitividad del territorio y la inclusión social y económica de sus habitantes. Por ello, un foco central del proceso estará puesto en el traspaso de competencias en materia de desarrollo productivo e innovación, el que deberá estar acompañado por recursos para su fortalecimiento. A nivel regional se crearán Programas Tecnológicos de Inversión, con la participación de las universidades regionales que superen la segmentación de la oferta pública existente y sean coherentes con la recuperación de la política de clusters. La institucionalidad regional en esta materia será un reflejo de la nacional, para lo cual crearemos los Consejos Regionales de Innovación y Competitividad, herederos de las Agencias Regionales de Desarrollo Productivo. De manera conjunta, se fortalecerán los Comités de Innovación de las regiones. Adicionalmente, para las regiones será relevante la existencia de los Centros de Desarrollo Empresarial que ofrecerán acciones de formación $y$ fortalecimiento en materia de gestión a las empresas de menor tamaño.

Para apoyar este proceso, la Subsecretaría de Desarrollo Regional (SUBDERE) contará con mandato especial. Estableceremos en la SUBDERE una unidad especializada de descentralización, la que impulsará, coordinará y evaluará el proceso de descentralización y transferencia de facultades y competencias a regiones, así como el traspaso de Servicios Públicos, proceso que será paulatino y por grupos de regiones. Ello se desarrollará mediante el fortalecimiento y entrega de atribuciones a la actual SUBDERE. Al mismo tiempo, se establecerá un organismo destinado a coordinar y apoyar la planificación y decisiones de los gobiernos regionales, que incluya el monitoreo de planes regionales plurianuales de desarrollo económico, social y productivo generados en acuerdo con los ministerios sectoriales involucrados. Los planes regionales tendrán un carácter obligatorio y constituirán el marco bajo el cual los recursos públicos apoyarán, a través de inversiones y gasto corriente, la materialización de una visión de desarrollo territorial integrada y de largo plazo.

Para dar curso al fortalecimiento de la descentralización y el desarrollo de las regiones se incrementará el gasto público regional y se generará información presupuestaria regional que incluya una desagregación regional de los presupuestos ministeriales, en aquellas asignaciones que sean efectivamente de este carácter. De esta forma, las regiones y el país sabrán exactamente los recursos con que van a contar, y ciudadanos y ciudadanas podrán exigir a sus gobiernos regionales si estos fondos no son utilizados en forma eficiente. Adicionalmente, es necesario traspasar al Gobierno Regional aquellos bienes necesarios para su funcionamiento.

En el plano de la inversión, en todas las regiones del país se crearán mecanismos de incentivos destinados a estimular la concreción de inversiones relacionadas con el asociativismo regional o comunal, de manera de incentivar esta práctica en materias de interés común. Además, crearemos un Fondo de Convergencia Regional para disminuir brechas y apoyar el desarrollo de los territorios más rezagados en materia de desarrollo socioeconómico. Al mismo tiempo, mejoraremos los criterios de composición y asignación del Fondo Nacional de Desarrollo Regional (FNDR) y disminuiremos las provisiones para traspasar estos recursos al presupuesto de inversiones. El FNDR se enmarcará en la estrategia de desarrollo regional con un sentido estratégico y de futuro.

Se deberán realizar los cambios normativos necesarios para establecer las condiciones que permitan que los Gobiernos Regionales tengan relaciones más estrechas de cooperación con las Municipalidades de la Región para el cumplimiento de objetivos comunes o complementarios, incluyendo presupuestos de inversión. La participación de las Municipalidades 


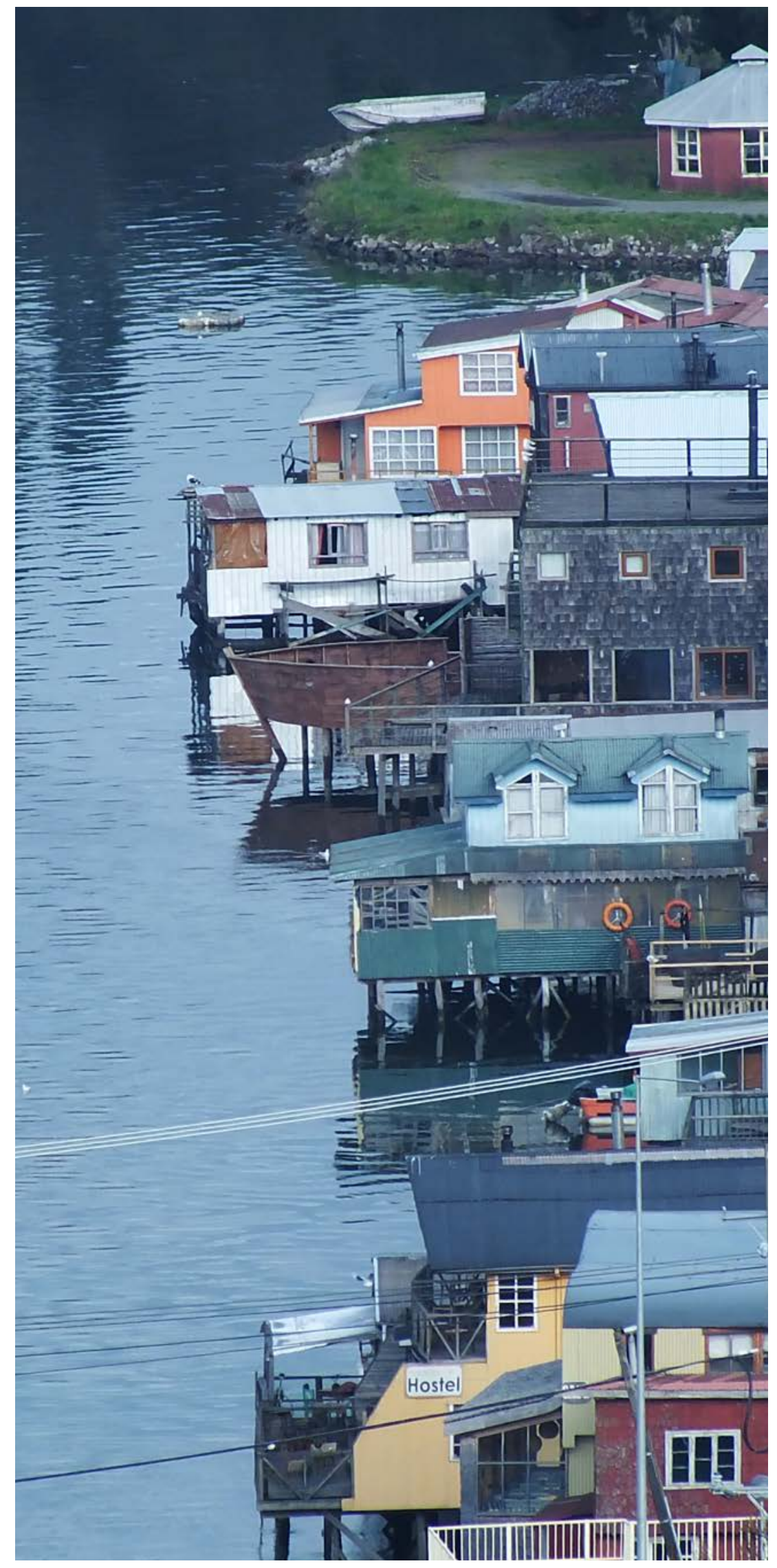

en la Elaboración de las Estrategias de Desarrollo Regional (EDR) y en el Plan Regional de Ordenamiento Territorial (PROT) debe ser obligatorio, e igualmente la asesoría del GORE en la Elaboración de los Planes de Desarrollo Comunal (Pladecos) para asegurar la coherencia de las inversiones locales y regionales.

Adicionalmente, realizaremos las modificaciones tendientes a mejorar los mecanismos de participación, transparencia y control ciudadano regional. Al mismo tiempo, contaremos con un sistema adecuado de incentivos, transparencia y rendición de cuentas que brinde seguridad jurídica a los agentes públicos en las regiones y al nivel central del Estado responsable de la disciplina fiscal. El Ministerio del Interior (SUBDERE) y los gobiernos regionales establecerán los mecanismos de consulta, planificación y rendición de cuentas a la comunidad, así como las reglas de transparencia de la gestión regional. Por otra parte, resulta fundamental que cada región cuente con un sistema de estadísticas que permita registrar el comportamiento en todos los ámbitos de intervención de los gobiernos regionales y posibilite el establecimiento de líneas base, información para el diseño, seguimiento y evaluación de políticas y programas, y para establecer los indicadores que permitan objetividad en las rendiciones de cuentas.

\section{Recursos Humanos}

Crearemos estímulos para atraer y retener personas calificadas, como también para 
incentivar la migración a regiones desde Santiago e incluso desde el extranjero, tanto en el ámbito laboral como académico. En la misma línea, extenderemos el Sistema de Alta Dirección Pública a cargos regionales, con el consecuente atractivo de remuneraciones.

Las universidades regionales deben ser las mejores socias del Gobierno Regional para impulsar el desarrollo del territorio. La Reforma Educacional promoverá que en cada región exista una oferta de educación superior y técnico profesional de calidad. Generaremos incentivos y oportunidades para que los jóvenes de esas regiones que salen a estudiar afuera, regresen a trabajar a sus lugares de origen, igual como buscamos que quienes salen a estudiar sus postgrados fuera del país regresen a Chile a trabajar.

Como se indicó, crearemos don nuevas universidades Públicas Estatales Regionales, en las regiones de O'Higgins y Aysén. Adicionalmente, crearemos Centros de Formación Técnica públicos en cada región, ligados a una Universidad Pública.

Se instalarán incentivos, a través de la Reforma Educacional, para que las universidades regionales cuenten con un elenco académico de excelencia y se establecerán y apoyarán procesos para garantizar mínimos de acreditación por carreras de universidades públicas regionales, de tal suerte que el Estado garantice la generación de capital humano para el desarrollo de las regiones.

Impulsaremos una nueva relación entre las universidades públicas y los gobiernos regionales que asegurará que las políticas de investigación, docencia y extensión colaboren con los planes de desarrollo productivo, sociales y culturales de las regiones y sirvan a los propósitos que la ciudadanía y su gobierno regional han definido. Para ello, a través de la Reforma Educacional, incorporaremos el mecanismo de Fondos Basales para las universidades públicas en función del fomento de la producción de bienes públicos en espacios regionales y macro regionales.

\section{Zonas Extremas y Territorios con estatutos especiales}

Las chilenas y chilenos que viven en territorios apartados tienen derecho a contar con estándares de vida similares al resto de la población, para lo cual es necesario enfrentar las diferencias en el costo de vida, las dificultades en conectividad, el acceso a los servicios de educación y salud, entre otros factores.

Por ello, en los primeros 100 días de Gobierno presentaremos el Plan Especial de Desarrollo de Zonas Extremas para las regiones de Magallanes, Aysén y Arica y Parinacota, que les dará un impulso potente de crecimiento y desarrollo. Además, hay zonas del país que se encuentran rezagadas respecto del desarrollo del resto y que requieren apoyo para surgir. Un ejemplo de estos casos es la zona de Arauco. Para eso, presentaremos un Plan de Desarrollo para Territorios Rezagados, que requieran impulso en materia de pobreza, desempleo, infraestructura pública, conectividad y capacidades productivas de esas zonas. 


\section{Y \\ MICHELIE}

CIUDAD,
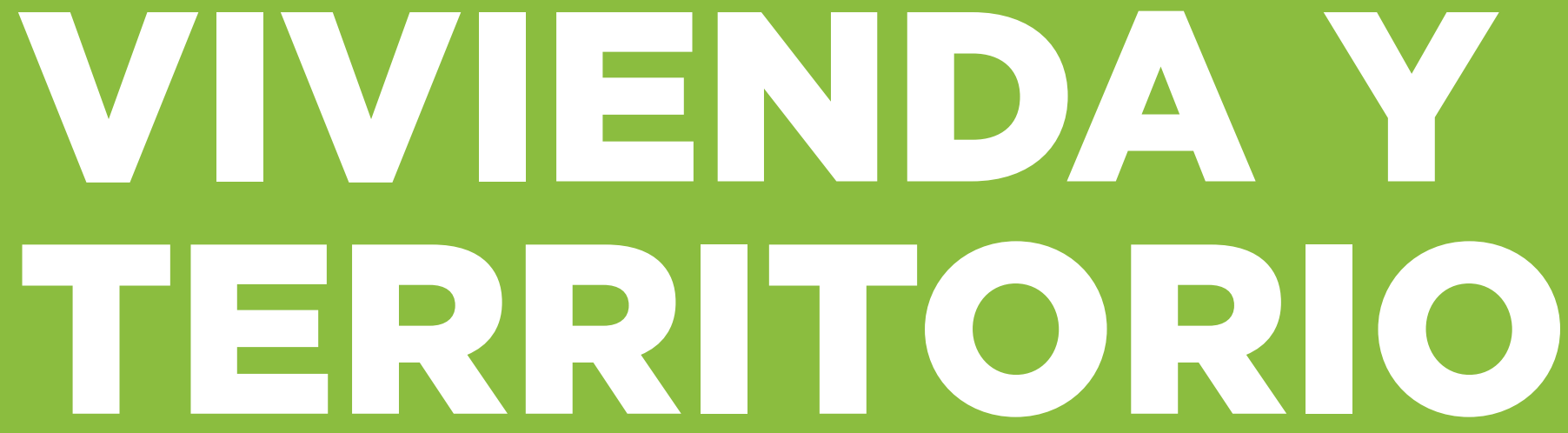

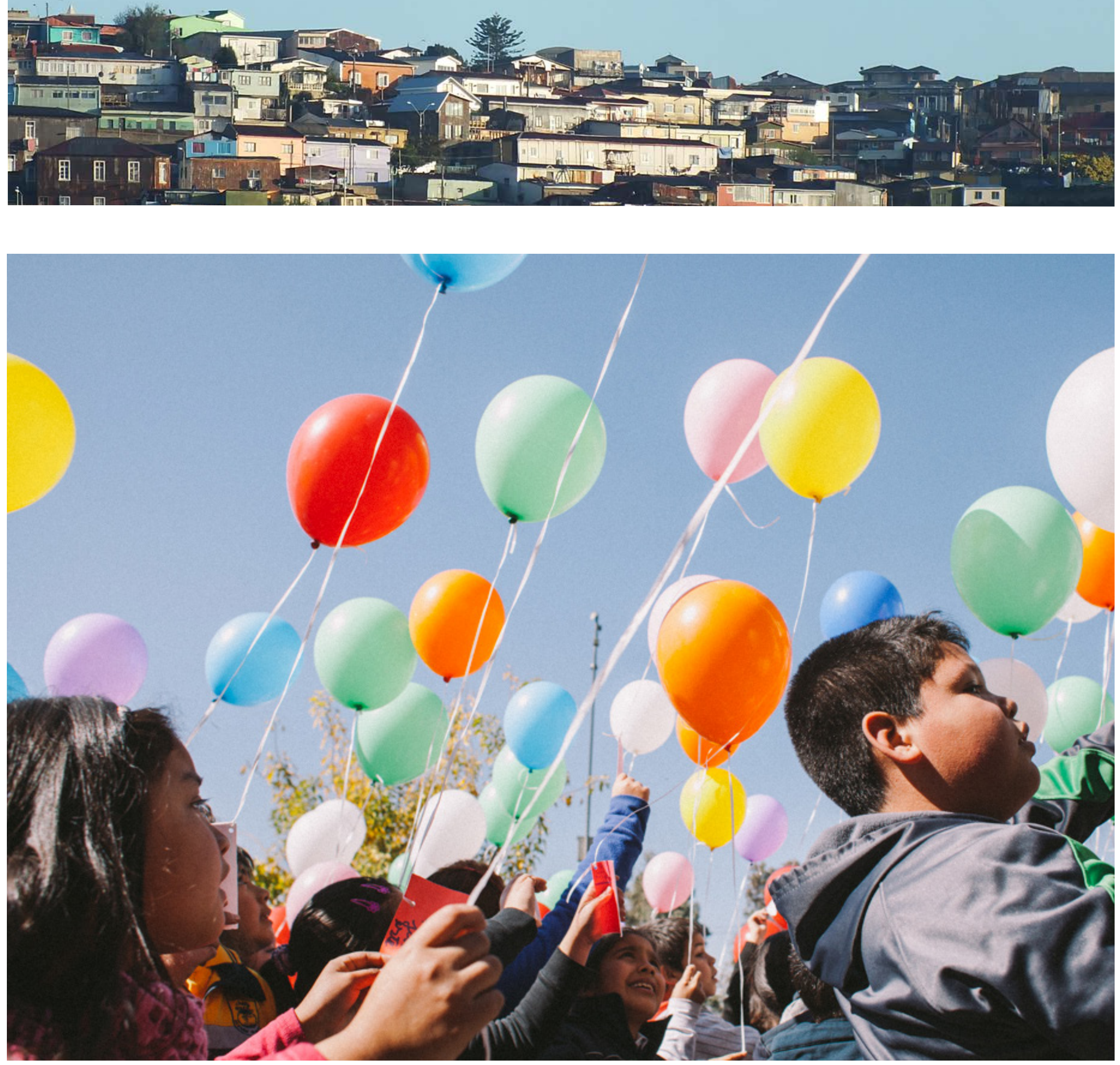


\section{CIUDAD, VIVIENDA Y TERRITORIO}

Nuestras ciudades son la expresión construida de nuestras desigualdades. Viviendo en un lugar u otro de nuestras ciudades, se abren muy diferentes oportunidades. Si asumimos que la buena ciudad es un derecho de todos, no podemos seguir construyéndola con las mismas diferencias que hay en los ingresos. El Estado debe ordenar el acceso a los bienes urbanos para todos.

Las ciudades deben ser equitativas y justas. No importa en el barrio donde alguien viva, todas las personas, en todos los barrios, deben tener calles en buen estado, viviendas decentes, transporte público adecuado, ciclovías y espacios peatonales, plazas y parques.

Las ciudades deben estar integradas socialmente. Hay espacios de nuestras ciudades que son testimonio de un notable progreso y parecen barrios de países desarrollados. Queremos que ese atractivo y a veces deslumbrante progreso, lo disfrute todo nuestro país y no unos pocos.

La construcción de la ciudad debe considerar la democracia y la participación. En todo nuestro territorio hay personas y grupos que se sienten atropellados por lo que para otros es el progreso. En la ciudad se expresan intereses económicos, materias del bien común frente a aspiraciones individuales o de grupos, lo que exige democracia y participación.

\section{Calidad del Espacio Público}

No queremos más desigualdad en los bienes públicos. Queremos que las personas pertenecientes a grupos vulnerables y de sectores medios puedan disfrutar de un espacio público de calidad. Crearemos en el Ministerio de Vivienda y Urbanismo el Plan "Chile Área Verde", que incorpora un Programa de Parques y Áreas Verdes. Este incluirá como una de sus principales iniciativas, la priorización de 30 comunas de intervención a lo largo de todo el país, el que representa un aporte significativo a la calidad de vida de las familias. En los primeros 100 días de Gobierno anunciaremos estas 30 comunas. En este desafío avanzaremos reactivando el programa de parques urbanos y modificándolo normativamente para facilitar su administración, tanto en la etapa de construcción como de mantención de los nuevos parques.

Desarrollaremos un Programa de Mejoramiento de Plazas, en el marco del Plan "Chile Área Verde", que permita generar un alto estándar de calidad material de estos espacios, respecto de: juegos infantiles, mobiliario, diseño paisajístico, iluminación, rejas de protección, entre otros aspectos.

Implementaremos el Plan Chile Accesible el que consistirá en intervenciones en centros cívicos que realmente permitan a las personas discapacitadas desplazarse y acceder a estos espacios, incorporando la mejora de rebajes, guías de avance seguro, despeje de aceras y mejoras de cruces. Consolidaremos centros cívicos en comunas vulnerables, con espacios peatonales, un centro cultural y la mejora del edificio consistorial, con diseños de primer nivel, acordes a la geografía, clima e identidad de la región.

Para proyectos inmobiliarios y de infraestructura de escala mayor estableceremos las normas y procedimientos para que estén obligados a resolver su impacto urbano y no solo su impacto vial, como hoy. Para esto, se guiarán por una metodología de "impacto urbano" del MINVU a fin que sus construcciones influyan positivamente en la calidad de vida de las ciudades en los aspectos patrimoniales, viales, culturales, económicos y ambientales, lo cual también contempla la definición de nuevos estándares de calidad en la ejecución de áreas verdes, luminaria y equipamiento. 
Crearemos un programa especial de conservación de la vialidad urbana para zonas metropolitanas y fomentaremos el uso de modos no motorizados de transporte, por sus positivos impactos en la salud, la descongestión y descontaminación de nuestras urbes. Estableceremos una política y programas que mejore la accesibilidad en las ciudades para los peatones. Además, como lo establecemos en el capítulo de Transportes y Telecomunicaciones implementaremos un Plan Maestro de inversiones en Ciclovías y otros modos de transporte no motorizado, a nivel nacional, tanto para las ciudades como en zonas rurales.

Para materializar una redistribución de la vialidad urbana, que incorpore a ciclistas y peatones, reformularemos los manuales de diseño vial y de tránsito existentes.

Crearemos programas de Escuelas Abiertas, para que estas se abran a la comunidad en actividades deportivas, recreativas y culturales, y programas focalizados de prevención de drogas.

\section{Barrios y Vivienda}

Hoy resulta necesario restablecer una política urbano habitacional que garantice equidad e integración social, continuando con lo realizado en el período 2006-2010. El haber implementado una exitosa política habitacional, nos permite hoy tener una mirada objetiva pero crítica, lo que nos motiva no sólo a realizar las correcciones en los programas de subsidios que se estiman indispensables, sino que además a enriquecerlos, siempre orientados a satisfacer las necesidades de vivienda, pero poniendo acento en la calidad de ésta y la de los barrios en los que se sitúan. Junto con lo anterior, cabe también plantearnos el desafío de generar nuevos programas habitacionales y de subsidios destinados a atender requerimientos de la ciudadanía que hoy no tienen respuesta o ayuda del Estado, en especial, para aquellos que ya tienen casa, pero que sus condiciones de vida están afectadas gravemente por el deterioro de sus viviendas y barrios y, para los que están en condiciones de ruralidad, revisando la normativa sanitaria, que impide su materialización.

Podemos señalar que el restablecimiento, ampliación y mejora de algunos programas y la creación de otros nuevos, vendrán acompañados de un gran desafío de gestión, entregando un rol muy importante al Estado en la búsqueda de los objetivos de equidad e integración, permitiendo mejorar las condiciones de vida de miles de chilenas y chilenos, pertenecientes a sectores vulnerables y sectores medios.

Hoy existen muchos chilenos que viven en extensos barrios con un nivel de deterioro que no les permite tener una vida digna para ellos y sus familias, por ello llevaremos adelante planes de regeneración urbana integral en territorios deteriorados, donde no sea posible recuperarlos urbana y/o socialmente con obras de mejoramiento.

En los primeros 100 días de Gobierno, definiremos y anunciaremos los 200 barrios en donde concretaremos la segunda parte del programa Quiero Mi Barrio, integrando también el Fondo Solidario Elección de Vivienda, que busca recuperar espacios públicos en zonas marcadas por el deterioro urbano y la vulnerabilidad social desde un enfoque integral, que articule a los diversos órganos públicos y privados que deben trabajar en conjunto para ello. Pondremos énfasis en el trabajo con las organizaciones locales incorporando desde su inicio a las Juntas de Vecinos y estableciendo metas conjuntas con los Centros de Desarrollo Vecinal.

Ligado a la iniciativa anterior, aplicaremos el Programa de Protección al Patrimonio Familiar (PPPF), que financia la reparación y mejoramiento de las viviendas, al menos a los 200 barrios 


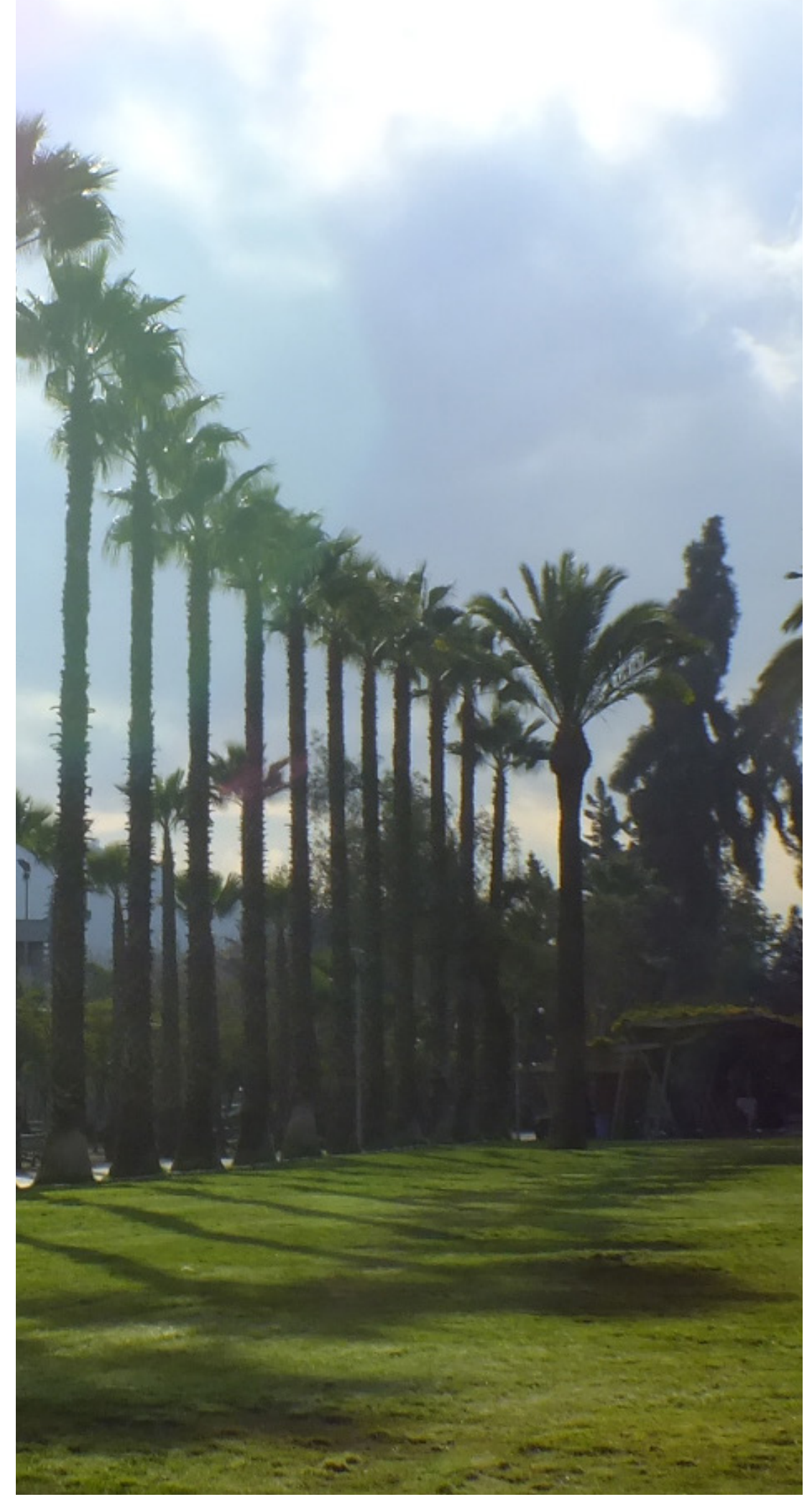

identificados. De esta manera la recuperación de barrios y comunidades se realizará de manera integral, actuando "de la puerta hacia adentro", como "de la puerta hacia afuera".

Haremos una revisión y cambios en los programas de subsidios que hoy existen para la clase media, a efectos de extender su uso, ya que una parte importante de la integración de la ciudad tiene que ver con que los sectores medios puedan ser destinatarios de las políticas urbanohabitacionales. Además, crearemos un nuevo subsidio destinado a mejorar espacios comunes o hacer reparaciones en viviendas de sectores medios.

En la actualidad se ha perdido una línea de atención especial para campamentos, que debe ser restablecida, para realmente terminar con los que viven en esta indigna condición, por ello elaboraremos un Plan de vivienda para los campamentos que hoy aún existen en Chile.

Vamos a financiar desde el Estado un programa masivo de esterilización para mascotas y nos comprometeremos con la labor de educar a nuestra ciudadanía en la tenencia responsable de animales de compañía. Para esto, dictaremos el reglamento correspondiente a la ley 20.380 , sobre protección de animales. Creemos que el Estado debe ser parte del compromiso con el cuidado y protección de los animales, poniendo los recursos para resolver un tema que tiene que ver con su bienestar, pero también con la salud pública.

Como una medida de protección a la clase media $\mathrm{y}$ sectores vulnerables, estableceremos una normativa que obligue a las empresas constructoras, a entregar a cada condominio el conjunto de especificaciones técnicas, los planos, el listado de proveedores y los subcontratistas de especialidades del inmueble vendido. Esto debe realizarse, junto al contrato de compraventa y al momento de solicitar a la dirección de obras del municipio el certificado de recepción final. 
El incumplimiento de esta disposición será penalizada con sanciones severas.

\section{Institucionalidad}

Con el propósito de velar por la política de infraestructura urbana y la coordinación en su ejecución, dotaremos de una institucionalidad permanente a la Comisión Interministerial de Ciudad, Vivienda y Territorio. Estará integrada por los ministros de Vivienda, quién la presidirá, de Obras Públicas, de Transporte y Telecomunicaciones, de Bienes Nacionales y el Subsecretario de Desarrollo Regional.

Avanzaremos decididamente en la implementación de la agenda institucional, surgida de la Política Nacional de Desarrollo Urbano, importante esfuerzo técnico alcanzado por el Estado de Chile. Entre otras materias esta Política señala un conjunto de iniciativas que vincula el trabajo del Gobierno Central con los niveles regionales y comunales, transfiriéndoles a estos últimos competencias, recursos y responsabilidades.

\section{Política de Suelos}

La Comisión Interministerial de Ciudad, Vivienda y Territorio elaborará una política de suelo con medidas legales, reglamentarias y de gestión que permitan garantizar que el Estado acceda a suelos públicos y privados de calidad, integrados socialmente con la ciudad y que permitan desarrollar en ellos distintas intervenciones urbanas y habitacionales.

El Ministerio de Bienes Nacionales contará con nuevas competencias, recursos e instrumentos legales que le permitirán proveer de terrenos para proyectos de los distintos ministerios. La gestión pública del suelo estará al servicio de la gestión urbana y habitacional.

\section{Garantías Territoriales}

Definiremos los estándares de equidad urbana aplicables a la evaluación de políticas, planes y programas, que permitirá contar con mapas regionales de línea base, que ilustrarán la situación actual de las déficit existentes en las comunas vulnerables del país en materia de calidad de vida.

Sobre la base de los déficits de calidad de vida se elaborarán planes de inversión multisectorial, en que distintas carteras se responsabilizarán del diseño y la ejecución de la inversión para reducir las brechas.

\section{Participación Ciudadana}

Impulsaremos un Plan de Ordenamiento Territorial, que permita establecer un nuevo equilibro entre los requerimientos del crecimiento económico, las necesidades de las comunidades y el respeto y cuidado por el medio ambiente. Equilibrio que debe nacer de la participación y voluntad de los ciudadanos, de manera descentralizada en el territorio, frente a la localización de infraestructuras energéticas, plantas agrícolas contaminantes, carreteras o la extensión desmedida de bosques productivos sobre suelo agrícola y comunidades indígenas.

Ampliaremos la participación ciudadana en la planificación territorialy local. Se requiere pasar de una participación informativa, a una participación dialogante y protagonista, en donde la voz de de los representantes locales realmente sea escuchada e integrada a las decisiones de políticas públicas. 
MEDIO

AMBIENTE 

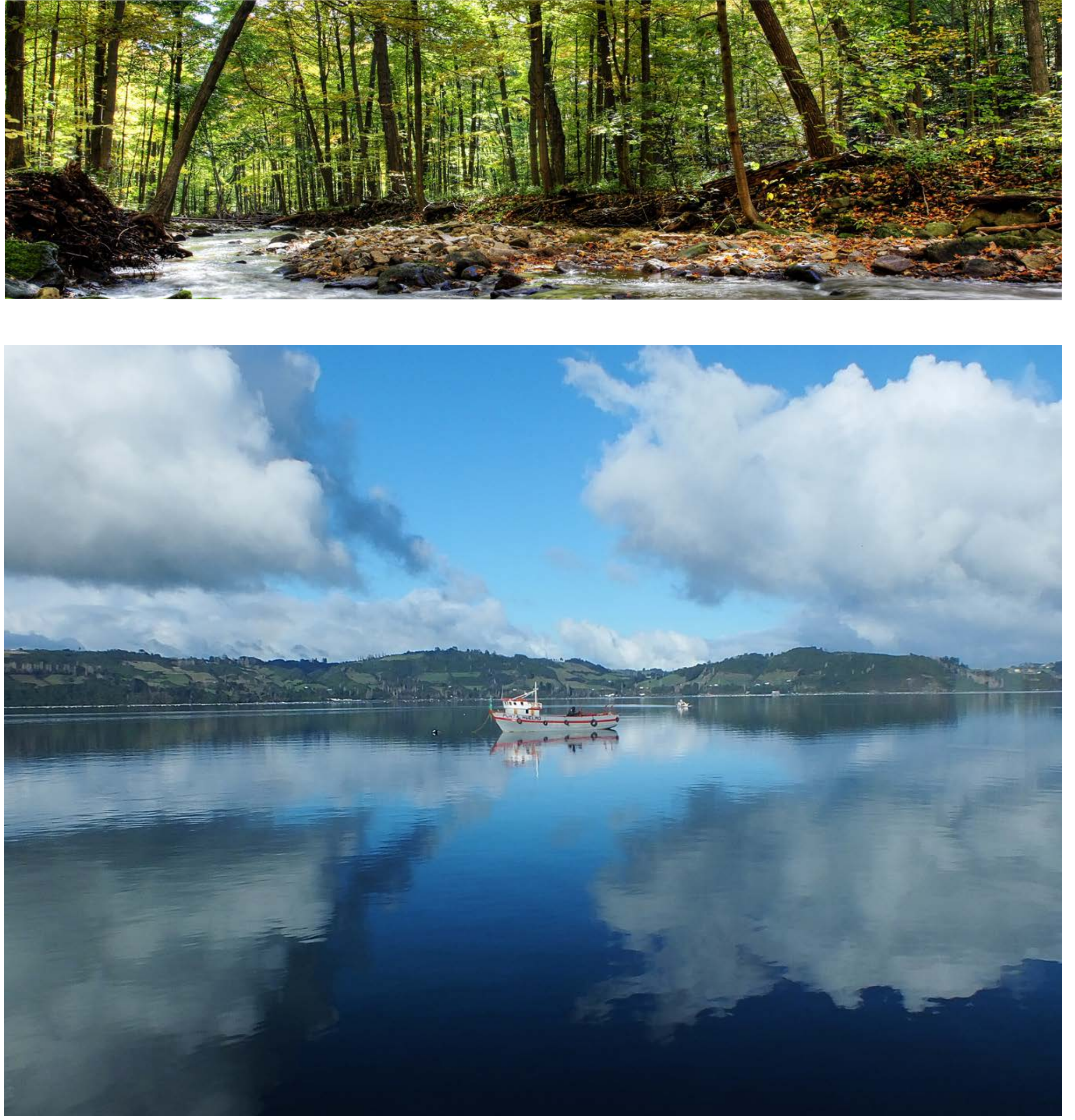
La desigualdad también se expresa en el medioambiente. El deterioro ambiental y la contaminación afectan con mayor severidad la calidad de vida de la población más vulnerable. Tenemos el deber de cambiar esta realidad. La sustentabilidad exige no sólo equilibrar crecimiento económico y protección ambiental, sino también, hacerlo con equidad social. Este será el eje de nuestra gestión: lograr mayor equidad ambiental.

En materia ambiental hemos avanzado. En el período 20062010 , cuando estaba presente con fuerza la demanda de mejores fórmulas de protección ambiental, las respuestas buscadas se orientaron a aquello que se estimó era el paso inicial de un "nuevo trato ambiental": crear una nueva institucionalidad y regulación ambiental que entregara mayor jerarquía política al tema medioambiental. Resultado de ello fue la creación del Ministerio del Medio Ambiente, el Servicio de Evaluación Ambiental y la Superintendencia del Medio Ambiente. Asimismo, se sentaron las bases para la creación de una judicatura especializada que tuvo como resultado la creación de los Tribunales Ambientales.

Hoy el desarrollo sustentable que nuestra ciudadanía reclama, implica un actuar decidido del Estado para conservar el patrimonio natural y cultural, hacer un uso racional de los recursos, impulsar una mejor calidad de vida y generar una visión y ocupación equilibrada y equitativa de los territorios, atendiendo la voz de nuestra gente que legítimamente exige mayor participación en las definiciones sobre los proyectos que inciden en su calidad de vida o que alteran zonas de gran valor ecológico.

\section{Un nuevo y activo rol del Estado inspirado en la equidad ambiental y el bien común}

El desarrollo sustentable al que aspiramos requiere un nuevo y activo rol del Estado. El Estado no puede renunciar a su obligación de propiciar un desarrollo sustentable y por ello debemos entregarle las herramientas necesarias para adoptar decisiones en beneficio de la sustentabilidad y del bien común, en forma preventiva y correctiva. Reconocemos el aporte a la sustentabilidad que crecientemente realiza el sector privado, pero no es suficiente. El Estado está llamado a ser el protagonista en la solución a la desigualdad y ello requiere mucho más que generar marcos regulatorios. El Estado requiere facultades respecto de la propiedad y gestión de los recursos naturales estratégicos y no renovables.

El Estado debe abordar el ordenamiento territorial, en un proceso amplio y convocante, donde como sociedad definamos aquello que estamos disponibles a incentivar en nuestros territorios, con una mirada integral que contemple lo ambiental, social y económico.

En materia de fortalecimiento institucional, es necesario evaluar el Sistema de Evaluación de Impacto Ambiental (SEIA,) a la luz de los objetivos iniciales que nos movieron a presentar la reforma a la institucionalidad ambiental en nuestro Gobierno, e impulsaremos con decisión los cambios necesarios que aseguren a todos los ciudadanos, organizaciones y empresarios, una institucionalidad validada desde el punto de vista técnico. Asimismo, reforzaremos la Superintendencia del Medio Ambiente dándole presencia organizada en cada región del país.

También es clave enfrentar las consecuencias del cambio climático que, como sabemos, implica impactos para nuestro país. Debemos generar políticas consistentes y por ello fortaleceremos el rol del Consejo de Ministros para la Sustentabilidad que impulsará políticas y regulaciones con eje en la sustentabilidad y en concordancia con medidas para hacerse cargo de los efectos del cambio climático.

\section{Participación Ciudadana, Descentralización y Ordenamiento Territorial}

ComoseindicóenelcapítulodeCuidad,ViviendayTerritorio impulsaremos un Plan de Ordenamiento Territorial, con participación ciudadana, que permita establecer un nuevo equilibro entre los requerimientos del crecimiento económico, las necesidades de las comunidades y el respeto y cuidado por el medio ambiente. Adicionalmente, 
la experiencia nos ha demostrado lo fundamental que resulta integrar la dimensión socio-ambiental en el proceso de toma de decisiones. Las comunidades no cuentan con información y recursos suficientes para hacer frente a las situaciones ambientales de sus territorios. Por ello, estableceremos los mecanismos institucionales y recursos para la entrega efectiva de orientación, mediación y defensa ambiental ciudadana, que facilite la solución de problemas ambientales locales. Para aquellas comunidades potencialmente afectadas por un proyecto sometido a evaluación ambiental, diseñaremos una instancia de apoyo técnico para analizar y entender las implicancias de la eventual instalación de esa actividad, y para facilitar una participación informada en la evaluación ambiental. Asimismo, avanzaremos en el diseño de nuevos mecanismos de participación, garantizando una mayor descentralización pues las realidades de los distintos territorios requieren respuestas acordes con sus particularidades.

Sabemos que parte importante de los conflictos socioambientales que existen en nuestro país tienen su origen en la ausencia de definiciones respecto del territorio y sus destinos, y donde las visiones de sus habitantes han sido escasamente consideradas. Debemos abordar el ordenamiento territorial en un proceso amplio y convocante. Aquello que estamos disponibles a incentivar en nuestro territorio, con una mirada integral que contemple lo ambiental, social y económico, esto es una mirada de sustentabilidad.

\section{Recursos Naturales y Agua}

Estamos llamados a establecer una nueva relación con nuestros recursos naturales, fuente de nuestra riqueza, donde el eje esté en aprovecharlos adecuadamente y no en agotarlos. El Estado, sobre la base de criterios de sustentabilidad, jugará un rol decisivo respecto de nuestros recursos naturales y su relación con actores privados y públicos.

El agua es clave. La Nueva Constitución reconocerá las aguas como bien nacional de uso público.
La actividad minera debe ajustarse a las nuevas exigencias socio-ambientales y debemos mostrar al mundo que nuestra vocación por la sustentabilidad nos impulsa a establecer los mejores estándares. El Consejo de Ministros para la Sustentabilidad deberá establecer los lineamientos de política para hacerse cargo de este objetivo.

\section{Cambio Climático}

Debemos configurar nuestra gestión ambiental en forma coherente con la importancia del desafío que implica el fenómeno del cambio climático. El Consejo de Ministros para la Sustentabilidad debe pasar a denominarse "Consejo de Ministros para la Sustentabilidad y el Cambio Climático". Este órgano debe elaborar, con la máxima celeridad posible, un nuevo plan nacional de cambio climático con una visión transversal e integrada, en adaptación, mitigación de impactos y creación de capacidades, orientando las medidas adoptadas hacia una economía baja en carbono que beneficiarán doblemente a Chile: aportarán tanto a la reducción de emisiones de gases de efecto invernadero como a la calidad del aire que respiramos en Chile y a la calidad de vida de los chilenos. Nuestra meta, como mínimo, es cumplir el compromiso de emisiones de gases de efecto invernadero, asumido por Chile el 2009 en la XV Conferencia de las Partes de Cambio Climático.

\section{Biodiversidad, Áreas Protegidas y Patrimonio}

Naciones Unidas y la OCDE tienen en el centro de sus preocupaciones y acciones la protección de la biodiversidad pues su pérdida es alarmante y constituye una amenaza para el desarrollo. Chile no puede estar ajeno a esta tarea siendo un país con una gran riqueza de biodiversidad que está amenazada. Debemos ser capaces de integrar el enfoque de protección de biodiversidad en forma transversal y para ello es indispensable fortalecer la investigación científica sobre ella, en alianza con nuestras universidades, centros de investigación, el Estado, el sector privado y las redes internacionales. 


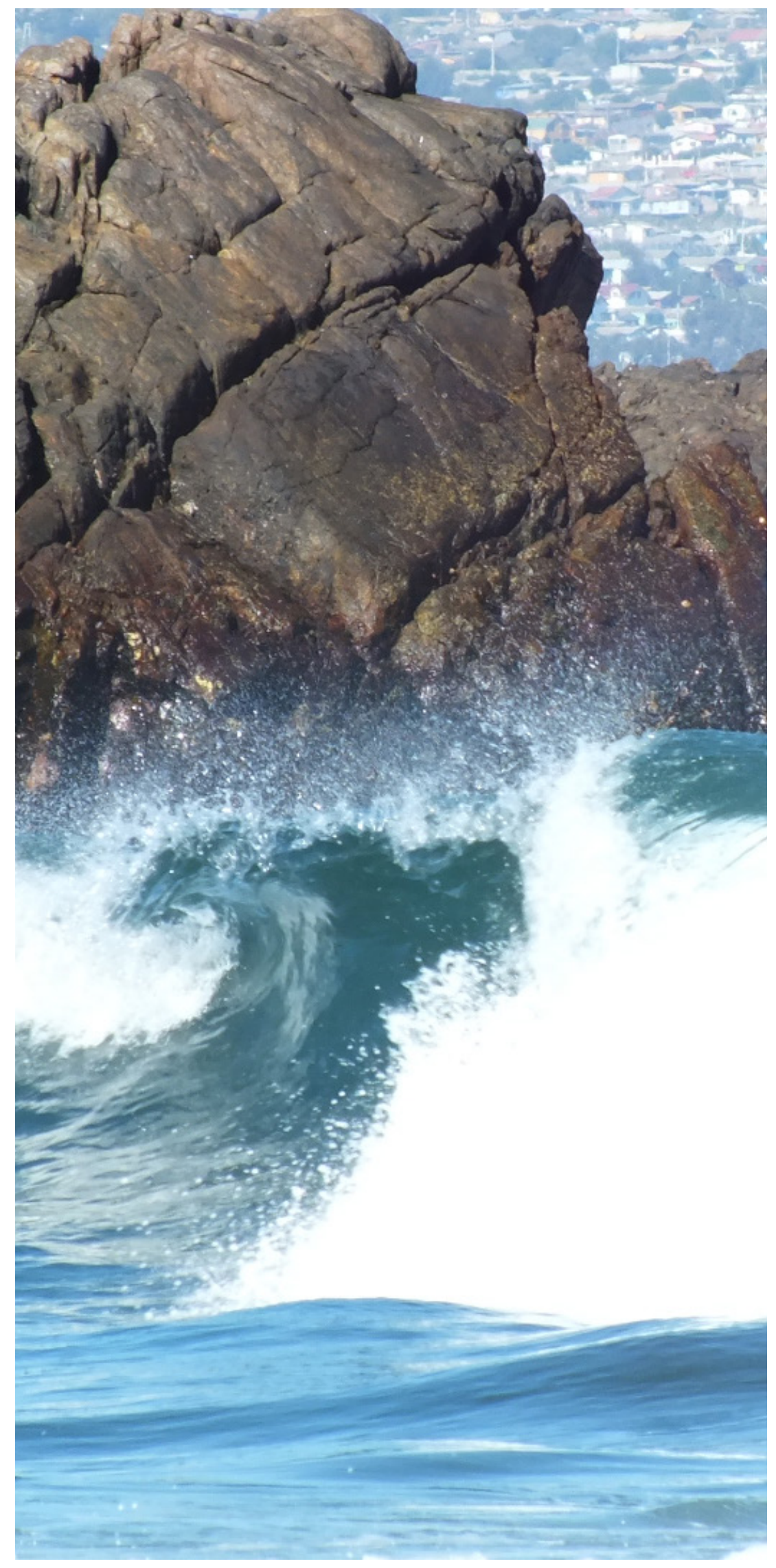

Completaremos la reforma ambiental iniciada en el período 2006-2010, dando cumplimiento a la ley que creó el el Ministerio del Medio Ambiente, tramitando el proyecto de ley que crea el Servicio de Biodiversidad y Áreas Protegidas, que definirá las categorías de protección y establecerá los rangos de prohibiciones y limitaciones de actividades para cada una de ellas, fortaleciendo la protección de la biodiversidad, que no sólo se restringe a las áreas protegidas. Evaluaremos la aplicación de la Ley de Bosque Nativo y estudiaremos una solución al estatuto jurídico que debe tener CONAF. En materia de transgénicos, abordaremos de modo participativo una política nacional de bioseguridad cumpliendo nuestros compromisos internacionales y elevando al Congreso su discusión.

\section{Ciudad y Territorios Sustentables con Buena Salud y Calidad de Vida}

Tenemos la obligación de avanzar en mecanismos para mitigar los efectos crónicos de la contaminación en la salud. Aceleraremos la elaboración y revisión de normas de emisión de aire así como de normas de calidad. Nuestros planes y medidas de prevención y descontaminación, que hoy pueden ser fiscalizados por la Superintendencia del Medio Ambiente, requieren inventarios de emisiones que debemos afinar y actualizar.

En materia de ruidos aplicaremos y perfeccionaremos la normativa que se vulnera con mucha frecuencia, y exigiremos su cumplimiento con firmeza.

En materia de olores tenemos herramientas que 
nos permiten actuar desde ya, pero iniciaremos aceleradamente el proceso de elaboración de la normativa pendiente.

Sobre residuos, daremos prioridad a proponer y tramitar una ley general de residuos. No soluciona el tema la normativa parcialy dispersa que tenemos hoy. Requerimos una ley integral. Buscaremos eliminar las barreras que hoy existen para que se puedan aplicar las mejores tecnologías disponibles y ya probadas en el mundo.

La participación de la sociedad civil y representantes de diversas áreas tanto académicas como técnicas, participarán en la elaboración de una Política de Calefacción Sustentable, que entre otras materias, aborde el uso residencial de la leña en Chile.

\section{Una Sociedad Responsable}

Impulsaremos un plan nacional de gestión de situaciones graves de contaminación existente, con la más amplia participación. Propondremos un plan integral para disminuir, hasta erradicar, la grave exposición a sustancias y pesticidas tóxicos que existan en aquellos territorios de grave exposición o con graves efectos heredados.

Asimismo, se elaborarán planes especiales y comprometerán recursos para comunidades que han sido profundamente afectadas por los costos ambientales, para mejorar la situación sanitaria de estas zonas, junto con un programa prioritario especial de fiscalización de la Superintendencia del Medio Ambiente (SMA), para los proyectos emplazados en las zonas más afectadas por cargas ambientales.

\section{Producción limpia, cuentas ambientales, educación ambiental, ciencia y tecnología}

Promoveremos la inversión y la operación de un observatorio de mejores tecnologías disponibles y las mejores prácticas ambientales para generar las bases de una producción limpia y sustentable, profundizando los incentivos al cumplimiento, reconociendo a las empresas responsables y apoyando especialmente a la pequeña y mediana empresa en el cumplimiento ambiental.

El sector público exigirá buenas prácticas ambientales, y preferirá productos amigables con el medio ambiente.

Avanzaremos en un Plan Nacional de Cuentas Ambientales, para que ejerciendo las facultades que entregamos al Ministerio del Medio Ambiente, éste coordine la elaboración y construcción progresiva de las cuentas ambientales, incluidos los activos y pasivos ambientales, y la capacidad de carga de las distintas cuencas ambientales del país.

Reforzaremos los contenidos de educación ambiental tanto en los programas de educación formal en los distintos niveles, como en la capacitación y sensibilización para distintos estamentos y grupos. Realizaremos decididos esfuerzos de investigación para enfrentar los desafíos de la sustentabilidad. Generaremos consorcios multi-institucionales (gobierno-academia-sectores productivos-ciudadanía) para abordar los problemas ambientales más relevantes. 


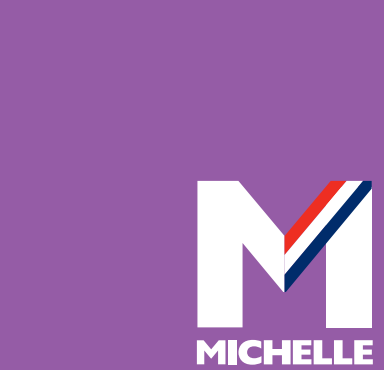

GULUURA

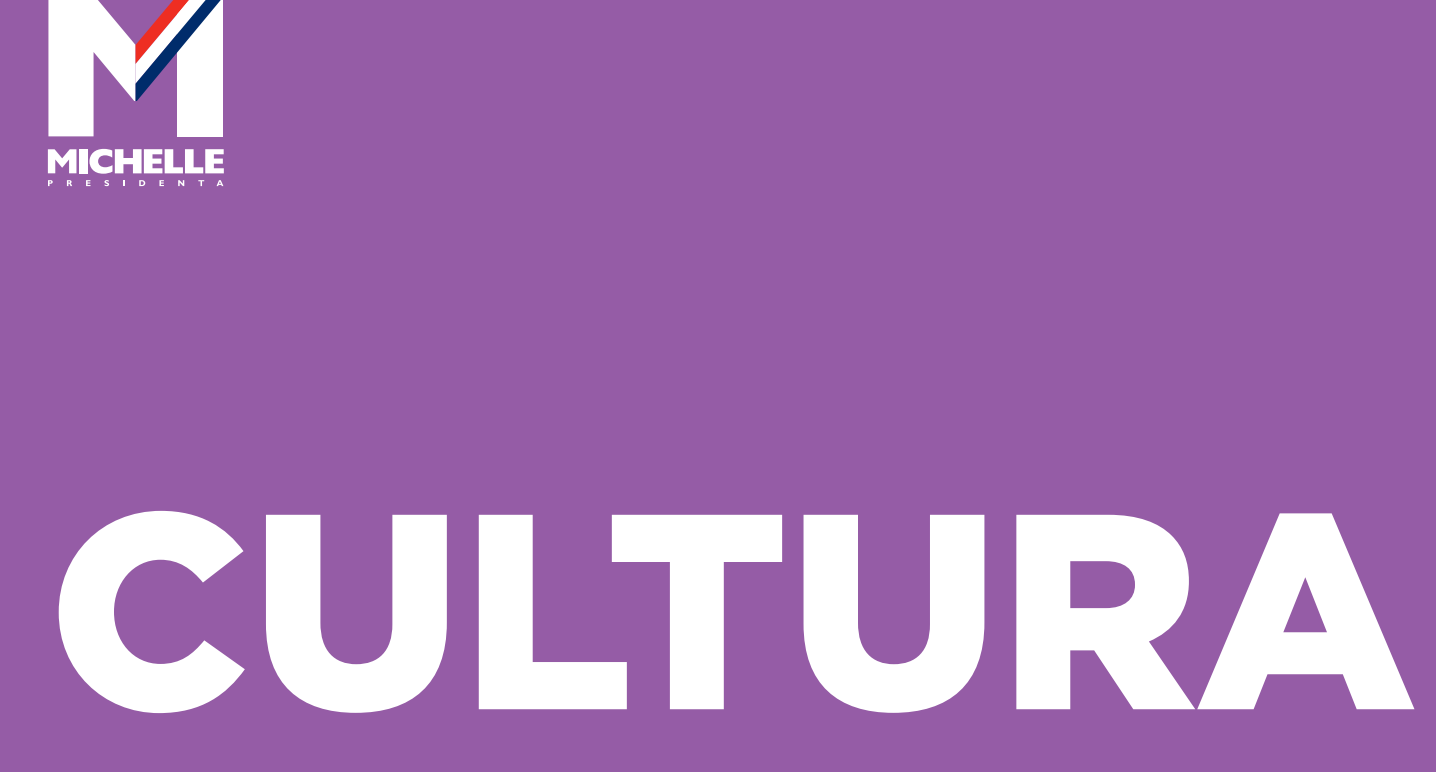

,

n Y

RES Den 

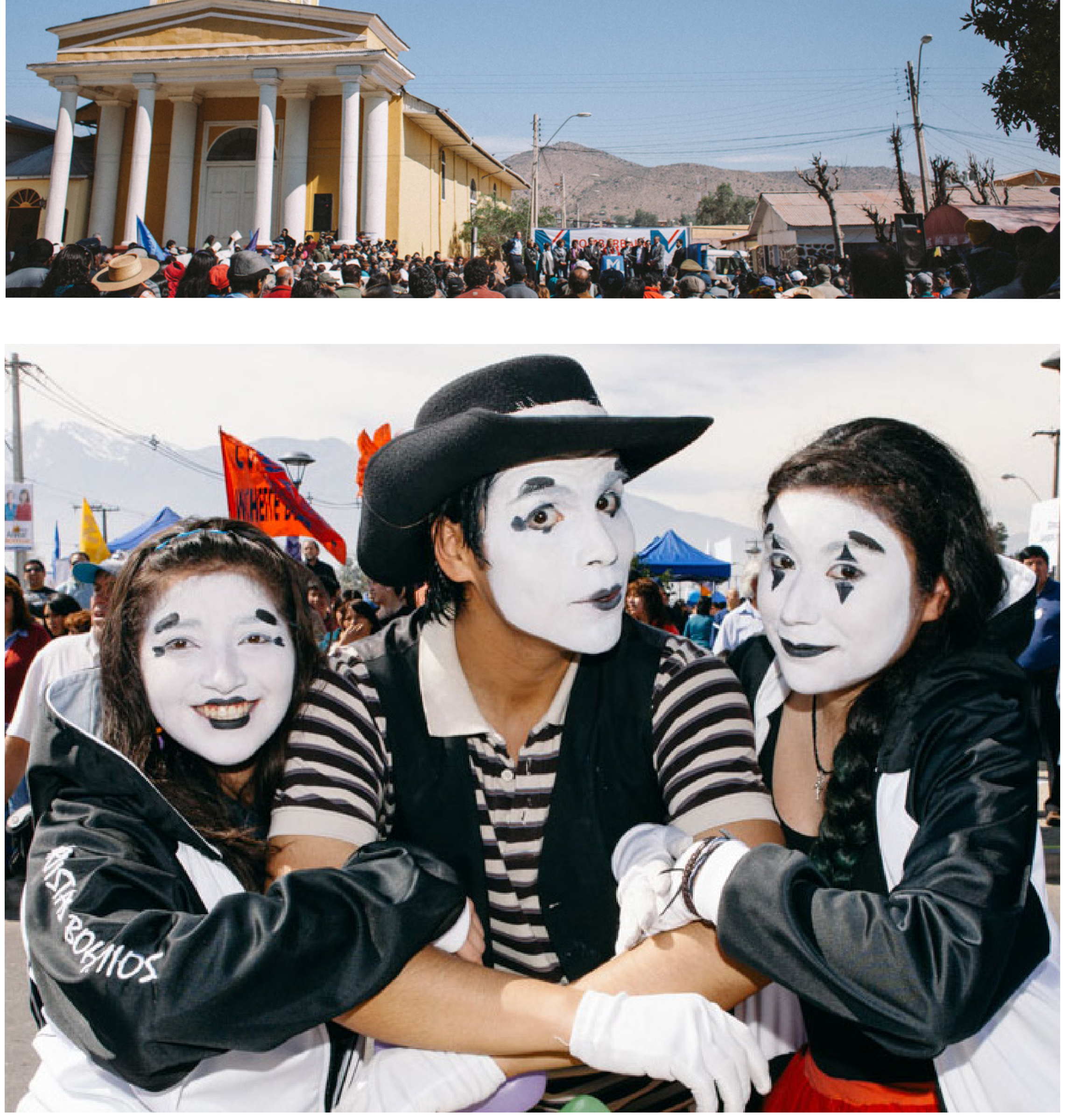


\section{CULTURA}

Resultan indudables los avances alcanzados en materia cultural a partir del retorno de la democracia. En una primera etapa, los esfuerzos se orientaron a reparar a nuestros creadores y artistas. Avanzamos paulatinamente en darle forma a la institucionalización del sector, pasando desde la División de Cultura del Ministerio de Educación hasta la creación del Consejo Nacional de la Cultura y las Artes. Asimismo, reestablecimos y aumentamos, año a año, los recursos públicos destinados a cultura.

En el período 2006 - 2010, se concretó el mayor crecimiento presupuestario de la historia en el sector, con un incremento de más del 100\%. Lamentablemente, en los últimos cuatro años esta tendencia se detuvo con un exiguo crecimiento de sólo $4 \%$, lo que ha implicado en la práctica el congelamiento del presupuesto sectorial. Hoy para el Estado chileno, la cultura tiene menor importancia que hace cuatro años.

A pesar de los avances, persisten importantes déficits, en particular respecto de la desigualdad en el acceso de la población a las obras y servicios culturales y patrimoniales y el desigual reconocimiento de las culturas y creaciones locales, además de la desigualdad en el acceso a la formación y educación en las artes y la necesidad de perfeccionar nuestra institucionalidad cultural, para hacernos cargo de los nuevos desafíos.

Los chilenos en democracia han relevado a la cultura como un factor fundamental de su existencia y desarrollo social. Las comunidades culturales demandan así un incremento sustantivo de la acción del Estado para fortalecer y profundizar un Chile de personas libres, pluralista, tolerante y capaz de terminar con las desigualdades y las discriminaciones, donde se viva la diversidad cultural, las relaciones pluriculturales y el cultivo de la memoria.

\section{Garantizar el acceso al arte y la cultura}

Fortaleceremos el acceso a la cultura y las artes, especialmenteen comunas con menoresoportunidades. Para esto, implementaremos un sistema que facilite y financie a la red pública de infraestructura cultural, así como a entidades privadas, planificar e implementar una adecuada programación de obras y Servicios Culturales y patrimoniales, en barrios y comunas del país, facilitando el encuentro con la oferta cultural de calidad.

Apoyaremos el funcionamiento de aquella infraestructura cultural que desarrolle una función pública en los niveles nacional, regional o comunal, estableciendo condiciones para su viabilidad. Para alcanzar este objetivo, estableceremos convenios de colaboración entre el Ministerio de la Cultura y los administradores de esta infraestructura. Además, promoveremos la difusión y el conocimiento de la cultura y tradición de norte a sur y la de nuestros pueblos originarios, para que esa tradición viva en cada rincón de nuestro territorio.

Crearemos un Fondo que permita acceder a los recursos básicos para el fomento de la participación y organización de las personas en torno a iniciativas culturales comunitarias que contribuyan a la integración social y al fortalecimiento de la identidad y diversidad cultural.

Para las comunas y localidades más pequeñas y retiradas, que presentan mayores problemas de acceso a los bienes culturales, crearemos un programa de pasantías, residencias y voluntariado para que artistas, cultores y gestores culturales de todas las disciplinas se instalen al menos durante 3 meses a desarrollar programas y actividades culturales en diálogo y coordinación con sus habitantes. 
Crearemos un Programa de fomento y difusión del arte y las culturas de los pueblos indígenas, con el objeto de rescatar, promover y difundir el arte de nuestros pueblos originarios mediante diversas iniciativas vinculadas a las diversas disciplinas y tradiciones.

Crearemos bibliotecas regionales en aquellas regiones en que no existen y fortaleceremos la red de bibliotecas públicas escolares, preescolares, y de la educación superior como también de sus colecciones con una presencia destacada de la producción local.

Pondremos en marcha una nueva política nacional de museos, que les permita financiarse y mejorar su gestión y contenidos que ofrecen a la ciudadanía. Adicionalmente, desarrollaremos una política sobre cultura digital, que nos permita aprovechar de mejor manera el desarrollo tecnológico, para, por una parte, ampliar las posibilidades para las políticas públicas de fomento a la creación cultural y, por la otra, democratizar, promover y facilitar, de mejor manera, el acceso a bienes culturales por parte de la ciudadanía.

\section{Cultura y Formación}

Implementaremos como política nacional el desarrollo de talentos artísticos juveniles, para lo cual crearemos 15 nuevos centros juveniles de cultura, con ello generaremos una red de 20 centros. Estos centros culturales buscarán brindar a los jóvenes con talento en las artes, especialmente los de menos oportunidades, un espacio de excelencia para su perfeccionamiento. Con esta red funcionando en régimen, más de 25.000 jóvenes accederán anualmente a una experiencia formativa. En los primeros 100 días de Gobierno, se identificarán las ciudades en las cuales se instalarán los nuevos centros, junto con la elaboración del plan anual de implementación.
Adicionalmente, se creará un programa para niños de enseñanza básica pertenecientes a establecimiento subvencionados, con talento sobresaliente en disciplinas artísticas.

Crearemos el Programa Nacional de Desarrollo Artístico dirigido a niños de pertenecientes a establecimientos de educación básica subvencionada, orientado a la creación de una red nacional de coros, cuerpos de baile. Adicionalmente, aumentará la cobertura cobertura de las orquestas juveniles a nivel de enseñanza básica.

Fortaleceremos el subsistema de escuelas artísticas de Educación General, propendiendo a su mejoramiento académico, de infraestructura y equipamiento; y a asegurar su sustentabilidad en el tiempo. Junto con esto, estableceremos una comisión de expertos para el análisis de curriculum, metodologías de aprendizaje y evaluación docente, para proponer los cambios necesarios de la actual enseñanza formal del arte en el nivel de educación general. Adicionalmente, perfeccionaremos e implementaremos el plan nacional de la lectura, para estudiantes de Educación General.

Crearemos un nuevo programa para el Arte y la Cultura, al interior de la jornada escolar completa, para el desarrollo artístico y creativo, de carácter masivo, que a partir de las experiencias del Consejo Nacional de la Cultura y las Artes, ofrezca formación en los diversos lenguajes artísticos desde la primera infancia.

Crearemos el Plan Nacional de Lectura y una Política Nacional del Libro que haga de Chile un país de lectores y lectoras desde la primera infancia. 


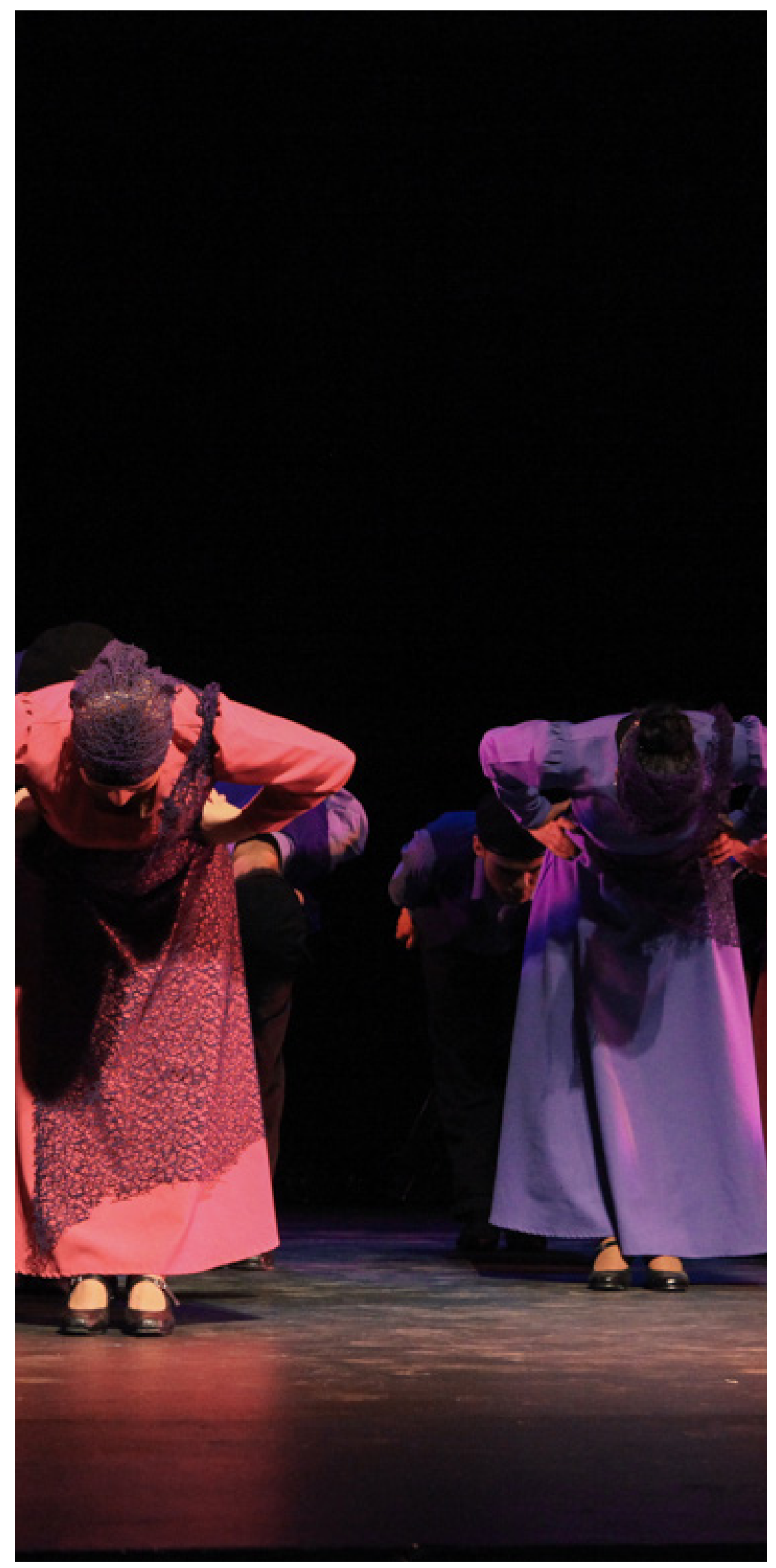

\section{Financiamiento y Fomento del Arte y la} Cultura

En cuatro años duplicaremos los recursos destinados a cultura en el Presupuesto de la Nación.

Aumentaremos el financiamiento de los programas de fomento del arte y la cultura, para dar un impulso a las industrias culturales y a lo que hoy se llama "economía creativa". Generaremos un Plan Nacional de Fomento de la industria y Economía Creativa chilena. Como sustento institucional crearemos el Comité de Coordinación de Fomento de la Economía Creativa, presidido por el Ministro de la Cultura, y representantes de ministerios de Agricultura y Relaciones Exteriores, CORFO, SERCOTEC y SERNATUR.

Modificaremos y perfeccionaremos los Fondos de Cultura y programas sectoriales. Entre otros aspectos, implementaremos programas de financiamiento no sujetos a concursabilidad en las distintas áreas creativas, destinados al financiamiento de proyectos cuyas importancia, envergadura, tiempos de ejecución u otras lo ameriten.

Crearemos un programa de internacionalización en el Ministerio de la Cultura "Chile país de Artistas", con el objeto de fortalecer y ampliar actuales esfuerzos, estimular y apoyar la circulación internacional de las obras artísticas de creadores nacionales, el conocimiento y valoración internacional de nuestros artistas y cultores.

Estableceremos convenios de colaboración entre el Ministerio de la Cultura y aquella infraestructura cultural que desarrolle una función pública en los niveles nacional, regional o comunal, destinado a dar sustentabilidad en el largo plazo a dichas instituciones.

\section{Institucionalidad}

En los primeros 100 días de Gobierno enviaremos al Congreso un proyecto de ley que crea el Ministerio de Cultura y Patrimonio, que será una institución con énfasis locales, que promueva la cultura, las artes y la 
interculturalidad, para lo cual, presentaremos un proyecto de ley al Congreso. Este Ministerio debe ser capaz de una acción de dinámica, moderna y eficiente, manteniendo y profundizando las estructuras participativas actuales y generando nuevos espacios y metodologías de participación de la sociedad civil; avanzando cualitativamente en fórmulas de descentralización efectiva; incrementando las responsabilidades en la incorporación de la cultura y las artes en la educación.

Implementaremos políticas públicas que permitan asegurar una adecuada protección y circulación de la producción audiovisual, musical, así como del libro.

Introduciremos modificaciones al Consejo Nacional de Televisión, incorporándolo al Ministerio de Cultura y Patrimonio, ampliando sus atribuciones, manteniendo su rol de regulador de la TV, enfatizando su rol de fomento de la calidad de la industria televisiva, tanto a nivel de TV abierta, pago, regional y comunitaria.

Enviaremos un proyecto de ley al Congreso para realizar un conjunto de modificaciones en materia de televisión pública. Se deben ampliar las facultades de TVN para un cumplimiento efectivo de los objetivos asociados con la misión pública que la ley le entrega. Al directorio se le aplicarán los deberes y régimen de responsabilidades de los directores de las Sociedades Anónimas y se debe imponer la obligación al Directorio del canal público de dar cuenta de su gestión una vez al año. TVN, debe incorporar financiamiento público de manera sistemática, con el objeto de que pueda producir bienes públicos socialmente valorados que los privados no tienen obligación de producir.

En el nuevo escenario de TV Digital, el canal público debiera desarrollar a lo menos dos frecuencias abiertas y gratuitas adicionales. Una, la del canal 24 horas, actualmente sólo en plataformas de pago, y otra para un canal educativo cultural. Son justamente estas iniciativas las que requieren de un decidido apoyo del Estado.

Incorporaremos las políticas culturales regionales a las estrategias de desarrollo regional y diseño de planes comunales de cultura como parte de los PLADECOS, de manera de generar coherencia y sinergia en el conjunto de las políticas públicas territoriales.
Perfeccionaremos la legislación y fiscalización del cumplimiento de los derechos laborales aplicables a los distintos sectores de la cultura. Además, crearemos un programa de "Buenas Prácticas Culturales", con sistematización de experiencias exitosas e intercambio de estas experiencias.

\section{Patrimonio}

Crearemos un Programa de Recuperación Regional de Infraestructura Patrimonial Emblemática. El programa contempla como parte sustancial para las decisiones de intervención la participación ciudadana en las comunas en donde se realicen intervenciones. En los 100 primeros días de Gobierno, comenzaremos la puesta en marcha de un programa de recuperación regional de infraestructura patrimonial emblemática en 4 regiones.

Diseñaremos e implementaremos un Programa Nacional de Sitios, Zonas y Bienes chilenos declarados Patrimonio de la Humanidad, el que deberá coordinar las acciones de los MinisteriosdelaCultura, ObrasPúblicas, ViviendayUrbanismo, Bienes Nacionales, Transportes y Telecomunicaciones, los Intendentes y autoridades comunales, con el propósito de contribuir eficazmente en la recuperación, preservación y divulgación de esos patrimonios.

Crearemos un Fondo del Patrimonio cultural material e inmaterial, con el objeto de financiar programas, iniciativas y proyectos de investigación, identificación, registros, puesta en valor, restauración, conservación, divulgación, y otras medidas de salvaguardia, y educación en todos los ámbitos del patrimonio cultural, material e inmaterial.

Crearemos un programa de Gestión Local del Patrimonio, que ponga a disposición recursos económicos y profesionales competentes a comunidades de nuestro país, poseedoras de expresiones del patrimonio cultural inmaterial y/o que se encuentran emplazadas en entornos geográficos y arquitectónicos de relevancia patrimonial.

Ratificaremos y aplicaremos las Convenciones de la Unesco, sobre las medidas que deben adoptarse para prohibir e impedir la importación, la exportación y la transferencia de propiedad ilícitas de bienes culturales. 


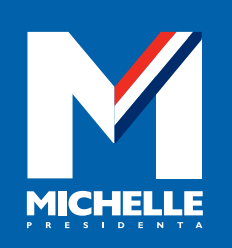

DEPORTE 

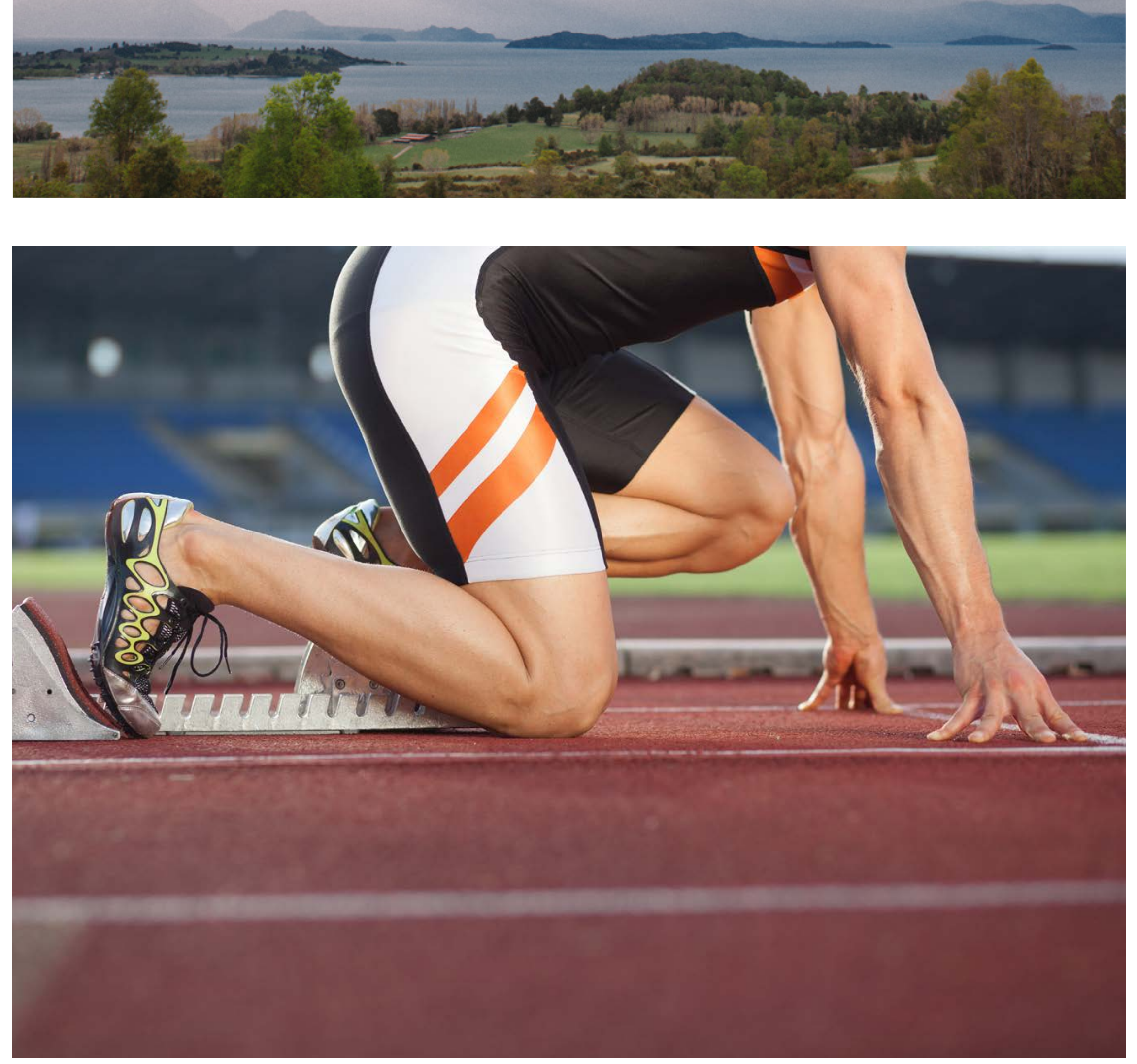


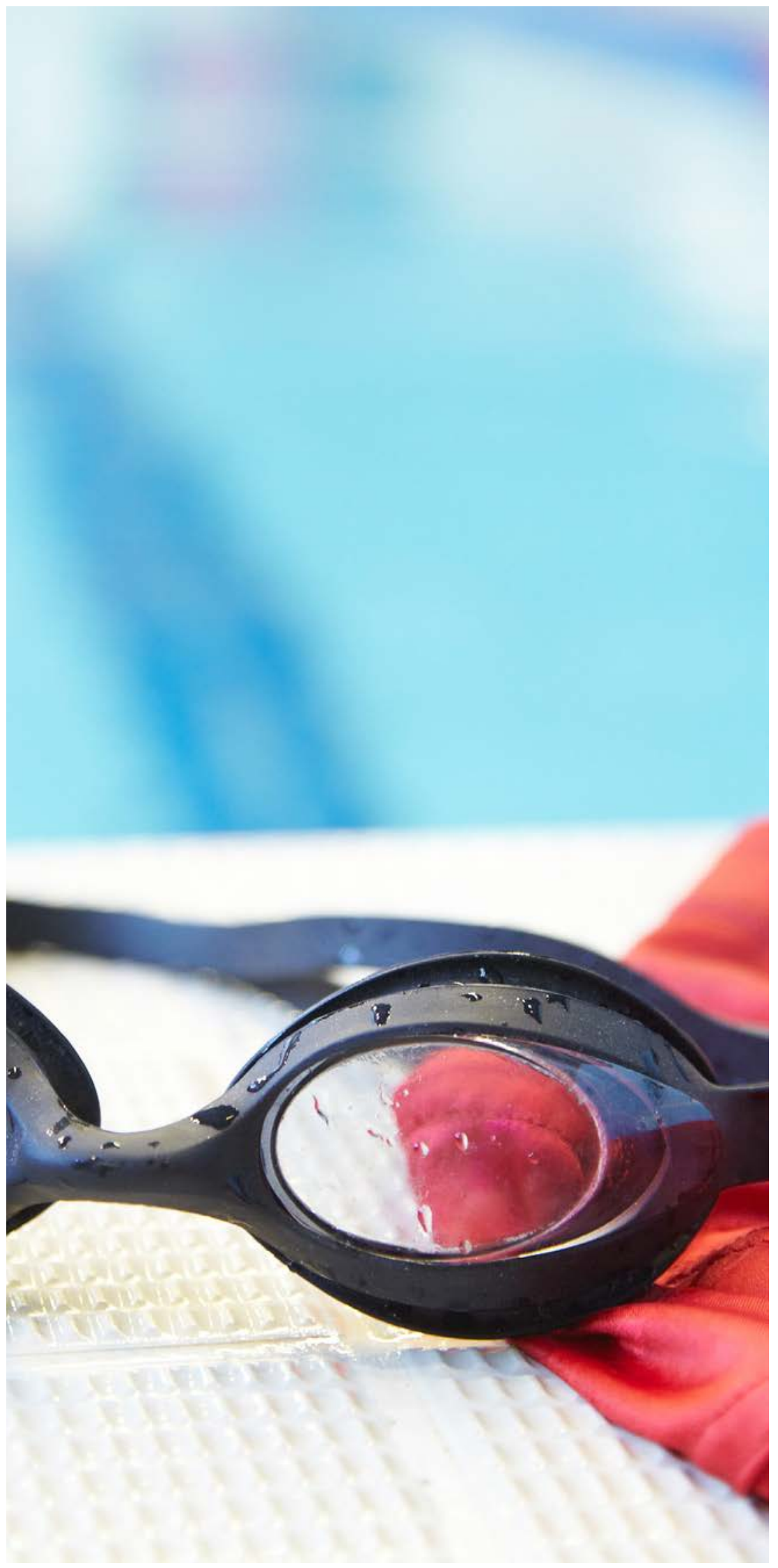

\section{DEPORTE}

El deporte y la actividad física son esenciales para el desarrollo de niñas, niños y jóvenes, además de contribuir a estilos de vida saludables y al bienestar en las siguientes etapas de la vida. Sin embargo, chilenos y chilenas en su mayoría seguimos siendo sedentarios, con una alta prevalencia de la obesidad. La práctica continua de algún deporte es más bien la excepción que la regla y necesitamos que la población, en todos los sectores socioeconómicos, particularmente de sectores medios y vulnerables, se incorporen a esta actividad. Implementaremos politicas deportivas y recreativas que consideren nuestra realidad desarrollando programas para llevar el deporte a las comunidades, utilizando los espacios públicos, las plazas y los parques, realizando esfuerzos multisectoriales (Salud, Educación, Obras Públicas, Vivienda y municipios).

Lo anterior, nos exige fortalecer la institucionalidad deportiva e impulsar políticas que permitan masificar la actividad física, junto con reinstalar programas que impulsen el deporte competitivo y de alto rendimiento.

Tras la creación del Ministerio del Deporte, existe consenso sobre las ventajas que esa nueva institucionalidad traerá al país. Una de las tareas prioritarias del nuevo Ministerio será abrir más oportunidades para que las personas realicen actividad física.

En materia de Infraestructura, se construirán 30 nuevos Centros Integrales de Deporte, instalaciones especializadas con un nuevo modelo de gestión, equipamiento y monitores capaces de apoyar la práctica deportiva de la comunidad e integrarla a actividades recreativas, particularmente al servicio de los liceos públicos de las comunas en que se ubiquen. Respecto de la administración de estos recintos (los nuevos y los ya existentes), el Ministerio de Deporte examinará caso a caso la 
institucionalidad que permita asegurar los recursos que se requieran para su funcionamiento, pudiendo recaer esta responsabilidad en el nivel comunal, regional o central. En los primeros 100 días de Gobierno estableceremos la ubicación de los 30 nuevos centros.

Para el alto rendimiento, se implementará un Laboratorio de Dopaje, un Centro de Recuperación Deportivo y se estudiarán e implementarán los requerimientos de los Centros de Entrenamiento Regional.

Crearemos el Comité Paraolímpico Chileno independiente del Comité Olímpico. Esto es reconocer el deporte como una expresión más de este grupo social. Estableceremos una línea de financiamiento para el desarrollo deportivo, competencia y alto rendimiento que permita el apoyo al desarrollo del deporte adaptado. Además, reconoceremos como equipamiento deportivo sillas de ruedas y otras ayudas técnicas del deporte adaptado para el financiamiento en los proyectos. En el deporte para personas con discapacidad se construirá y equipará el primer Centro de Actividad Física y Deportivo para población con discapacidades, dotándolo de profesionales especializados.

Crearemos el programa "Deporte en tu Comuna", en que cada municipio puede diseñar un Plan Deportivo o incorporar en su Plan de Desarrollo Comunal el deporte (incorporando los planes deportivos barriales), con el objeto que éste considere las necesidades de la comunidad organizada.

En general los niños tienen pocas instancias en que puedan desarrollar diversos deportes además del fútbol. Por eso, en los primeros 100 días de Gobierno, definiremos el plan de implementación para la reposición del programa de las escuelas deportivas, que en esta oportunidad contemplará varias disciplinas (fútbol, voleibol, basquetbol, etc.) y en las que participarán sólo en el primer año 30.000 niños y niñas.

Desarrollaremos Olimpiadas Escolares y de Educación Superior para incentivar la práctica deportiva y descubrir nuevos talentos. También desarrollaremos olimpiadas de deporte para personas discapacitadas.

Avanzaremos en la profesionalización de las dirigencias deportivas, con mayores exigencias de control y transparencia en el manejo de recursos. Enfrentaremos el desperfilamiento de funciones y roles de las instituciones ligadas al Alto Rendimiento y restableceremos el trabajo directo con los deportistas de élite, mediante una planificación de mediano y largo plazo que defina objetivos, costos, proyección a futuro y resultados, reponiendo el Programa Bicentenario. El financiamiento tendrá una mirada integral, incorporando el equipo técnico requerido y las necesidades propias de los deportistas: viáticos que aseguren su mantención, seguros adecuados, cotizaciones en previsión y salud, y aseguramiento de estudios.

Trabajaremos para lograr que Chile esté bien representado en el deporte de alta competitividad a nivel mundial. Lo que han logrado destacados deportistas que han conseguido importantes triunfos muestra que es posible y que debe ser respaldado con una política eficiente desde el Estado.

Aumentaremos y perfeccionaremos los incentivos para deportistas de élite. Generaremos programas de Atención Integral a Deportistas, que no sólo considere el aporte financiero para su preparación, entrenamiento y competencia, sino un conjunto de beneficios complementarios que permitan su mantención en el circuito durante y con posterioridad a su carrera deportiva. 


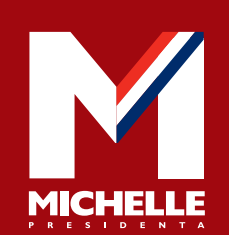

TRANSPORTE Y TELECOMUNICACIONES 

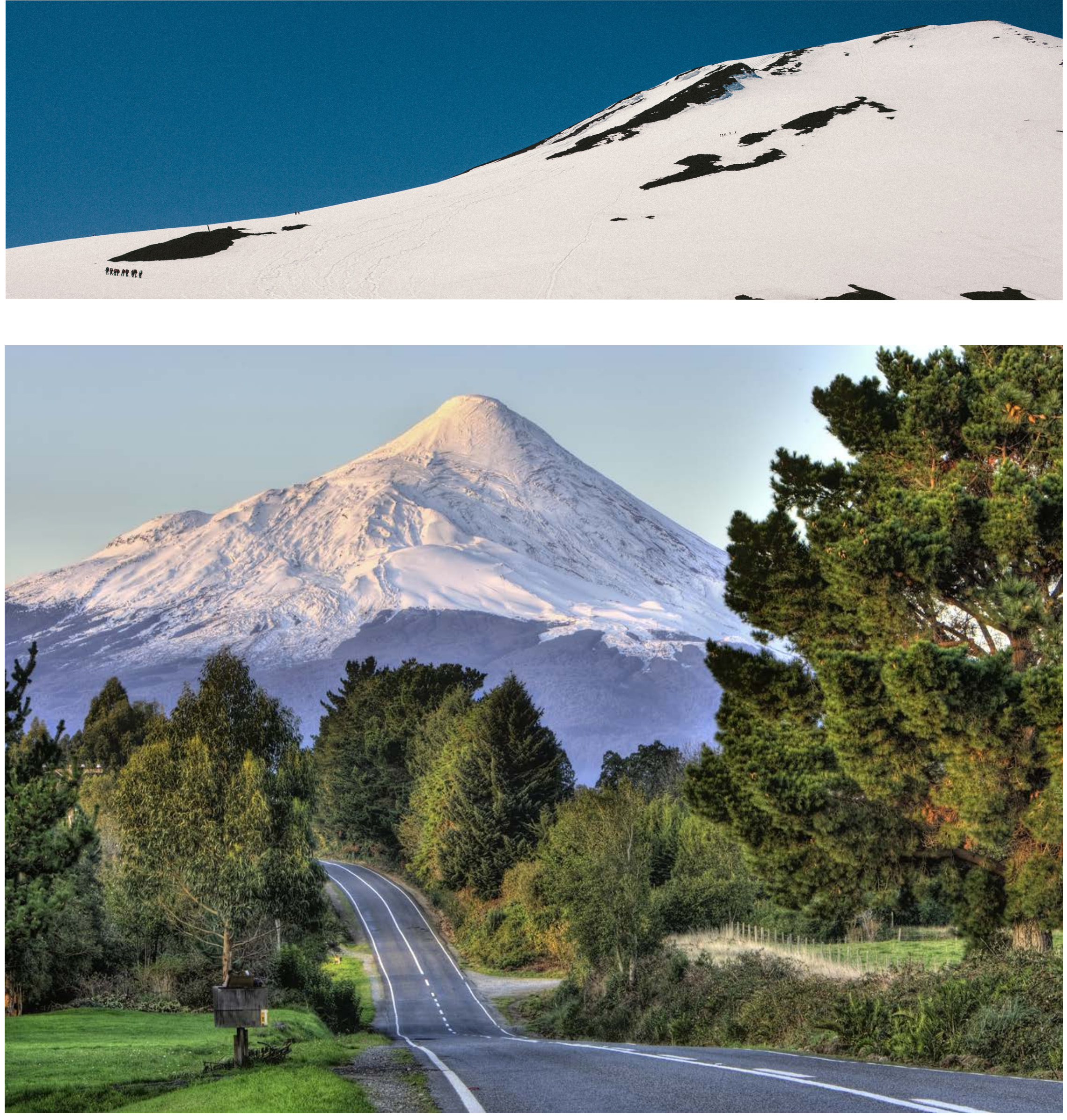


\section{TRANSPORTE Y TELECOMUNICACIONES}

La movilidad a la que aspiramos requiere garantizar un transporte digno, de calidad y accesible para todos los chilenos, pero en particular para los menos privilegiados. Ello implica potenciar el transporte público urbano e interurbano. La movilidad de los bienes y servicios también es de suma importancia por su impacto en la competencia en los mercados, así como el acceso de las empresas y hogares a bienes de alta calidad y bajos precios, en definitiva, es un factor determinante del crecimiento económico.

En términos institucionales, la infraestructura de transporte requiere de una planificación de largo plazo que considere todos los modos de transporte y la dimensión urbana en el caso de las ciudades. En lo inmediato, la coordinación delas inversiones en infraestructura de transporte, se realizará en la Comisión Interministerial de Ciudad, Vivienda y Territorio, que estará integrada por los ministros de Vivienda, quién la presidirá, de Obras Públicas, de Transporte y Telecomunicaciones, de Bienes Nacionales y el Subsecretario de Desarrollo Regional.

Por otro lado, en cuanto a la gestión de los sistemas de transporte en las ciudades, crearemos la Autoridad Metropolitana de Transportes para cada área metropolitana.

Procuraremos que las personas y también los bienes se transporten de la forma más eficiente posible desde una perspectiva social, fomentando el empleo de aquellos medios que generen menores tasas de contaminación, congestión y accidentes. Invertiremos la totalidad de los recursos para subsidiar el transporte público aprobados por ley, tanto para las comunas donde opera el Transantiago como para el resto del país. De este modo financiaremos programas de renovación deflota, transporteescolary subsidio para transporte en zonas aisladas, además de incrementar las inversiones en infraestructura vial.

Aceleraremos las inversiones de superficie del Transantiago, tanto en corredores o vías exclusivas como de infraestructura operacional, avanzando en el desarrollo de infraestructura vial y tecnologías de control de flota en Santiago, permitiendo así aumentar la velocidad de estos servicios, disminuyendo los tiempos de espera y de viaje de los usuarios. Se priorizarán medidas de gestión de tráfico, así como inversiones en paraderos y estaciones de intercambio.

Mejoraremos la gestión del sistema mediante un control acucioso de la operación y de las responsabilidades contractuales de los operadores. Hay que trabajar en conjunto con los operadores para mejorar recorridos y la calidad de servicio además de reducir los niveles de evasión.

Mejoraremos la calidad de servicio, entendida no sólo como la disminución de los tiempos de viaje, sino que también con aspectos de seguridad, limpieza y con un sistema de información ajustado a la realidad de quienes lo usan.
Agilizaremos el desarrollo de los proyectos de trenes suburbanos de acercamiento, Melipilla-Alameda y analizaremos otros que puedan ser socialmente rentables, y los asociaremos al mismo medio de pago de los servicios del Transantiago. Junto con acelerar la construcción de las líneas 6 y 3 del Metro, se iniciarán los Estudios de Factibilidad, que consideren la ampliación de la línea 3 hacia Quilicura y la línea 2 hacia El Bosque y San Bernardo.

Iniciaremos los estudios económicos, de ingeniería y rentabilidad social de proyectos regionales para definir su implementación: una estación intermodal en Valparaíso que conecte Merval con los servicios de Trolebuses en Estación Barón; medio de pago único y electrónico en Gran Valparaíso-Viña y Concepción; la introducción de una solución de transporte masivo moderno de buses o tranvía en Antofagasta; introducir una solución de alto nivel, tranvía u otro, en Concepción, en conexión con el servicio de trenes, potenciando el uso actualmente deprimido de este servicio más la ampliación del ferrocarril suburbano Biotrén; planes de reordenamiento vial en las capitales de cada región; habilitación de programas de gestión de tránsito que prioricen al transporte público, en ciudades como Temuco, Valdivia, Puerto Montt, La Serena y otras; potenciar los actuales programas de transporte escolar y subsidios para transporte en zonas aisladas, ambos programas financiados con la ley de subsidio nacional al transporte público; mejoramiento al sistema de transporte público de buses en ciudades regionales mediante reformas que disminuyan la antigüedad promedio de la flota, regulen la frecuencia y horarios de los servicios, por medio de sistemas basados en localización automática de vehículos, y que reduzcan la tarifa pagada por los adultos mayores. Al igual que en Santiago, introduciremos en los proyectos viales del programa de concesiones del MOP la dimensión de transporte público. Adicionalmente, potenciaremos los actuales programas de transporte escolar y subsidios para transporte en zonas aisladas.

En materia de combate a la congestión formaremos un panel de expertos, con participación de organizaciones ciudadanas, políticas, y empresariales, que prepare un paquete de medidas "pro-movilidad" en el año 2014 .

Fomentaremos el uso de modos no motorizados de transporte, por sus positivos impactos en la salud, la descongestión y descontaminación de nuestras urbes. Estableceremos una política y programas que mejoren la accesibilidad en las ciudades para los peatones. Estableceremos un Plan Maestro de inversiones en Ciclovías y otros modos de transporte no motorizado, a nivel nacional, tanto para las ciudades como en zonas rurales. Se construirán 100 kilómetros de ciclovías de alto estándar en todo el país y triplicaremos la capacidad de estacionamientos en las estaciones del MERVAL, Biotrén y Metro de Santiago, entre otras medidas. 
Es necesario avanzar en una modernización del transporte de carga. Ello implica promover una consolidación de un sector que se caracteriza por su atomización, alta informalidad y baja capacidad utilizada. Sería beneficioso avanzar a un modelo de empresas de logística que ofrezcan servicios integrados, respaldando una mayor asociatividad y tecnologización de los microempresarios existentes. Para aumentar la eficiencia logística del traslado de la carga en la macro zona central y abaratar los costos de transporte de mercaderías, evaluaremos el proyecto de construir un centro de distribución de carga al sur de Santiago conectado con los puertos mediante trenes, junto con estudiar su financiamiento y dependencia institucional. De este modo también se reducirá la congestión vial y los costos de mantención de carreteras en la zona.

En materia de telecomunicaciones reduciremos la brecha digital y aumentaremos la conectividad, para que los beneficios de la sociedad de la información estén disponibles para todos los chilenos. Así, los ejes centrales en esta materia estarán en proteger al consumidor, generar mayor inclusión en el acceso a servicios de telecomunicaciones e impulsar la competencia en esta industria.

Seguiremos del lado de los consumidores. Reforzaremos las facultades de los organismos fiscalizadores, aumentando el personal destinado a estas labores y estudiaremos modificaciones de ley para endurecer las multas y simplificar el proceso de cargos ante un deficiente servicio. Impondremos estándares internacionales que permitan implementar normativas técnicas a los servicios de telecomunicaciones, acordes con nuestro grado de desarrollo. Incluiremos nuevos controles en los contratos de servicios: impedir la inclusión de cláusulas abusivas, aprobación previa de la autoridad para todo contrato de los servicios que se comercialicen en el mercado, obligación de incorporar estándares de calidad de servicios y fórmulas de compensaciones en los contratos de los servicios, junto con mejorar la transparencia en el contenido de cada contrato.

Para el acceso a Internet y a banda ancha estableceremos una normativa que permita un amplio acceso de la población, con obligaciones expresas para las empresas, entre otras, de servicio en su zona de concesión, atención de usuarios y cumplimiento de normativas técnicas.

Es sabido que la televisión digital terrestre ha sido materia de una ardua discusión por casi 5 años en el Congreso, pero aún resta el desafío mayor que es la digitalización total del servicio en un plazo de 5 años. Esta tarea se ha ejecutado en todos los países desarrollados, demandando grandes esfuerzos del sector privado como estatal, destinados al cumplimiento de los plazos de digitalización, como también de la adopción de la tecnología por parte de los ciudadanos.
Por tanto, velaremos por el cumplimiento de las normas que se han impuesto al mundo privado en esta materia y haremos que TVN se transforme en un actor relevante en el empuje de la digitalización y en la apertura de nuevos actores, por la vía de prestar servicios de infraestructura a terceros, mejorando con ello el pluralismo y calidad del derecho a la libertad de expresión, al posibilitar que existan más actores que puedan acceder a informar y entretener a las personas.

Licitaremos concesiones de infraestructura de fibra óptica - de acceso abierto a todos los proveedores de telecomunicaciones- en comunas de menoresingresos delasáreas metropolitanas del país (Gran Santiago, Gran Concepción y Gran Valparaíso). Estas redes permitirán a los proveedores de servicios competir por ofrecer banda ancha de alta velocidad telefonía y televisión a un precio menor al actual. En los establecimientos públicos, estableceremos acceso a Internet de alta velocidad, para todos los y las estudiantes en sus aulas, como también la posibilidad de contar con WiFi gratuito en el mismo recinto. Se pondrá especial énfasis en el desarrollo de la infraestructura necesaria para la conectividad, nacional e internacional, vía fibra óptica para zonas extremas del país y reforzamiento de enlaces satelitales de los territorios insulares.

La Ley que creó la nueva figura de las radios comunitarias ciudadanas, enviada al Congreso en 2007, ha sido un avance importante para estos medios. Sin embargo y en la práctica, esta disposición todavía no es una realidad, ya que el proceso de transformación de las antiguas radios de mínima cobertura, como la disposición de una franja del dial destinado a las radios comunitarias se ha ejecutado con lentitud. Con el objeto de acelerar este proceso, estudiaremos la ampliación del fondo de desarrollo de telecomunicaciones a las radios comunitarias.

En materia de competencia en la industria de las telecomunicaciones, modificaremos el régimen tarifario vigente, concentrado exclusivamente en los servicios públicos de telefonía para que, con previo pronunciamiento del Tribunal de Defensa de la Libre Competencia, se puedan fijar otras tarifas destinadas a público final o a otros proveedores de telecomunicaciones, entre ellas las de acceso a internet. Estableceremos un organismo independiente y colegiado que resuelva divergencias que se presenten entre las partes en el proceso de fijación de tarifas.

Adicionalmente, modificaremos el régimen de concesiones para que se pueda prestar múltiples servicios a través de una misma red. Promoveremos el uso compartido de infraestructura, lo que ayudará a bajar el impacto en nuestras ciudades, como también mejorar la competencia en este mercado, siendo necesario incentivar la desintegración vertical en el mercado, separando el rol de proveedor de infraestructura de la de servicios. 


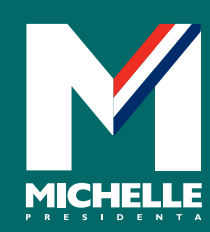

MUNICIPIOS 


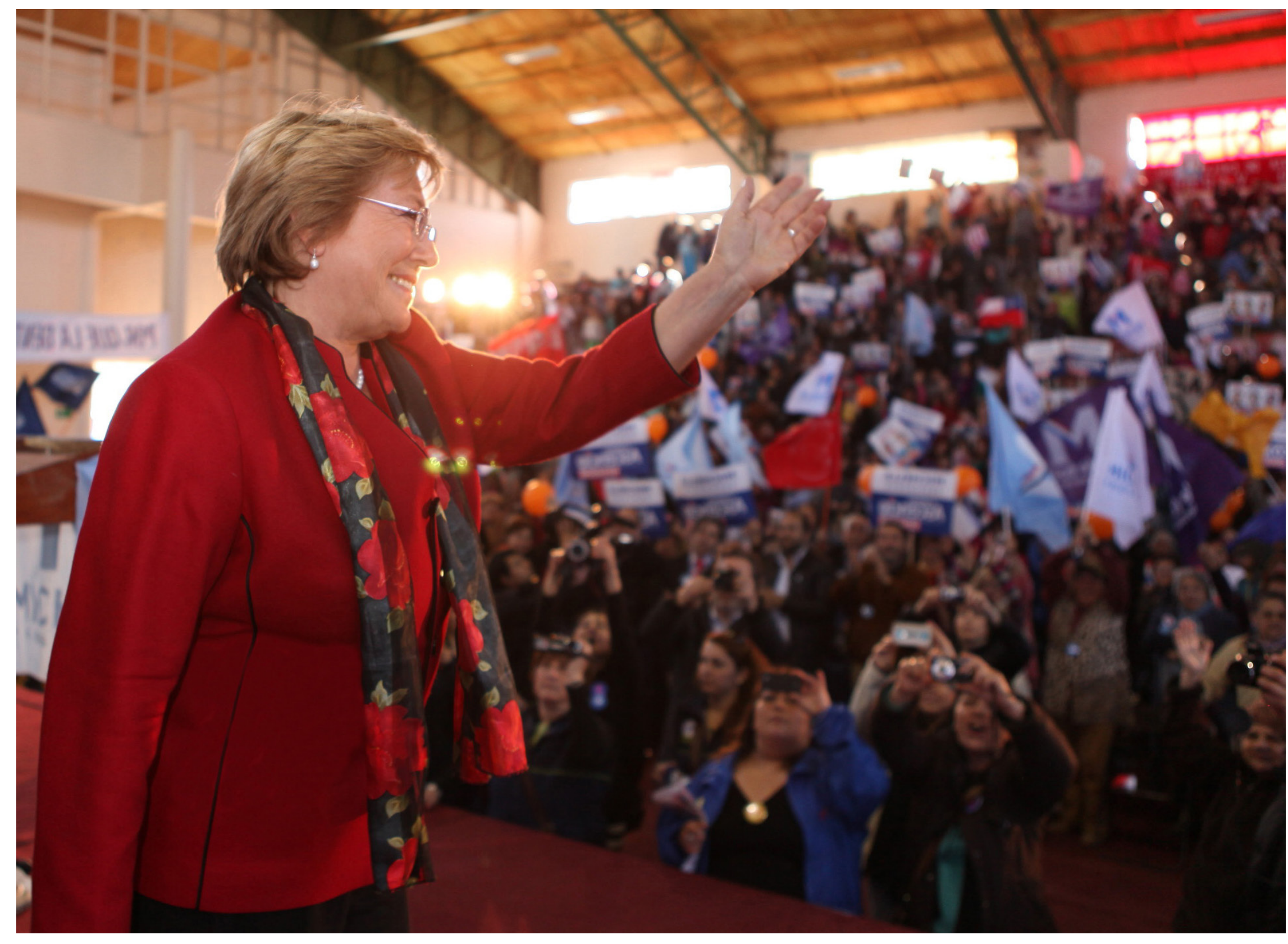




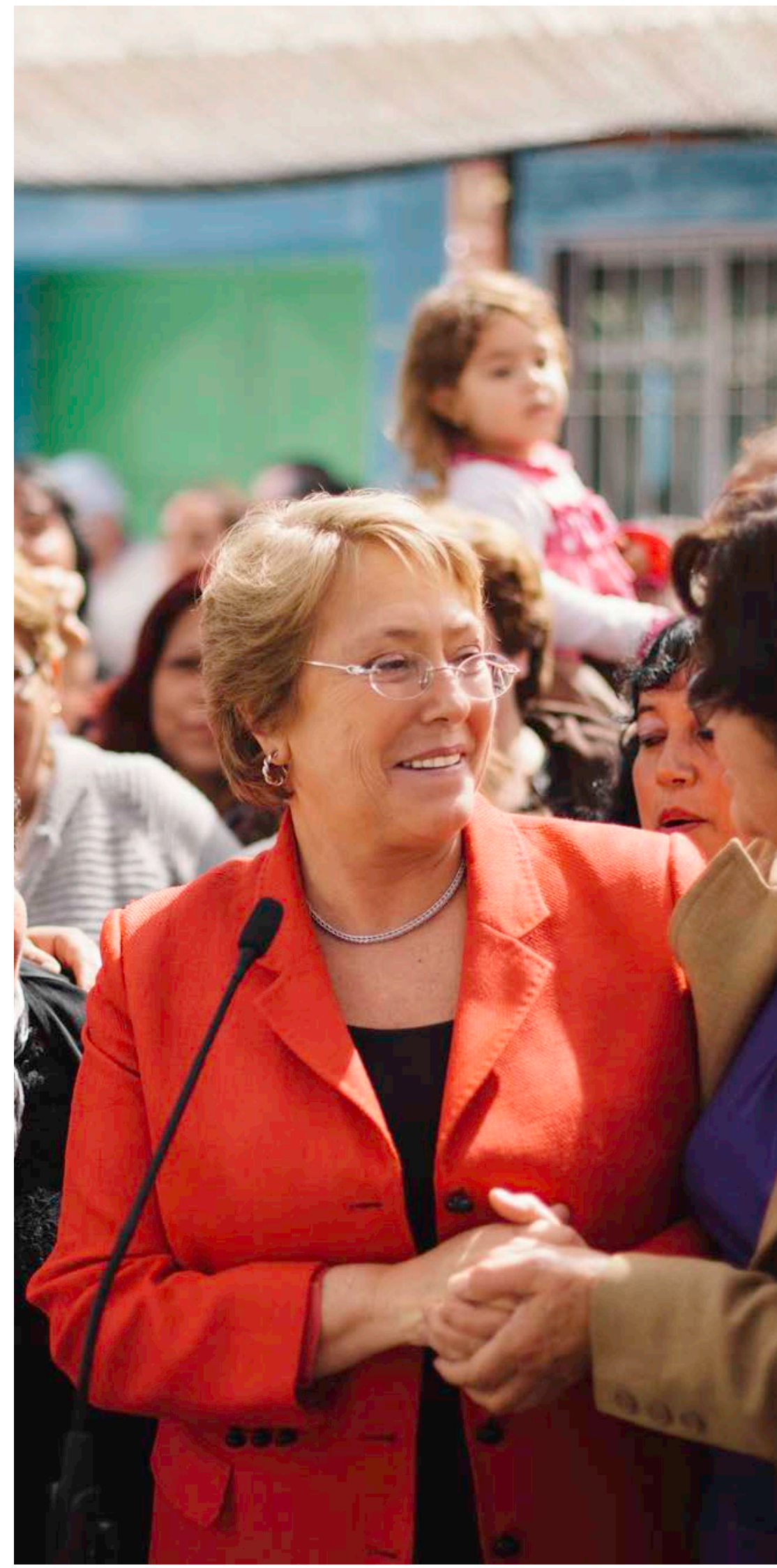

\section{MUNICIPIOS}

Los desafíos que enfrentamos en la actualidad a nivel local nos exigen interpretar adecuadamente el momento político y los cambios que la sociedad ha experimentado, más aún cuando son los municipios, en cuanto instituciones con mayor cercanía a los ciudadanos, los que están llamados a ser el primer enlace en este esfuerzo.

En materia Institucional, el objetivo estratégico es que los municipios pasen de cumplir una función exclusivamente de administración, a la constitución de verdaderos Gobiernos Locales, ampliando las actuales funciones que desarrollan y entregándoles un mayor grado de autonomía en la gestión. Esto es posible, mediante el traspaso de competencias, recursos propios, autonomía administrativa y facultades.

En primer lugar, estudiaremos la constitución de un conjunto básico de servicios municipales garantizados con un determinado nivel de calidad, sujeto a indicadores objetivos auditables, que permitan romper las inequidades territoriales y sociales que afectan a los habitantes de las distintas comunas. Para hacer esto posible se requerirá una progresiva transferencia de competencias y recursos desde programas y servicios nacionales al nivel local.

Una de las demandas más importante de los ciudadanos, las organizaciones sociales en los territorios, las regiones y también los municipios, es participar en la toma de decisiones sobre los temas que les afectan o incumben directamente.

Avanzar en esta dirección no es tarea fácil. Para ello se requiere impulsar cambios culturales profundos y conformar nuevas conductas y/o prácticas políticas, tanto en la dirigencia político-social, como en los ciudadanos, promoviendo una cultura de derechos y deberes.

Adicionalmente, debemos perfeccionar y ampliar los mecanismos de participación comunal, mejorando la legislación que establece los Consejos Comunales de Organizaciones de la Sociedad Civil, estableciendo como política pública los Fondos Concursables y presupuestos participativos, ampliando el ámbito de acción de las Oficinas de Información y Reclamos, mejorando la regulación sobre consultas ciudadanas y plebiscitos. 
Debemos fortalecer el Concejo Municipal, entregándole mayores facultades, atribuciones y también responsabilidades y otorgarles a los concejales la responsabilidad de acompañar y monitorear una o más áreas del quehacer municipal con la obligación de rendir cuentas.

Sobre la dotación y el estatuto jurídico de los funcionarios municipales se propone retomar el debate sobre el Art. 121 de la constitución que permite a los alcaldes descentralizar la gestión de personal de acuerdo a las particularidades de cada municipio, impulsando la norma legal que otorgue la facultad de revisar la estructura de plantas. La discusión sobre el Art. 121, debe incorporar la revisión de las normas laborales de los funcionarios municipales, con el debido resguardo de la carrera funcionaria y participación de todos los estamentos, permitiendo que éstos trabajen en condiciones de dignidad y de resguardo de sus derechos como trabajadores.

En el ámbito de la modernización promoveremos el asociativismo a nivel provincial y regional para la solución de problemas comunes y para abordar las cuestiones propias del gobierno de áreas metropolitanas. Debemos impulsar una agenda digital local, que avance en lograr una conexión de banda ancha en las comunas e incorpore plenamente las Tecnologías de la Información y las Comunicaciones (TICs) a la gestión municipal.

Respecto de la institucionalidad, debemos implementar una nueva estrategia con los municipios rurales que permita desarrollar los instrumentos necesarios para superar las dificultades y necesidades especiales que presentan los ciudadanos del mundo rural.

En materia de Financiamiento, los municipios requieren de más recursos. Para ello se impulsará un conjunto de medidas entre las que destacamos: aumentar los recursos del Fondo Común Municipal (FCM), estudiando el fortalecimiento del aporte público $\mathrm{y}$ avanzando sustantivamente en la descentralización de decisiones de inversión; estudiar compensaciones, con cargo al presupuesto nacional, por las exenciones de diversos tributos de beneficio municipal, por ejemplo, por exención del pago de los derechos de aseo, del pago de contribuciones, o por la construcción de viviendas sociales, materias que gravan en mayor medida a los municipios más pobres del país; corregir, mediante una modificación a la Ley de Rentas Municipales, las discriminaciones e injusticias que existen, en particular para que los grandes contribuyentes financien adecuadamente las prestaciones y servicios que reciben de los municipios, $\mathrm{y}$; asegurar normativamente que cualquier nueva función o tarea que se le asigne a los municipios deberá contemplar el financiamiento respectivo.

En materia de Ciudad y Territorio, el municipio como gobierno local debe velar por garantizar la calidad del conjunto de servicios que entrega a la ciudadanía. Para ello, será fundamental la participación de los ciudadanos. La ciudadanía demanda una Comuna Limpia y verde. Trabajaremos una política pública para la gestión de residuos sólidos domiciliarios y basuras sobre la base de mantención de la limpieza de calles y espacios públicos, incorporando un concepto integral de manejo de residuos, incentivando formas de recuperación, reutilización, reciclaje y gestión integral de residuos voluminosos, eliminando los botaderos ilegales.

Además, crearemos un nuevo programa especial local con nuevos recursos, donde las comunas con mayor presencia rural indígena, que además sean rezagadas y vulnerables, podrán financiar apoyos de profesionales y técnicos para llevar adelante los proyectos locales de desarrollo.

Los chilenos quieren vivir en una Comuna Amable. Impulsaremos la recuperación y conservación adecuada de espacios públicos y áreas verdes desde el MINVU en coordinación con los municipios.

Impulsaremos el desarrollo de una comuna ambientalmente sustentable por lo que trabajaremos en la instalación de una cultura de sustentabilidad ambiental con los ciudadanos, para que sean conscientes de los valores y oportunidades dados por su medio ambiente, y de los derechos y responsabilidades.

Promoveremos el derecho de los ciudadanos a vivir en ciudades o localidades más seguras. Esto implica fortalecer el rol de prevención social y situacional que los municipios ejercen, para lo que incorporaremos la seguridad ciudadana como un eje transversal y con preponderancia en el organigrama municipal. 


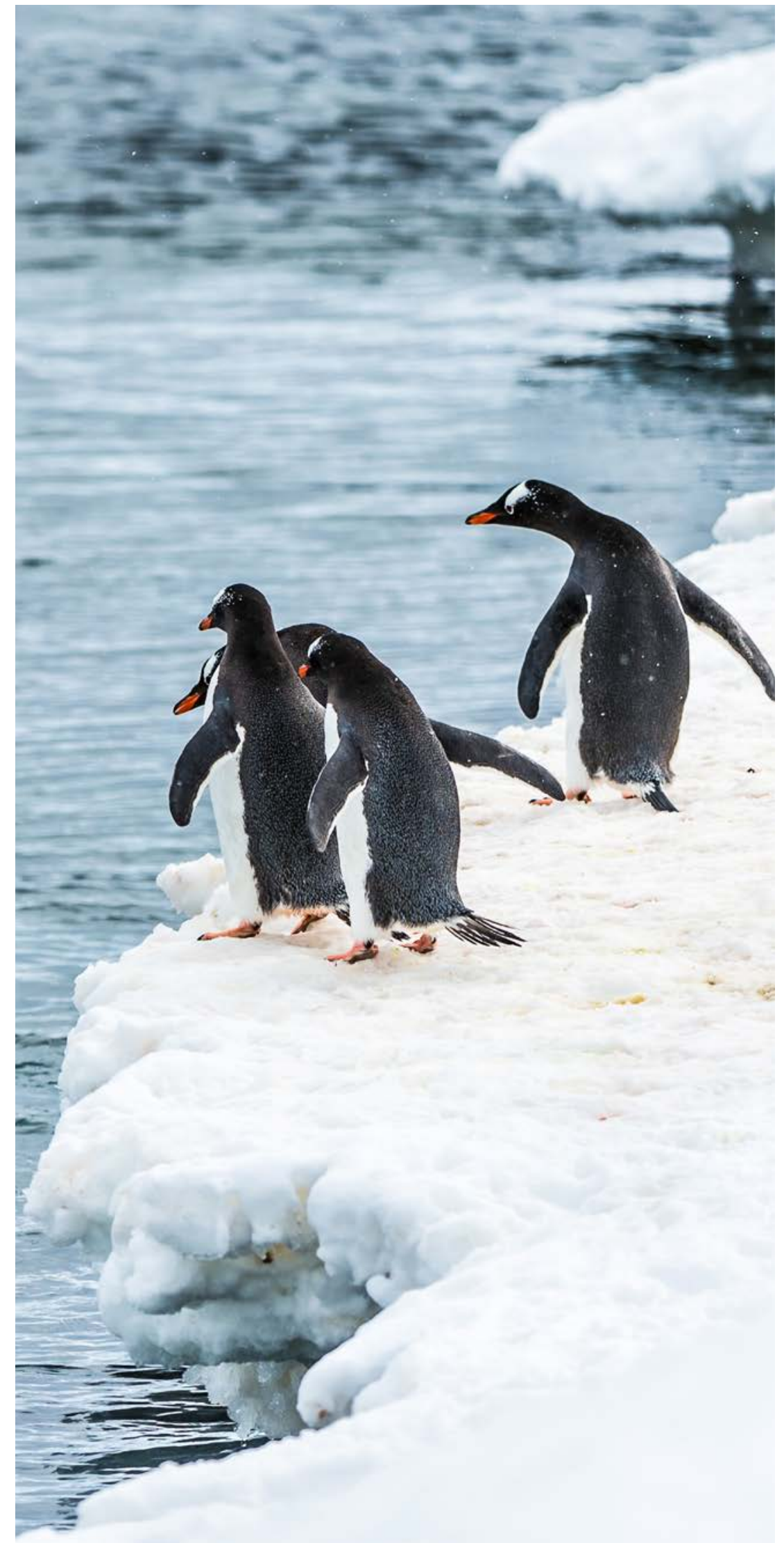

\section{DEFENSA}

La Defensa Nacional transita por una etapa nueva de su historia, y puede y debe realizar un aporte sustantivo al país. Lo anterior es posible porque entre 1990 y el año 2010, ésta experimentó un proceso de reforma y modernización institucional importante, en el contexto de la expansión de las libertades y profundización de la democracia en Chile mediante políticas públicas que aspiraban a un amplio respaldo político y ciudadano en un contexto democrático. La consolidación de la gobernabilidad democrática sobre la defensa, sumado a su control por parte de la sociedad, mediante el fortalecimiento de las instituciones democráticas, son los ejes sobre los que se avanzó durante dicho período. La normalidad democrática no sólo ha reimpulsado y reforzado la relación entre FFAA y sociedad chilena, sino que ha estimulado la modernización de las instituciones militares, de su equipamiento, sistemas y contenidos de enseñanza, fortaleciendo su aporte sustantivo a la política exterior.

Sin embargo, el proceso de reformas democratizadoras y modernizadoras está incompleto y, se podría señalar, ha experimentado un retroceso. A partir del 2010, año que entró en vigencia la Ley $\mathrm{N}^{\circ} 20.424$, Estatuto Orgánico de la Defensa Nacional, algunas reformas continuaron, pero la mayor parte de éstas se estancaron $\mathrm{y}$, en algunos aspectos, hubo retrocesos como resultado de la gestión de la autoridad política realizada entre el 2010 y el 2013.

Durante el período 2014-2018, la política de Defensa Nacional tendrá como objetivo principal de mediano y largo plazo, generar una Comunidad de Seguridad en América del Sur que garantice la paz y elimine definitivamente la amenaza de la guerra, siendo el Consejo de Defensa de UNASUR la institución para avanzar en esta materia. En el mismo sentido, se fomentará la cooperación y extensión de medidas de confianza mutua y de prevención de crisis con nuestros vecinos y en la región, así como también el compromiso colectivo y verificable de una política de plena transparencia de los presupuestos y las adquisiciones militares entre los países de la región. Por otra parte, se profundizará con fuerza el proceso ya tan avanzado de diálogo, cooperación e integración con Argentina y se 
extenderá a Perú; y en la medida en que los objetivos de tal política se materialicen, se podrá revisar el concepto de disuasión, y avanzar hacia un nuevo concepto de política de defensa centrado en la cooperación mutua, la integración y el diálogo.

Con Bolivia lo fundamental será retomar el camino del diálogo, iniciado en 1999, y el clima de confianza mutua conseguido durante el período 2006-2010. La plena normalización de las relaciones con Bolivia es un objetivo al que aspiramos. Asimismo, buscaremos dar pasos significativos para la proyección de las relaciones entre América del Sur y el Asia Pacífico.

En el ámbito doméstico nuestro objetivo fundamental será retomar con ímpetu las reformas institucionales para el desarrollo de una Defensa Nacional mejor preparada para las tareas que le entregue la autoridad civil, logrando ser más transparente, y más eficiente y eficaz. En este sentido, se considera necesario el fortalecimiento del mando del Jefe del Estado Mayor Conjunto en lo relativo a su empleo en tiempos de paz incluso en instancias tales como la preparación, prevención y reacción ante emergencias, así como de su responsabilidad social.

Asimismo, el financiamiento de la Defensa Nacional debe ser consistente con el funcionamiento del sistema democrático en plenitud. De esta forma se enviará una indicación sustitutiva al Congreso Nacional respecto del proyecto de ley que deroga la ley reservada del cobre en la que se establezca que la asignación de los recursos para el financiamiento de la Defensa Nacional se realizará mediante la formulación de una planificación presupuestaria cuatrienal, que contemple el financiamiento de los programas y proyectos de inversión y los gastos de operación y mantenimiento de equipamiento. El proyecto de Ley de Presupuestos de cada año incorporará la anualidad correspondiente de la planificación presupuestaria cuatrienal. Además, y como un reforzamiento del control democrático sobre las instituciones de la Defensa Nacional, el Congreso Nacional deberá ser informado respecto de cómo se ejecuta el gasto en defensa y de cómo se desarrollan e implementan los programas y proyectos a los cuales se les asignaron partidas presupuestarias, así como todo lo relativo al proceso de adquisiciones en sus aspectos reservados y secretos.

De la misma forma, la indicación sustitutiva contendrá la eliminación de los denominados "pisos" de financiamiento, cuya existencia es injustificada, especialmente a la luz de las asignaciones que la defensa ha obtenido, las que superan con creces a aquellos "pisos". Por otra parte, se eliminarán los excedentes de uso exclusivo de la Defensa y la inflexibilidad en su administración, con lo que se optimizará la eficiencia financiera y presupuestaria.

Chile debe cumplir a cabalidad las obligaciones internacionales de derechos humanos. Para ello, tal como lo señalamos en el capítulo de derechos humanos, reformaremos la competencia de la Justicia Militar, de manera tal que las causas con civiles víctimas de delitos cometidos por militares y carabineros sean conocidas por tribunales ordinarios. Se avanzará desde el actual modelo de fuero militar hacia uno nuevo caracterizado por la igualdad de las garantías procesales entre ciudadanos civiles y uniformados, con una judicatura letrada y plenamente independiente de la estructura de mando militar.

Concluiremos la modernización de la carrera militar, terminando con las distorsiones previsionales. Consolidaremos la inclusión de género y de la diversidad sexual. También reforzaremos el rol de la auditoría ministerial y fortaleceremos el control de gestión y la transparencia, eliminando conflictos de interés y asegurando el cumplimiento normativo en adquisiciones y relaciones con proveedores.

Las FFAA son parte fundamental de la República y, como tal, de la estructura de la comunidad nacional y de sus instituciones, mereciendo nuestroapoyoypreocupación por su desarrollo institucional permanente, respeto y colaboración con sus mandos, convencidos que éstas, a su vez, harán de mejor manera su importante aporte a la vida nacional, según lo instruya la autoridad política de la Nación. 


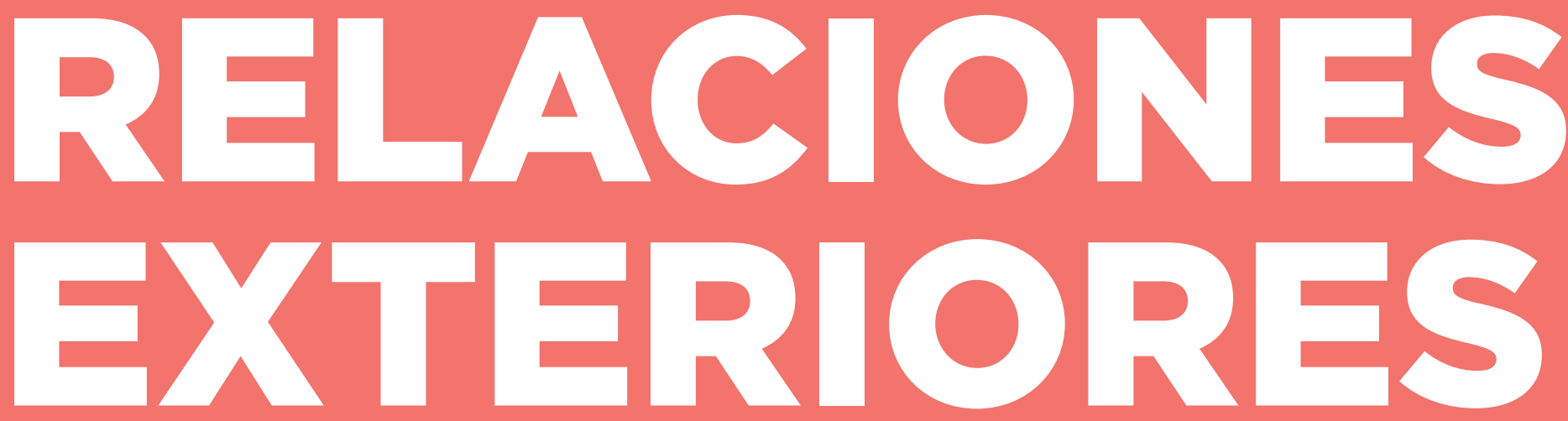




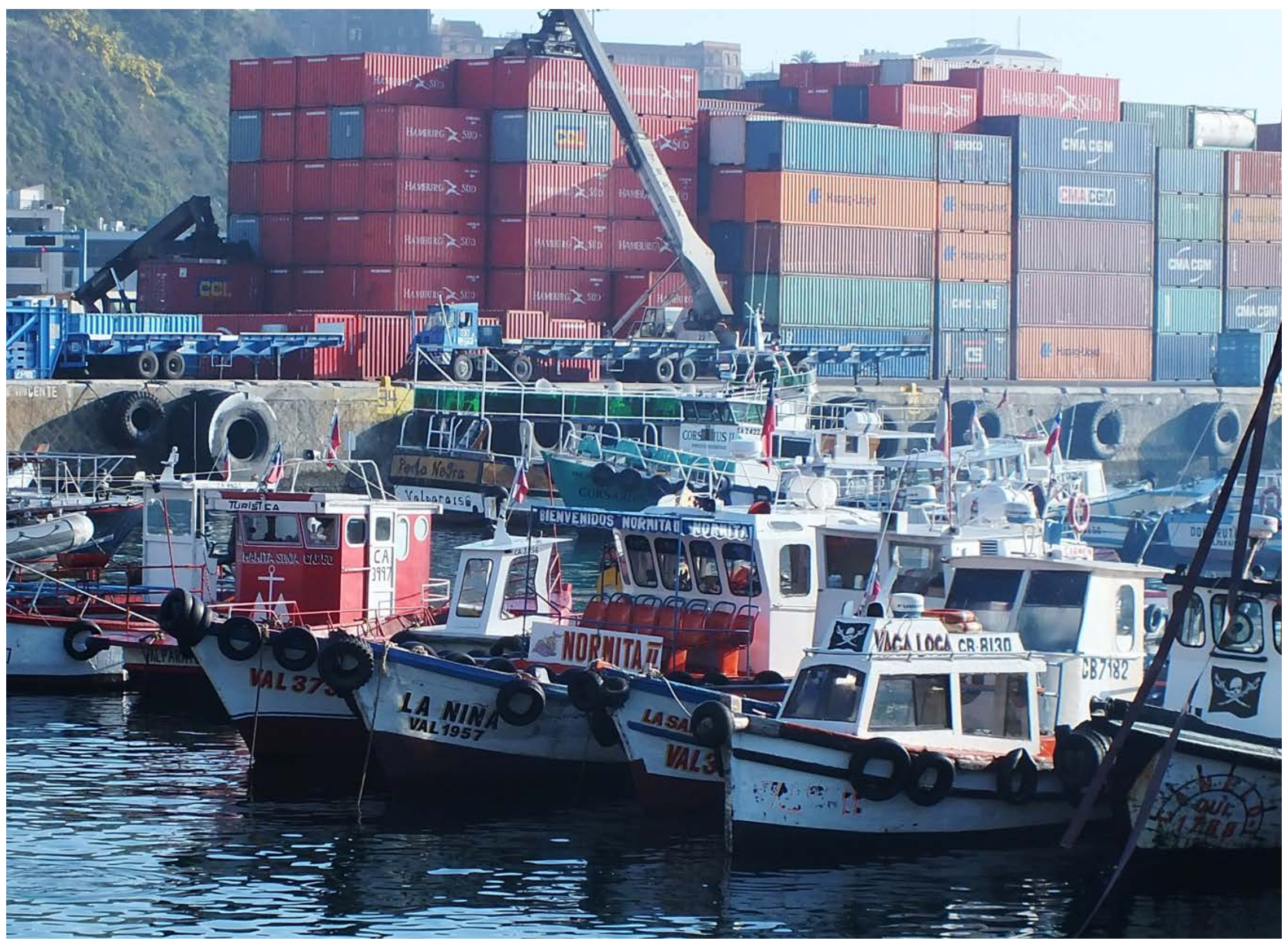




\section{RELACIONES EXTERIORES}

El escenario económico internacional ha sido, en la última década muy favorable para América Latina y en particular para Chile, aunque es probable que sea un poco menos auspicioso en los años que vienen. El fracaso de la Ronda de Doha de la OMC, así como las dinámicas propias de la globalización, está llevando a la conformación y ampliación de grandes bloques económicos regionales.

La negociación iniciada entre EE.UU y la Unión Europea, la creciente articulación de ASEAN con China, Japón y Corea, y en nuestra región la mayor integración entre América del Norte y Centro América son manifestaciones de dicha tendencia. Ello hace más evidente el déficit de integración entre los países sudamericanos y la dispersión de iniciativas que no logran construir un horizonte común de convergencia.

El cambio de estrategia internacional de los EEUU para privilegiar la relación con Asia del Pacífico, ha puesto fin a décadas de prioridad de la Alianza Atlántica, no obstante de la negociación comercial y de inversiones iniciada con la Unión Europea.

El eje de la política internacional del siglo XXI está en el Pacífico. La política exterior de Chile en el próximo gobierno debe contribuir a lograr una mayor unidad regional. Debemos fortalecer nuestra participación en los distintos mecanismos de integración actualmente existentes en América Latina $y$, en especial en América del Sur, así como constituir a este bloque de países como una región. Hay que impulsar puentes de entendimiento por sobre diferencias ideológicas y subregionales. UNASUR debe constituirse en un punto de confluencia de las iniciativas de integración de América del Sur, mientras CELAC debe ser una instancia de coordinación política en la región.

En este marco, valoramos los esfuerzos de integración en la Alianza del Pacífico, pero nos abocaremos a orientar nuestra participación en esta iniciativa en una perspectiva no excluyente o antagónica con otros proyectos de integración existentes en la región en los que Chile también participa. Asimismo, recuperaremos el impulso inicial de la Alianza, como una plataforma comercial para proyectarse colectivamente en la región asiática.

Chile ha perdido presencia en la región, sus relaciones vecinales son problemáticas, se ha impuesto una visión mercantil de nuestros vínculos latinoamericanos y se han ideologizado las opciones de inserción externa. Nuestro país debe recuperar su papel de promotor activo de la convergencia regional, confirmando su compromiso con una política de integración regional activa y vinculante. Chile debe valorizar positivamente la diversidad que caracteriza a América Latina y enfrentar efectivamente los desafíos que plantean nuestras relaciones vecinales.

La articulación de relaciones más estrechas, pero flexibles en intensidad, con la región del Asia Pacífico, debe ser un objetivo prioritario de la política exterior de Chile. Más aún si se constata que la importancia de esta región se ve reforzada por la contribución estratégica que ésta podría aportar a las proyecciones de nuestro país en América Latina y el Caribe, en general, y con América del Sur, en particular. Para ello, Chile debe consolidar su condición de "país puerto" y "país puente" entre las naciones latinoamericanas del Atlántico Sur y el Asia Pacífico, lo que requiere mejorar la interconectividad, aumentar la capacidad de nuestros puertos y perfeccionar nuestros servicios. Chile está en condiciones de desempeñar un rol de vínculo entre las economías de ambas orillas del Pacífico, aprovechando las fuertes relaciones comerciales que tenemos en la región, así como nuestra extensa red de tratados de libre comercio. Por ello, favoreceremos vínculos colectivos latinoamericanos con ASEAN.

Tenemos preocupación ante la urgencia por negociar el acuerdo Transpacific Partnership (TPP). Para velar por el interés de Chile se debe hacer una revisión exhaustiva de sus alcances e implicaciones. Para nuestro país es prioritario impedir aspectos cuestionables que pudieran surgir en este acuerdo, pues, mal manejado, se transformaría en una renegociación indirecta de nuestro TLC con EEUU, debilitando acuerdos ya establecidos en materia de propiedad intelectual, farmacéuticos, compras públicas, servicios e inversiones, o llevaría a la instalación de nuevas normas en el sector financiero.

Nuestras relaciones con la Unión Europea y con EEUU han ido madurando en todas sus expresiones, en base a los diversos Tratados y Acuerdos, entre los que se destacan el de Asociación y el TLC, respectivamente. Reimpulsaremos nuestro diálogo político, económico y de cooperación con la UE, con una nueva agenda centrada en la ciencia, tecnología, investigación e innovación, para el desarrollo de nuestra competitividad internacional, con participación de las pymes, las universidades, Conicyt y Agci. Con los Estados y el gobierno central de los EEUU buscaremos una ampliación de la calidad de la cooperación en áreas similares a las señaladas. 
Chile requiere de instituciones internacionales fuertes y respetadas por la comunidad internacional, por lo que deberemos incrementar nuestro rol y actividad en esos organismos. El país será miembro del Consejo de Seguridad de la ONU por dos años, lo que nos plantea una oportunidad para expresar nuestra opinión y nuestra acción en pro de la Paz y Seguridad, así como de los Derechos Humanos y la Equidad a nivel internacional.

Una concepción moderna e incluyente de nuestra acción internacional requiere de un Sistema Integrado de Política Exterior, y nos muestra que ésta ha dejado de ser un ámbito exclusivo de las cancillerías. En el caso de las regiones del país, la actividad internacional ha ido adquiriendo legitimidad y un trabajo bastante generalizado en el exterior por parte de sus autoridades. En paralelo, existen iniciativas de vinculación regional públicoprivadas, que realizan universidades, organizaciones sociales $\mathrm{y}$ asociaciones de gremios productivos, que buscan promover sus propios intereses en el exterior de modo independiente y autónomo.

Se repondrán mecanismos de consulta y coordinación con el sector productivo, las organizaciones de trabajadores, el Congreso y la sociedad civil en general, de manera que las definiciones y líneas de trabajo llevadas a cabo en el ámbito de las relaciones económicas internacionales, recuperen su condición de Política de Estado con una legitimidad fundada en una amplia participación.

Para el cumplimiento de los objetivos señalados, se debe instaurar una nueva diplomacia que exige una Cancillería moderna, con flexibilidad y capacidad de respuesta a los desafíos del siglo XXI, contando con un personal especializado y una carrera funcionaria basada en capacidades y mérito, acompañada de un diseño y visión estratégica que genere el ya mencionado Sistema Nacional de Política Exterior.

Las migraciones internacionales han adquirido una importancia creciente en Chile. Según estimaciones del Departamento de Extranjería y Migración del Ministerio del Interior, la población inmigrante en Chile se sitúa en torno a las 400 mil personas, mientras la población chilena residente en el extranjero, se estima en 860 mil.

Desarrollaremos una política y cultura migratoria basada en la promoción y aplicación de los instrumentos internacionales ratificados por Chile sobre Derechos Humanos y de las Personas Migrantes, lo mismo que en los principios de Política Migratoria acordados en el marco de la Conferencia Sudamericana de Migraciones, asumiendo el Estado de Chile un rol activo en acciones de asentamiento humanitario, residencia regular, protección de las victimas de Trata de Personas y desarrollo de las personas migrantes.

En relacióna los chilenos en el exterior, dotaremosa los organismos del Estado de un rol activo en materia de reconocimiento efectivo de los derechos ciudadanos de los chilenos y chilenas residentes en el exterior, así como el aumento del vínculo permanente con nuestro país de las comunidades chilenas de todo el mundo.

Por lo anterior, evaluaremos modificaciones la legislación migratoria quecambieelenfoqueactual, basadoen una perspectiva de seguridad y de gestión de mano de obra inmigrante, por una perspectiva de inclusión, integración regional y un enfoque de derechos que aseguren la inserción efectiva de esta población al país y que permita una coordinación dinámica, cooperadora y eficiente de todos los entes públicos relacionados con la política migratoria.

Fortaleceremos la estructura pública de extranjería y migraciones en las regiones y comunas de mayor presencia migratoria con el fin de diseñar e implementar políticas públicas tendientes a lograr una mayor y más rápida inclusión de los inmigrantes.

Acercaremos los servicios del Estado a los chilenos en el exterior, a través de la red consular, buscando su representación en las instancias de participación ciudadana y asegurar el pleno ejercicio de sus derechos ciudadanos en su país de residencia.

Nos comprometemos a impulsar la tramitación, hasta su aprobación, de un proyecto de ley que otorgue el derecho a voto de chilenos en el extranjero.

Mediante estas propuestas queremos definir el contenido del interés de Chile en la esfera internacional como una política de Estado, que tenga consenso y continuidad. Por lo mismo, convocaremos a un amplio diálogo que incluya a los demás poderes públicos, a los gobiernos regionales y a todas las instancias de la sociedad civil para la construcción de estos acuerdos. 


\section{MICHELLE}

DERECHOS

CIUDADANOS 

SUPERAGIÓN $D E$ LA

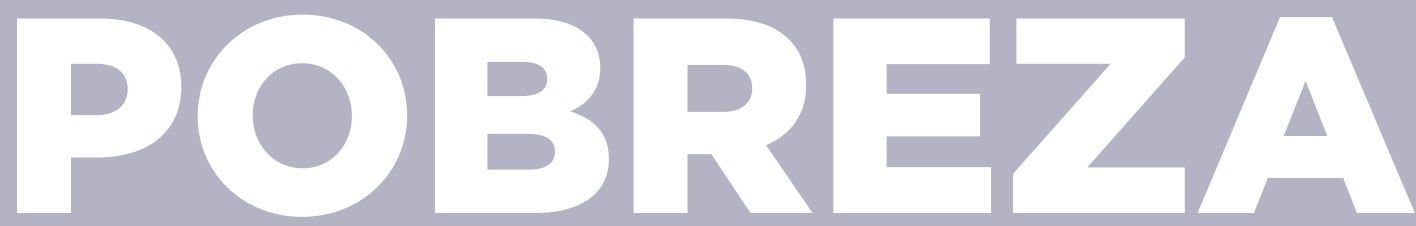



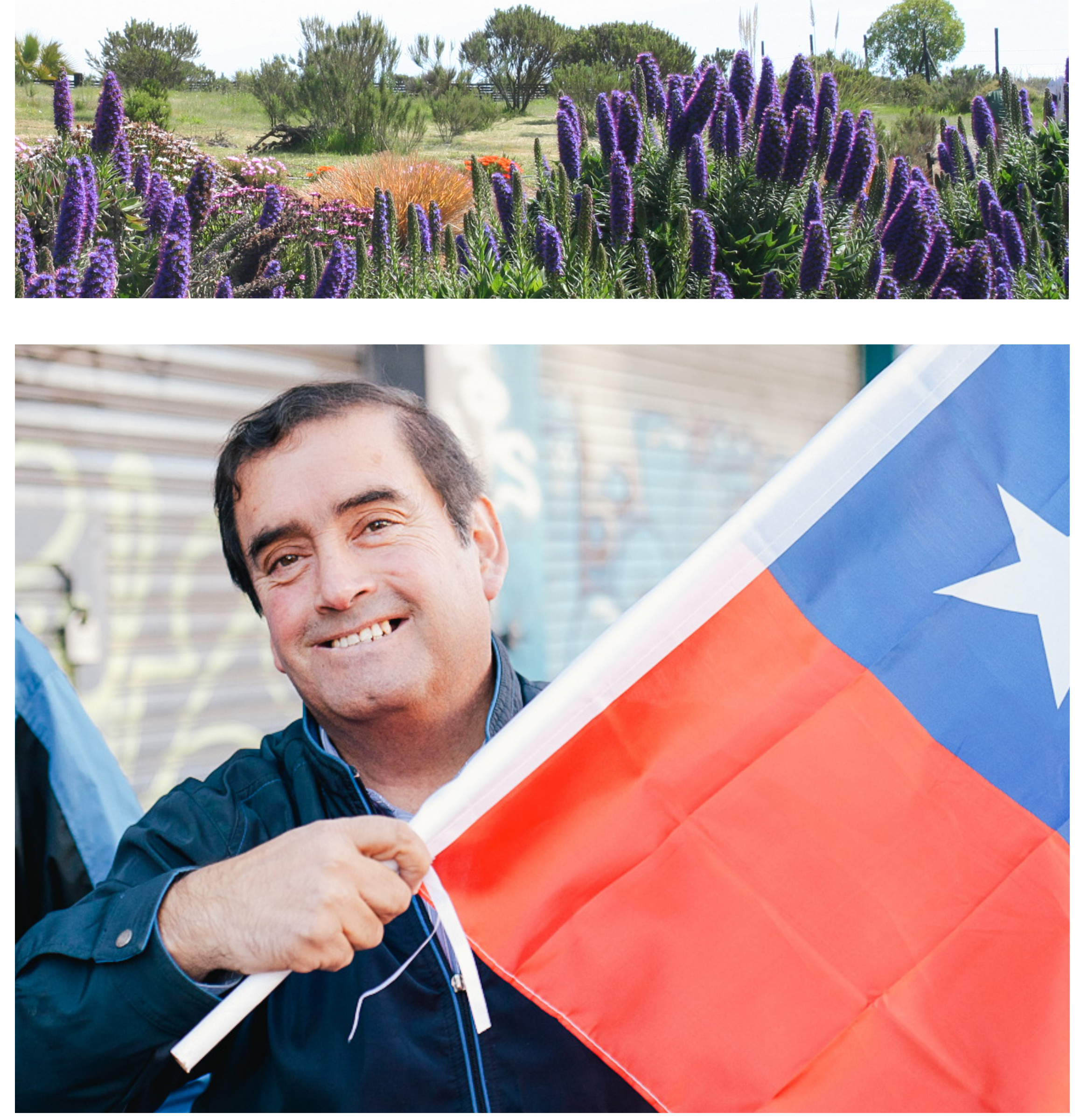


\section{SUPERACIÓN DE LA POBREZA}

Chile exhibe positivos resultados en materia de reducción de pobreza. Al margen de la polémica con el Gobierno por la metodología de estimación de las cifras y del debate más sustantivo acerca de la vigencia y representatividad de esta forma de medición, el problema de la pobreza es más complejo y no se agota en las cifras de pobreza absoluta. La pobreza es un fenómeno dinámico, puesto que las familias transitan por episodios de pobreza más de alguna vez a lo largo de su ciclo vital.

La desigualdad es especialmente crítica e intolerable para los más pobres, que se ven cotidianamente expuestos a las dificultades que trae consigo contar con escasos recursos económicos para satisfacer las necesidades básicas de sus familias. Pero, es también crítica para muchos compatriotas que se encuentran en una situación de extrema vulnerabilidad ante la eventual pérdida de su empleo, la enfermedad de un familiar o cualquier otro gasto no planificado que se convierte en un temor permanente a lo que pueda deparar el futuro.

Si bien la pobreza sigue siendo una urgencia a resolver, la vulnerabilidad o la fragilidad de los sectores no pobres de la sociedad, incluyendo la inmensa mayoría de las capas medias, se ha transformado en el desafío a superar. El sujeto de una nueva política social debe ser la sociedad chilena en su conjunto.

Las políticas y programas públicos orientados a reducir la pobreza deben apuntar simultáneamente a garantizar umbrales mínimos, a ampliar oportunidades, y mejorar el dominio de personas y comunidades sobre sus propios proyectos de desarrollo. Las iniciativas a desarrollar deben reconocer e incorporar en sus lineamientos no sólo los déficits, sino también, y con particular fuerza, los recursos disponibles en las personas, co-responsabilizando a los ciudadanos mediante un estilo de participación renovado, propio de este nuevo ciclo político.

Fortalecer la protección social es la respuesta que Chile necesita para hacer frente a su reto permanente de reducir la pobreza y abatir su expresión más extrema, pero sobre todo, para abordar con decisión el fenómeno más estructural de las distintas formas de desigualdad que segregan a la sociedad chilena.

\section{En los primeros 100 días de Gobierno, enviaremos al Congreso, con discusión inmediata, el proyecto de ley del Aporte Familiar Permanente Marzo. Este Aporte Familiar se entregará en el mes de marzo de cada año, tendrá un monto de $\$ 40.000$ por causante, siendo estos: i) los beneficiarios de subsidio familiar; ii) los beneficiarios de asignación familiar y de asignación maternal, y iii) las familias que perciben transferencias monetarias asociadas al Ingreso Ético Familiar y aquellas que sin recibirlas sean usuarias del Subsistema Seguridades y Oportunidades. El aporte cubrirá a cerca de dos millones de familias, lo que representa cerca de 7 millones de personas.}

Crearemos el Fondo para el Fortalecimiento de Comunidades en Situación de Pobreza. Este Fondo permitirá, entre otras materias, financiar el diseño y la ejecución de Planes Locales de Desarrollo Social. La asignación de recursos específicos para el diseño y ejecución de cada plan deberá priorizar aquellos territorios donde la pobreza en sus múltiples dimensiones tiene mayor incidencia, concentración y profundidad. Lo importante es otorgar a las regiones amplios márgenes de libertad para priorizar recursos y proponer criterios de inversión a partir de los particulares perfiles de carencias que enfrentan los distintos territorios del país y sin perder de vista la estructura de oportunidades socioeconómicas que ofrece cada territorio.

Para la puesta en marcha de este Fondo reasignaremos los recursos que actualmente destina el FOSIS, a tareas de apoyo psicosocial y sociolaboral, a financiar iniciativas de apoyo al emprendimiento y la empleabilidad de las familias beneficiarias del Ingreso Ético Familiar. En una segunda fase avanzaremos incorporando a este Fondo otros recursos provenientes de programas que ejecutan otros ministerios y servicios públicos con finalidades similares, de manera tal de simplificar la oferta pública de programas sociales que ponen 
múltiples exigencias y requisitos a miles de chilenos para acceder a beneficios que en ocasiones se duplican y otras veces no llegan.

Los Planes Locales de Desarrollo Social financiarán tres tipos de actividades: expansión de capacidades, bienestar comunitario e inversión para las oportunidades.

Por otra parte, dado que la participación laboral es fundamental para enfrentar la pobreza, ampliaremos la cobertura de los subsidios al trabajo de la mujer y de formación para el trabajo para mujeres y jóvenes.

\section{Debemos mejorar y hacer más exigentes nuestros instrumentos de medición $y$ caracterización de la pobreza. Debemos establecer} instrumentos de medición más precisos y adecuados a la multiplicidad de situaciones de pobreza. Proponemos medir la pobreza de diversas formas: pobreza absoluta, hogares de menores ingresos, vulnerabilidad y privaciones multidimensionales del bienestar. Actualizaremos nuestra línea de pobreza, de manera tal de visibilizar la situación de carencias en que viven miles de familias chilenas, incorporando una dimensión multidimensional del bienestar.

Aplicaremos la Encuesta CASEN cada dos años, intercalando mediciones con representatividad nacional/regional (cada dos años) con otras representativas de la situación de bienestar de todas las comunas del país (cada 4 años).

Iniciaremos un proceso para superar en forma gradual la Ficha de Protección Social (FPS) en tanto instrumento de focalización, de manera tal de transitar hacia la asignación de transferencias monetarias por el mecanismo de la exclusión de los sectores de mayores ingresos. De esta forma, es el Estado quien asume la responsabilidad de identificar y seleccionar, no el ciudadano.

En el intertanto, la FPS debe permitir de la forma más fidedigna posible identificar a los hogares, asegurándoles un acceso justo y equitativo a los ingresos que les permitan una sustentabilidad digna. Para esto debemos establecer una administración transparente y justa de la Ficha, ajustando los procedimientos operativos; identificar a personas y familias y ordenarlas por estratos sociales; establecer un nuevo modelo de cálculo del puntaje que recoja los recursos provenientes de los ingresos y el consumo familias en función de las necesidades del hogar, corrigiendo la fórmula de la Capacidad Generadora de Ingresos.

En lo inmediato, en los primeros 100 días de Gobierno implementaremos cambios a la Ficha de Protección Social buscando restablecer dichos beneficios.

Respecto de la Institucionalidad, el Ministerio de Desarrollo Social estará al servicio de la Protección Social Universal. Trabajaremos en generar un Sistema Integrado de Información Social con desagregación territorial, que articule toda la información de que dispone el Ministerio, que permita realizar adecuadas caracterizaciones de las personas y familias, pero también de las condiciones del entorno donde las personas realizan su vida cotidiana, trabajan o estudian que, como sabemos, son muy desiguales a lo largo y ancho del país.

Para apoyar y hacer posible la puesta en marcha del Fondo Regional de fortalecimiento de capacidades y de los Planes Locales de Desarrollo Social, haremos una importante reestructuración del Fondo de Solidaridad e Inversión Social, recuperando el espíritu para el que fue creado el FOSIS: el apoyo a iniciativas locales de innovación social.

Crearemos una nueva institucionalidad para la medición de la pobreza. Reconstruiremos la credibilidad del proceso de medición, análisis y entrega de las cifras en sus cuatro etapas: elaboración del cuestionario, medición de ingreso per cápita vía CASEN, construcción de la variable de ingresos y entrega de cifras y datos de pobreza, distinguiendo roles precisos de distintas instituciones, incluyendo un ente autónomo encargado de la supervisión y validación del proceso. 
M DERECHOS HUMANOS 


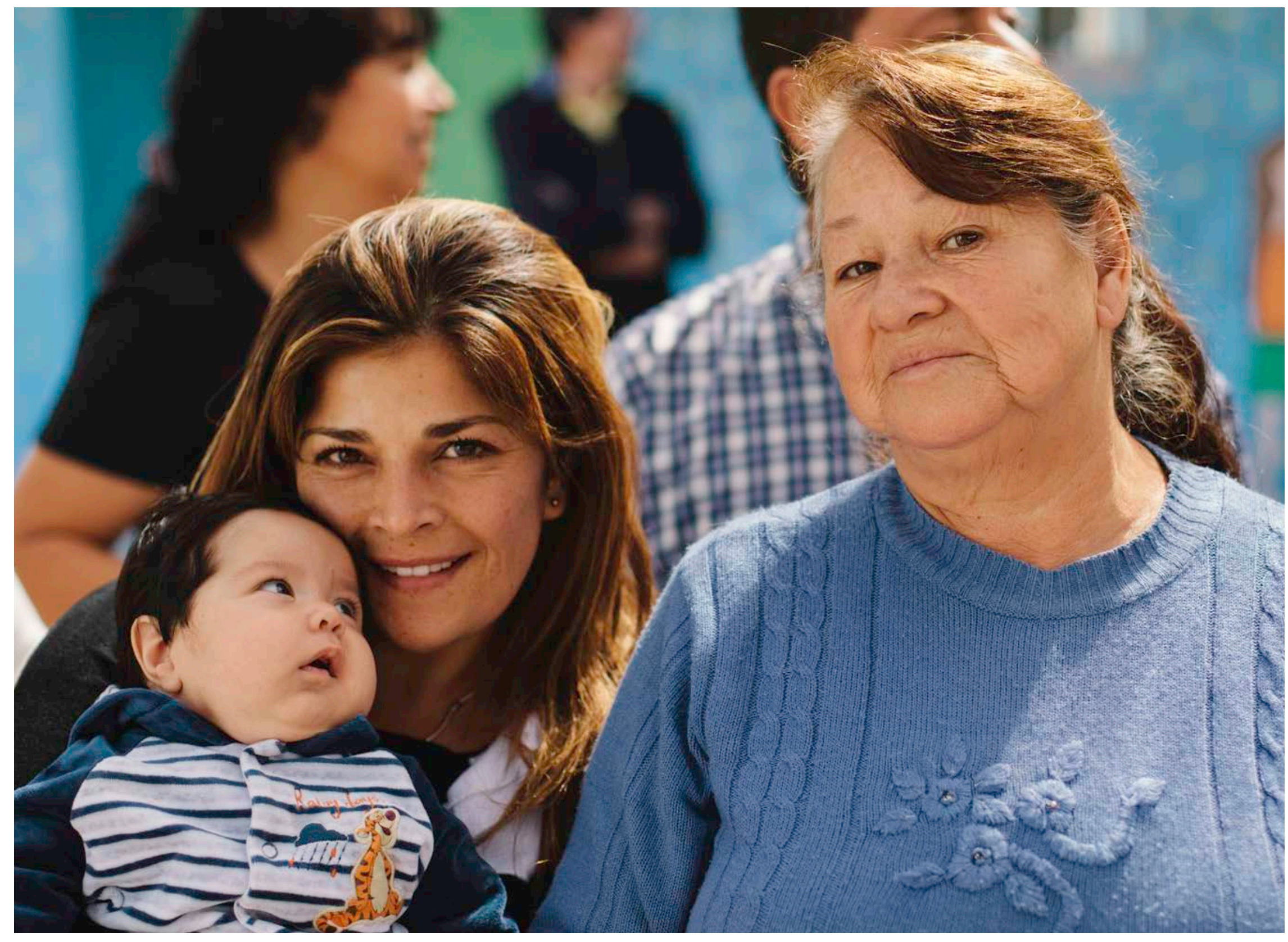




\section{DERECHOS HUMANOS}

Los Derechos Humanos deben ser el fundamento principal y eje articulador del accionar del Estado, tanto del Gobierno, de los poderes e instituciones del Estado y en especial de la actividad legislativa y las políticas públicas que se adopten. A su vez, los derechos humanos deben ser la base normativa mínima de una sociedad democrática, que permita la convivencia nacional en torno a principios de dignidad, igualdad, justicia, diversidad y tolerancia.

Adoptaremos todas las medidas necesarias para la plena vigencia y eficacia de los derechos humanos resguardando y mejorando la institucionalidad ya alcanzada. Impulsaremos una nueva normativa que aplique los principios y tratados internacionales.

Asimismo se debe continuar con la exigencia de verdad, justicia y reparación en relación a los crímenes de lesa humanidad ocurridos en dictadura, adecuando la normativa y los medios necesarios para tal objetivo. Al mismo tiempo, se deben desarrollar planes de educación y memoria histórica tendientes a desterrar definitivamente la posibilidad de que tan graves atentados a la vida y dignidad humana se repitan y a fomentar una cultura de la paz y la tolerancia.

El avance de la sociedad democrática y el empoderamiento de los ciudadanos y ciudadanas presentan nuevos desafíos para la plena vigencia de los derechos humanos. La ciudadanía exige el término de los abusos y la satisfacción de necesidades individuales y sociales, reclamando equidad, calidad y derechos en materia de salud, vivienda digna, empleo, seguridad pública, educación, medio ambiente sano, el derecho al trabajo, a negociación colectiva, entre otros.

El Gobierno, en lo que le corresponde, debiera hacerse cargo de estas expresiones y exigencias, las que se deben abordar con una genuina visión de derechos humanos, con los deberes y obligaciones correspondientes, promoviendo el reconocimiento legal o constitucional en su caso.

Por tanto, enfrentamos desafíos no sólo en cuanto a las violaciones que se cometieron bajo la dictadura, sino también en cuanto a garantías para aquellos derechos surgidos en democracia.
Durante el Gobierno, adoptaremos una Política de Estado Explícita e Integral en Derechos Humanos, que contemple, a lo menos, los siguientes cuatro ejes: promoción y garantía de la vigencia integral de todos los derechos humanos; una institucionalidad adecuada para el diseño y monitoreo de esa Política de Estado; políticas públicas concebidas con "enfoque de derechos"; verdad, justicia y reparación a las víctimas de los crímenes de lesa humanidad de la Dictadura, a sus familiares y a la sociedad toda.

Reconoceremos con el máximo valor en la Constitución, los tratados y convenciones internacionales sobre derechos humanos $\mathrm{y}$, en especial, incorporaremos una norma que establezca que, en toda interpretación constitucional o legal, deben primar dichos tratados o convenciones. Estableceremos en forma expresa en la carta fundamental que los Crímenes de Lesa Humanidad cometidos, tanto en tiempo de guerra como en tiempo de paz, son delitos imprescriptibles cualquiera sea la fecha en que se hayan cometido y no susceptibles de amnistía, ni indulto general o particular.

Impulsaremos medidas legislativas y administrativas que impidan la impunidad en materia de DDHH, tales como impedir toda aplicación en los juicios sobre Crímenes de Lesa Humanidad del D.L. N².191, de Amnistía de 1978, y de las normas que regulan la prescripción en materia de delitos comunes o de la prescripción en materia de responsabilidades civiles.

Crearemos un sistema único de información relativa al estado y resultados de los procesos judiciales sobre Crímenes de Lesa Humanidad. Apoyaremos el mantenimiento de las instituciones de la sociedad civil de defensa y promoción de los derechos de las víctimas de los Crímenes de la Dictadura, especialmente de las que poseen una trayectoria histórica y simbólica en la materia.

Solicitaremos la designación de Jueces de dedicación exclusiva para los juicios por las graves violaciones a los derechos humanos y asignaremos recursos especiales al Poder Judicial para estos efectos. Fortaleceremos el Programa de Derechos Humanos del Ministerio del Interior, los departamentos de derechos humanos del Servicio Médico legal y la Policía de Investigaciones, a través de la designación de recursos humanos, tecnológicos y materiales. 
Debemos fortalecer la institucionalidad existente. Esta hoy considera al Instituto Nacional de Derechos Humanos y el Museo de la Memoria y los Derechos Humanos. Pero no resulta suficiente. Crearemos la Subsecretaría de Derechos Humanos en el Ministerio de Justicia y Derechos Humanos, con dotación de recursos humanos y presupuestarios que permitan el trabajo de coordinación y ejecución en materia de derechos humanos. Ampliaremos la presencia del INDH a nivel de regiones en forma gradual. Impulsaremos la creación de la Defensoría del Pueblo u Ombudsman.

Reformaremos la justicia militar, limitándola a sujetos militares, bienes jurídicos militares y en recintos militares. Reformaremos la Ley 18.314 para adecuarla a estándares internacionales en relación al derecho a un juicio justo.

Diseñaremos un Plan Nacional de Educación en Derechos Humanos, para todos los niveles educacionales, que sea participativo y de formación integral.

Incentivaremos la investigación académica en temas de derechos humanos y memoria histórica. Promoveremos el desarrollo de materiales y estrategias didácticas en la enseñanza de los derechos humanos e incorporación de las Tecnologías de la Información y Comunicaciones como herramienta de formación en los temas de los derechos humanos.

Fortaleceremos la educación de derechos humanos en todas las escuelas matrices y/o academias de las FF.AA., Carabineros y Policía de Investigaciones, elaborando una propuesta de actualización curricular que incorpore la formación en temas de derechos humanos desde su aspecto teórico y normativo, así como formación en los protocolos de actuación.

Promoveremos la ratificación de la Convención sobre Imprescriptibilidad de los Crímenes de Guerra y Crímenes de Lesa Humanidad, de 1968 y ratificaremos el conjunto de tratados de derechos humanos del sistema de Naciones Unidas y OEA pendientes.

Adicionalmente, estableceremos legalmente las medidas destinadas a asegurar el cumplimiento y respeto en el país de las decisiones jurisdiccionales internacionales en materia de Derechos Humanos.
Adoptaremos medidas, legislativas si fueren necesarias, para reconocer el derecho de las víctimas de las graves violaciones a los derechos humanos y sus familiares, a obtener reparaciones civiles de los victimarios y, en su caso, del Estado. Revisaremos las actuales leyes reparatorias. Asignaremos a una entidad estatal permanente que se haga cargo del reconocimiento, acogida, asistencia jurídica, social y de reparación para las víctimas de Crímenes de la Dictadura.

Desarrollaremos un programa sistemático y nacional de recuperación y conservación de testimonios de la memoria histórica de violación masiva y sistemática de los derechos humanos. Desarrollaremos una política de recuperación de todos los sitios de memoria histórica donde se violaron los derechos humanos, velando por su mantención básica y permanente. Desarrollaremos una estrategia específica para vincular a los sitios de memoria histórica con las nuevas generaciones.

Revisaremos lo referido a los archivos judiciales de las violaciones a los Derechos Humanos que tienen un periodo de 50 años para poder ser conocidos y revisados.

Adicionalmente, desarrollaremos una iniciativa legal para regular el derecho a reunión y revisaremos los reglamentos, protocolos y práctica de las Fuerzas Policiales para su adecuación a estándares internacionales.

La complejidad del mundo actual se plasma en el avance, reconocimiento y protección de nuevos derechos humanos. Los derechos de niños/as y adolescentes, sexuales y reproductivos, los derechos de los pueblos indígenas y los de la tercera edad, entre otros, constituyen un desafío y una prioridad para nuestro país en tanto buscan asegurar que aquellas personas que se encuentran en desventaja social en el acceso y goce de derechos, lo hagan en condiciones de igualdad y no discriminación.

En definitiva, adoptaremos un sistema integral de promoción y protección de los derechos humanos, que junto con hacerse cargo de las deudas aún pendientes con las víctimas de las graves violaciones a los derechos humanos del pasado, también fortalezca la garantía y respeto de los derechos civiles, políticos, económicos, sociales y culturales. 


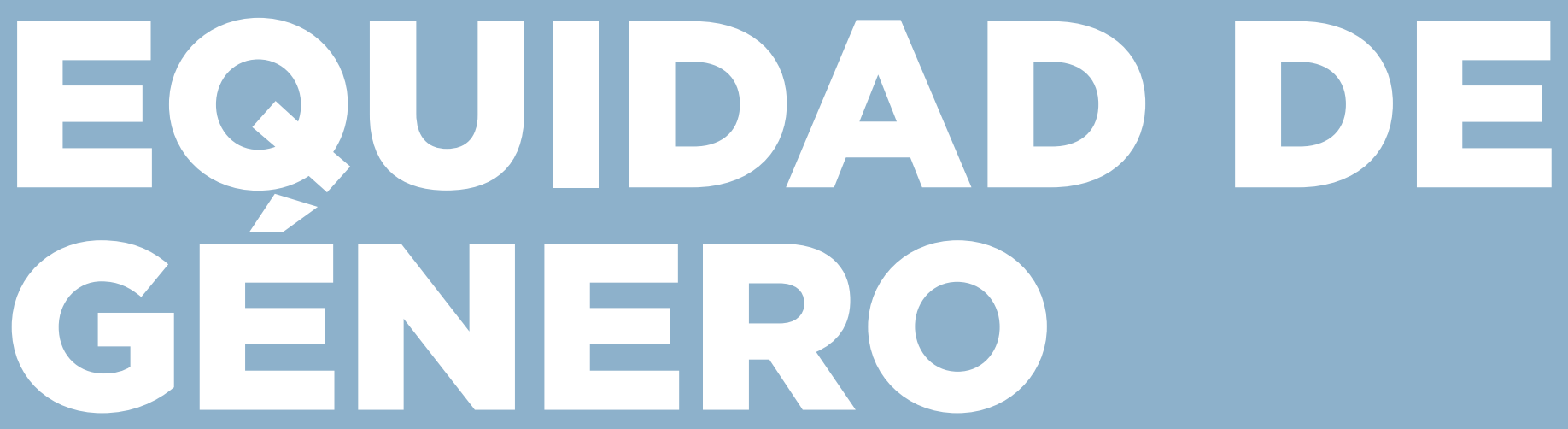




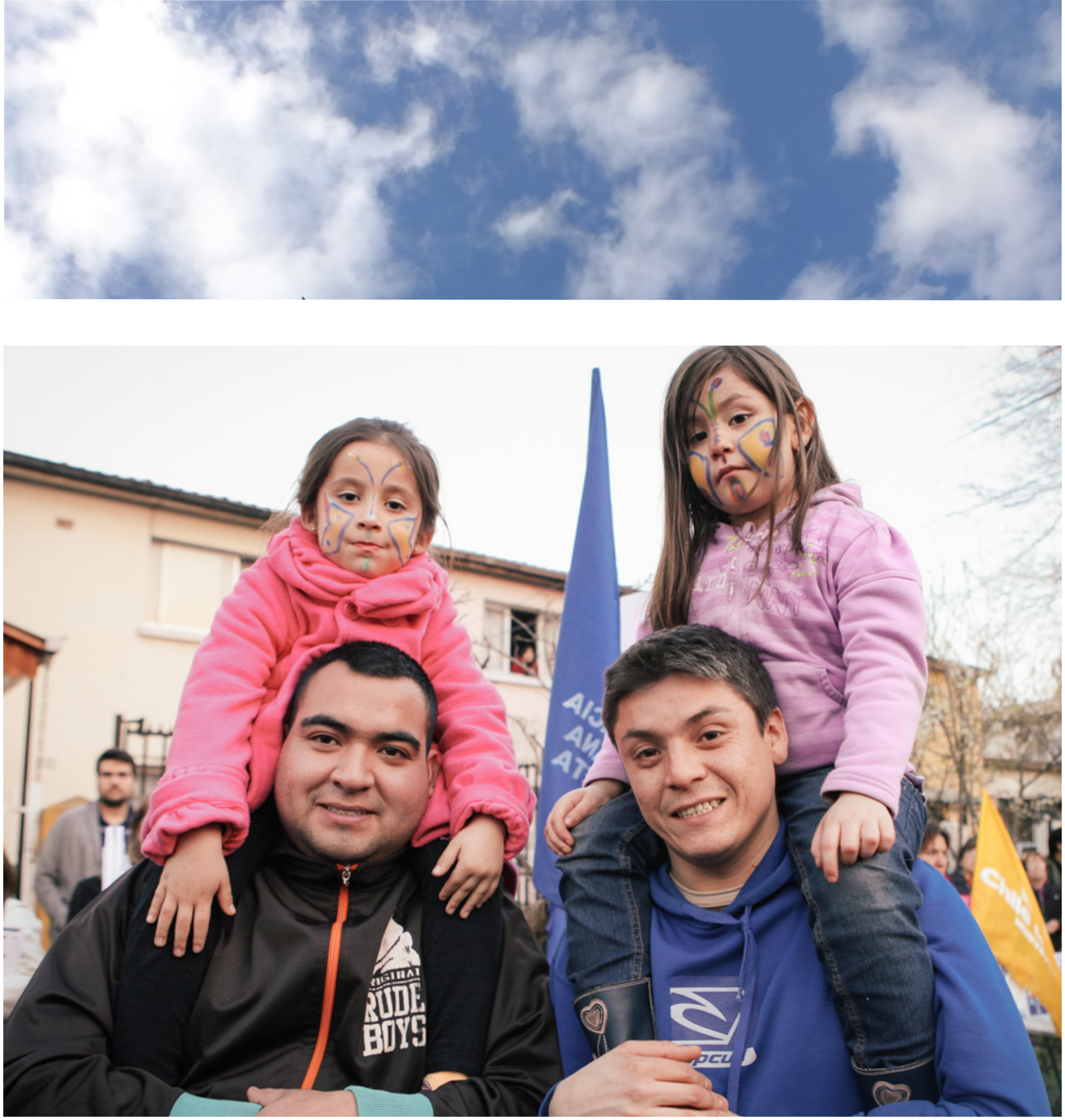




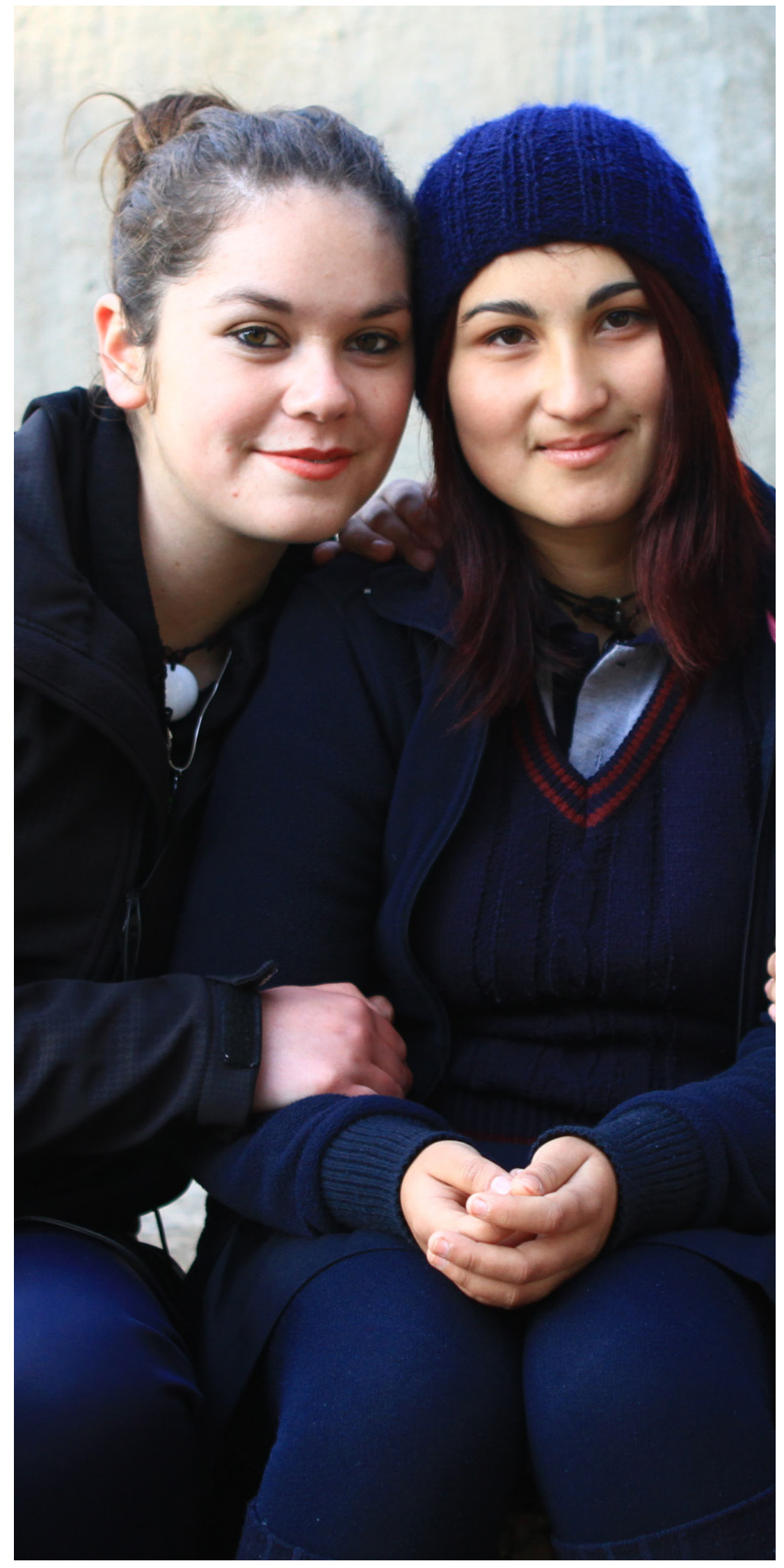

\section{EQUIDAD DE GÉNERO}

El esfuerzo para lograr la igualdad entre hombres y mujeres se ha debilitado desde 2010. El año pasado Chile retrocedió del lugar 46 al 87 en el índice de igualdad de género que elabora el Foro Económico Mundial. Si bien la participación laboral femenina se acerca al $50 \%$, esta cifra se concentra en la población de mayores recursos, y no ha traído aparejada una redistribución de las responsabilidades domésticas y familiares, por lo que la carga global de trabajo de las mujeres sigue siendo superior a la de los hombres.

Los salarios de las mujeres son menores en promedio a los que reciben los hombres por el mismo tipo de trabajo. En la política la situación no es mejor: hay menos mujeres en cargos de poder en el gobierno y en cargos de representación popular. En las elecciones municipales de 2012 se presentaron menos candidatas que en los comicios de 2008 y el promedio de parlamentarias llega al 13\%, contra el $21 \%$ de los Congresos de América Latina.

La expresión más cruda de la discriminación es la violencia de género, una de cada tres mujeres ha vivido violencia física, sexual o psicológica por parte de sus parejas o ex parejas.

Esta realidad impone la necesidad de una Nueva Agenda de Género basada en los derechos, igualdad y autonomía de las mujeres, impulsada por una institucionalidad renovada y de mayor rango. Dentro de los primeros 100 días de Gobierno enviaremos al Congreso el proyecto de ley que crea el Ministerio de la Mujer, buscando situar la igualdad entre mujeres y hombres al más alto nivel en la agenda política. Junto con ello, reinstalaremos el Consejo de Ministros para la Igualdad de Oportunidades y fortaleceremos su funcionamiento, generando una instancia permanente de asesoría técnica.

El despliegue de esta agenda será transversal, se vinculará estrechamente con las principales políticas públicas que se impulsarán. Así, el enfoque de género estará presente, entre otras áreas, en el diseño en las reformas educacional, el sistema electoral, las políticas laborales y la Nueva Constitución Política. Similar visión existirá en el Sistema Nacional de Inversiones, en el diseño del sistema nacional de cuidado y en la reforma al régimen de salas cunas para hijos e hijas de trabajadores, que asegurará la no discriminación de las trabajadoras e incluirá la corresponsabilidad en la crianza.

En el plano local, impulsaremos el fortalecimiento y ampliación de las Oficinas Municipales de la Mujer y la Equidad de Género, con el objetivo de promover la participación igualitaria en las políticas de desarrollo local. 
Impulsaremos el diseño e implementación del Sistema Nacional de Cuidado, que se hará cargo de dos problemas centrales. Por un lado, de la concentración tradicional de las múltiples tareas de cuidado en las mujeres, situación incompatible con su creciente participación en el trabajo remunerado. Por el otro, de una oferta insuficiente y dispersa de servicios de cuidado públicos, subsidiados o privados con grandes diferencias de calidad según la capacidad económica de las familias. En un país que envejece, el cuidado, tanto de personas mayores como de enfermos postrados, discapacitados y de niñas y niños, pasa a ser un tema prioritario para el Estado y la sociedad.

Promoveremos políticas destinadas a reforzar la autonomía de las mujeres. Esto incluye una ley de derechos sexuales y reproductivos acorde a las realidades y opciones de las personas; educación sexual laica y humanista en los colegios; acceso a servicios de salud sexual y reproductiva; disponibilidad efectiva de métodos anticonceptivos, incluyendo la anticoncepción de emergencia; y despenalización de la interrupción voluntaria del embarazo en caso de peligro de la vida de la madre, violación o inviabilidad del feto.

Reforzaremos las políticas de prevención de la violencia de género, duplicando las actuales Casas de Acogida y aumentando los centros de la mujer en las comunas con mayores índices de violencia. Dentro de los primeros 100 días de Gobierno detallaremos dónde se implementarán estas 24 nuevas Casas de Acogida. Crearemos un registro único de casos de violencia contra las mujeres y de femicidio y avanzaremos en la especialización de fiscales y jueces. También ampliaremos el concepto de acoso sexual al ámbito educacional. Modificaremos la actual Ley de Violencia Intrafamiliar incorporando todo tipo de violencia de género, no sólo aquella que se vive dentro de las familias o entre cónyuges.

Fortaleceremos la fiscalización de las normas existentes contra la discriminación de género en materia laboral, modificaremos la ley de igualdad de remuneraciones para hacerla efectiva, suprimiremos las normas que impidan autonomía real de las mujeres en relación a sus derechos patrimoniales y promoveremos la ley de reforma a la sociedad conyugal, actualmente aprobada en la Cámara de Diputados.

Como se indicó en el capítulo de Trabajo impulsaremos una reforma al régimen de salas cuna para hijos e hijas de trabajadores, que asegurará la no discriminación de las trabajadoras e incluirá la corresponsabilidad en la crianza, eliminando el sesgo tradicional de género de la actual legislación laboral. Esta política complementará el significativo aumento de salas cuna y jardines infantiles, que garanticen la provisión de educación parvularia de calidad para niños y niñas.

Dispondremos medidas de participación equilibrada de mujeres y hombres en el Congreso, las directivas de los partidos políticos, las instituciones públicas, en cargos directivos y directorios de empresas con participación del Estado, en el gabinete ministerial y gobiernos regionales; desarrollaremos programas de difusión de derechos y un Fondo Nacional para apoyar iniciativas que fortalezcan la asociatividad y liderazgo de las mujeres. Adicionalmente, incorporaremos acciones afirmativas para la contratación femenina dentro de las políticas de selección del Sistema de Alta Dirección Pública.

Enfrentaremos las principales barreras que limitan el acceso de las mujeres al mundo del trabajo, desarrollando programas de formación y capacitación laboral, de apoyo al emprendimiento, de salud odontológica y extensión horaria en salas cunas, jardines y colegios.

Respecto de la vinculación con el sistema educativo, reinstalaremos en la formación docente, los programas de estudio y textos escolares, ejes y lineamientos educativos que permitan modificar prácticas y estereotipos de género y que promuevan el respeto por la diversidad sexual. Adicionalmente, evaluaremos, diseñaremos e implementaremos programas de derechos humanos con enfoque de igualdad de género en todo el ciclo escolar, junto con establecer la institucionalidad más apropiada dentro del Ministerio de Educación, para proteger y asistir, dentro de otros temas, a alumnos y alumnas afectados por prácticas discriminatorias. Fiscalizaremos el cumplimiento y apoyaremos la continuidad de la educación de las adolescentes embarazadas o madres y se implementarán programas para la prevención de abuso infantil en jardines públicos y privados.

Crearemos un programa integral de Calidad de Vida y Autocuidado de las mujeres que considere mayor prontitud en el acceso y mejor accesibilidad a la atención preventiva en salud física y mental, programas recreativos, de autocuidado, cultura y deportes en las comunas. También en elámbito de la calidad de vida, promoveremos en la actual normativa de vivienda mecanismos que faciliten el acceso igualitario de hombres y mujeres a los subsidios públicos. 
Y

PUEBLOS

INDIIGEN/AS 


\section{PUEBLOS INDÍGENAS}

Queremos un Chile de todos con los Pueblos Indígenas incluidos plenamente. Miramos nuestra historia, lo que hemos hecho bien, lo que está pendiente y lo que hay que corregir. Una nueva relación deberá estar basada no sólo en los derechos individuales sino también en los derechos colectivos de los Pueblos Indígenas, con una propuesta real de participación y superación de toda forma de marginación, racismo y discriminación. Reconocemos así que el Estado y la sociedad chilena mantienen una deuda histórica. No hemos logrado su pleno reconocimiento y por ello tenemos grandes desafíos por delante.

Al inicio del Gobierno, anunciaremos una detallada Agenda para el Desarrollo de los Pueblos Originarios, que incorporará, entre otras, las áreas de educación, salud, tierras y desarrollo productivo.

Los cuatro ejes sobre los cuales se fundamentará la Política Indígena del próximo Gobierno son:

\section{El Estado de Chile tiene obligaciones que debe} cumplir. Es un deber del Estado de Chile implementar los tratados que ha ratificado en materia de derechos de los Pueblos Indígenas y adecuar su legislación para que sea acorde con dichos estándares y elaborar una nueva política indígena con enfoque de derechos.

La nueva política indígena se fundamentará en el marco internacional de derechos que garantizan a los Pueblos Indígenas que ellos pueden proveer, su mejor forma de desarrollo político, económico, social y con pertinencia cultural. En dicho sentido implementaremos en plenitud el Convenio 169 de la OIT y asumiremos las tareas inconclusas y los nuevos desafíos, entre otros: asumir la defensa de la lengua de los Pueblos Indígenas y del reconocimiento de sus autoridades; mejorar sus condiciones de vida, a poyar su economía y productividad; proteger sus prácticas culturales y su medicina ancestral; consolidar la libre manifestación de sus creencias y de su espiritualidad; promover mejores y más amplios espacios de participación política, social y cultural, respetando su autonomía y autodeterminación y extendiendo sus derechos políticos. El sello de la próxima década debe ser el del reconocimiento e implementación efectiva de los derechos de los Pueblos Indígenas en Chile. Tenemos por delante el desafío impostergable de reconocer constitucionalmente a los Pueblos Indígenas en el marco de la discusión de una Nueva Constitución para Chile, y debatir ahí un nuevo modo de convivencia como sociedad pluricultural. Esta idea alude a la existencia en un territorio con diversas culturas. Lo fundamental es que estas culturas se relacionan, vale decir no sólo comparten un espacio común, sino que desarrollan un intercambio y una influencia mutua.

Los Pueblos Indígenas y la sociedad en general serán actores fundamentales en este debate. Debemos analizar en conjunto la mejor forma de participación de los Pueblos Indígenas en su propio destino y en los del país.

Por uncaminodePaz, DiálogoyEntendimiento. La falta de reconocimiento de los derechos indígenas ha llevado a una profunda crisis en la relación de los Pueblos con nuestra sociedad y el Estado, que todos lamentamos profundamente. Corregiremos esta situación y los errores cometidos en el pasado y reemprenderemos la tarea de reconstruir confianzas, alejándonos de la represión y la violencia. Buscaremos una forma de entendernos con voluntad de diálogo y de justicia. Consideramos muy importantes las recomendaciones de los Relatores de Naciones Unidas y de otros organismos internacionales que han examinado la realidad de los Pueblos Indígenas en nuestro país y han formulado importantes indicaciones, especialmente en relación con situaciones de tensión y conflicto.

Construir juntos una nueva relación para mejorar la calidad de vida, tanto de las comunidades indígenas rurales como para la población indígena urbana. Respetar los derechos de los Pueblos Indígenas y sus Recursos Naturales. Los Pueblos Indígenas tienen derecho a decidir sobre el uso de sus tierras y lugares donde habitan. Impulsaremos una política efectiva respecto de los indígenas urbanos. Buscaremos en conjunto la mejor forma de emplear los recursos naturales 
en beneficio del país y con respecto de los derechos de los pueblos indígenas. Esto es apuntar nuestra mirada hacia un modelo de vida que integre distintas visiones sobre el desarrollo, sobre el medio ambiente y sobre la economía. Sin duda que un tema fundamental en esta materia es el derecho a la participación y consulta de los Pueblos Indígenas. Para tal efecto, debemos replantear y revisar el tema de la consulta y consensuar, en un proceso participativo con los Pueblos y sus autoridades, los mecanismos que mejor representen sus derechos a partir de procesos ya encaminados.

Las propuestas se ordenan en cuatro áreas, que se exponen a continuación.

\section{Reformas políticas, legislativas e institucionales}

Garantizaremos la participación plena de los Pueblos Indígenas en todo el proceso de debate y decisión sobre una Nueva Constitución, teniendo presente la idea de un Estado pluricultural que garantice sus derechos colectivos.

Realizaremos un proceso de consulta con los Pueblos Indígenas para garantizar la participación política de éstos en los distintos niveles de toma de decisiones. Desarrollaremos un proceso de consulta con los Pueblos Indígenas para establecer reformas que generen espacios de autonomía y autodeterminación a nivel territorial mediante la generación de Estatutos Especiales de Autonomía.

Impulsaremos una nueva institucionalidad indígena que recoja la experiencia histórica de entidades como Conadi y de la Ley Indígena y que eleve el estándar de la relación de los Pueblos Indígenas con el Estado. En efecto, los asuntos indígenas han estado a cargo de la Conadi, una institución que es una corporación dependiente de un Ministerio, lo que resta fuerza a su accionar. Necesitamos darle un estatus diferente a un tema tan importante para Chile. Por esto, en los primeros 100 días de Gobierno enviaremos un proyecto de ley con discusión inmediata, que confiere rango de Ministro de Asuntos Indígenas al Director de la Conadi. Pero este es el primer paso. Para que tenga más fuerza esta institución se enviará al Congreso el proyecto de ley que crea el Ministerio de Asuntos Indígenas, que será además el encargado de colaborar con el Presidente de la República en la definición de una política indígena para Chile. Junto a este, enviaremos el proyecto de ley que crea el Consejo de Pueblos Indígenas, autónomo y representativo de los diversos pueblos que existen en Chile. El Consejo deberá tener funciones consultivas y resolutivas y garantizar la debida representación por Pueblos, entre otras materias. Esta iniciativa será con consulta de los Pueblos Indígenas.

Adecuaremos los marcos regulatorios actualmente vigentes a las normas del Convenio 169, de manera develar por su adecuada implementación y respeto. Esto incluye la revisión y eventual modificación -con consulta- del reglamento general de consulta en proceso de aprobación como también respecto del nuevo reglamento del Sistema de Evaluación de Impacto Ambiental recientemente en vigencia, a objeto de que ambos instrumentos cumplan efectivamente con los estándares del Convenio 169. Además, se evaluará un mecanismo de financiamiento a estos procesos de consulta.

Estudiaremos e implementaremos, en consulta con los pueblos indígenas, procedimientos e iniciativas para proteger efectivamente los recursos naturales $\mathrm{y}$ económicos de los Pueblos Indígenas.

\section{Política de Tierras y Aguas Indígenas}

Además de la generación de Estatutos Especiales de Autonomía a nivel territorial y local, se otorgará mayor jerarquía a las Áreas de Desarrollo Indígena (ADI) a través de una nueva y mejor ordenación territorial.

Estudiaremos mecanismos alternativos a la compra de 


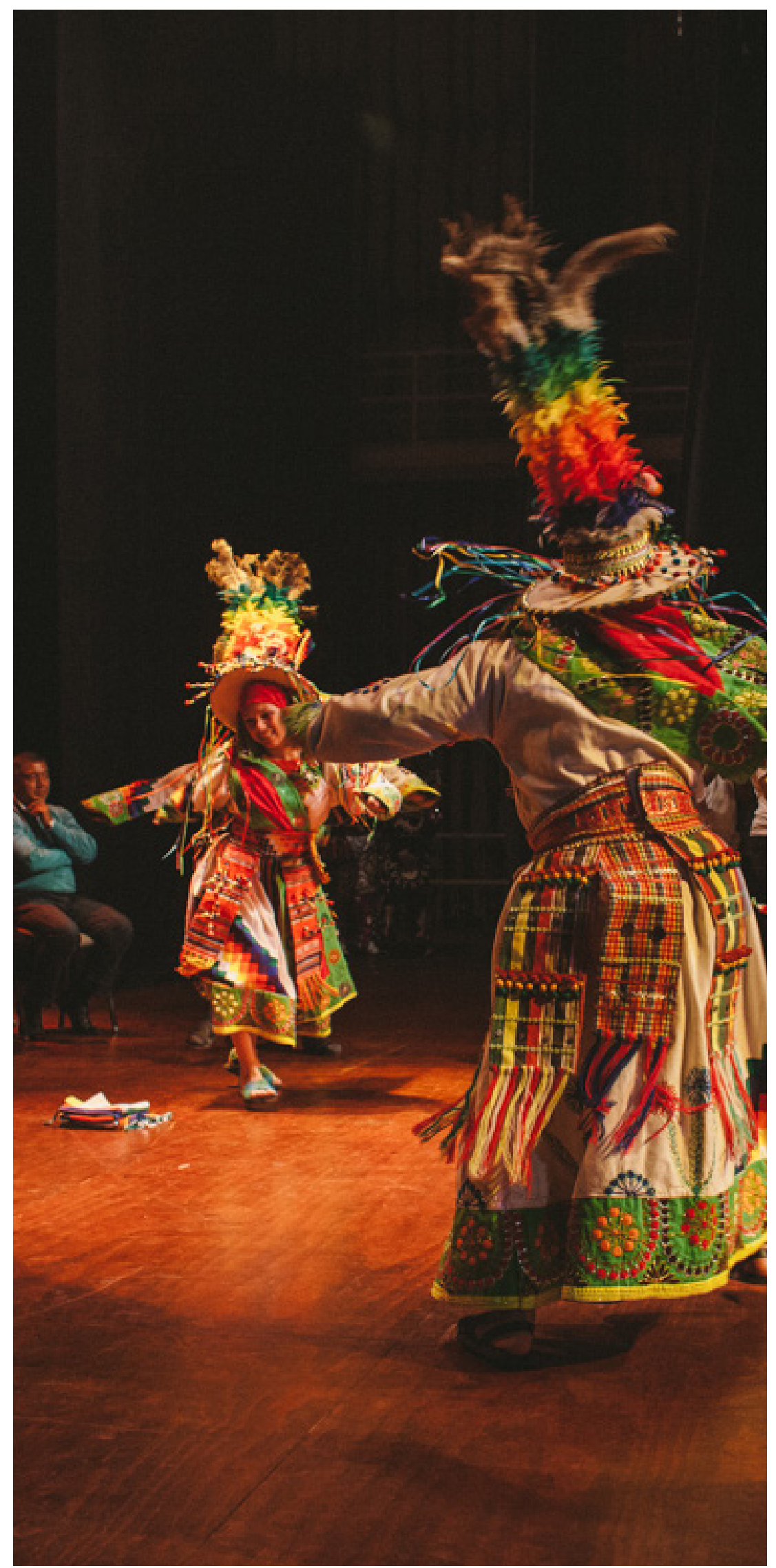

tierras para poder satisfacer las demandas pendientes. Se dará cumplimiento al proceso de restitución de tierras indígenas y se proporcionarán los recursos para proteger los derechos de los Pueblos sobre sus tierras y recursos ancestrales. Se respetarán todos los compromisos asumidos de compras de tierras, con un acompañamiento técnico y productivo a las comunidades.

Se estudiará especialmente la situación de las tierras fiscales que actualmente ocupan los Pueblos Indígenas y cuyo traspaso está aún pendiente. Se estudiarán las denuncias sobre contaminación y los problemas de impacto ambiental que actualmente afectan a muchas tierras indígenas a objeto de adoptar las medidas de mitigación que correspondan.

\section{Reformas en materia de orden público y defensa de los derechos humanos de los Pueblos Indígenas}

Nos comprometemos firmemente a la no aplicación de la Ley Antiterrorista a miembros de los Pueblos Indígenas por actos de demanda social. La Ley Antiterrorista será modificada para adecuarla a los estándares internacionales, tal como le han recomendado al Estado de Chile los órganos internacionales de protección de derechos humanos.

Una comisión de personalidades representativas de la sociedad chilena e indígena estudiará los casos judiciales 
que se han producido como resultado de la aplicación de ésta ley, investigará las denuncias de violencia y abuso policial contra comunidades indígenas, particularmente mapuche y rapa nui y sobre todo respecto de los niños y niñas mapuches; y dará especial atención a las familias indígenas y a los pequeños parceleros afectados por las situaciones de tensión vividas en la Región de la Araucanía. Esta Comisión propondrá, en el plazo de 6 meses desde constituido el nuevo Gobierno, las medidas y recomendaciones necesarias para atender todas estas situaciones de manera adecuada y con respeto a los estándares internacionales de derechos humanos.

El Defensor del Pueblo tendrá entre sus competencias la defensa de los derechos indígenas. Se fortalecerán y extenderán los esfuerzos de capacitación y educación en derechos humanos de los encargados del orden público y del Poder Judicial para el cumplimiento adecuado de sus funciones.

\section{Políticas sectoriales}

Se garantizará la introducción transversal de la dimensión indígena en las políticas públicas, para que se estudiarán e implementarán las metodologías y las modificaciones institucionales que hagan posible cumplir con este objetivo. Esto es fundamental para otorgar pertinencia indígena a los planes y programas ministeriales, adecuándolos y flexibilizándolos de acuerdo a las características de cada región y Pueblo Indígena.
En el marco de la Reforma a la Educación, se impulsará la implementación de una educación intercultural para todos los chilenos y chilenas que garantice la integración de contenidos sobre historia y cosmovisión indígena en toda la enseñanza de manera de que nuestros estudiantes tengan conciencia y respeto por el valor que tiene la cultura de los Pueblos Indígenas para el desarrollo de Chile. Particularmente importante será la ampliación de jardines infantiles indígenas. Se impulsará la creación de Institutos Culturales Indígenas y reforzaremos el programa de Beca Indígena para la educación superior.

Implementaremos un Programa de Desarrollo Rural Indígena, que considera las áreas de desarrollo integral de comunidades indígenas y el desarrollo de la oferta pública sectorial culturalmente pertinente.

Se dará especial impulso a políticas relacionadas con programas de Salud intercultural, mediante iniciativas de reconocimiento $y$ fomento de acuerdo a las recomendaciones de la Organización Mundial de la Salud (OMS).

Retomaremos la Consulta Nacional Indígena Urbana, desarrollada durante el 2007, e impulsaremos, en un proceso plenamente participativo, una política efectiva respecto de los indígenas urbanos, orientada a reforzar sus prácticas culturales e identitarias, los espacios ceremoniales, la salud intercultural y el emprendimiento indígena. Asimismo, desarrollaremos programas que tiendan al mejoramiento y fortalecimiento de sus capacidades productivas y artísticas. La política pública indígena urbana tendrá un carácter nacional. 


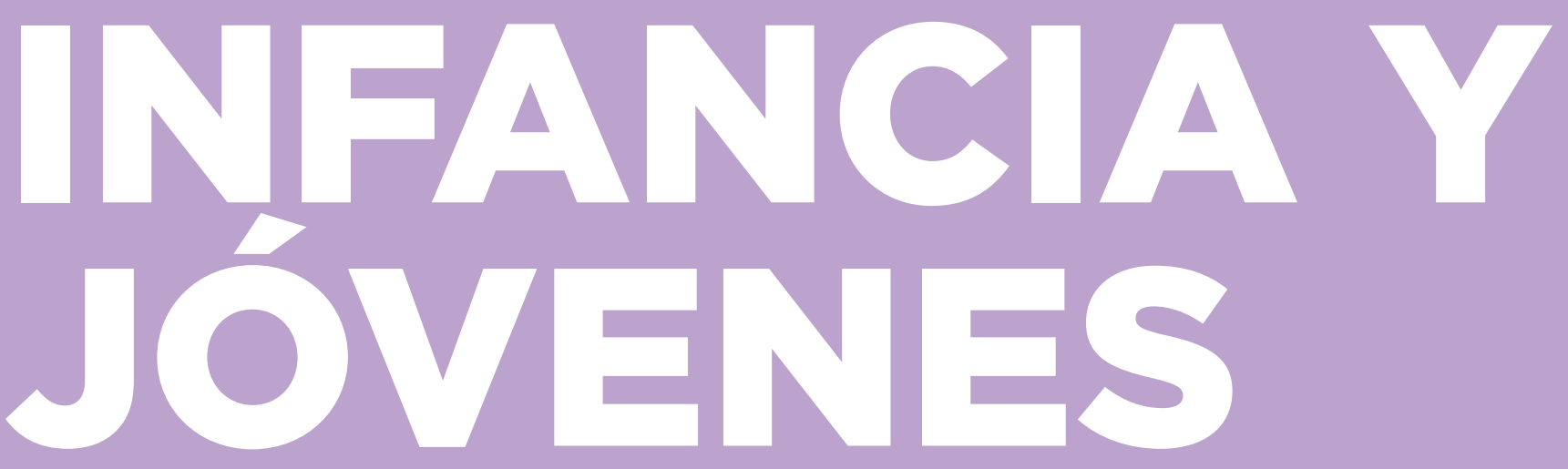



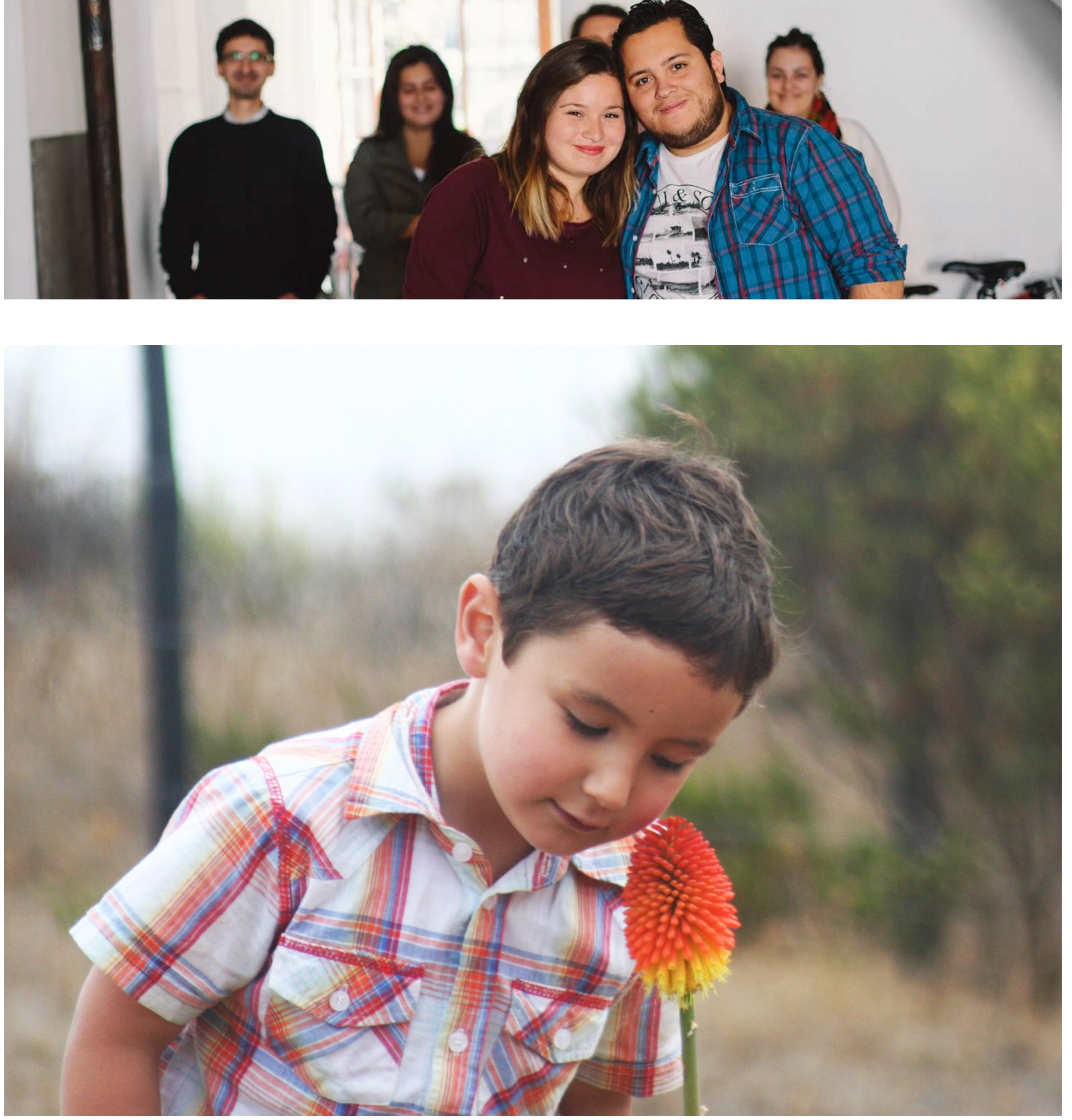
El próximo Gobierno volverá a situar al centro de sus políticas públicas a la Infancia, creando un sistema de protección integral que beneficiará en la vida de cerca de 4 millones de personas menores de 18 años.

La protección integral de los derechos de los niños y niñas es una base fundamental para superar la desigualdad. Debemos situar al centro de nuestras políticas públicas la Infancia. Crearemos el Consejo Nacional de la Infancia que se encargará de la coordinación de los organismos con competencia en materias relacionadas y asumirá la responsabilidad de impulsar la reforma normativa e institucional, que plasmará una nueva relación del Estado con los niños y niñas, fundada en el respeto de sus derechos.

Enviaremos un proyecto de Ley de Protección Integral a los Derechos de la Infancia y la Adolescencia, marco jurídico de reconocimiento de todos los derechos consagrados en la Convención de derechos del Niño y establecimiento de garantías a todos los niños, niñas y adolescentes, sin discriminación alguna. Se establecerán los mecanismos de exigibilidad de los derechos. Esta Ley derogará la actual Ley de Menores, $\mathrm{N}^{\circ}$ 16.628.

Este nuevo marco jurídico implicará reformar los siguientes instrumentos: la Ley $\mathrm{N}^{\circ} 20.032$, fortaleciendo las competencias del Estado para una actuación efectiva y eficaz en materia de protección especial y; transformado al SENAME en el Servicio Nacional de Protección de Menores, dependiente del Ministerio de Desarrollo Social, y la Ley $\mathrm{N}^{\circ} 19.620$ que dicta normas sobre adopción de menores. La actual ley de Adopción presenta vacíos que ponen en disputa el interés superior del niño y otros intereses.

De esta manera, crearemos el Código de Infancia. Instrumento Jurídico que integrará todo el cúmulo de leyes dispersas en materias referidas a los niños y adolescentes, armonizándolas con la Ley de Protección Integral de derechos y los convenios internacionales de infancia.

Se abordarán con sentido de urgencia las vulneraciones de derechos de los niños provenientes de prácticas institucionales. Para disminuir la victimización secundaria que sufren los niños víctimas de delitos sexuales, se constituirá una comisión con todas las instituciones concurrentes en materia de delitos sexuales cometidos contra niños y adolescentes, con el propósito de conciliar un procedimiento, que regido por el interés superior del niño, permita a su vez a todos los organismos cumplir con lo que la ley les mandata.

Además, dotaremos al Servicio Médico Legal de una Unidad Forense Móvil para cada Región y Unidades Forense Hospitalarias en las Capitales Regionales, con el propósito de mejorar la oportunidad y la calidad de la pericia, factores que inciden en la victimización secundaria que sufren los niños víctimas de delitos sexuales.

Eliminaremos la lista de espera del SENAME de niños con medida judicial para mejorar la ejecución de las medidas de protección emanadas por los Tribunales de Familia.

El Programa de Defensa del Niño se encargará de representar debidamente los derechos de los niños, niñas y adolescentes en los procesos judiciales, para lo cual revisará la situación judicial de miles de niños internados en residencias. Por otra parte, en el ámbito penal, podrá hacerse parte como querellante en la persecución de los delitos que afectan a los niños de los sistemas residenciales, contribuyendo a reducir la victimización secundaria en el sistema penal, evitando salidas judiciales insatisfactorias para los niños.

Fortaleceremos también ámbitos de la vida cotidiana de los niños. Esto es relevante para la población, marcando el carácter universal de la preocupación del Estado por la infancia y adolescencia, reconociendo la responsabilidad de apoyar a la familia en su rol principal de agente del bienestar y desarrollo de los niños y niñas. Las medidas que se proponen en este ámbito son: definiremos una Política de Fortalecimiento de la Capacidad Parental de la familia; fortaleceremos el Subsistema de Protección de Infancia Chile Crece Contigo; fortaleceremos la participación social y la capacidad de incidencia de los niños y adolescentes en el ámbito comunal, barrial u otros contextos, y; crearemos un programa de generación de espacios urbanos para la infancia: ludoteca, biblioteca, mediateca, espacios para actividades escolares y espacios de recreación en el exterior. 


\section{JÓVENES}

Abrir más oportunidades a la población juvenil será uno de los ejes del desarrollo del próximo gobierno. Ser joven muchas veces significa carecer de algo: capacidad para hacerse oír por autoridades y dirigentes; experiencia para encontrar un empleo; redes de apoyo para concretar un proyecto o una idea; asertividad para convencer a los demás que las cosas se pueden hacer de un modo diferente. Un país que no confía en sus jóvenes está condenado a anquilosarse en sus prácticas y visiones.

Reforzaremos la institucionalidad pública, de manera que el Instituto de la Juventud (INJUV) pueda realizar una efectiva coordinación de las políticas multisectoriales, y crearemos en el Ministerio de Desarrollo Social una Subsecretaría de la Juventud. Al mismo tiempo, el INJUV debe ser el encargado de la ejecución de las políticas públicas, programas, planes y proyectos diseñados para la juventud.

Los jóvenes serán objetivos prioritarios de las políticas de educación, salud, cultura, deporte y capacitación. En efecto, la reforma educacional, constituye una de las tres reformas estructurales del presente programa, con un especial énfasis en educación general y educación superior. En salud, se establecen programas especiales para jóvenes en materia odontológica. En cultura se pondrá especial dedicación al acceso a la formación de jóvenes en las distintas expresiones artísticas, así como el acceso al disfrute de la cultura. En deporte se implementarán múltiples medidas que benefician fundamentalmente a la población joven, como la construcción y orientación de la actividad de centros polideportivos hacia los establecimientos educacionales. En materia de capacitación, los jóvenes serán un grupo prioritario, implementándose programas masivos de formación.

Complementariamente a estas políticas, desarrollaremos un programa que brinde asistencia específica a jóvenes vulnerables que ni trabajan ni estudian y que están al margen de cualquier sistema de protección o política pública. Además, en el ámbito laboral, fomentaremos las prácticas laborales profesionales y técnicas en el servicio público de regiones, con posibilidades de carrera en el servicio público y continuidad de estudios.

También promoveremos la participación ciudadana de los jóvenes, incentivándolos a integrarse en las organizaciones de su comuna y estimulando la creación de centros de alumnos e introduciendo la temática de participación y cultura cívica en los establecimientos educacionales.

Crearemos un Programa de Voluntariado Nacional de carácter permanente, de vinculación con la sociedad, desarrollado por jóvenes, estudiantes y profesionales, abordando temáticas multisectoriales. Este tipo de programa genera empatía positiva entre organismos del Estado y los jóvenes organizados, y los vincula de manera concreta a las necesidades del país. Para los estudiantes de educación superior, implementaremos la realización de trabajos voluntarios en todas las regiones del país, en temporada de verano e invierno. Para el éxito de la iniciativa se requiere un trabajo coordinado entre las instituciones educativas, las organizaciones estudiantiles y los municipios y otras organizaciones locales que ayuden a identificar las necesidades de las localidades de destino.

Como se indicó en el capítulo de Seguridad Pública, revisaremos la ley 20.000 entregando el conocimiento de las faltas consideradas en esta norma a los Juzgados de Policía Local. Estableceremos por reglamento la determinación de los niveles de droga que debe considerarse constitutiva de micro tráfico $\mathrm{y}$, consecuencialmente, aquella que le está permitido portar a una persona para su consumo personal. Adicionalmente, el reglamento que considera a la marihuana en la lista 1) entre las drogas más peligrosas.

El INJUV fomentará la creación de estructuras juveniles en todos los municipios y suscribirá convenios de desempeño, dispondrá de fondos participativos e implementará programas con las estructuras juveniles de las distintas municipalidades, con el objetivo de desarrollar temáticas locales y desafíos nacionales en materia de juventud.

En una alianza con Sernatur, se ampliará significativamente la cobertura del programa de giras de estudio en enseñanza media para colegios municipales. Con esto se estimula el turismo en fechas de baja temporada, a la vez que se brinda una oportunidad a jóvenes vulnerables de acceder a conocer su país.

Crearemos un Fondo que dará financiamiento a 1.000 proyectos anuales de y para jóvenes, a lo largo del país. Se debe tener especial cuidado en los sistemas de postulación, de manera tal que no se generen sesgos en contra de los jóvenes más vulnerables, quienes pueden tener mayores dificultades para plantear sus proyectos. Se motivará a postular a este Fondo a la red de centro de alumnos de todo el país, a clubes juveniles, ONGs de jóvenes y otras organizaciones en las cuales participan jóvenes.

Se implementará el uso de una nueva tarjeta joven con un fuerte incremento de las actividades y beneficios asociados, otorgándole valor y sentido de pertenencia a este grupo. Buscaremos alcanzar una cobertura de 4 millones de jóvenes, independiente de su condición económica, haciendo un esfuerzo focalizado en su distribución a los jóvenes más vulnerables.

Para hacer más atractiva la tarjeta, se coordinará con los oferentes un programa de fomento a los usos de butacas vacías de diversas expresiones artísticas, culturales y deportivas. La meta es entregar en todo el país en los meses de enero, febrero y julio (vacaciones de verano e invierno) un total de 500.000 entradas gratuitas. Para ello se realizarán licitaciones públicas de entradas de bajo costo y se realizarán convenios con entidades culturales y deportivas. 

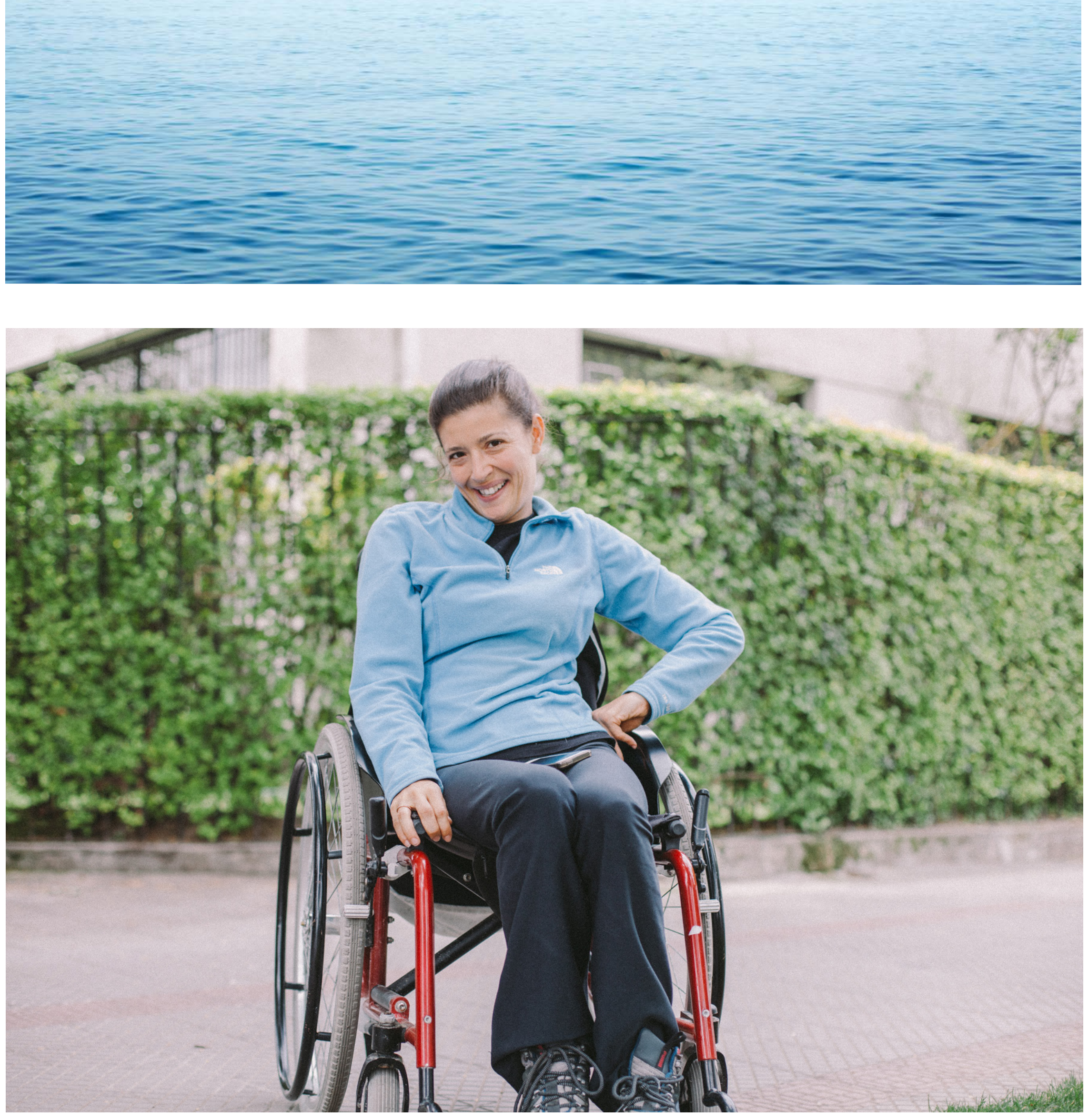


\section{DISCAPACIDAD}

La construcción del sistema de protección social en Chile se ha fundamentado en asegurar derechos a todos los chilenos y chilenas que frente a vulnerabilidades ven mermadas sus posibilidades de desarrollo e inclusión social. Hasta ahora, las acciones se han dirigido a las familias en situación de mayor vulnerabilidad a través de programas como Chile Solidario, Chile Crece Contigo, el reciente Ingreso Ético así como la propia Reforma Previsional.

Avanzar en materia de protección social desde un enfoque de derechos es un compromiso ineludible en el marco de nuevas realidades que configuran nuevas situaciones de vulnerabilidad.

En Chile, más de 2 millones de personas tienen algún tipo de discapacidad, de las cuales más de un millón tienen discapacidad física. En uno de cada tres hogares chilenos vive una persona con discapacidad, asociada a situaciones de dependencia y pobreza. Sólo la mitad de las personas con discapacidad ha completado la educación básica y el $71 \%$ de las personas con discapacidad no realiza ningún tipo de trabajo remunerado. Por otra parte, en los últimos años ha existido una gran brecha de acceso a servicios de rehabilitación por parte de las personas con discapacidad.

Como país estamos al debe con el cumplimiento de los compromisos en el marco de la "Convención Internacional para los Derechos de las Personas con Discapacidad" y su Protocolo Facultativo, ratificado en 2008 por nuestro país.

Para avanzar de verdad en una mayor inclusión, debemos asumir ésta como una tarea colectiva y llevarla adelante desde una mirada integral.

El Estado, no cuenta con la institucionalidad necesaria para enfrentar este tema, quedando en manos principalmente de instituciones $\sin$ fines de lucro, sin un enfoque común. Se agrega el hecho de que el Servicio Nacional de la Discapacidad (SENADIS) carece de las atribuciones suficientes para coordinar, promover y fiscalizar la inclusión de las personas en situación de discapacidad y el respeto a sus derechos.

Establecer la institucionalidad pública será una prioridad. Crearemos la Subsecretaría de la Discapacidad, que impulsará de manera transversal el tema, teniendo como eje la integración y necesidades de las personas con discapacidad y sus familias.

Crearemos una Comisión Asesora Presidencial que elaborará participativamente, un plan nacional para abordar la Discapacidad, la Salud Mental y el Cuidado. Esta comisión de carácter transversal tendrá un enfoque de inclusión, contemplando también aspectos de infraestructura urbana y políticas de inclusión laboral, entre otras. Llevaremos adelante un segundo estudio nacional de discapacidad que permita tener a fines de 2014, una estrategia integral para los próximos 10 años en el tema de discapacidad y salud mental. Ella deberá contar con los diagnósticos y propuestas de los Ministerios de Salud, Educación, Transportes y Telecomunicaciones, de Desarrollo Social, del Trabajo y Previsión Social, Vivienda y Urbanismo y del Servicio Nacional de Discapacidad.

En el ámbito laboral, incorporaremos un enfoque de inclusión a programas regulares de SENCE, FOSIS, SERCOTEC y otros, considerando que las personas con discapacidad son el colectivo vulnerable más significativo actualmente. Fortaleceremos el trabajo del sistema de Intermediación Laboral asignando los recursos necesarios que permitan abordar de manera pertinente los procesos de intermediación laboral para personas en situación de discapacidad y sus programas municipales de fomento productivo. 
Adecuaremos los procesos de selección y normativa de contratación en el sector público para que los servicios cumplan con la disposición de acceso preferente a las personas en situación de discapacidad a la administración pública, terminando con situaciones de discriminación y exclusión.

En materia educativa, abordaremos las necesidades de la educación parvularia para asegurar el acceso de niños y niñas con discapacidad a este nivel de enseñanza fortaleciendo capacidades del sistema público de salas cuna y jardines infantiles. Revisaremos y mejoraremos el funcionamiento de proyectos de integración escolar en niveles básicos y medio a fin de reorientar las acciones de los equipos multiprofesionales e interdisciplinarios hacia requerimientos más pertinentes de los estudiantes con necesidades diferentes.

Velaremos por la eliminación de las barreras de acceso a la educación superior de estudiantes con discapacidad e incrementaremos el número de ayudas técnicas para estudiantes universitarios.

En el área de la salud, potenciaremos la Red de Salud Mental Comunitaria, basada en una red de dispositivos de carácter territoriales como parte de la red de salud general a partir de los Centros de Salud Mental Comunitarios (COSAM).

Incorporaremos la cobertura de órtesisy prótesis en los seguros de salud, mediante modalidad de Garantía Explícita de Salud (GES), logrando el traspaso desde el SENADIS al MINSAL de las ayudas técnicas, eliminando los actuales procesos de postulación.
Estableceremos un plazo máximo, para la evaluación de discapacidad por parte de la Comisión de Medicina Preventiva e Invalidez (COMPIN), de los Servicios de Salud.

Generaremos un plan nacional de Demencias (Alzheimer) y la creación gradual de 15 centros pilotos de atención (centros diurnos, uno por región), como dispositivos especializados, con dependencia técnica de los COSAM de las comunas, que trabaje en red con la atención primaria.

Fortaleceremos los servicios de rehabilitación de 4 hospitales regionales, de acuerdo a las macrozonas, que permitan avanzar en el acceso equitativo a ellos de la población a lo largo del país, en especial, de la población adulta.

Incorporaremos al arancel de FONASA y a la cobertura de seguros privados, las prestaciones de Terapeutas Ocupacionales. Incrementaremos el número de becas en los programas de formación de especialistas para Medicina Física y Rehabilitación y para Técnicos Ortoprotesistas. Evaluaremos la incorporación del GES de la rehabilitación post accidente vascular encefálico (AVE) como principal causa de discapacidad adquirida en los adultos. Además, estudiaremos la regulación de la condición de preexistencia en los seguros de salud cuando las personas con discapacidad dejan de ser carga o son contratadas y deben cotizar directamente, a fin de evitar la pérdida de beneficios de su programa de salud previo.

Evaluaremos la incorporación universal del examen denominado "screening de hipoacusia neonatal", que incluya a los recién nacidos del país. La evaluación debe considerar la etapa diagnóstica, la amplificación y la terapia de seguimiento posterior. 


\section{Y \\ MICHELIE}

IGUALDAD Y NO DISCRIMINACIÓN Y PARTICIPACIÓN E INCLUSION 

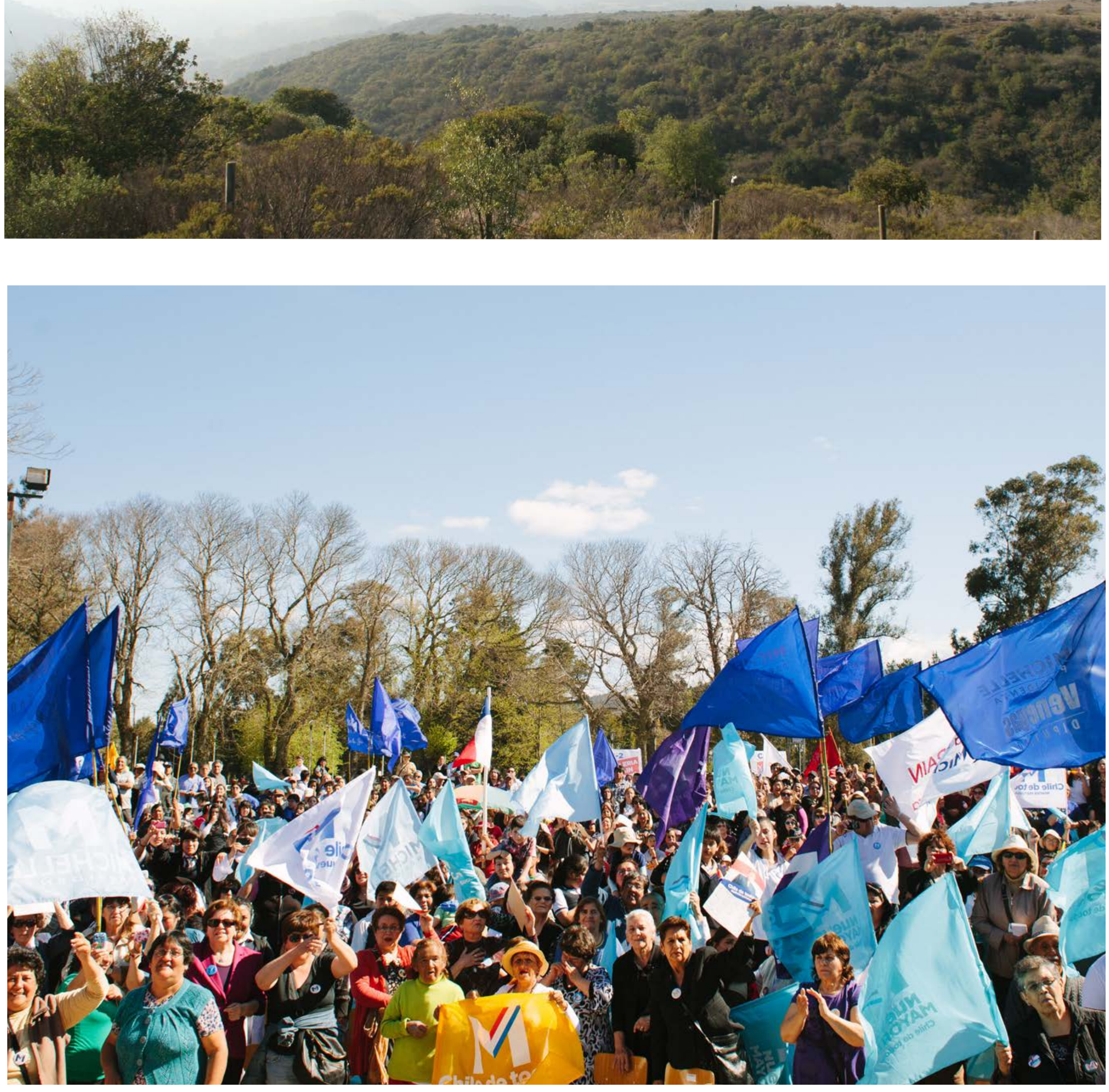


\section{IGUALDAD Y NO DISCRIMINACIÓN}

Un país más inclusivo y menos desigual es un país que valora la diversidad, promoviendo y garantizando la igualdad de derechos de todos y todas. Construir el Chile de Todos es impensable sin un compromiso irrestricto con la erradicación de toda forma de discriminación ya sea por motivos de raza o etnia, nacionalidad, situación socioeconómica, lengua, ideología u opinión política, religión o creencia, sindicación o participación en organizaciones gremiales, sexo, orientación sexual, identidad de género, discapacidad, enfermedad, estado civil, edad, filiación o apariencia personal.

La igualdad y no discriminación no es sino el respeto a los Derechos Humanos en todas sus dimensiones y erradicar las vulneraciones requiere de cambios culturales que sin duda trascienden un gobierno. Esta es una tarea país, que debe comprometernos a todos y todas. El compromiso de la Nueva Mayoría aspira a sentar las bases de una sociedad que respeta la diferencia justamente garantizando igualdad de derechos a todos y todas.

En ese contexto, la elaboración de una Nueva Constitución Políticaofrece una oportunidad inmejorable para impulsar el cambio cultural que implica la erradicación de la discriminación desde una perspectiva normativa, al ser esta la base sobre la que se estructura nuestro sistema político, convivencia social y legitimidad de las leyes.

De manera inmediata haremos cumplir la legislación vigente que obliga a cada uno de los órganos de la administración del Estado, dentro de las áreas de su competencia, a elaborar e implementar las políticas destinadas a garantizar a toda persona, el goce $\mathrm{y}$ ejercicio de sus derechos y libertades reconocidos por la Constitución, las leyes y los tratados internacionales ratificados por Chile. Lo anterior deberá manifestarse en medidas concretas que avancen en esta dirección y que se reflejen a nivel simbólico, institucional, legal y de política pública.

Desarrollaremos y haremos seguimiento a los mecanismos para que el enfoque de inclusión esté apropiadamente incorporado en el diseño, implementación y evaluación de políticas y programas públicos.
Dotaremos al Instituto Nacional de Derechos Humanos con las capacidades para promover y coordinar la aplicación del principio de igualdad ante la ley y no discriminación, de modo que los esfuerzos que el Estado haga en este sentido sean coordinados y eficientes, maximizando los recursos públicos y exaltando, en definitiva, a la diversidad como una virtud social.

Garantizaremos y entregaremos los apoyos para que funcionen de manera adecuada programas obligatorios de prevención de la discriminación en todo el sistema escolar, incluyendo la capacitación a docentes y asistentes de la educación.

En materia legislativa, promoveremos una reforma a la Ley 20.609, de no discriminación, respondiendo a la demanda transversal de las organizaciones de la sociedad civil que intervinieron en su tramitación, de tal modo que no quede reducida simplemente a la consagración de una acción judicial, sino que se establezca el deber para el Estado de elaborar políticas públicas contra la discriminación, acciones afirmativas a favor de los grupos históricamente discriminados y medidas de reparación.

Junto a ello, evaluaremos una iniciativa en contra de la incitación al odio, que contemple todas las categorías establecidas en la actual ley de no discriminación.

Impulsaremos las reformas legislativas que garanticen el respeto pleno de los derechos de las personas que forman parte de la Diversidad Sexual y de Género, en el marco de los tratados internacionales suscritos por nuestro país, incluyendo:

Matrimonio igualitario: convocaremos a un debate abierto, con participación amplia para la elaboración y posterior envío de un proyecto de ley en esta materia.

Ley de identidad de género: las personas transgénero son probablemente uno de los grupos que se encuentran en mayor situación de vulnerabilidad en nuestra sociedad. A raíz de la discordancia entre su nombre legal y su identidad de género, tienen barreras de acceso básicas al mundo laboral, siendo víctimas de situaciones de discriminación y vulneración de derechos fundamentales. Promoveremos 
la tramitación de la ley de identidad de género, que se encuentra en trámite, respondiendo a la necesidad de consagrar legalmente el derecho a la identidad de género, y estableciendo un procedimiento judicial, de acuerdo a normas internacionales suscritas por nuestro país, que permita a las personas trans adecuar su nombre y sexo registral de acuerdo a su propia identidad de género.
Por vía administrativa garantizaremos el acceso a los programas sociales de todos los tipos de familia. Desarrollaremos un programa educativo a nivel nacional de formación y prevención de toda forma de discriminación, elaborado e implementado de manera participativa con representantes de la sociedad civil, conteniendo estrategias de prevención, promoción y protección de los derechos humanos en su conjunto.

\section{PARTICIPACIÓN E INCLUSIÓN}

La invitación del proyecto de la Nueva Mayoría es a participar para transformar y llevar adelante reformas profundas que permitan derrotar la enorme desigualdad existente en nuestro país. En ese sentido, uno de los ámbitos en que hoy chilenos y chilenas viven esta desigualdad es también a la hora de participar en la toma de decisiones.

Llevaremos adelante medidas que fortalezcan y den institucionalidad tanto a la participación política como a la participación ciudadana en la gestión pública, garantizando que todos y todas tengamos el mismo derecho a influir en las decisiones que nos afectan y sin ningún tipo de discriminación arbitraria. Nuestro Gobierno integrará transversalmente el enfoque de participación ciudadana a toda política pública sectorial. Para ello, comenzaremos por revisar y fortalecer la institucionalidad y mecanismos de participación ciudadana ya existentes (Ley 20.500), sobre asociaciones y participación ciudadana en la gestión pública, Ley de Municipios y Juntas de Vecinos, mejorando los estándares y desarrollando programas que fortalezcan una ciudadanía corresponsable y que ejerza adecuadamente el control social.

Revisaremos y perfeccionaremos el diseño, ejecución y evaluación de los mecanismos de participación ciudadana hoy existentes en los programas y políticas públicas sectoriales en todas sus etapas, como por ejemplo los que lleva adelante el Servicio de Evaluación Ambiental.

Apuntando a que la participación se lleve adelante con un enfoque de derechos y de manera transversal, crearemos un Consejo de Participación Ciudadana y Fortalecimiento de la Sociedad Civil, que se relaciona con el Ministerio Secretaría General de Gobierno. Este tendrá como tarea la difusión y promoción del derecho a la Participación Ciudadana y la fiscalización para que los órganos públicos cumplan adecuadamente con sus obligaciones en esta materia. ElConsejo estará conformado por representantes de la Ciudadanía y el poder Ejecutivo, y coordinará un sistema Integral de Participación Ciudadana del que formarán parte todos los Consejos de Sociedad Civil creados al alero de la ley 20.500. Tendrá presencia regional en el territorio para garantizar, entre otras cosas, procesos de Participación Ciudadana descentralizados.

El Consejo tendrá como una de sus funciones el diseño y aplicación, conjuntamente con organizaciones territoriales, funcionales y de la sociedad civil en general, de un informe periódico anual que tenga como resultado un Índice de Participación Ciudadana que de cuenta de los avances y dificultades en la materia, así como la difusión de buenas prácticas.

Diseñaremos e implementaremos de manera participativa una Estrategia Integral de Fortalecimiento de la Sociedad Civil, lo que implica la redefinición de los objetivos, los montos y formas de asignación del Fondo de Fortalecimiento de las Organizaciones de Interés Público.

Crearemos una División de Participación Ciudadana en la SEGEGOB, de tal manera de dar adecuado seguimiento y control del cumplimiento de metas ministeriales en materias de participación.

Las y los dirigentes sociales y vecinales son actores fundamentales en nuestra democracia y en general en la vida comunitaria. Promoveremos programas que fortalezcan su liderazgo, y reconozcan su labor. 
ADULIOS

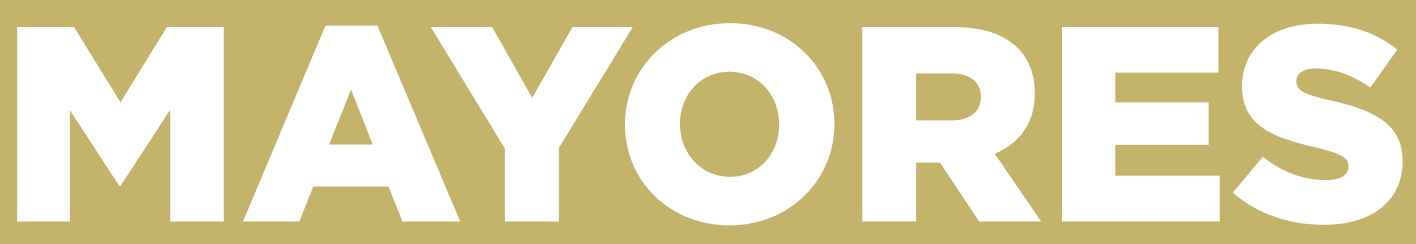



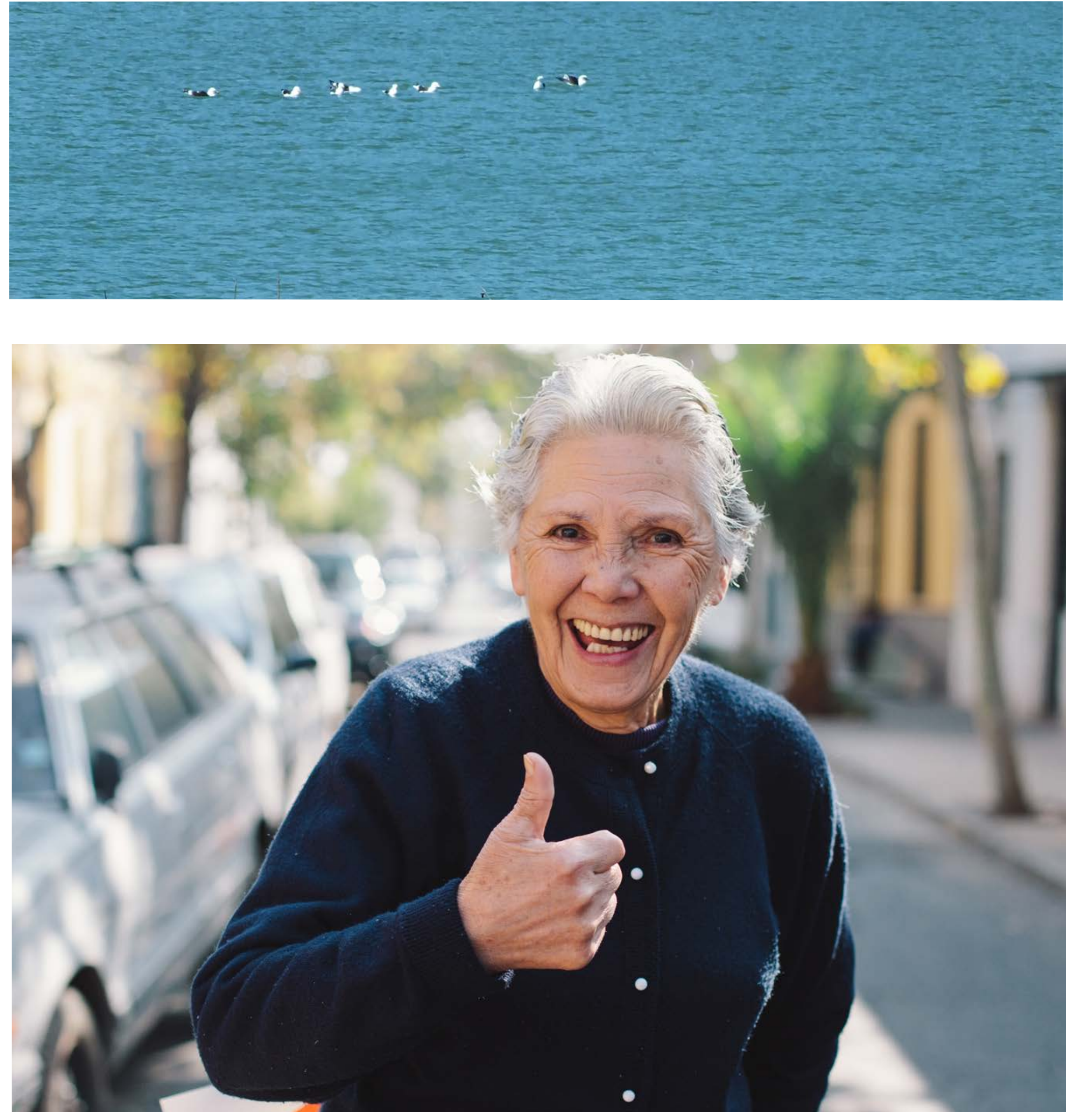


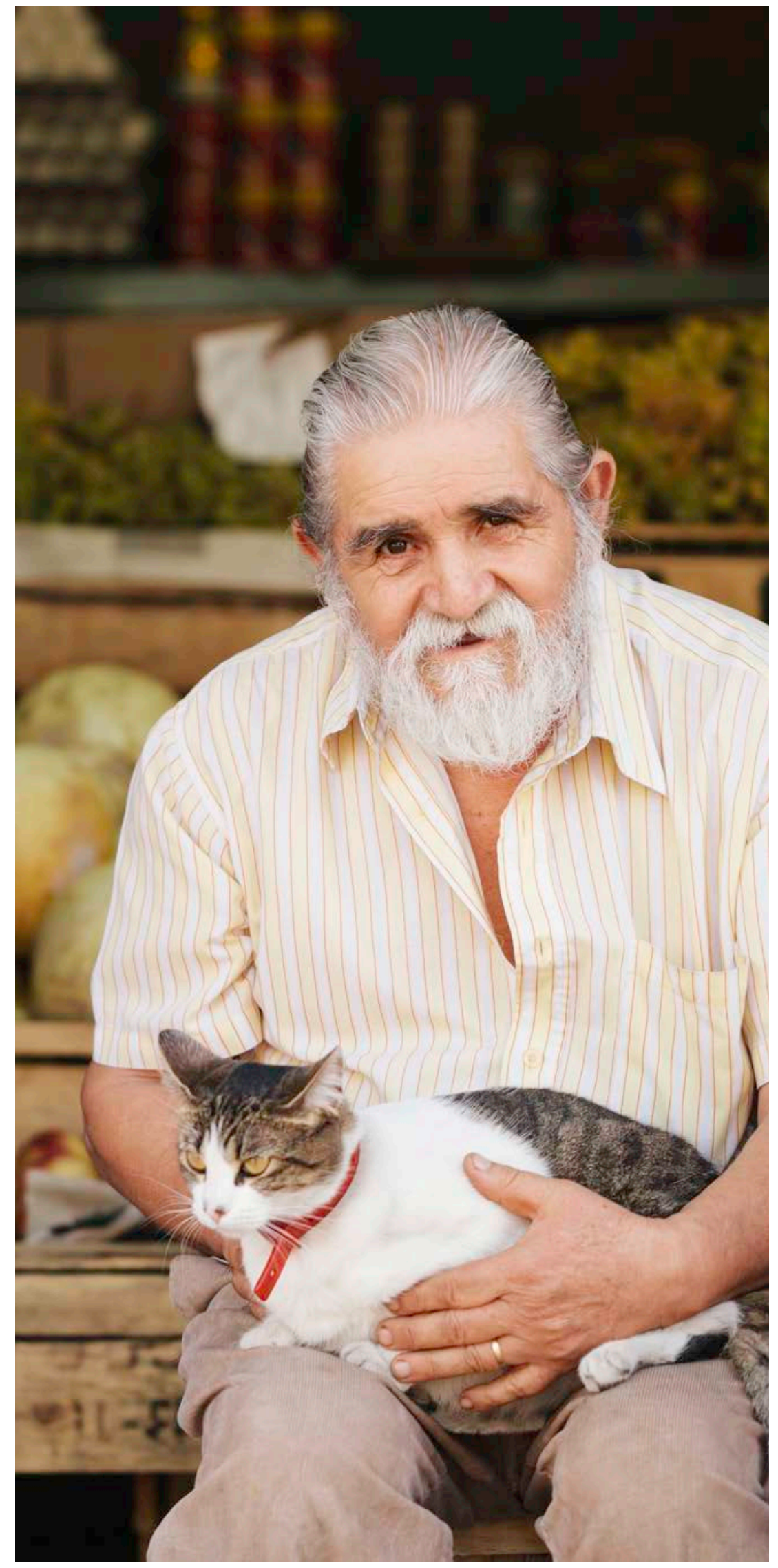

\section{ADULTOS MAYORES}

El envejecimiento de la población chilena es acelerado y adicionalmente han crecido fuertemente los segmentos de adultos mayores de mayor edad. Cada vez más chilenos sobrepasan la barrera de los 80 años.

El grupo de los 75 años y más, es el que más crece de manera proporcional y se ve más afectado por enfermedades crónicas que tienen como consecuencia la pérdida de funcionalidad, autonomía y situación que deriva finalmente en dependencia.

En Chile hay apróximadamente 400.000 personas mayores con algún grado de dependencia leve, moderada o severa, es decir, que requieren de otra persona para realizar una o más actividades básicas de la vida diaria, la mayoría tiene más de 75 años y predominantemente son mujeres.

Este importante y creciente grupo etario tiene hoy demandas sentidas en materia de pensiones, salud, políticas de cuidado a las personas con problemas de dependencia, recreación y cultura, así como otros beneficios sociales.

El presente programa incluye importantes anuncios hacia los adultos mayores en materia de salud, particularmente en la prevención de enfermedades crónicas no transmisibles, que afectan la calidad de vida de este grupo de edad. Entre otras medidas, implementaremos un programa de prevención para adultos con riesgo de presentar diabetes o hipertensión arterial, que generará hábitos de alimentación saludable, actividad física y manejo de stress. Estableceremos programas orientados a mantener la autovalencia y evitar que el sedentarismo, los estados depresivos y el aislamiento potencien sus niveles de dependencia y postración.

En materia de pensiones se estableció que en la medida que se apruebe la reforma al sistema tributario, será posible avanzar en modificaciones tanto en el monto de las pensiones como en la cobertura del Sistema de Pensiones Solidarias, creado en 2008.

Sin perjuicio de lo anterior, sabemos que muchos adultos mayores han perdido el beneficio del bono de invierno, 
producto de cambios mínimos en sus ingresos. Por ello, en los primeros 100 días de Gobierno restituiremos el Bono de Invierno a aquellos adultos mayores que lo hayan perdido, sin haber experimentado modificaciones relevantes a sus condiciones socioeconómicas. Adicionalmente, hay pensionados que perdieron el beneficio de la Pensión Básica Solidaria (PBS) sin que exista una razón aparente. A ellos les restituiremos el pago de la PBS si su situación socioeconómica no ha experimentado cambios.

Adicionalmente, evaluaremos e implementaremos una normativa que permita hacer extensiva la asignación por muerte a la totalidad de los adultos mayores que tienen PBS y a los beneficiarios de APS con saldo cero en su cuenta individual.

En materia de recreación, extenderemos el programa de vacaciones tercera edad a un mayor número de beneficiarios y combinaremos destinos consolidados con destinos emergentes en todas las regiones del país. Esta expansión permitirá que más de 220.000 adultos mayores participen de esta significativa política pública.

En transporte, evaluaremos la implementación de subsidios a los adultos mayores en los sistemas de las distintas regiones.

Ahora bien, las personas en situación de dependencia total o parcial seguirán incrementándose a un fuerte ritmo en las próximas décadas, como consecuencia de una combinación de factores demográficos, médicos y sociales. Hasta ahora, los cuidados que requieren las personas mayores han sido provistos por sus familiares, principalmente mujeres, como parte de un rol tradicional. Pero la incorporación de éstas al mundo laboral, el cuestionamiento y modificación de los roles tradicionales de hombres y mujeres, junto con cambios en los modelos de familia tradicional, han generado la necesidad de buscar una forma en que esta necesaria función social sea asumida de manera corresponsable, y que no descanse de manera discriminatoria sólo en ellas. La situación se vuelve más aguda cuando las necesidades de una persona mayor obligan a quien le cuida a dejar de trabajar, reduciendo el ingreso familiar y muchas veces condenando a la familia a la marginalidad y pobreza.
Necesitamos agregar un nuevo componente al sistema de protección social, el Sistema Nacional de Cuidado, enfocado en servicios sociales en materia de cuidados. Ello incluye tanto la promoción de la autonomía de las personas mayores, así como el apoyo sistemático y continuo a quienes están en situación de dependencia.

Se brindarán servicios de tele asistencia y de ayuda domiciliaria a personas autovalentes, además de apoyo para adecuar sus viviendas a las necesidades especiales de seguridad y desplazamiento.

Para los adultos mayores de alta dependencia en situación de abandono, se establecerá una red pública de establecimientos con un sistema de atención que integre las prestaciones del sistema de pensiones y del sistema de salud público, junto con los demás cuidados necesarios. Se pondrán en funcionamiento 15 establecimientos, uno en cada región, con el objeto de contar con una oferta pública asegurada y establecer el estándar de atención para esta población. Durante los 100 primeros días de Gobierno, se identificará la ubicación geográfica de los establecimientos y el plan anual de implementación.

También se regularizará el régimen vigente de residencias de larga estadía para adultos mayores y se constituirá un registro obligatorio de estos centros y de quienes brindan servicios de cuidados domiciliarios. Quienes provean este tipo de servicios deberán cumplir con una nueva normativa que establecerá estándares de calidad y atención, para garantizar que las personas bajo su responsabilidad estén adecuadamente protegidas y seguras.

Avanzaremos en el reconocimiento de los derechos del Adulto Mayor. En cada región habrá un centro que ofrecerá atención pública, gratuita, de calidad para personas mayores que están abandonadas, que no tienen familia, evitándose que caigan en situación de indigencia. Además, dispondremos del Fondo Nacional de Medicamentos, de una red pública de centros de atención para adultos mayores, de una política general de respeto a sus derechos y promoción de una vida activa, saludable, con espacios de recreación, acceso a la cultura e integrada a la sociedad. 


\section{AVANCEMOS JUNTOS HACIA UN CHILE DE TODOS}

Este programa de Gobierno es más que una suma de medidas ordenadas por áreas. Es una mirada sobre el momento que está viviendo Chile, sobre los grandes desafíos que enfrentamos para hacer de nuestro país una nación con prosperidad, con crecimiento, con progreso, con emprendimiento y con oportunidades para todos y todas. Un país sin desigualdad. Un país con participación ciudadana, con viviendas dignas, barrios integrados, ciudades amables. Un país sin abusos ni letra chica. Un país con regiones más autónomas y poderosas. Un país que respeta a sus habitantes en toda su diversidad. Un país donde todos sabemos que somos importantes. Un país que se debe a su gente y que le ofrece una mejor vida.

Esa es la apuesta que queremos hacer junto a todos ustedes. Ese es el horizonte que nos alienta. Ese es el país que queremos y que estamos llamados a construir. Juntos.

Para que este sueño colectivo sea una realidad, no sólo necesitamos un programa de Gobierno. Debemos ir más allá de este programa; debemos comprender que, tan esencial como tener una carta de navegación, es tener la voluntad conjunta de que esta nave que nos importa y nos compromete a todos llegue a buen puerto. Y voluntad no es voluntarismo. Voluntad es la disposición permanente a construir, a escuchar a los diferentes actores. Es también la apertura para que muchos y muchas se sumen y se hagan parte de las decisiones que deberemos tomar y de las soluciones. Es cooperar, en la certeza de que nuestras diferencias nos hacen más diversos, nos fortalecen.Que tenemos un destino común que nos convoca y nos invita a pasar por sobre las ventajas individuales, para edificar una sociedad de todos. Es confiar los unos en los otros y cuidar esa confianza entre todos, desde la fiscalización, el control ciudadano, el diálogo y la transparencia.

Este es un momento en nuestra historia que reclama lo mejor de cada uno de nosotros. ¿Por qué? Porque es un momento determinante, en el que podemos elegir 
como país dar el gran salto que necesitamos para crecer incluyendo, para incluir creciendo. Porque no podemos desperdiciar esta oportunidad. Y también porque esta tarea no es fácil. Porque hay quienes no tienen interés en que la situación actual cambie, quienes no quieren renunciar a los privilegios de la desigualdad que obstaculizan el desarrollo de nuestra sociedad. Porque hay quienes ven ventajas inmediatas en esta desigualdad, en el abuso y en la falta de oportunidades de millones de chilenos y chilenas.

Nada de eso debe hacernos dudar. El futuro es bueno. Un país con más educación, con más conocimiento, con empleo decente, con más integración con equidad de género, con más dignidad, con más salud y más protección social es también un país donde se puede emprender, un país confiable. Es un país que sabe dialogar, es un país que entrega herramientas a todos sus habitantes y que también promueve la competitividad, la innovación, la productividad, el crecimiento sustentable. Es un país que crece y se engrandece en todo sentido.

Es una tarea importante, que nos pide que estemos a la altura.

Nuestro compromiso ante los ciudadanos y las ciudadanas es hacer de este objetivo que hemos construido entre todas y todos, el primer mandato del Gobierno de la Nueva Mayoría. Y lo haremos responsablemente, con gobernabilidad.

Cuatro años es poco tiempo para la magnitud del desafío. Algunos cambios debemos implementarlos de inmediato, otros quedarán en marcha. Este es el comienzo de un proyecto transformador de largo plazo. Estamos hablando de hacer los cambios necesarios en el modelo de desarrollo que ha tenido Chile y que debieran orientar nuestros esfuerzos como país por las próximas décadas.
Este programa asegura que los cambios que el país requiere ocurrirán. No hay más tiempo que perder. La implementación de las medidas que contempla este programa requiere que las personas estén en el centro del quehacer del gobierno.

Este programa nos obliga a enaltecer el valor del servicio público y comprometer a los mejores en las tareas que llevaremos adelante. Ese es el buen gobierno que los chilenos y chilenas esperan. Es el buen gobierno que nuestra economía necesita para dar el salto que nos lleve a un desarrollo inclusivo.

Las transformaciones incluidas en este programa necesitan estar acompañadas de otros cambios. Cambios en las relaciones entre gobernantes y ciudadanos. Cambios en las relaciones entre hombres y mujeres, entre empresarios y trabajadores, entre vecinos y vecinas. Son los espacios de confianza que necesitamos para hacer las cosas bien, lo correcto y con sentido de futuro.

Este es el inicio de un nuevo ciclo político y social. No pertenece a una candidata, ni a un grupo político determinado: pertenece a una patria entera y sobre todo a su gente, que es la que la hace andar. Y es justamente porque el tiempo nos apremia, que debemos comenzar este camino cuanto antes.

Sabemos cuáles son las tareas. Hemos propuesto un modo de abordarlas que constan en este programa. Pero los más grandes logros de un país se construyen junto a los ciudadanos y ciudadanas.

Esta es la invitación. Este es el compromiso.

Sólo la certeza y la confianza de un destino en común, de un anhelo en común y de un esfuerzo en común serán capaces de hacer realidad el Chile de Todos que merecemos y queremos. 
M 
Chile de todos. 
M 